\title{
Investigation of chemical and physical properties of carbon nanotubes and their effects on cell biomechanics
}

Chenbo Dong

Follow this and additional works at: https://researchrepository.wvu.edu/etd

\section{Recommended Citation}

Dong, Chenbo, "Investigation of chemical and physical properties of carbon nanotubes and their effects on cell biomechanics" (2014). Graduate Theses, Dissertations, and Problem Reports. 5504.

https://researchrepository.wvu.edu/etd/5504

This Dissertation is protected by copyright and/or related rights. It has been brought to you by the The Research Repository @ WVU with permission from the rights-holder(s). You are free to use this Dissertation in any way that is permitted by the copyright and related rights legislation that applies to your use. For other uses you must obtain permission from the rights-holder(s) directly, unless additional rights are indicated by a Creative Commons license in the record and/ or on the work itself. This Dissertation has been accepted for inclusion in WVU Graduate Theses, Dissertations, and Problem Reports collection by an authorized administrator of The Research Repository @ WVU.

For more information, please contact researchrepository@mail.wvu.edu. 


\title{
Investigation of chemical and physical properties of carbon nanotubes and their effects on cell biomechanics
}

\author{
By \\ Chenbo Dong \\ Dissertation submitted to the Benjamin M. Statler College of Engineering and Mineral \\ Resources at West Virginia University \\ in partial fulfillment of the requirements for the degree of \\ Doctor of Philosophy \\ in the \\ Chemical Engineering Department \\ Committee Members \\ Prof. Cerasela Zoica Dinu, Committee Chairperson \\ Prof. Nianqiang Wu \\ Prof. Charter Stinespring \\ Prof. David Klinke \\ Prof. Yon Rojanasakul \\ Department of Chemical Engineering \\ Morgantown, West Virginia \\ 2014
}

Keywords: Carbon nanotubes, Atomic Force Microscopy, Biomechanics, Toxicity Copyright 2014 Chenbo Dong 


\title{
ABSTRACT \\ Investigation of chemical and physical properties of carbon nanotubes and their effects on cell biomechanics
}

\begin{abstract}
Chenbo Dong
Carbon nanotubes (CNTs) are used for a variety of applications from nanocircuits, to hydrogen storage devices, and from designing optical fibers to forming conductive plastics. Recently, their functionalization with biomolecules led to exciting biological and biomedical applications in drug delivery or bioimaging. However, because of CNTs interactions with biological systems and their ability to translocate and persist into the circulatory and lymphatic systems and biological tissues, concerns about CNTs intrinsic toxicity have risen. It is thus necessary to develop and implement sensitive analysis technologies that allow investigation of CNTs toxicity upon uptake into a biological system.
\end{abstract}

This thesis provides a comprehensive guide of experiments that have been performed during my Ph.D. tenure at West Virginia University in the Department of Chemical Engineering, in the group of Prof. Cerasela Zoica Dinu. Briefly:

Chapter one presents a systematic study of the CNTs physical and chemical properties and how these properties are changed upon exposure to chemical agents normally used during their cleaning and purification processes. Also, this chapter shows how acid oxidation treatment leads to improved CNTs biocompatibility. Specifically, by incubating CNTs in a strong acid mixture we created a user-defined library of CNTs samples with different characteristics as recorded using Raman energy dispersive $\mathrm{x}$-ray spectroscopy, atomic force microscopy, or 
solubility tests. Systematically characterized CNTs were subsequently tested for their biocompatibility in relation to human epithelial cells or enzymes. Such selected examples are building pertinent relationships between CNTs biocompatibility and their intrinsic properties by showing that acid oxidation treatment lowers CNTs toxicity making CNTs feasible platforms to be used for biomedical applications or the next generation of biosensors. (Publication: Chenbo Dong, Alan S Campell, Reem Eldawud, Gabriela Perhinschi, and Cerasela Zoica Dinu, Effects of acid treatment on structure, properties and biocompatibility of carbon nanotubes, Applied Surface Science, 2013, 268, 261-268.)

Chapter two shows how exposure to CNTs changes the biomechanical properties of fixed human lung epithelial cells (BEAS-2B cells). Specifically, by using Atomic Force Microscopy (AFM) nanoindentation technology, we demonstrated that cellular exposure to multi-walled carbon nanotubes (MWCNTs) for 24h induces significant changes in cellular biomechanics leading to increased cellular stiffness. The MWCNTs incubation also seemed to alter the surface area of the cells. Consequently, measures of the mechanical properties of the exposed cell could be used as indicators of its biological state and could offer valuable insights into the mechanisms associated with CNTs-induced genetic instability. (Publication: Chenbo Dong, Linda Sargent, Michael L Kashon, David Lowry, Jonathan S. Dordick, Steven H. Reynolds, Yon Rojanasakul and Cerasela Zoica Dinu, Expose to carbon nanotubes leads to change in cellular biomechanics, Advanced Healthcare Materials, 2013, 7, 945-951.)

Chapter three links together the MWCNTs exposure duration, internalization and induced biomechanical changes in fixed cells. Our findings indicated that changes in biomechanical 
properties of the fixed cells are a function of the uptake and internalization of the MWCNTs as well as their uptake time. Specifically, short exposure time did not seem to lead to considerable changes in the elastic properties in the cellular system. However, longer cellular exposure to CNTs leads to a higher uptake and internalization of the nanotubes and a larger effect on the cell mechanics. Such changes could be related to CNTs interactions with cellular elements and could bring information on the CNT intrinsic toxicity.

Chapter four talks about the potential of purified forms of CNTs with increased hydrophilicity to affect live human lung epithelial cells when used at occupational relevant exposure doses for particles not otherwise regulated. Specifically, our results showed that exposure to MWCNTs affects the dynamics and the biomechanical properties of live cells by reducing the activity of the mitochondria and inducing cell cycle arrest. Our analysis emphasized that cellular toxicity observed upon exposure to MWCNTs is a synergism resulting from multiple types of interactions that could be analyzed by means of intracellular mechanical changes.

This thesis contains Appendices of additional projects/publications for which I served as the first author:

(1) Chenbo Dong, and Cerasela Zoica Dinu, Molecular trucks and complementary tracks for bionanotechnological applications, Current Opinion in Biotechnology, 2013, 24, 612-619.

(2) Chenbo Dong, Zijie Yan, Jacklyn Kokx, Douglas B. Chrisey and Cerasela Zoica Dinu, Antibacterial and surface-enhanced Raman scattering (SERS) activities of AgCl cubes synthesized by pulsed laser ablation in liquid, Applied Surface Science, 2012, 258(10), 92189222. 


\section{Dedication}

To my parents: Lingxia Chen and Juying Dong 


\section{Acknowledgement}

I would like to express my special appreciation and thanks to my advisor Professor Cerasela Zoica Dinu for her constant advice and assistance. Her encouragement on my research allows me to grow as a research scientist. Her advice on both research as well as on my career have been priceless. I would also like to thank my committee members, Professor Nianqiang Wu, Professor Charter Stinespring, Professor David Klinke, and Professor Yon Rojanasakul for serving as my committee members even at hardship. I also want to thank staff scientists in WVU shared facility, without their help and support some of my work would not occur.

I would also like to thank all the other members of both Prof. Dinu's lab with whom I have worked closely over past 4 years as well as the other staff and faculty in the Chemical Engineering Department at WVU. Having been in Chemical Engineering Ph.D. program these years have all had an impact on my career.

Last but not the least, I would like to thank my friends and family who have always supported me. 


\section{Table of Contents}

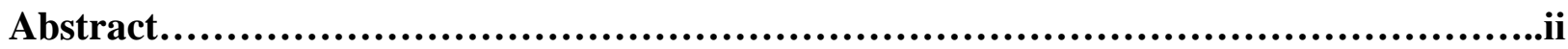

Dedication.........................................................................................v

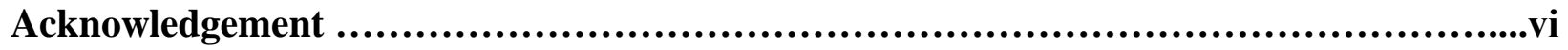

Table of Contents ..............................................................................vii

List of Figures............................................................................viii

List of Tables...........................................................................xv

List of symbols/nomenclature ....................................................xviii

Chapter 1: Effects of acid treatment on structure, properties and biocompatibility of carbon nanotubes.......................................................................1

Chapter 2: Exposure to carbon nanotubes leads to changes in the cellular biomechanics...32 Chapter 3: Carbon nanotubes uptake induces biomechanical cellular changes in a time dependent manner....................................................................59

Chapter 4: Toxicity and biomechanical induced effects of purified MWCNTs on live epithelial cell................................................................90 


\section{List of Figures}

Chapter 1: Effects of acid treatment on structure, properties and biocompatibility of carbon nanotubes

Scheme 1: Time-dependent incubation of pristine CNTs (SW- and MWs) with a mixture of sulfuric and nitric acid leads to acids oxidized CNTs.

Figure 1: EDX elemental analysis of pristine SWCNTs (a) and MWCNTs (b). The insets show the changes in the $\mathrm{O}$ and Fe contents with the acid treatment time employed

Figure 2: SEM image of (a) pristine SWCNTs, (b) pristine MWCNTs (c) 6h acid treated SWCNTs and (d) 6h acid treated MWCNTs respectively; the scale bar is $1 \mu \mathrm{m}$.

Figure 3: Raman spectra of pristine, 1, 3 and $6 \mathrm{~h}$ acid treated SWCNTs (a) and MWCNTs (b).

Figure 4: Solubility of pristine and acid treated SWCNTs (a) and MWCNTs (b) in deionized (di) water and phosphate buffer saline (PBS).

Figure 5: The average length distribution and the standard deviation of SWCNTs (a) and MWCNTs (b) with the acid treatment time.

Figure 6: Cytotoxicity of pristine and $6 \mathrm{~h}$ acid treated SWCNTs in BEAS-2B human 
epithelial cells after 24,48 and $72 \mathrm{~h}$ respectively. 


\section{Chapter 2: Exposure to carbon nanotubes leads to changes in the cellular biomechanics}

Figure 1: Raman spectra of pristine and $1 \mathrm{~h}$ acid-washed MWCNTs. (a) Pristine MWCNTs. (b) 1h acid-washed MWCNTs. 4 independent bands have been identified for both samples, i.e. $\mathrm{D}$ band around $1340 \mathrm{~cm}^{-1}, \mathrm{G}$ band at $1585 \mathrm{~cm}^{-1}, \mathrm{G}^{\prime}$ band around $2670 \mathrm{~cm}^{-1}$, and band around $2910 \mathrm{~cm}^{-1}$. Shifts in these bands are noticed for the $1 \mathrm{~h}$ acid-washed MWCNTs samples.

Figure 2: (a) Schematic overview of the atomic force microscopy (AFM)-based analysis of epithelial cells (control and cells exposed to $1 \mathrm{~h}$ acid-washed MWCNTs). (b) Topography image of a control cell. (c) Topography image of a cell exposed to $1 \mathrm{~h}$ acid-washed MWCNTs for $24 \mathrm{~h}$. The scale bar indicates $10 \mu \mathrm{m}$.

Figure 3: (a) Topography image of a single control cell; the cell body is dashed black and the cell nucleus is dashed red. (b) Indentation (elastic mapping) and Young modulus of the control cell identified in Figure 3a. (c) Histogram of the Young modulus distribution of the single control cell shown in Figure 3a. (d) Histogram of the Young modulus distribution of the nucleus region of the single control cell shown in Figure 3a. (e) Histogram of the Young modulus distribution of control cells and cells exposed to $1 \mathrm{~h}$ acid-washed MWCNTs for $24 \mathrm{~h}$. The Gaussian fit reveled a considerable shift towards higher stiffness for the cells exposed to $1 \mathrm{~h}$ acid-washed MWCNTs. (f) Histogram of the Young modulus distribution of nucleus region of control cells and cells exposed to $1 \mathrm{~h}$ acid-washed MWCNTs for $24 \mathrm{~h}$. The Gaussian fit shows that there is a considerable shift towards higher stiffness for the nucleus of the cells exposed to 
$1 \mathrm{~h}$ acid-washed MWCNTs. (g) Statistical analysis of average Young modulus distribution of control cells and cells exposed to $1 \mathrm{~h}$ acid-washed MWCNTs for $24 \mathrm{~h}$. All differences were considered statistically significant for $\mathrm{p}<0.05$. 


\section{Chapter 3 Carbon nanotubes uptake induce biomechanical cellular changes in a time dependant manner}

Figure 1: (a) Raman spectrum of Alexa-BSA, MWCNTs and Alexa-BSA-MWCNTs. (b) UV-Vis spectrophotometric analysis of free Alexa-BSA and Alexa-BSA immobilized onto the MWCNTs.

Figure 2: Normalized FITC signal of control cells, MWCNTs, cells treated with AlexaBSA and cells treated with Alexa-BSA-MWCNTs at (a) $1 \mathrm{~h} \mathrm{(b)} 3 \mathrm{~h} \mathrm{(c)} 6 \mathrm{~h} \mathrm{(d)} 12 \mathrm{~h}$ and summary of FITC signal for cells treated with Alexa-BSA-MWCNTs at different time point (e)

Figure 3: (a) Elastic modulus distribution histogram of control cells (b) Average elastic modulus of control cells and cells treated with MWCNTs at different time point (whole cell body) (c) Average elastic modulus of control cells and cells treated with MWCNTs at different time point (nucleus) 


\section{Chapter 4: Toxicity and biomechanical induced effects of purified MWCNTs on live epithelial cell}

Figure 1: (a) FTIR spectrum of pristine MWCNTs and $1 \mathrm{~h}$ purified MWCNTs. (b) FITC intensity of control cells, $1 \mathrm{~h}$ purified MWCNTs, BEAS-2B cells treated with Alexa-BSA and cells treated with Alexa-BSA-MWCNT conjugates. (c) (\%) Changes in the viability of the cells exposed to $24 \mu \mathrm{g} / \mathrm{cm}^{2}$ of $1 \mathrm{~h}$ purified MWCNTs. Changes are considered significant for $\mathrm{p}^{*}<0.5$.

Figure 2: Fluorescence Activated Cell Sorting (FACS) was used to evaluate the changes in cell cycle upon exposure to purified MWCNTs. Gating and cell cycle analysis were done for PI-stained BEAS-2B cells upon $24 \mathrm{~h}$ exposure to $1 \mathrm{~h}$ purified MWCNTs. (a) Forward scatter (FSC) and side scatter (SSC) 2D-plot showing a representative gating of the live cell population.

(b) Scatter plot selection of single cells. Cell cycle analysis of controls (c), and Cells exposed to $1 \mathrm{~h}$ purified MWCNTs respectively (d).

Figure 3: (a) Topography of a control BEAS-2B cell and height profile of the cell body. (b) Topography of a cell treated with $1 \mathrm{~h}$ purified MWCNTs and height profile of the cell body.

(c) Average height and surface area of control cells and cells exposed to $1 \mathrm{~h}$ purified MWCNTs; 15 individual cells have been analyzed for each sample changes are considered significant for $\mathrm{p}^{*}<0.05$.

Figure 4: (a) Schematic diagram of force-indentation profile of control cell and cell exposed to purified MWCNTs. The red curve represents the approach curve of the tip and the 
blue curve is detached curve of tip from the surface. "*” indicates the point of that tip deflected during the acquisition of the force-indentation profile. (b) Histogram of the Young modulus distribution of the whole cell and the nucleus region of control BEAS-2B cells and cells exposed to $1 \mathrm{~h}$ purified MWCNTs for $24 \mathrm{~h}$. All differences were considered statistically significant for $\mathrm{p}^{*}$ $<0.05$.

Figure 5: Proposed mechanism for the MWCNT-induced cyto- and geno-toxicity. Upon cellular uptake, the $1 \mathrm{~h}$ purified MWCNTs associate with microtubules to inhibit the transport or affect the activity of mitochondria, and induce cellular biomechanical changes. 


\section{List of Tables}

Chapter 1: Effects of acid treatment on structure, properties and biocompatibility of carbon nanotubes

Table 1: Relative intensity of representative Raman peaks of pristine and acid treated CNTs.

Table 2: Loading and retained activity of immobilized SBP onto acid oxidized MWCNTs. 


\section{Chapter 2: Exposure to carbon nanotubes leads to changes in the cellular biomechanics}

Table 1: Young modulus distribution of control cells (13 individual cells were analyzed) and cells incubated with $1 \mathrm{~h}$ acid-washed MWCNTs for $24 \mathrm{~h}$ (15 individual cells were analyzed). A Randomized block design was used for the experimental design and data analysis. 
Chapter 4: Toxicity and biomechanical induced effects of purified MWCNTs on live epithelial cell

Table 1: Young's modulus distribution of control cells and cells exposed to purified MWCNTs. 


\section{List of symbols/nomenclature}

1. CNTs: Carbon nanotubes

2. SWCNTs: Single walled carbon nanotubes

3. MWCNTs: Multi walled carbon nanotubes

4. EDX: Energy dispersive X-ray spectroscopy

5. SEM: Scanning Electron Microscopy

6. DMEM: Dulbecco's Modified Eagle Medium

7. FBS: Fetal bovine serum

8. SBP: Soybean peroxidase

9. EDC: carbodiimide hydrochloride

10. NHS: N-hydroxysuccinimide

11. PBS: Phosphate buffered saline

12. MES: 2-(N-morpholino)ethanesulfonic acid

13. ABTS: 2,2'-Azinobis [3-ethylbenzothiazoline-6-sulfonic acid]

14. BCA: bicinchonic acid assay

15. BEAS-2B: human bronchial lung epithelial cells

16. FACS- Fluorescent Actived Cell Sorting

17.WST-2-(4-Iodophenyl)-3-(4-nitrophenyl)-5-(2,4-disulfophenyl)-2H-tetrazolium, monosodium salt 


\title{
Chapter 1: Effects of acid treatment on structure, properties and biocompatibility of carbon nanotubes
}

\begin{abstract}
Carbon nanotubes (CNTs) are promising to be the next generation of viable tools for bioapplications. Further advances in such bioapplications may depend on improved understanding of CNTs physical and chemical properties as well as control over their biocompatibility. Herein we performed a systematic study to show how acid oxidation treatment changes CNTs physical and chemical properties and leads to improved biocompatibility. Specifically, by incubating CNTs in a strong acid mixture we created a user-defined library of CNTs samples with different characteristics as recorded using Raman energy dispersive x-ray spectroscopy, atomic force microscopy, or solubility tests. Systematically characterized CNTs were subsequently tested for their biocompatibility in relation to human epithelial cells or enzymes. Such selected examples are building pertinent relationships between CNTs biocompatibility and their intrinsic properties by showing that acid oxidation treatment lowers CNTs toxicity providing feasible platforms to be used for biomedical applications or the next generation of biosensors.
\end{abstract}




\section{Introduction}

Carbon nanotubes (CNTs) are nanoscale diameter materials of tubular shape and micrometer length with many interesting properties that make them viable candidates for a wide range of applications including electrical circuits ${ }^{1}$, hydrogen storage $^{2}$, fiber optics ${ }^{3}$, and conductive plastics ${ }^{4}$. In recent years, CNTs functionalization with biomolecules such as proteins ${ }^{5}$, enzymes ${ }^{6,7}$ or nucleic acid $^{8}$ opened up exciting bioapplications in biolabeling ${ }^{9}$, biosensing ${ }^{10}$, drug delivery ${ }^{11}$, bioseparation ${ }^{12}$ and tissue engineering ${ }^{13}$. However, further development of such bioapplications is hindered by: 1) CNTs' limited available surface area for biomolecule functionalization $^{14}$, 2) lack of understanding of CNTs growth mechanisms in uncontaminated forms ${ }^{15}$, 3) CNTs structural instability since larger nanotubes are prone to kinking and collapsing $^{16,17}$, and 4) CNTs cytotoxicity and associated health risks posed during their manufacturing and processing ${ }^{18}$. These challenges are mainly associated with the fact that asproduced CNTs form large aggregates in liquid enviroments since their hydrophobic walls are prone to van der Waals interactions ${ }^{19}$. Thus, in order to increase CNTs bioapplications ${ }^{20}$ and reduce their aggregation ${ }^{21}$ and cytotoxicity $^{22}$, it is critical to overcome their intrinsic hydrophobicity and tendency to form conglomerates in solution.

Numerous attempts have been made to overcome CNTs hydrophobicity and increase their hydrophilicity; these include gas- ${ }^{23}$ and liquid-phase activation ${ }^{24}$, and oxidation with strong oxidants including hydrogen peroxide ${ }^{25}$, potassium permanganate ${ }^{26}$, potassium hydroxide ${ }^{27}$, and nitric and/or sulfuric acid ${ }^{6,7,28}$. Among these attempts, nitric and sulfuric acid oxidation is regarded as the most prevalent treatment since it is easy to implement in both laboratory and industrial settings ${ }^{20}$. When CNTs are oxidized with such aggressive acids, their hydrophilicity is 
increased by the introduction of oxygen-containing functional groups, i.e., carboxyl ${ }^{29}$, carbonyl 26,29, and phenol groups ${ }^{30}$. Moreover, during such oxidation treatments amorphous carbon ${ }^{31}$ and residual metal catalyst particles are removed, possibly resulting in reduced intrinsic toxicity of $\mathrm{CNTs}^{22}$. Despite the fact that wide evaluations of the effects of acid oxidation on CNTs have been carried out, systematic investigations of changes in physical and chemical properties and how such changes can be further employed for increasing CNTs biocompatibility and thus their bioapplications are still lacking.

Herein we performed a systematic study of the changes in physical and chemical properties of CNTs upon user-controlled treatment with nitric and sulfuric acid. Further, we assessed how treatment affects CNTs biocompatibility in relation to cellular and enzymatic systems $^{6,7,10}$. Our hypothesis was that selected biological examples will help build pertinent relationships between CNTs biocompatibility and their intrinsic properties and demonstrate how interface reactions between a biological molecule and the nanomaterial can be further used to provide systems with lower toxicity to for selected bioapplications as well as feasible platforms for the next generation of biosensors. 


\section{Material and Methods}

\section{Acid oxidation of CNTs}

Acid oxidation treatment of single and multi-walled carbon nanotubes (SW- and MWCNTs respectively) was employed to generate a library of samples with different physical and chemical properties. Specifically, commercial SWCNTs (85\% purity, Unidym Inc.) and MWCNTs (95\% purity, Nanolab Inc. (PD15L5-20)) were incubated in a concentrated sulfuric (96.4\%, Fisher, USA) and nitric acid (69.5\%, Fisher, USA) mixture in a ratio of $3: 1(\mathrm{~V} / \mathrm{V})$. The CNTs/acid mixture (where CNTs can refer to either SW- or MWCNTs) was subsequently sonicated in an ice bath (Branson 2510, Fisher, USA) for 1, 3, or $6 \mathrm{~h}$, at a constant temperature of $23^{\circ} \mathrm{C}$. When the required time elapsed, CNTs/acid mixture was diluted with deionized (di) water and filtered through a GTTP $0.2 \mu \mathrm{m}$ polycarbonate filter membrane (Fisher, USA). Several cycles of resuspension in di water were employed to remove acidic residues or catalysts. The CNTs were isolated on the filter, subsequently dried in a vacuum desiccator and stored at room temperature for further use.

\section{Energy Dispersive X-ray analysis (EDX) of CNTs}

Energy dispersive X-ray analysis (EDX) was used for quantitative elemental analysis of pristine and acid oxidized CNTs. Samples $(1 \mathrm{mg} / \mathrm{ml}$ in di water) were deposited on silica wafers and dried under vacuum. The experiments were performed on a Hitachi S-4700 Field Emission Scanning Electron Microscope (USA) with a S-4700 detector combining secondary (SE) and backscattered (BSE) electron detection (all in a single unit), operating at $20 \mathrm{kV}$. Results are presented as a percent of elements relative to the most dominant element. 


\section{Scanning Electron Microscopy (SEM) of CNTs}

Samples ( $1 \mathrm{mg} / \mathrm{ml}$ in di water of both pristine and acid treated CNTs) were dried on silica wafers under vacuum and imaged using a Hitachi S-4700 Field Emission Scanning Electron Microscope (USA) with a field emission at $10 \mathrm{kV}$.

\section{Raman spectroscopy of CNTs}

Raman spectroscopy (performed on a Renishaw InVia Raman Spectrometer, CL532-100, $100 \mathrm{~mW}$, USA) allowed determination of the chemical structure and any modifications resulted from the acid oxidation of both pristine and acid treated CNTs. Briefly, CNTs deposited on glass slides (Fisher, USA) were excited through a $20 \mathrm{x}$ microscope objective using an Argon ion $\left(\mathrm{Ar}^{+}\right)$ laser beam with a spot size of $<0.01 \mathrm{~mm}^{2}$ operating at $514.5 \mathrm{~nm}$. Detailed scans were taken in the 100 to $3200 \mathrm{~cm}^{-1}$ range; low laser energy (i.e., $<0.5 \mathrm{mV}$ ) and exposure time of $10 \mathrm{sec}$ were used to prevent unexpected heating effects.

\section{CNTs solubility measurement}

The solubility of CNTs (pristine and acid oxidized) was evaluated in di water ( $\mathrm{pH} 6.25$ ) and Phosphate Saline Buffer (PBS, pH 7, 100 mM ionic strength). Briefly, CNTs were diluted in the solvent of interest to yield to a $3 \mathrm{mg} / \mathrm{ml}$ solution. The suspension was then centrifuged at $3000 \mathrm{rpm}$ for $5 \mathrm{~min}$; subsequently, part of the supernatant $(0.8 \mathrm{~mL})$ was removed and filtered through a $0.2 \mu \mathrm{m}$ GTTP filter membrane. The filter membrane was then dried under vacuum and the amount of CNTs was weighted. The solubility of the CNTs was calculated based on the volume used for suspension and the initial starting amount. 


\section{CNTs length measurement}

An atomic force microscope (AFM, Asylum Research, USA) was used to evaluate the length of pristine and acid treated CNTs. A Si tip (Asylum Research, 50-90 KHz AC240TS, USA) helped perform tapping mode in air. CNTs samples (i.e., pristine, 1, 3 or $6 \mathrm{~h}$ acid treated SW and MWCNTs) were dispersed in di water (to yield solutions of $0.1 \mathrm{mg} / \mathrm{ml}$ concentration), deposited on mica surfaces $(9.5 \mathrm{~mm}$ diameter, $0.15-0.21 \mathrm{~mm}$ thickness, Electron Microscopy Sciences, USA) and allowed to dry over night under vacuum. Scan images of 10,5 or 1 ( $\mu \mathrm{m} \mathrm{x}$ $\mu \mathrm{m})$ areas were acquired. Specially, the individual carbon nanotube in AFM topography image was selected and the length was measured using the Igor Pro 6.34A software. For each sample, at least 30 individual CNTs were counted and measured to obtain average length distribution.

\section{Cell culture and treatment with CNTs}

Non-tumorigenic human bronchial epithelial cells (BEAS-2B) were purchased from American Type Culture Collection (ATCC, USA). The cells were cultured in DMEM medium supplemented with 5\% fetal bovine serum (FBS), $2 \mathrm{mM} \mathrm{L-glutamine} \mathrm{and} \mathrm{100-units/ml}$ penicillin/streptomycin (all reagents were purchased from Invitrogen, USA). Cells were passaged weekly using $0.05 \%$ trypsin (Invitrogen, USA) and kept in $5 \% \mathrm{CO}_{2}$ at $37^{\circ} \mathrm{C}$.

Pristine and acid oxidized SWCNTs were dispersed in di water by sonication, filtered through the $0.2 \mu \mathrm{m}$ GTTP filter membrane, resuspended in cellular media and sonicated at room temperature to form stable dispersions. For treatment, BEAS-2B cells were seeded overnight in a 12 well plates (Fisher, USA) at a density of 3.5E5 cells/well, and allowed to reach confluence. Subsequently, the cells were exposed to $100 \mu \mathrm{g} / \mathrm{ml} \mathrm{SWCNTs;} 24 \mathrm{~h}$ post exposure, the cells were 
incubated with $6.5 \mu \mathrm{g} / \mathrm{mL}$ Hoechst 33342 dye (Molecular Probes, USA) for $30 \mathrm{~min}$ at $37^{\circ} \mathrm{C}$ and analyzed for apoptosis by scoring the percentage of cells with intensely condensed chromatin and/or fragmented nuclei using fluorescence microscopy (Leica Microsystems, USA). Approximately 1000 cell nuclei from ten random fields were analyzed for each sample. The apoptotic index was calculated as the percentage of cells with apoptotic nuclei relative to the total number of analyzed cells. At least 3 independent trials were performed for each sample.

\section{Functionalization of CNT with enzyme}

Soybean peroxidase (SBP, Bioresearch, USA) was covalently attached to 1, 3 or $6 \mathrm{~h}$ acid treated MWCNTs using 1-ethyl-3-[3-dimethylaminopropyl] carbodiimide hydrochloride (EDC; Acros Organics, USA) and N-hydroxysuccinimide (NHS, Pierce, USA) ${ }^{32}$. Briefly, 2 mg CNTs (MWCNTs) were dispersed in $160 \mathrm{mM}$ EDC and $80 \mathrm{mM}$ NHS (total volume of $2 \mathrm{~mL}$ in MES (2(N-morpholino)ethanesulfonic acid sodium salt, $50 \mathrm{mM}, \mathrm{pH} 4.7$, Sigma, USA) for $15 \mathrm{~min}$ at room temperature with shaking at $200 \mathrm{rpm}$. The activated MWCNTs were next filtered through the $0.2 \mu \mathrm{m}$ GTTP filter membrane, washed thoroughly with MES buffer to remove any ester residues, immediately dispersed in $2 \mathrm{~mL}$ of $1 \mathrm{mg} / \mathrm{mL}$ SBP solution in PBS (100 mM, pH 7.0) and incubated for 1,3 or $6 \mathrm{~h}$ at room temperature with shaking at $200 \mathrm{rpm}$. The resulting SBPMWCNT conjugates were filtered and washed extensively with PBS to remove any unbound enzyme $^{32}$. The supernatants and washes were collected to quantify enzyme loading.

\section{Enzyme loading}

The amount of SBP attached to MWCNTs (i.e., SBP loading) was determined using standard BCA assay kit (Pierce, USA) and subtracting the amount of enzyme washed out in the 
supernatant and washes from the amount of SBP initially added to the MWCNTs. Briefly, the working reagent $(1000 \mu \mathrm{L})$ was prepared by mixing 50 parts of reagent $A$ with 1 part of reagent $\mathrm{B}$ (the reagents are provided with the kit). The mixture of reagents $\mathrm{A}$ and $\mathrm{B}$ was further added to $50 \mu \mathrm{L}$ solutions of SBP-containing samples (i.e., the samples isolated in the form of the supernatant and washes respectively). The resulting solutions were incubated at $37^{\circ} \mathrm{C}$ for $30 \mathrm{~min}$. Absorbance at $562 \mathrm{~nm}$ was determined on a spectrophotometer (Fisher, USA). Control calibration curves were prepared by serial dilutions of SBP (free in solution) into the working reagent.

\section{Enzyme activity assay}

The activity of SBP was measured by monitoring the oxidation reaction of 2,2'-Azinobis [3-ethylbenzothiazoline-6-sulfonic acid] (ABTS, Sigma, USA) in the presence of hydrogen

peroxide $\left(\mathrm{H}_{2} \mathrm{O}_{2}\right.$, Sigma, USA). $20 \mu \mathrm{l}$ of the SBP-MWCNTs conjugates were added to $0.65 \mathrm{ml}$ ABTS solution (0.5 mM final concentration, Pierce, USA) and mixed; subsequently, $20 \mu \mathrm{H}_{2} \mathrm{O}_{2}$ solution ( $0.2 \mathrm{mM}$ final concentration) was added to the sample in order to initiate the reaction. The change in absorbance was monitored spectrophotometrically at $412 \mathrm{~nm}$ immediately upon addition of $\mathrm{H}_{2} \mathrm{O}_{2}$. The initial reaction rate was calculated from the slope of the linear time-course. The extinction coefficient of the oxidized ABTS product is $32,400 \mathrm{M}^{-1} \mathrm{~cm}^{-1}$ at $412 \mathrm{~nm}^{33}$. The activity of the immobilized enzyme is reported as specific activity relative to free enzyme activity. The activity of the free enzyme was determined using an equivalent amount of free enzyme (based on loading data) and the protocol provided above.

\section{Statistical analysis}

All results are presented as mean \pm standard deviation. 


\section{Results and Discussion}

We prepared a library of single and multi-walled carbon nanotubes (SW- and MWCNTs) using liquid phase oxidation with a strong nitric and sulfuric acid mixture ${ }^{6,7}$. The approach is shown in Scheme 1; sonication in the acid mixture attacks the graphene sheets on the $\mathrm{C}-\mathrm{C}$ bands ${ }^{34}$, introduces defects and oxidizes the CNTs at the defect sites leading to shorter nanotubes. To reduce the reaction rate for acid attack, the water bath sonicator was maintained at room temperature. The carboxylic acidic groups introduced in SW- and MWCNTs were determined previously using acid-base titrations ${ }^{35,36}$ or the formation of a dodecylamine zwitterions ${ }^{37}$.

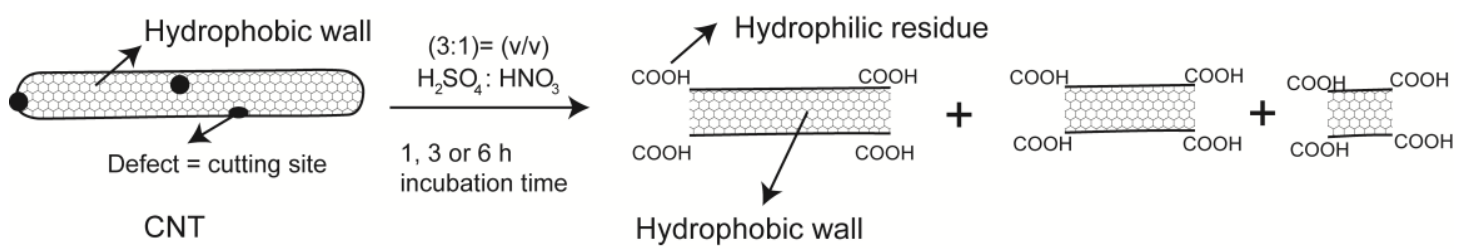

Scheme 1: Time-dependent incubation of pristine CNTs (SW- and MWCNTs) with a mixture of sulfuric and nitric acid leads to acid oxidized CNTs.

We further investigated the chemical composition of pristine and acid oxidized CNTs using Energy dispersive X-ray analysis $(\mathrm{EDX})^{20,38}$. EDX spectra of pristine SW- and MWCNTs are shown in Figure 1a and b respectively, as a plot of X-ray counts vs. energy (in keV). The analysis revealed the presence of high contents of carbon $(\mathrm{C})$ and oxygen $(\mathrm{O})$, with iron $(\mathrm{Fe})$ as metal catalyst in both pristine SW- and MWCNTs samples. The energy peaks correspond to the various elements in the sample, with Fe yielding two peaks at $0.70 \mathrm{keV}$ and $6.40 \mathrm{keV}^{39}$. Other elements (e.g., Al, Si, Cl, S etc.) were also present but in very low quantity. The Fe peak was larger for the SWCNTs sample when compared to the MWCNT one. The difference was reflective of their pristine characteristics since SWCNTs purity was $85 \%$ while the purity of 
pristine MWCNTs was 95\%, per manufacturer information (see materials and methods). The insets in Figure 1 show the changes in the $\mathrm{O}$ and Fe contents with the acid oxidation treatment time for both SW- and MWCNTs samples. As shown, Fe content decreased with the treatment time for both SW- and MWCNTs samples indicating removal of the metal catalyst. The decrease in the Fe content was more pronounced for the SWCNTs when compared to MWCNTs samples. This is a reflection of the different purities of the two samples chosen in these experiments. For the $\mathrm{O}$ content, the change was also dependent on the sample characteristics. The relative low purity SWCNTs samples contain more amorphous carbon ${ }^{40}$ than the higher purity MWCNTs ${ }^{41}$. Thus, the acid treatment led to a significant increase of the $\mathrm{O}$ content with the acid treatment time for the SWCNTs (Figure 1a, inset) when compared to a smaller increase for the MWCNTs samples.

a)

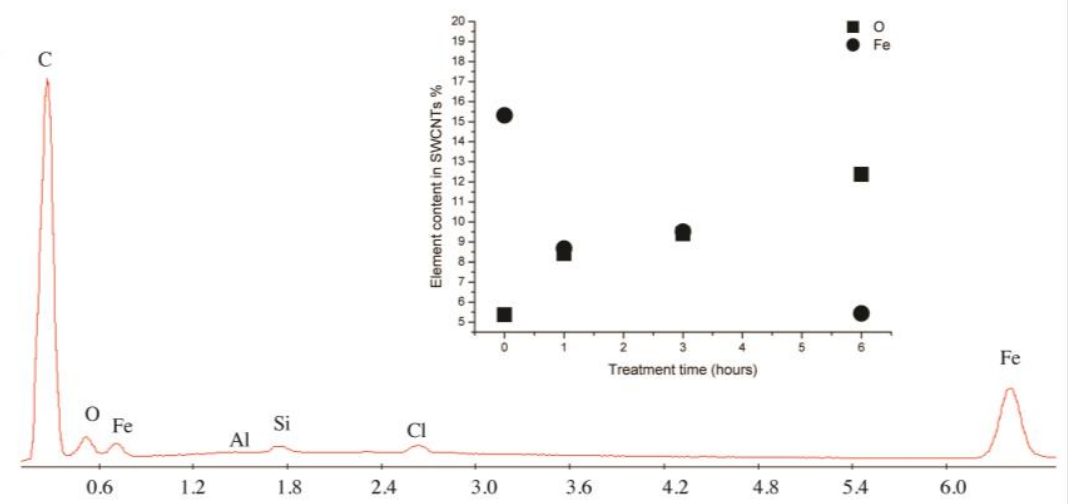

b)

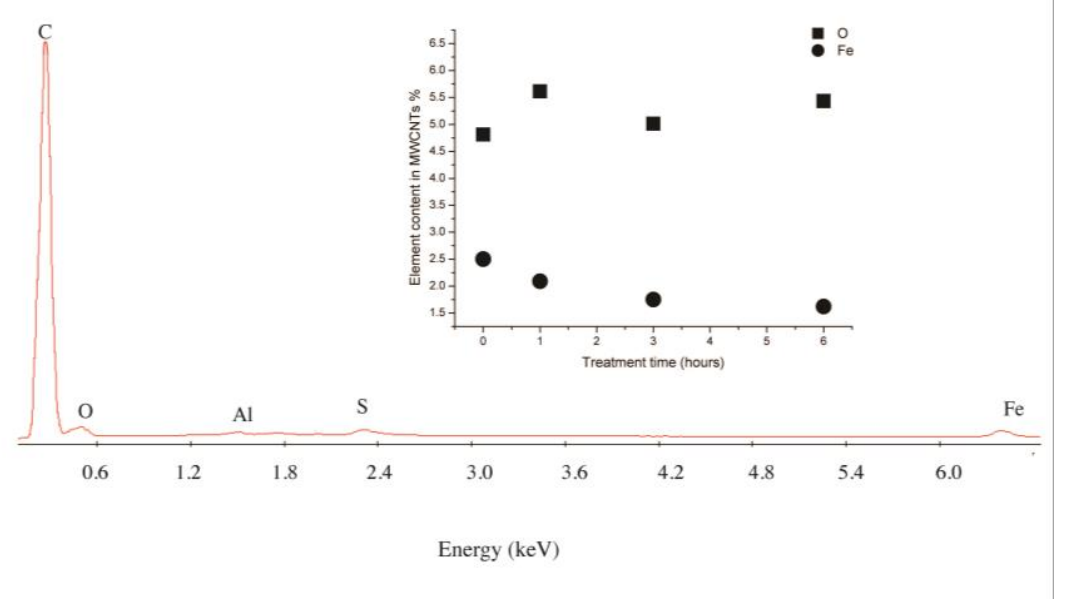


Figure 1: EDX elemental analysis of pristine SWCNTs (a) and MWCNTs (b). The insets show the changes in the $\mathrm{O}$ and $\mathrm{Fe}$ contents with the acid treatment time employed under user-control.

Figure 2 shows the SEM images of the pristine and acid treated samples (both SW- and MWCNTs). As shown, user-controlled acid treatment did not lead to significant morphological changes either for SW- or MWCNTs samples.

a)

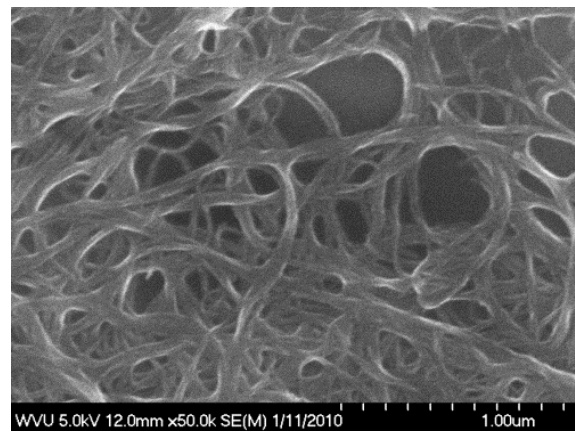

c)

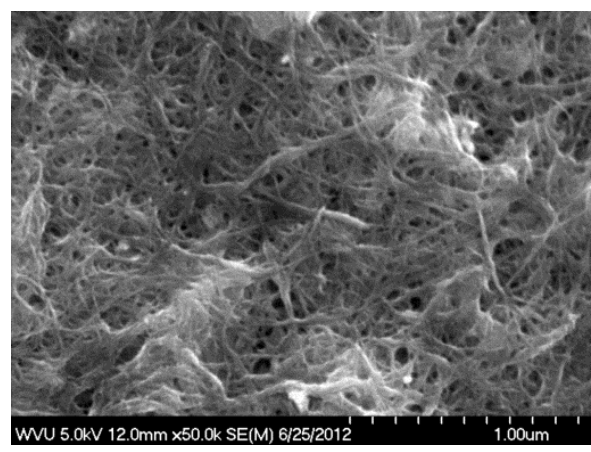

b)

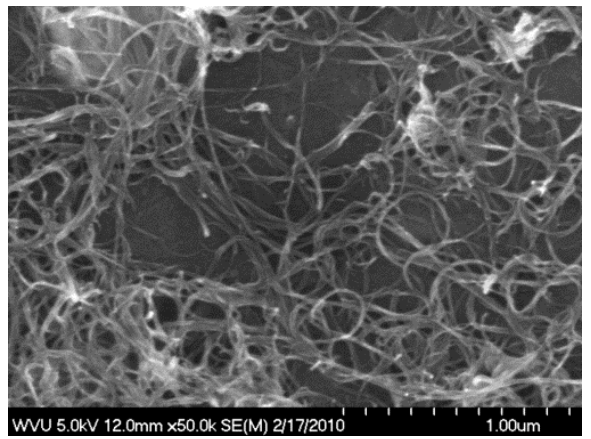

d)

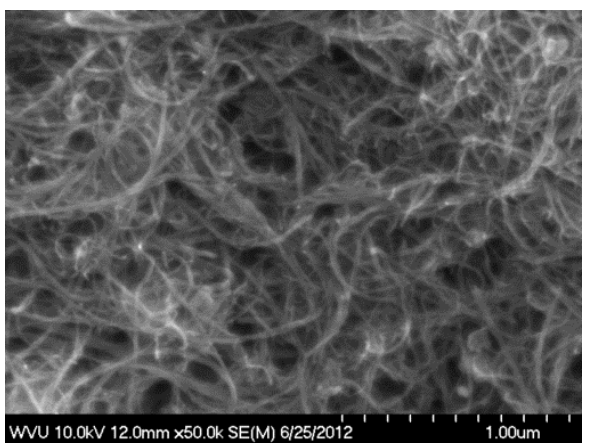

Figure 2: SEM image of (a) pristine SWCNTs, (b) pristine MWCNTs and (c) $6 \mathrm{~h}$ acid treated SWCNTs (d) $6 \mathrm{~h}$ acid treated MWCNTs respectively; the scale bar is $1 \mu \mathrm{m}$.

The structural changes upon acid treatment of the CNTs samples were investigated using Raman spectroscopy ${ }^{42-44}$. Figure 3 shows the Raman spectra of pristine and acid treated SW-and MWCNTs. The Raman analysis of the SWCNTs reveals the presence of 4 bands (Figure 3a), the so-called D (disorder mode) band around $1340 \mathrm{~cm}^{-1}, \mathrm{G}^{-}$and $\mathrm{G}^{+}$bands at around $1545 \mathrm{~cm}^{-1}$ and $1590 \mathrm{~cm}^{-1}$ respectively, and G' band at $2650 \mathrm{~cm}^{-122,45}$. The Raman analysis of the MWCNTs also 
reveals the presence of 4 bands (Figure $3 \mathrm{~b}$ ), with the D band around $1340 \mathrm{~cm}^{-1}, \mathrm{G}$ band at 1585 $\mathrm{cm}^{-1}, \mathrm{G}^{\prime}$ band at $2650 \mathrm{~cm}^{-1}$, and another band at $2920 \mathrm{~cm}^{-146,47}$. The D band around $1340 \mathrm{~cm}^{-1}$ is related to the non-crystalline $\mathrm{C}$ species, i.e., defects in the $\mathrm{CNTs}^{48}$, while the $\mathrm{G}$ band observed around $1585 \mathrm{~cm}^{-1}$ is indicative of a high degree of ordering and well-structured C-based structures $^{42}$. The size of the $\mathrm{D}$ band relative to the $\mathrm{G}$ band can be used as a qualitative measurement for the formation of undesired forms of $\mathrm{C}^{49}$. Both pristine and acid treated CNTs (SW- and MWCNTs) have a relatively small D band at around $1350 \mathrm{~cm}^{-1}$, with the $\mathrm{D}$ band being wider and shifted towards higher frequency in the acid treated samples when compared with the pristine ones. The ratio of intensity of $\mathrm{D}$ peak relative to the $\mathrm{G}$ peak represents the degree of CNTs functionalization ${ }^{49}$. Higher $I_{\mathrm{D}} / I_{\mathrm{G}}$ ratio suggests higher level of functionalization ( $I$ represents the peak's relative intensity).

a)

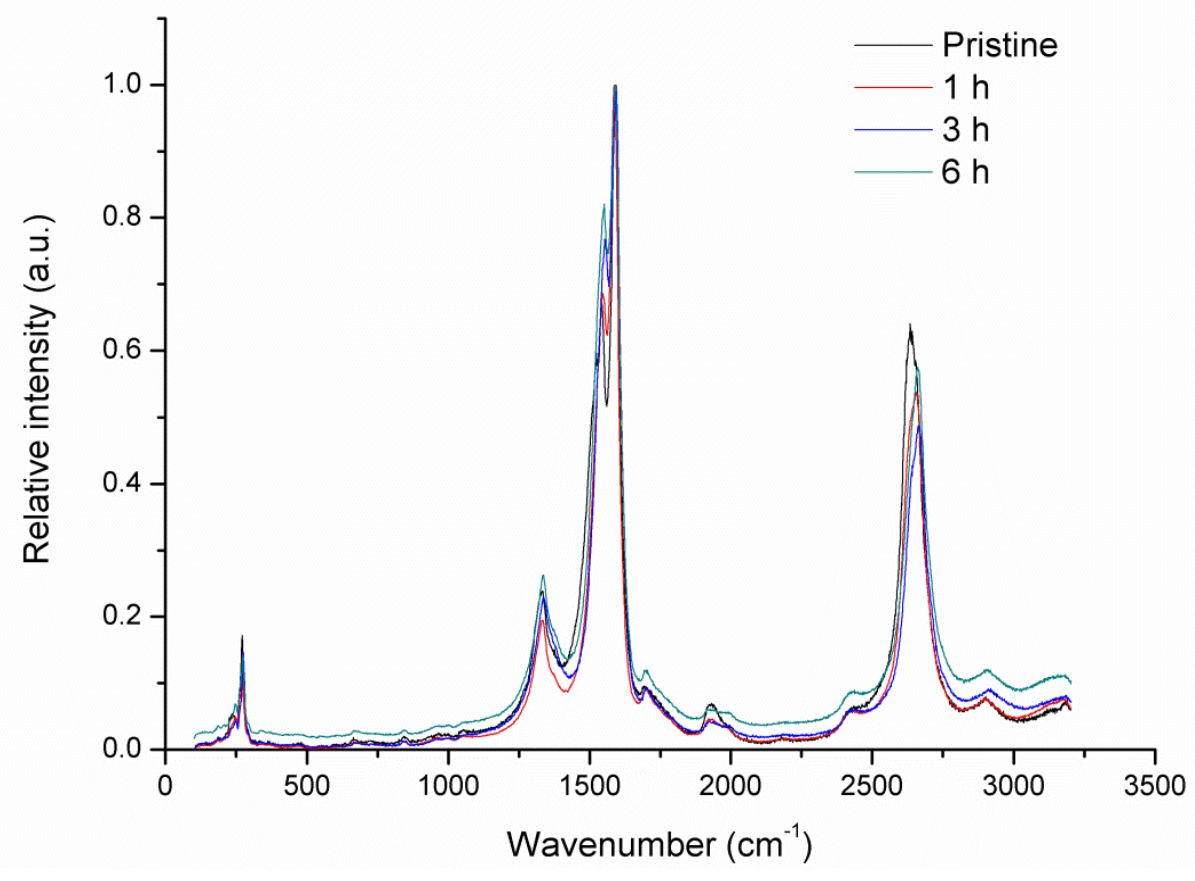


b)

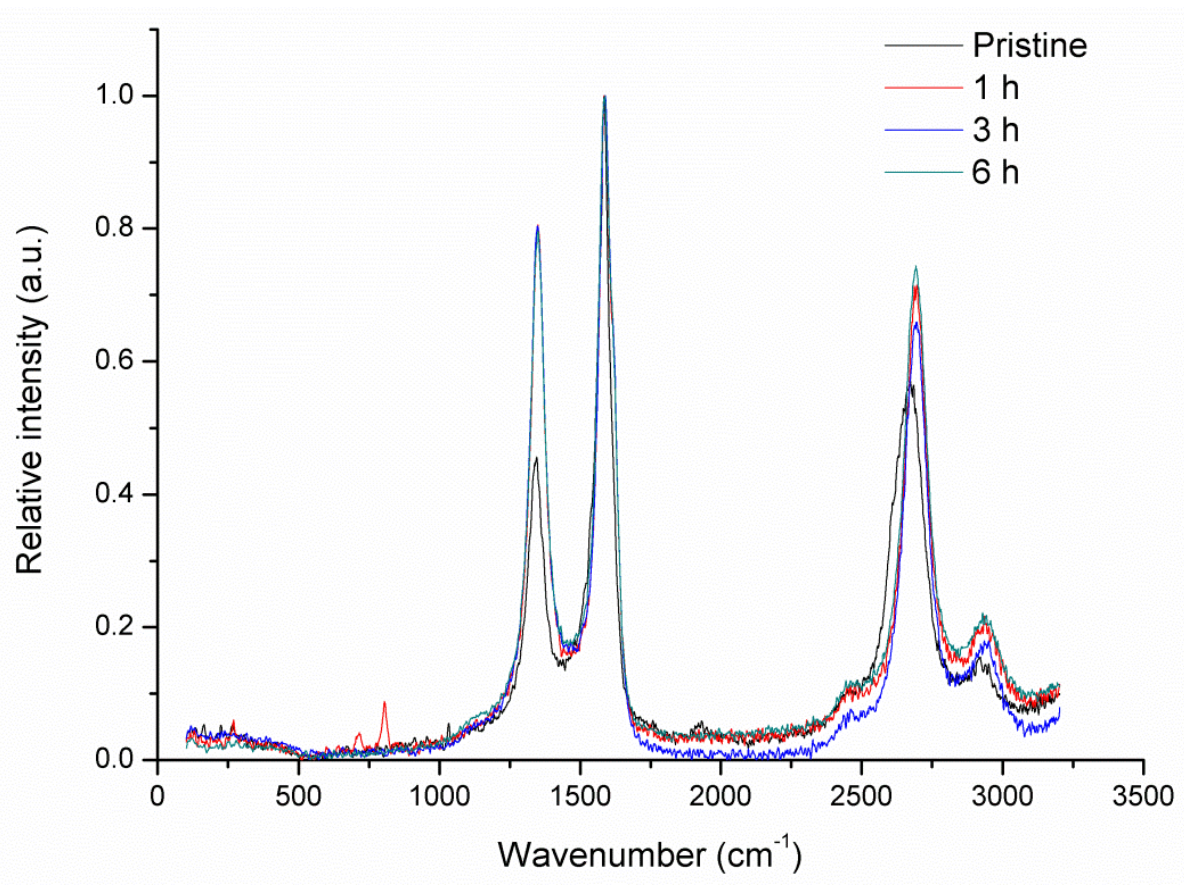

Figure 3: Raman spectra of pristine, 1,3 and $6 \mathrm{~h}$ acid treated SWCNTs (a) and MWCNTs (b).

$\mathrm{D}$ band, G band and $I_{\mathrm{D}} / I_{\mathrm{G}}$ ratio of the various CNTs samples (both SW and MWCNTs) are shown in Table 1. The ratio of $I_{\mathrm{D}} / I_{\mathrm{G}}$ for SWCNTs changed minimally from 0.237 for pristine to 0.263 after $6 \mathrm{~h}$ acid treatment. For 1 and $3 \mathrm{~h}$ acid oxidized SWCNTs, the $I_{\mathrm{D}} / I_{\mathrm{G}}$ ratio seemed to have decreased. Previous reports have shown that for relatively low purity CNTs (in this particular example the SWCNTs' purity is $85 \%$; see materials and methods) the $I_{\mathrm{D}} / I_{\mathrm{G}}$ does not provide precise overall information on the sample structure ${ }^{50}$, and the $I_{\mathrm{D}} / I_{\mathrm{G}}$ ratio might be both a reflection of washing away amorphous carbon while simultaneously inducing carboxylic acid groups $^{20}$. For instance, in the initial $1 \mathrm{~h}$ SWCNTs acid treatment, the effect of washing away amorphous $\mathrm{C}$ (which is known to lead to decreased $I_{\mathrm{D}} / I_{\mathrm{G}}{ }^{51}$ ) suppressed the effect of adding carboxylic acid groups (which is known to lead to increased $I_{\mathrm{D}} / I_{\mathrm{G}}{ }^{52}$ ). However, after $6 \mathrm{~h}$, most of the amorphous $\mathrm{C}$ was removed and the $I_{\mathrm{D}} / I_{\mathrm{G}}$ became indicative only of the degree of functionalization with carboxylic groups. 


\begin{tabular}{cccc}
\hline CNT & $\begin{array}{c}\text { D band } \\
\text { position }(\mathbf{c m}-\mathbf{1})\end{array}$ & $\begin{array}{c}\text { G band } \\
\text { position }(\mathbf{c m}-\mathbf{1})\end{array}$ & $\begin{array}{c}\boldsymbol{I}_{\boldsymbol{D}} / \boldsymbol{I}_{\boldsymbol{G}} \\
\text { Intensity ratio }\end{array}$ \\
\hline Pristine SWCNTs & 1328 & 1590 & 0.237 \\
1 h cut SWCNTs & 1333 & 1587 & 0.195 \\
3 h cut SWCNTs & 1336 & 1592 & 0.229 \\
6 h cut SWCNTs & 1336 & 1595 & 0.263 \\
Pristine MWCNTs & 1345 & 1586 & 0.457 \\
1 h cut MWCNTs & 1347 & 1586 & 0.783 \\
3 h cut MWCNTs & 1349 & 1586 & 0.788 \\
6 h cut MWCNTs & 1351 & 1589 & 0.796 \\
\hline
\end{tabular}

Table 1: Relative intensity of representative Raman peaks of pristine and acid treated CNTs.

$I_{\mathrm{D}} / I_{\mathrm{G}}$ for MWCNTs increased from 0.457 for pristine to 0.788 for $3 \mathrm{~h}$, and 0.796 after $6 \mathrm{~h}$ acid treatment respectively. This increase in the level of functionalization has a similar trend to the increase in the $\mathrm{O}$ or decrease in the Fe catalyst content as observed through the EDX analyses (Figure 1). Specifically, for the high purity MWCNTs most of the Fe catalysts are removed during the $3 \mathrm{~h}$ treatment time (see inset Figure $1 \mathrm{~b}$ ) this leading to removal of the defects in the MWCNTs structure. Since defects are where the promotion of the carboxylic groups formation takes place ${ }^{53}$, and since for the MWCNTs there was a small decrease in the Fe and a small increase in the $\mathrm{O}$ content (Figure $1 \mathrm{~b}$ inset) from the $3 \mathrm{~h}$ to $6 \mathrm{~h}$ treatment time, the $I_{\mathrm{D}} / I_{\mathrm{G}}$ for MWCNTs will be minimally changed between these time points as indicated in Table 1 . Such analyses confirm that the acid treatment introduced CNTs chemical property changes i.e., added functional free carboxylic acid groups, to both SW- and MWCNTs sample.

We further investigated how the degree of CNTs dispersion in water-based environments is influenced by the acid treatment time. We used two solvents with different pH's and ionic strengths, i.e. di water ( $\mathrm{pH}$ 6.25) and Phosphate Saline Buffer (PBS, pH 7, $100 \mathrm{mM})$. The results (Figure 4) indicated that the solubility of CNTs in both di water and PBS was improved upon the acid treatment, with increased acid treatment times leading to increased solubility. Generally, 
pristine and acid oxidized SWCNTs (either 1, 3 or 6 h cut) were more dispersed in PBS when compared to di water (Figure 4a). MWCNTs did not show a similar trend; specifically, pristine and $1 \mathrm{~h}$ cut MWCNTs were more soluble in PBS, however, after longer acid treatment times (i.e., 3 and $6 \mathrm{~h}$ ) the solubility was higher in water when compared to PBS (Figure 4b). The changes in the solubility observed for the MWCNTs samples after longer acid treatment times are correlated with the changes in the functionality of these samples and number of carboxylic acidic groups being generated. Specifically, longer acid treatment times will lead to higher number of carboxyl groups being generated (see Figure 1 and Figure 3). When the MWCNTs acid treated samples are placed in water-based environments, carboxylate anions groups are generated by the deprotonation of carboxylic acid groups ${ }^{54}$. At high ionic strength, the probability for these anions to form aggregates ${ }^{55}$ increases thus leading to the lower solubility observed for the 3 and $6 \mathrm{~h}$ acid treated MWCNTs placed in PBS when compared to solubility of these samples placed in water.

a)

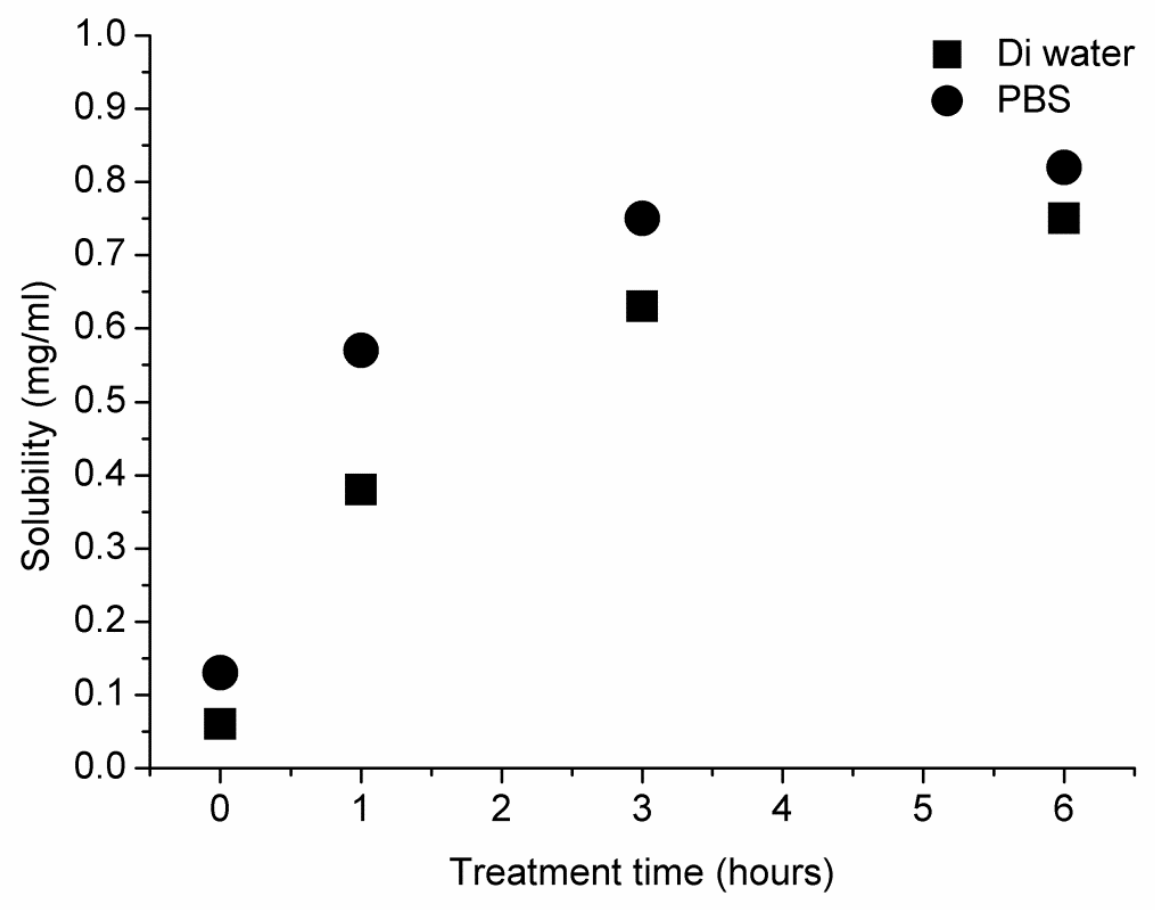


b)

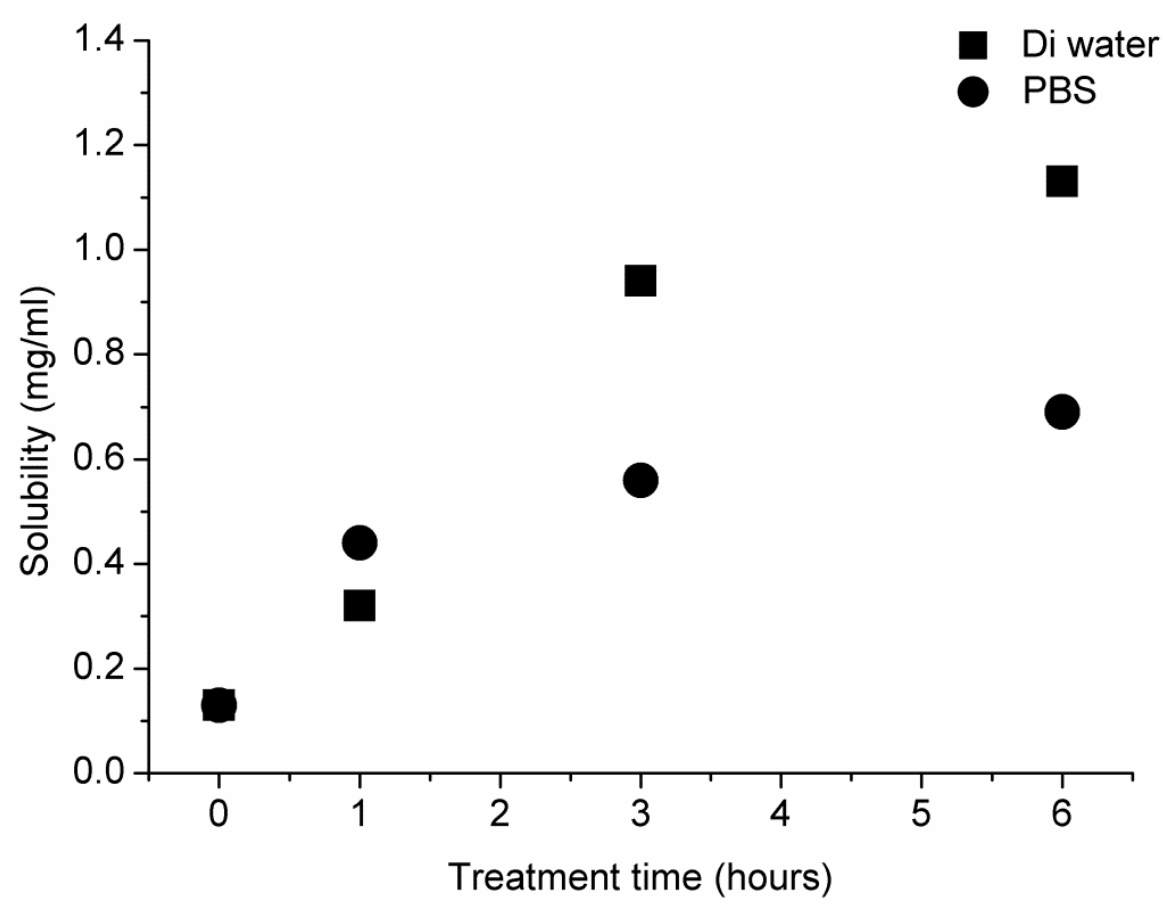

Figure 4: Solubility of pristine and acid treated SWCNTs (a) and MWCNTs (b) in deionized (di) water and phosphate buffer saline (PBS).

Atomic Force Microscopy (AFM) and tapping mode ${ }^{56}$ was used to analyze the morphology and quantify the length of the CNTs samples. Specifically, cross sectional areas from $(10 \times 10)$ to $(1 \times 1) \mu \mathrm{m} \times \mu \mathrm{m}$ were scanned to derive the length of at least $30 \mathrm{CNTs} / \mathrm{sample}$ (both SW- and MWCNTs; pristine, 1, 3 and $6 \mathrm{~h}$ cut). Pristine and acid treated CNTs length distributions are shown in Figure 5; a general non-linear distribution towards shorter CNTs was observed with the increase in the acid treatment time. 
a)

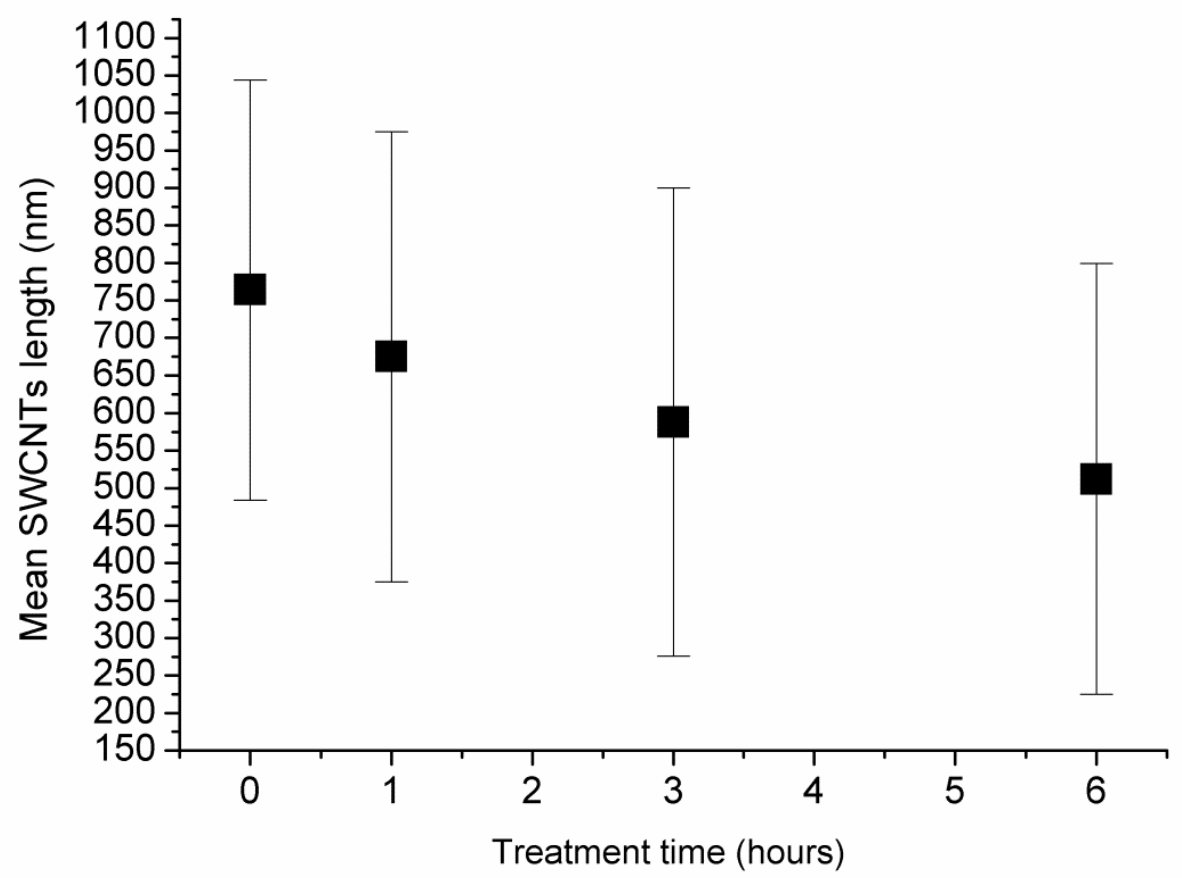

b)

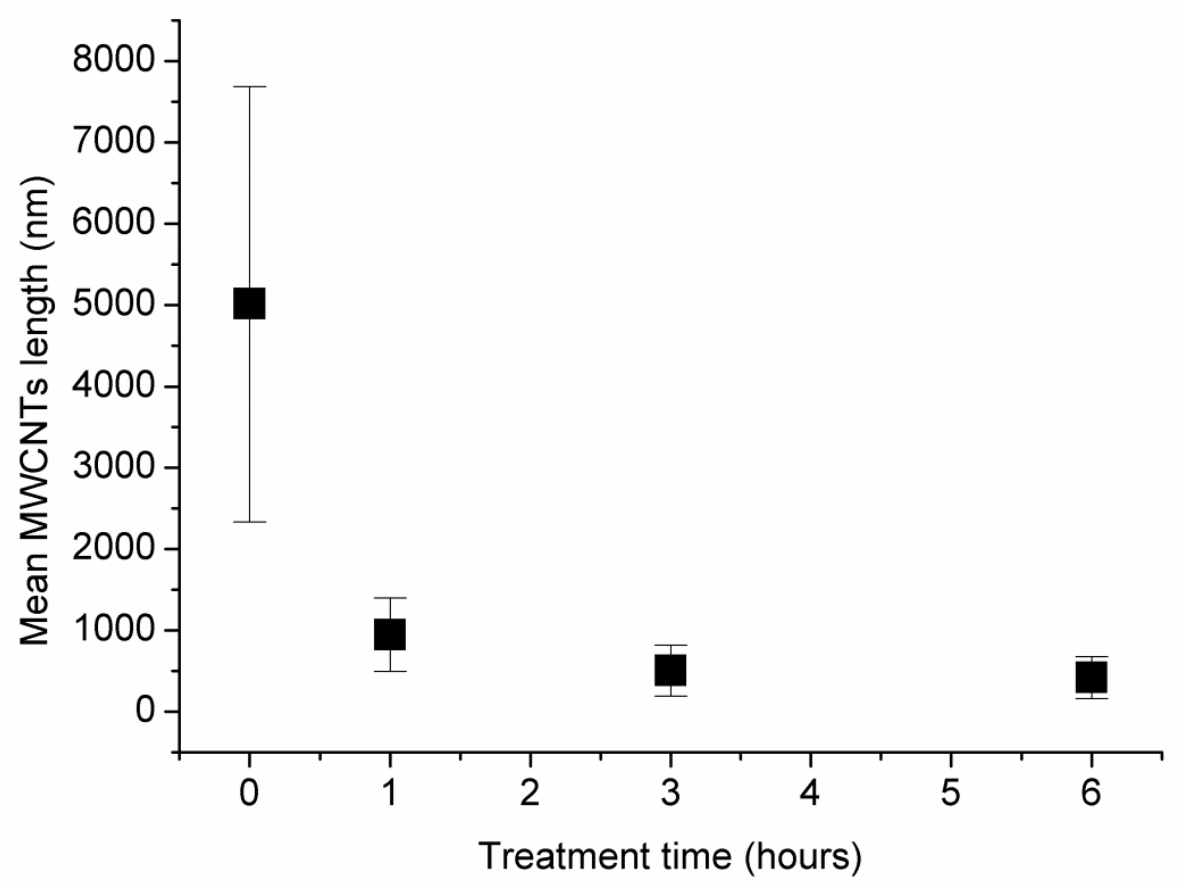

Figure 5: The average length distribution and the standard deviation of SWCNTs (a) and MWCNTs (b) with the acid treatment time.

Having established that the acid treatment influences the chemical and physical 
properties of pristine CNTs (both SW- and MWCNTs), we proceeded to examine whether usercontrolled acid treatment would also affect CNTs biocompatibility. First, we performed a systematic study on the cellular toxicity resulted from the incubation of immortalized human bronchial epithelial cells with acid treated SWCNTs. Previous in vivo studies have shown that cellular exposure to SWCNTs results in macrophages without nuclei ${ }^{57,58}$, with SWCNTs inducing chromosome aberration ${ }^{18}$. However, to our knowledge, no studies that looked at the influence of the different acid treatment times to BEAS-2B immortalized human bronchial epithelial cells have been performed. Moreover, to our knowledge, there is no correlation in the literature on how cellular toxicity depends on the SWCNTs physical and chemical properties as impaired by the acid treatment time and how such toxicity can be controlled.

In our experiments, BEAS-2B cells were exposed to SWCNTs for 24 to $72 \mathrm{~h}$ at Permissible Exposure Limit for particulates not otherwise regulated (i.e., $100 \mu \mathrm{g} / \mathrm{ml}$ of SWCNTs, based on previous laboratory exposure levels ${ }^{58,59}$ ). Figure 6 shows the percentage of apoptotic BEAS-2B cells upon exposure to SWCNTs; our data shows that the cytotoxicity of the $6 \mathrm{~h}$ acid treated SWCNTs is lower than that of pristine SWCNTs. Specifically, the percentage of apoptotic cells for pristine SWCNTs is about 19\% while the percentage of apoptotic cells for $6 \mathrm{~h}$ acid treated SWCNTs is about $15 \%$ upon $72 \mathrm{~h}$ incubation. These results are comparable to control cells (cells that have not been exposed to SWCNTs) and they emphasize that user-controlled acid treatment time can be employed to create a library of sample of SWCNTs that have high biocompatibility with cellular system.

We hypothesized that the observed trend is due to the changes in the chemical and physical structure of the SWCNTs upon acid functionalization. Specifically, shorter and more hydrophilic SWCNTs (see our previous EDX and AFM results) would be predominantly taken 
up by the cells through endocytosis ${ }^{60}$, while for the longer SWCNTs the uptake mechanism is predominantly through piercing ${ }^{61}$. Further, the longer SWCNTs once taken up by the cells can localize at the cell nucleus and interfere with the normal progression of cells to division ${ }^{58,60}$ thus leading to the observed results. In the future, such library can be utilized for instance for the cellular delivery of drugs or molecules of interest ${ }^{11}$.

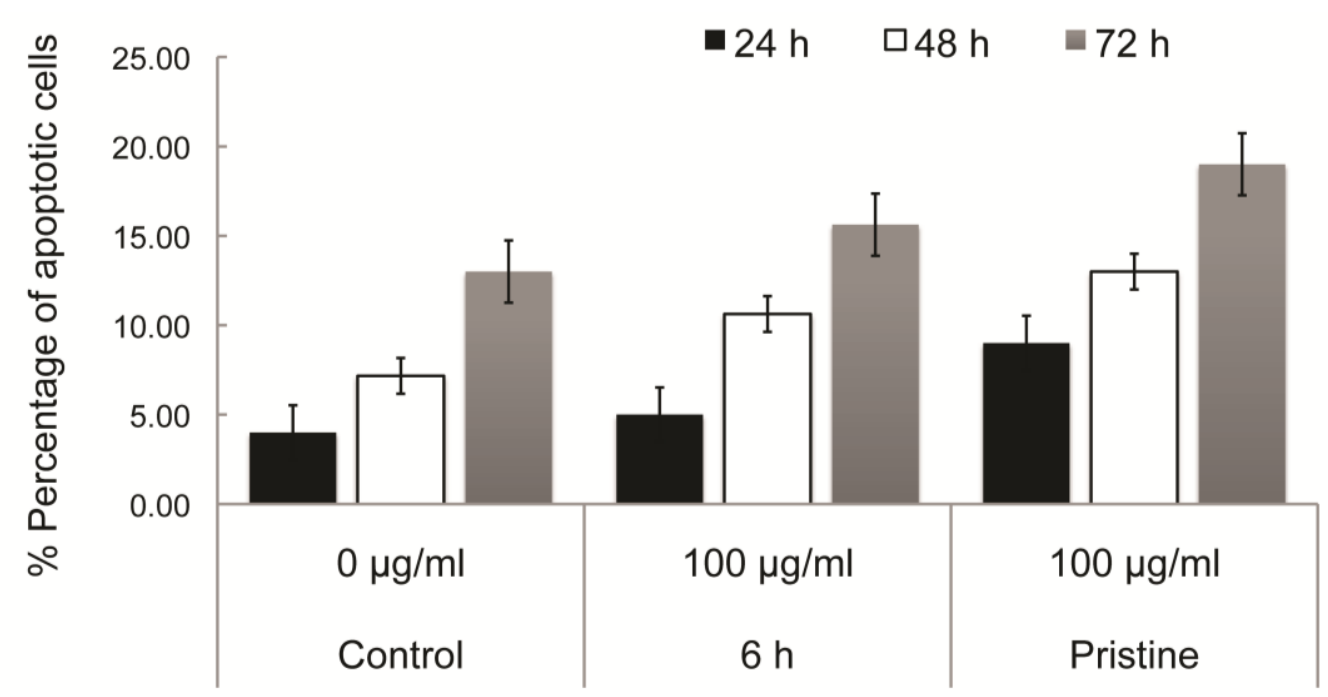

Figure 6: Cytotoxicity of pristine and $6 \mathrm{~h}$ acid treated SWCNTs to BEAS-2B human epithelial cells after 24,48 and $72 \mathrm{~h}$ respectively.

Secondly, we tested the biocompatibility of the CNTs in relation to enzyme immobilization. Enzyme immobilization provides enzyme reutilization and eliminates costly enzyme recovery and purification processes. CNTs have high surface area ${ }^{62}$ that facilitates the preparation of enzyme-CNTs conjugates with high enzyme loadings per unit weight of material $^{63,64}$ and promote protein activity and stability in strongly denaturing environments ${ }^{63-67}$. A test enzyme, namely soybean peroxidase (SBP) was immobilized through covalent binding to MWCNTs $^{64,65,68-73}$. Table 2 shows the loading (defined as the amount of the enzyme immobilized onto the MWCNTs) and the retained specific activity of the enzyme after immobilization. Our 
results show that the physical and chemical properties of the CNTs influence the enzyme loading and retained specific activity. The lowest activity was observed for the SBP immobilized onto the $1 \mathrm{~h}$ acid treated MWCNTs, while the activity of SBP immobilized onto 3 and $6 \mathrm{~h}$ acid treated MWCNTs showed similar values. The lower activity observed for the SBP immobilized onto $1 \mathrm{~h}$ acid treated MWCNTs can be attributed to the lower solubility of these CNTs (see Figure $4 \mathrm{~b}$ ). Specifically, lower solubility of the MWCNTs leads to larger conglomerate formation (due to predominant van der Waals interactions between the MWCNTs hydrophobic walls) thus resulting in a lower surface area exposed for immobilization of SBP. Further, SBP (a $40 \mathrm{kDa}$ molecular weight enzyme) has an isoelectric point of $3.9^{74}$; thus, at the working PBS's $\mathrm{pH}$, the protein will have a negative charge which will lead to stronger interactions with the more hydrophobic substrates of $1 \mathrm{~h}$ acid treated MWCNTs when compared to the less hydrophobic 3 and $6 \mathrm{~h}$ acid treated samples. Stronger binding of the SBP to the substrate will further lead to a reduction in the protein activity ${ }^{32,74}$. Such example demonstrated the utility of creating biocompatible MWCNTs nanosupports for biosensors applications ${ }^{10}$; such enzyme-nanosupport-based application can further be employed for decontamination of bacteria and spores ${ }^{32}$.

\begin{tabular}{|c|c|c|}
\hline Sample & $\begin{array}{c}\text { Loading } \\
(\mathrm{mg} \mathrm{SBP/mg} \mathrm{MWNT)}\end{array}$ & $\begin{array}{c}\text { Retained } \\
\text { Specific } \\
\text { Activity }(\%)\end{array}$ \\
\hline $1 \mathrm{hr}$ Cut Covalent & $0.185 \pm 0.03$ & $56.38 \pm 32.06$ \\
\hline $3 \mathrm{hr}$ Cut Covalent & $0.282 \pm 0.06$ & $28.18 \pm 6.52$ \\
\hline $6 \mathrm{hr}$ Cut Covalent & $0.265 \pm 0.15$ & $33.97 \pm 9.82$ \\
\hline
\end{tabular}

Table 2: Loading and retained specific activity of immobilized SBP onto acid treated MWCNTs. 


\section{Conclusion}

Our results have shown that user-controlled acid oxidation treatment of CNTs led to the formation of a library of samples with different physical and chemical properties. Specifically, we have shown that CNTs treatment with a nitric and sulfuric acid mixture results in removal of metal catalyst, an increase in the number of functional groups having electron accepting ability, and generation of shorter CNTs with higher solubility in aqueous environments. Our results were confirmed by Raman spectroscopy, SEM, AFM, EDX and solubility tests. Further, we have shown that CNTs acid treatment improves nanotube biocompatibility as tested by direct incubation with human epithelial cells or with test enzymes. User-controlled design of CNTs

biocompatibility can lead to new types of analytical tools for life science and biotechnology ${ }^{75-77}$. 


\section{Reference}

1 Shao, F. F., Ng, T. W., Fu, J., Shen, W. \& Ling, W. Y. L. Electrical circuits from capillary flow driven evaporation deposition of carbon nanotube ink in non-porous $\mathrm{V}$-grooves. $J$ Colloid Interf Sci 363, 425-430, doi:DOI 10.1016/j.jcis.2011.07.019 (2011).

2 Nikitin, A. et al. Hydrogen storage in carbon nanotubes through the formation of stable C-H bonds. Nano Lett 8, 162-167, doi:Doi 10.1021/N1072325k (2008).

3 Cusano, A. et al. Charge transfer effects on the sensing properties of fiber optic chemical nano-sensors based on single-walled carbon nanotubes. Carbon 47, 782-788, doi:DOI 10.1016/j.carbon.2008.11.014 (2009).

4 Ng, M. H. A., Hartadi, L. T., Tan, H. \& Poa, C. H. P. Efficient coating of transparent and conductive carbon nanotube thin films on plastic substrates. Nanotechnology 19, doi:Artn 205703 Doi 10.1088/0957-4484/19/20/205703 (2008).

5 Holt, B. D., Dahl, K. N. \& Islam, M. F. Cells Take up and Recover from ProteinStabilized Single-Wall Carbon Nanotubes with Two Distinct Rates. ACS nano 6, 34813490, doi:10.1021/nn300504x (2012).

6 Dinu, C. Z., Bale, S. S., Chrisey, D. B. \& Dordick, J. S. Manipulation of Individual Carbon Nanotubes by Reconstructing the Intracellular Transport of a Living Cell. Adv Mater 21, 1182-1186, doi:DOI 10.1002/adma.200801721 (2009).

7 Dinu, C. Z. et al. Perhydrolase-nanotube-paint sporicidal composites stabilized by intramolecular crosslinking. $J$ Mol Catal B-Enzym 75, 20-26, doi:DOI 10.1016/j.molcatb.2011.11.003 (2012).

8 Chen, H., Wang, J., Liang, G., Zhang, P. \& Kong, J. A novel exonuclease III aided amplification method for sensitive nucleic acid detection based on single walled carbon 
nanotube induced quenching. Chem Commun (Camb) 48, 269-271, doi:10.1039/c1cc16127j (2012).

9 Ho, D. A. Beyond the Sparkle: The Impact of Nanodiamonds as Biolabeling and Therapeutic Agents. ACS nano 3, 3825-3829, doi:Doi 10.1021/Nn9016247 (2009).

10 Claussen, J. C., Franklin, A. D., ul Haque, A., Porterfield, D. M. \& Fisher, T. S. Electrochemical Biosensor of Nanocube-Augmented Carbon Nanotube Networks. ACS nano 3, 37-44, doi:Doi 10.1021/Nn800682m (2009).

11 Bhirde, A. A. et al. Targeted Killing of Cancer Cells in Vivo and in Vitro with EGFDirected Carbon Nanotube-Based Drug Delivery. ACS nano 3, 307-316, doi:Doi 10.1021/Nn800551s (2009).

12 Fernandez-Sanchez, C. et al. Plasma-activated multi-walled carbon nanotube-polystyrene composite substrates for biosensing. Nanotechnology 20, doi:Artn 335501 Doi 10.1088/0957-4484/20/33/335501 (2009).

13 Cellot, G. et al. Carbon nanotubes might improve neuronal performance by favouring electrical shortcuts. Nat Nanotechnol 4, 126-133, doi:Doi 10.1038/Nnano.2008.374 (2009).

14 Ji, L. L., Shao, Y., Xu, Z. Y., Zheng, S. R. \& Zhu, D. Q. Adsorption of Monoaromatic Compounds and Pharmaceutical Antibiotics on Carbon Nanotubes Activated by $\mathrm{KOH}$ Etching. Environ Sci Technol 44, 6429-6436, doi:Doi 10.1021/Es1014828 (2010).

15 Kimura, Y. et al. Synthesis of Stacked-Cup Carbon Nanotubes in a Metal Free Low Temperature System. Nanosci Nanotech Let 3, 4-10, doi:DOI 10.1166/nnl.2011.1111 (2011).

16 Amer, M., Bushmaker, A. \& Cronin, S. Anomalous kink behavior in the current-voltage 
characteristics of suspended carbon nanotubes. Nano Res 5, 172-180, doi:DOI 10.1007/s12274-012-0197-2 (2012).

17 Vilatela, J. J., Elliott, J. A. \& Windle, A. H. A Model for the Strength of Yarn-like Carbon Nanotube Fibers. ACS nano 5, 1921-1927, doi:Doi 10.1021/Nn102925a (2011).

18 Sargent, L. M. et al. Single-walled carbon nanotube-induced mitotic disruption. Mutation research 745, 28-37, doi:10.1016/j.mrgentox.2011.11.017 (2012).

19 Zhang, S., Shado, T., Bekaroglu, S. S. \& Karanfil, T. The impacts of aggregation and surface chemistry of carbon nanotubes on the adsorption of synthetic organic compounds. Environ Sci Technol 43, 5719-5725 (2009).

20 Wepasnick, K. A. et al. Surface and structural characterization of multi-walled carbon nanotubes following different oxidative treatments. Carbon 49, 24-36, doi:DOI 10.1016/j.carbon.2010.08.034 (2011).

21 Marsh, D. H., Rance, G. A., Zaka, M. H., Whitby, R. J. \& Khlobystov, A. N. Comparison of the stability of multiwalled carbon nanotube dispersions in water. Phys Chem Chem Phys 9, 5490-5496, doi:10.1039/b708460a (2007).

22 Porter, A. E. et al. Uptake of Noncytotoxic Acid-Treated Single-Walled Carbon Nanotubes into the Cytoplasm of Human Macrophage Cells. Acs Nano 3, 1485-1492, doi:Doi 10.1021/Nn900416z (2009).

23 Park, J. G., Li, S., Liang, R., Zhang, C. \& Wang, B. Structural changes and Raman analysis of single-walled carbon nanotube buckypaper after high current density induced burning. Carbon 46, 1175-1183, doi:DOI 10.1016/j.carbon.2008.04.019 (2008).

24 Guo, W. et al. An efficient strategy for the purification of cloth-like single walled carbon nanotube soot produced by arc discharge. Carbon 48, 3769-3777, doi:DOI 
10.1016/j.carbon.2010.06.039 (2010).

25 Qu, Z. H. \& Wang, G. J. Effective Chemical Oxidation on the Structure of Multiwalled Carbon Nanotubes. J Nanosci Nanotechno 12, 105-111, doi:DOI 10.1166/jnn.2012.5145 (2012).

26 Li, L. X. \& Li, F. The effect of carbonyl, carboxyl and hydroxyl groups on the capacitance of carbon nanotubes. New Carbon Mater 26, 224-228, doi:Doi 10.1016/S1872-5805(11)60078-4 (2011).

27 Chen, L. F., Xie, H. Q., Li, Y. \& Yu, A. Surface Chemical Modification of Multiwalled Carbon Nanotubes by a Wet-Mechanochemical Reaction. J Nanomater, doi:Artn 783981 Doi 10.1155/2008/783981 (2008).

28 Shin, Y. R., Jeon, I. Y. \& Baek, J. B. Stability of multi-walled carbon nanotubes in commonly used acidic media. Carbon 50, 1465-1476, doi:DOI 10.1016/j.carbon.2011.11.017 (2012).

29 Smith, B. et al. Colloidal Properties of Aqueous Suspensions of Acid-Treated, MultiWalled Carbon Nanotubes. Environ Sci Technol 43, 819-825, doi:Doi 10.1021/Es802011e (2009).

30 Georgakilas, V. et al. Multipurpose organically modified carbon nanotubes: From functionalization to nanotube composites. $J$ Am Chem Soc 130, 8733-8740, doi:Doi 10.1021/Ja8002952 (2008).

31 Datsyuk, V. et al. Chemical oxidation of multiwalled carbon nanotubes. Carbon 46, 833840, doi:DOI 10.1016/j.carbon.2008.02.012 (2008).

32 Dinu, C. Z. et al. Enzyme-Based Nanoscale Composites for Use as Active Decontamination Surfaces. Adv Funct Mater 20, 392-398, doi:DOI 
10.1002/adfm.200901388 (2010).

33 Marks, N. E., Grandison, A. S. \& Lewis, M. J. Challenge testing of the lactoperoxidase system in pasteurized milk. Journal of Applied Microbiology 91, 735-741 (2001).

34 Forrest, G. A. \& Alexander, A. J. A model for the dependence of carbon nanotube length on acid oxidation time. J Phys Chem C 111, 10792-10798 (2007).

35 Hamon, M. A. et al. End-group and defect analysis of soluble single-walled carbon nanotubes. Chem Phys Lett 347, 8-12 (2001).

$36 \mathrm{Hu}, \mathrm{H}$. et al. Determination of the acidic sites of purified single-walled carbon nanotubes by acid-base titration. Chem Phys Lett 345, 25-28 (2001).

37 Marshall, M. W., Popa-Nita, S. \& Shapter, J. G. Measurement of functionalised carbon nanotube carboxylic acid groups using a simple chemical process. Carbon 44, 1137-1141, doi:DOI 10.1016/j.carbon.2005.11.010 (2006).

38 Kulshrestha, N. et al. Healing of Broken Multiwalled Carbon Nanotubes Using Very Low Energy Electrons in SEM: A Route Toward Complete Recovery. ACS nano 5, 1724-1730, doi:Doi 10.1021/Nn102288u (2011).

39 Kozhuharova, R. et al. Synthesis and characterization of aligned Fe-filled carbon nanotubes on silicon substrates. J Mater Sci-Mater El 14, 789-791 (2003).

40 Hirano, A., Tanaka, T., Urabe, Y. \& Kataura, H. Purification of Single-Wall Carbon Nanotubes by Controlling the Adsorbability onto Agarose Gels Using Deoxycholate. $J$ Phys Chem C 116, 9816-9823, doi:Doi 10.1021/Jp301380s (2012).

41 Biris, A. R. et al. Multiwall carbon nanotubes synthesized by RF-CCVD on novel $\mathrm{CaO}$ supported catalysts. Phys Lett A 372, 6416-6419, doi:DOI 10.1016/j.physleta.2008.08.030 (2008). 
42 Dresselhaus, M. S., Jorio, A., Hofmann, M., Dresselhaus, G. \& Saito, R. Perspectives on Carbon Nanotubes and Graphene Raman Spectroscopy. Nano Lett 10, 751-758, doi:Doi 10.1021/N1904286r (2010).

43 Mishra, A. K. \& Ramaprabhu, S. Nano magnetite decorated multiwalled carbon nanotubes: a robust nanomaterial for enhanced carbon dioxide adsorption. Energ Environ Sci 4, 889-895, doi:Doi 10.1039/C0ee00076k (2011).

44 Dong, C. B., Yan, Z. J., Kokx, J., Dinu, C. Z. \& Chrisey, D. B. Antibacterial and surfaceenhanced Raman scattering (SERS) activities of $\mathrm{AgCl}$ cubes synthesized by pulsed laser ablation in liquid. Appl Surf Sci, doi:10.1016/j.apsusc.2011.07.076 (2011).

45 Maultzsch, J. et al. Raman characterization of boron-doped multiwalled carbon nanotubes. Appl Phys Lett 81, 2647-2649, doi:Doi 10.1063/1.1512330 (2002).

46 Dervishi, E. et al. Morphology of multi-walled carbon nanotubes affected by the thermal stability of the catalyst system. Chem Mater 19, 179-184, doi:Doi 10.1021/Cm0622371 (2007).

47 Yang, C. W., Hu, X. U. \& Zhang, Y. A study of the functionalization on multi-walled carbon nanotubes. 2006 1st IEEE International Conference on Nano/Micro Engineered and Molecular Systems, Vols 1-3, 83-86 (2006).

48 Kalbac, M. et al. Defects in Individual Semiconducting Single Wall Carbon Nanotubes: Raman Spectroscopic and in Situ Raman Spectroelectrochemical Study. Nano Lett 10, 4619-4626, doi:Doi 10.1021/N1102727f (2010).

49 Dittmer, S. et al. In situ Raman studies of single-walled carbon nanotubes grown by local catalyst heating. Chem Phys Lett 457, 206-210, doi:DOI 10.1016/j.cplett.2008.04.008 (2008). 
50 Wepasnick, K. A., Smith, B. A., Bitter, J. L. \& Fairbrother, D. H. Chemical and structural characterization of carbon nanotube surfaces. Anal Bioanal Chem 396, 1003-1014, doi:DOI 10.1007/s00216-009-3332-5 (2010).

51 Shao, L. et al. Removal of amorphous carbon for the efficient sidewall functionalisation of single-walled carbon nanotubes. Chem Commun, 5090-5092, doi:Doi 10.1039/B712614j (2007).

52 Tchoul, M. N., Ford, W. T., Lolli, G., Resasco, D. E. \& Arepalli, S. Effect of mild nitric acid oxidation on dispersability, size, and structure of single-walled carbon nanotubes. Chem Mater 19, 5765-5772, doi:Doi 10.1021/Cm0717581 (2007).

$53 \mathrm{Gu}, \mathrm{L}$. R. et al. Single-walled carbon nanotube as a unique scaffold for the multivalent display of sugars. Biomacromolecules 9, 2408-2418, doi:Doi 10.1021/Bm800395e (2008).

54 Shieh, Y. T., Liu, G. L., Wu, H. H. \& Lee, C. C. Effects of polarity and pH on the solubility of acid-treated carbon nanotubes in different media. Carbon 45, 1880-1890, doi:DOI 10.1016/j.carbon.2007.04.028 (2007).

55 Shieh, Y. T., Chen, J. Y., Twu, Y. K. \& Chen, W. J. The effect of pH and ionic strength on the dispersion of carbon nanotubes in poly(acrylic acid) solutions. Polym Int 61, 554-559, doi:Doi 10.1002/Pi.3203 (2012).

56 Heister, E. et al. Higher Dispersion Efficacy of Functionalized Carbon Nanotubes in Chemical and Biological Environments. ACS nano 4, 2615-2626, doi:Doi 10.1021/Nn100069k (2010).

57 Bussy, C. et al. Carbon nanotubes in macrophages: Imaging and chemical analysis by Xray fluorescence microscopy. Nano Lett 8, 2659-2663, doi:Doi 10.1021/N1800914m 
(2008).

58 Sargent, L. M. et al. Induction of aneuploidy by single-walled carbon nanotubes. Environmental and molecular mutagenesis 50, 708-717, doi:10.1002/em.20529 (2009).

59 Maynard, A. D. et al. Exposure to carbon nanotube material: aerosol release during the handling of unrefined single-walled carbon nanotube material. Journal of toxicology and environmental health. Part A 67, 87-107, doi:10.1080/15287390490253688 (2004).

60 Jin, H., Heller, D. A., Sharma, R. \& Strano, M. S. Size-Dependent Cellular Uptake and Expulsion of Single-Walled Carbon Nanotubes: Single Particle Tracking and a Generic Uptake Model for Nanoparticles. Acs Nano 3, 149-158 (2009).

61 Pogodin, S. \& Baulin, V. A. Can a Carbon Nanotube Pierce through a Phospholipid Bilayer? Acs Nano 4, 5293-5300, doi:Doi 10.1021/Nn1016549 (2010).

62 Chakraborty, S. et al. Surface area measurement of functionalized single-walled carbon nanotubes. J Phys Chem B 110, 24812-24815 (2006).

63 Asuri, P., Karajanagi, S. S., Vertegel, A. A., Dordick, J. S. \& Kane, R. S. Enhanced stability of enzymes adsorbed onto nanoparticles. $J$ Nanosci Nanotechnol 7, 1675-1678 (2007).

64 Asuri, P. et al. Increasing protein stability through control of the nanoscale environment. Langmuir 22, 5833-5836 (2006).

65 Karajanagi, S. S. et al. Protein-assisted solubilization of single-walled carbon nanotubes. Langmuir 22, 1392-1395 (2006).

66 Alonso-Lomillo, M. A. et al. Hydrogenase-Coated Carbon Nanotubes for Efficient H2 Oxidation. Nano Letters 7, 1603-1608 (2007).

67 Yu, X., Chattopadhyay, D., Galeska, I., Papadimitrakopoulos, F. \& Rusling, J. F. 
Peroxidase activity of enzymes bound to the ends of single-wall carbon nanotube forest electrodes. Electrochemistry Communications 5, 408-411 (2003).

68 Asuri, P., Bale, S. S., Karajanagi, S. S. \& Kane, R. S. The protein-nanomaterial interface. Curr Opin Biotechnol 17, 562-568 (2006).

69 Asuri, P. et al. Water-soluble carbon nanotube-enzyme conjugates as functional biocatalytic formulations. Biotechnol Bioeng 95, 804-811 (2006).

70 Asuri, P., Karajanagi, S. S., Dordick, J. S. \& Kane, R. S. Directed assembly of carbon nanotubes at liquid-liquid interfaces: nanoscale conveyors for interfacial biocatalysis. $J$ Am Chem Soc 128, 1046-1047 (2006).

71 Joshi, K. A. et al. A disposable biosensor for organophosphorus nerve agents based on carbon nanotubes modified thick film strip electrode. Electroanalysis 17, 54-58 (2005).

72 Li, J., Wang, Y.-B., Qiu, J.-D., Sun, D.-c. \& Xia, X.-H. Biocomposites of covalently linked glucose oxidase on carbon nanotubes for glucose biosensor. Analytical and Bioanalytical Chemistry 383, 918-922 (2005).

73 Jia, N. et al. Bioelectrochemistry and enzymatic activity of glucose oxidase immobilized onto the bamboo-shaped CNx nanotubes. Electrochimica Acta 51, 611-618 (2005).

74 Zhang, W. C., Dai, X. H., Zhao, Y., Lu, X. M. \& Gao, P. J. Comparison of the Different Types of Surfactants for the Effect on Activity and Structure of Soybean Peroxidase. Langmuir 25, 2363-2368, doi:Doi 10.1021/La803240x (2009).

75 Lin, Y. et al. Advances toward bioapplications of carbon nanotubes. Journal of Materials Chemistry 14, 527-541 (2004).

76 Sun, Y. P., Fu, K., Lin, Y. \& Huang, W. Functionalized carbon nanotubes: properties and applications. Acc Chem Res 35, 1096-1104 (2002). 
77 Baughman, R. H., Zakhidov, A. A. \& de Heer, W. A. Carbon nanotubes--the route toward applications. Science 297, 787-792 (2002). 


\title{
Chapter 2: Exposure to carbon nanotubes leads to changes in the cellular biomechanics
}

\begin{abstract}
We demonstrated that exposure to multi-walled carbon nanotubes induces significant changes in cellular biomechanics leading to increased stiffness, especially at the nuclear region. Consequently, measures of the mechanical properties of cell could be used as indicators of its biological state and could offer valuable insights into the mechanisms associated with CNTsinduced genetic instability.
\end{abstract}




\section{Introduction}

Carbon nanotubes (CNTs) are rolled-up cylindrical structures of single or multiple sheets of graphene (single-walled carbon nanotubes-SWCNTs or multi-walled carbon nanotubesMWCNTs) that have high aspect ratio ${ }^{1,2}$, high electrical and thermal conductivity ${ }^{3,4}$, ultra-light weight $^{5}$, and high mechanical strength ${ }^{6}$. Their unique properties provide a tremendous potential for applications in fields as diverse as electronics ${ }^{7}$, aerospace industries ${ }^{8}$, sensors ${ }^{9}$, actuators ${ }^{10}$ or composites $^{11}$. Based on their properties, researchers have also been exploring CNTs potential for biological and biomedical applications as drug delivery systems ${ }^{12}$, substrate for cells growth in tissue regeneration ${ }^{13}$, therapeutic agents ${ }^{13}$, or as vectors for gene transfection ${ }^{14}$. Such broad applications of CNTs have led to an increased production level and thus increased concerns regarding human and environmental exposure. Further, given their applications in the biomedical field $^{15-19}$, understanding how biological systems interact with this nanomaterial is urgently needed to create safer therapies ${ }^{16,20-22}$, and to regulate occupational exposures ${ }^{23-25}$.

. CNTs genotoxicity has been attributed to a variety of factors including metal impurities, length, size, number of walls, surface area, dispersion, and/or CNTs surface functionalization. ${ }^{26-}$ ${ }^{29}$ Recent work has shown that in vitro and in vivo exposure to SWCNTs can lead to alterations in DNA structure ${ }^{26,27} \cdot 30,31$ For instance, recent studies have shown that 24 to $72 \mathrm{~h}$ exposure of epithelial cells to SWCNTs induced centrosome fragmentation and aneuploidy ${ }^{30,32}$ similar to the genotoxin vanadium pentoxide ${ }^{33}$. Likewise, cellular exposure to MWCNTs disrupted the mitotic spindle by association with microtubules ${ }^{34}$, induced polyploidy ${ }^{24}$ and changes in chromosome number in a fashion similar to crocidolite asbestos ${ }^{26,32,35}$ 
Studies have shown that cancer development is related to alterations in cell mechanics including changes in the cell structure ${ }^{36}$, morphology $y^{37}$, and responses to mechanical stimuli ${ }^{38}$. The mechanical changes of cells are regulated by dynamic networks of cytoskeletal filaments such as microtubules ${ }^{39}$ and actin, and by signaling molecules ${ }^{40}$. Alterations for mechanical structure of an individual cell could reveal important information about changes in cytoskeletal networks, with changes in the cell rigidity being correlated with malignant transformation and cancer progression ${ }^{41}$. Studies have shown that SWCNTs can induce actin bundling and influence cell proliferation in exposed cells. ${ }^{42}$ Other studies have shown that MWCNTs interact with microtubules, blocking mitosis and leading to cell death by apoptosis ${ }^{34}$. Given the complex effects of CNTs on increased genetic instability, as well as the association of CNTs with the cytoskeletal filaments, it is important that we begin to understand how exposure to these nanomaterials affects cellular biomechanics that may be functionally linked to mechanisms involved in CNTs-induced genotoxicity and potentially for cancer development.

Studies have demonstrated the effectiveness of nanoindentation based on atomic force microscopy (AFM) on assessing differences between cancer cells and normal cells based on their mechanics. For instance, displacement curves of the AFM cantilever versus vertical position of the scanner demonstrated that cancer cells have greater variability in their force behavior when compared to normal cells ${ }^{38,43}$. Also, nanomechanical-based functional analysis has been used to detect metastatic tumor cells in bodily fluids, with changes in nanomechanical properties of such cells being associated with shape changes inherent to metastatic adenocarcinoma cells $\mathrm{s}^{41,44}$. 
Herein, we have examined the biomechanics of epithelial cells exposed to MWCNTs with diameters of 10-20 nm and lengths $<1 \mu \mathrm{m}$. Our hypothesis was that MWCNTs permissible exposure limit ${ }^{45}$ leads to morphological and cytomechanical cellular changes that can be detected using nanoindentation ${ }^{41}$. Our observations suggest that measures of the mechanical properties of cells upon MWCNTs exposure could be used as indicators of their biological state with MWCNTs-induced increased cellular stiffness suggesting the potential for genetic instability and cancer development. 


\section{Materials and Methods}

\section{Multi-walled carbon nanotubes (MWCNTs) acid washing}

Commercial multi-walled carbon nanotubes (MWCNTs, Nanolab Inc. PD15L5-20, USA) were suspended in a mixture of $3: 1(\mathrm{~V} / \mathrm{V})$ concentrated sulfuric acid (96.4\%, Fisher, USA) and nitric acid (69.5\%, Fisher, USA) and placed for $1 \mathrm{~h}$ in a water and ice bath sonicator (Branson 2510, Fisher, USA). Subsequently the mixture was diluted in deionized (di) water and filtered through a GTTP $0.2 \mu \mathrm{m}$ polycarbonate filter membrane (Fisher, USA); the filtration process was repeated at least 6 times to remove catalysts or impurities.

\section{Characterization of MWCNTs}

Energy dispersive X-ray analysis (EDX) allowed quantitative elemental analysis of pristine and $1 \mathrm{~h}$ acid-washed MWCNTs. Samples $(1 \mathrm{mg} / \mathrm{ml}$ in water $)$ were vacuum dried on silica wafers. Experiments were performed on a Hitachi S-4700 Field Emission Scanning Electron Microscope (USA) combining secondary (SE) and backscattered (BSE) electron detection in a single unit and operating at $20 \mathrm{kV}$.

The chemical structure of MWCNTs (both pristine and $1 \mathrm{~h}$ acid-washed) was investigated using Raman spectroscopy. Experiments were performed at room temperature using a Renishaw InVia Raman Spectrometer (CL532-100, 100 mW, USA). Nanotubes (1 mg) were mounted on clean glass slides (Fisher, USA) and irradiated through a 20x microscope objective using an argon ion $\left(\mathrm{Ar}^{+}\right)$laser beam with a spot size of $<0.01 \mathrm{~mm}^{2}$ operating at $514.5 \mathrm{~nm}$. Low laser energy of $<0.5 \mathrm{mV}$ and an exposure time of $10 \mathrm{sec}$ prevented local heating effects; scans in 100 to $3200 \mathrm{~cm}^{-1}$ range were acquired. 
An atomic force microscope (AFM) and Si tips (AC240TS, 50 to $90 \mathrm{kHz}$, Asylum Research, USA) was used to investigate the length of both pristine and $1 \mathrm{~h}$ acid-washed MWCNTs. Nanotubes $(10 \mu \mathrm{g} / \mathrm{mL}$, pristine or $1 \mathrm{~h}$ acid-washed) were deposited on mica surfaces (9.5 mm diameter, 0.15-0.21 mm thickness, Electron Microscopy Sciences, USA) and dried under vacuum. Scans of $10 \mu \mathrm{m} \times 10 \mu \mathrm{m}$ area were acquired using tapping mode in air; at least 30 individual nanotubes from different slides were analyzed for an average length distribution.

\section{MWCNTs solubility tests}

The solubility of pristine and $1 \mathrm{~h}$ acid washed MWCNTs in water, phosphate buffer or dulbecco modified eagle medium (DMEM, Invitrogen, USA) with or without fetal bovine serum (FBS, Invitrogen, USA) were determined by centrifuging the corresponding solution suspension

(initial concentration $3 \mathrm{mg} \mathrm{mL}^{-1}$ for pristine and $1 \mathrm{~h}$ acid-washed MWCNTs) at $3000 \mathrm{rpm}$ for 5 min and then filtering the supernatant $(0.8 \mathrm{~mL})$ through a $0.2-\mu \mathrm{m}$ GTTP membrane. After complete drying under vacuum, the amount of pristine and $1 \mathrm{~h}$ acid-washed MWCNTs on the membrane was weighted and the solubility was calculated based on the initial amount and volume of the starting sample.

\section{Cell culture and cell treatment}

Immortalized human bronchial epithelial cells (BEAS-2B, ATCC, USA) of passages 4-6 were cultured in DMEM media supplemented with $10 \%$ FBS. Cells of at least $90 \%$ purity and $80 \%$ viability from a single lot were used for all experiments.

BEAS-2B cells plated in $50 \mathrm{~mm}$ parallel culture dishes (BD Biosciences, USA) at a 
density of $1 \times 10^{5}$ cells per dish for $24 \mathrm{~h}$ or $1 \mathrm{~h}$ and then exposed to $24 \mu \mathrm{g} / \mathrm{cm}^{2}$ MWCNTs. For biomechanical analysis, the BEAS-2B cells (control-unexposed or exposed) were washed with phosphate saline buffer (PBS, Invitrogen, USA) two times for 5 min each and then fixed with 4\% glutaraldehyde solution (Sigma, USA) for 30 min, washed again and further analyzed in PBS.

\section{Biomechanical studies}

A commercially available atomic force microscope (AFM) integrated with an inverted fluorescence microscope (MFP-3D-BIO; Asylum Research, TE2000-U, USA) was used to probe the cellular topography and mechanical properties of the cellular samples. Cells were imaged in liquid Petri dishes using contact mode and Olympus TR400-PB cantilevers with spring constants of $0.09 \mathrm{~N} / \mathrm{m}$. Scan speeds at $0.25 \mathrm{~Hz}$, pixel resolutions of 512, and scan angle of $90^{\circ}$ (with respect to the cantilever) were employed for the topography imaging. Cellular biomechanics was investigated using the Sneddon's modification of the Hertz model developed for a four-sided pyramid $^{47,48} \cdot 46,47$ Specifically, force-displacement curves were converted into force-indentation curves ${ }^{48}$ with the assumption that the indented sample is extremely thick in comparison to the indentation depth. The cell stiffness (Young's modulus, E) was related to the indentation of the tip, $\delta$ through equation (1):

$$
E=\frac{\pi}{2} \frac{1-v^{2}}{\tan \alpha} \frac{F}{\delta^{2}} \text {, where the Poisson's ratio for the cells was } v=0.5^{47} \text { and } \alpha=36^{\circ} \text { is the }
$$

open angle of the tip. The loading force on the cantilever $F$ was calculated by simultaneously recording cantilever's deflection multiplied by the spring constant of the cantilever $(k=0.09$ $\mathrm{N} / \mathrm{m})$.

\section{Statistical analysis}

The cell culture experiments were performed using a complete randomized block design. 
Each block contained 2 cell culture dishes which were randomly assigned either vehicle or MWCNTs treatment. Three blocks were run in total. For each culture, 4 to 7 cells were examined and averaged into a single value as cells from the same culture are not independent. The variables, including Young's modulus, surface area and height were analyzed using the Proc Mixed procedure in SAS/Stat for Windows (SAS, Cary NC) with experimental block modeled as a random effect. All differences were considered statistically significant at $\mathrm{p}<0.05$. 


\section{Results and Discussion}

We used acid-washed MWCNTs prepared from pristine MWCNTs incubated in a mixture of sulfuric and nitric acid for $1 \mathrm{~h}$ followed by subsequent washing steps in water ${ }^{49}$. Figures $1 \mathrm{a}$ and $1 \mathrm{~b}$ depicted the Raman spectra of pristine and 1h acid-washed MWCNTs. Both samples showed a small D band (disorder mode) at $\sim 1340 \mathrm{~cm}^{-1}$; the D band was wider and had a higher frequency for the $1 \mathrm{~h}$ acid-washed sample. This shift indicates that acid treatment introduced additional functional groups, i.e. free carboxylic acid groups ${ }^{50}$. The $1 \mathrm{~h}$ acid-washed MWCNTs spectra also showed a shift in the G mode $(1585 \mathrm{~nm})$ with increased intensity towards higher frequency, an indication of metal catalyst removal, increase in the number of functional groups having electron-accepting capability, and/or increase in amorphous carbon (see Supporting Information Table $\mathrm{S} 1)$. The ratio of relative intensity of $\mathrm{D}$ to $\mathrm{G}$ peaks $\left(\mathrm{I}_{\mathrm{D}} / \mathrm{I}_{\mathrm{G}}\right)$ is defined as the degree of functionalization ${ }^{51,52}$; the higher this ratio, the higher the level of functionalization. Our results indicate that $I_{D} / I_{G}$ was 0.45 for pristine and 0.78 for $1 \mathrm{~h}$ acidwashed MWCNTs, further confirming that acid treatment greatly increased the number of functional groups on the nanotubes.

a)

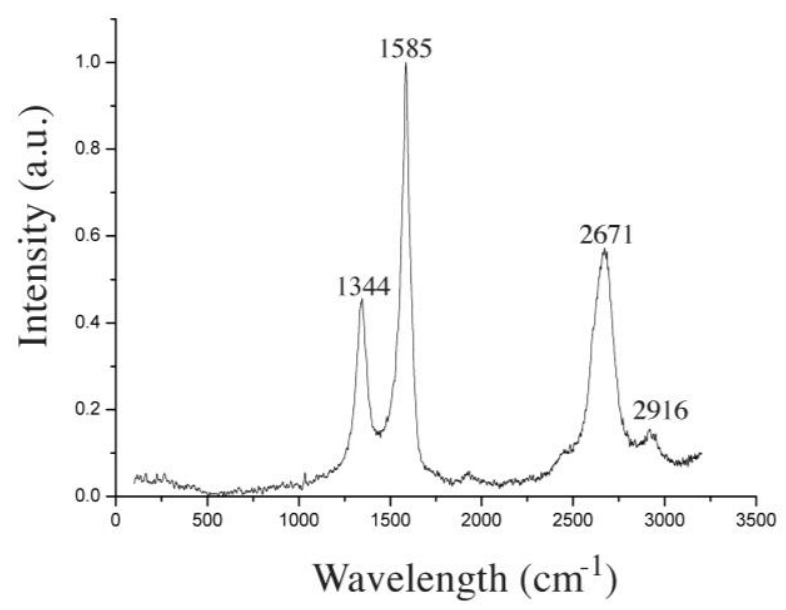


b)

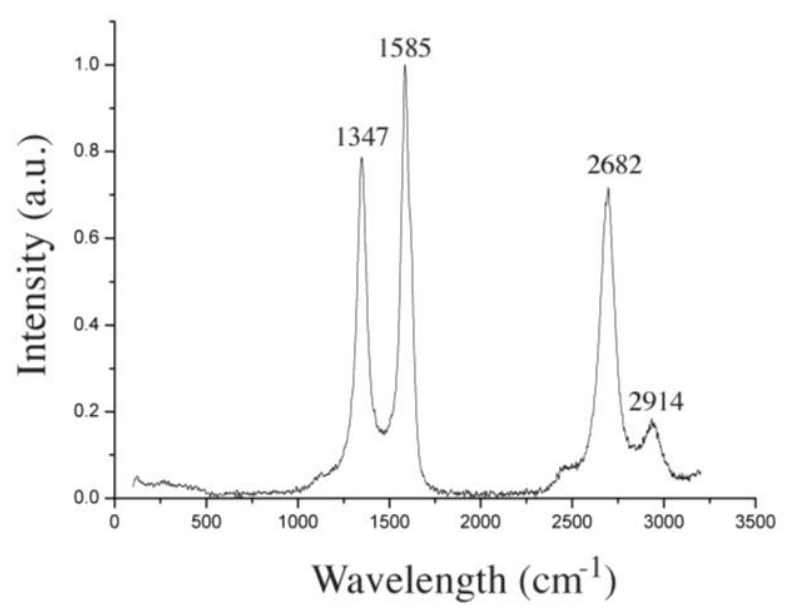

Figure 1: Raman spectra of pristine and $1 \mathrm{~h}$ acid-washed MWCNTs. (a) Pristine MWCNTs. (b) $1 \mathrm{~h}$ acid-washed MWCNTs. Four independent bands have been identified for both samples, i.e. D band around $1340 \mathrm{~cm}^{-1}, \mathrm{G}$ band at $1585 \mathrm{~cm}^{-1}, \mathrm{G}^{\prime}$ band around $2670 \mathrm{~cm}^{-1}$, and band around $2910 \mathrm{~cm}^{-1}$. Shifts in all bands are noticed for the $1 \mathrm{~h}$ acid-washed MWCNTs samples.

The presence of the carboxyl groups was further confirmed by energy-dispersive X-ray spectroscopy. Acid washing led to removal of catalysts and impurities (i.e., 25\% decrease in $\mathrm{Fe}$ in the $1 \mathrm{~h}$ acid-washed sample when compared with the pristine sample) and an increase of $17 \%$ in the $\mathrm{O}$ content. As a result of free carboxylic acid groups being added upon treatment ${ }^{50}$, the $1 \mathrm{~h}$ acid-washed MWCNTs have a higher dispersity (see Supporting Information Table S2) when compared to pristine MWCNTs. Further, their lengths were reduced by $81 \%$ as confirmed by atomic force microscopy (AFM) (final length $947 \pm 451 \mathrm{~nm} /$ mean \pm standard deviation; see Supporting Information Table S3).

Cell culture experiments were performed using a complete randomized block design. In a randomized block design, the experimenter divides subjects into subgroups called blocks, such that the variability within blocks is less than the variability between blocks. Then, subjects within 
each block are randomly assigned to each treatment conditions. This design reduces variability within treatment conditions and potential confounding, producing a better estimate of treatment effects. Briefly, human bronchial epithelial cells (BEAS-2B) seeded at the concentration of $10^{5}$ cells were exposed to $24 \mu \mathrm{g} / \mathrm{cm}^{2} 1 \mathrm{~h}$ acid-washed MWCNTs (a permissible exposure limit for particulates not otherwise regulated ${ }^{45}$ ) fully dispersed in culture media, for $24 \mathrm{~h}$ at $37^{\circ} \mathrm{C}$. Upon exposure, "free" $1 \mathrm{~h}$ acid-washed MWCNTs (i.e., $1 \mathrm{~h}$ acid-washed MWCNTs not associated with or taken up by the cells) were removed by washing.

Contact mode AFM was used to probe the topography and biomechanics of the cells ${ }^{53}$. To avoid changes in cellular properties during observation and analysis, samples were fixed with 4\% glutaraldehyde. Fixed cell topography was imaged by establishing mechanical contact between the AFM tip and individual cells in nonzero imaging force ${ }^{53}$ with a scan rate of $0.25 \mathrm{~Hz}$ and a pixel resolution of $176 \mathrm{~nm} /$ pixel (Figure 2a). A representative control cell body (i.e., for a cell not exposed to $1 \mathrm{~h}$ acid-washed MWCNTs) is shown in Figure $2 \mathrm{~b}$ while a representative cell exposed to $1 \mathrm{~h}$ acid-washed MWCNTs is shown in Figure 2c. The surface of the control cell appeared smooth and homogenous, in contrast with a significantly different morphology and increased roughness observed for the cell exposed to $1 \mathrm{~h}$ acid-washed MWCNTs. Interestingly, the exposed cells also showed a significant increase in their average surface area $(\sim 37.7 \%, \mathrm{p}$ $<0.05)$ when compared with control cells. However, the increase in average height $(\sim 10.5 \%)$ observed for the exposed cells was not significant when compared to the increase in the control cells (Figure 2d). 
a)

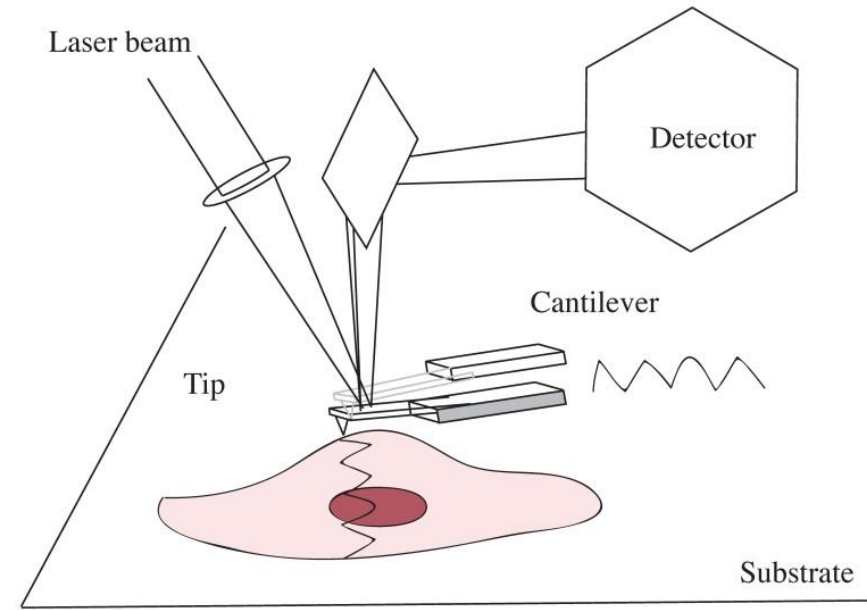

b)

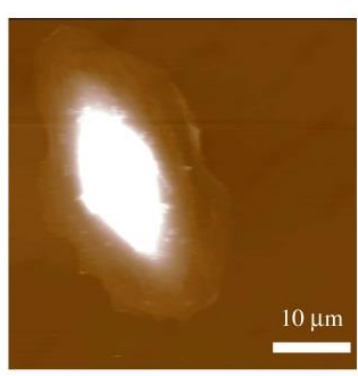

c)

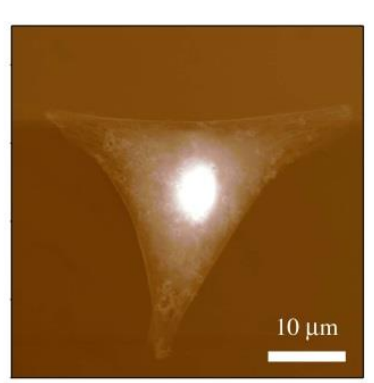

d)

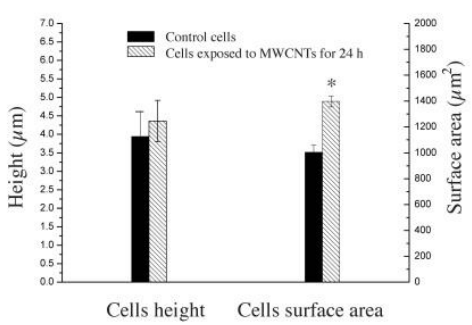

Figure 2: (a) Schematic overview of the atomic force microscopy (AFM)-based analysis of epithelial cells (control and cells exposed to $1 \mathrm{~h}$ acid-washed MWCNTs). (b) Topography image of a control cell. (c) Topography image of a cell exposed to $1 \mathrm{~h}$ acid-washed MWCNTs for $24 \mathrm{~h}$. The scale bar indicates $10 \mu \mathrm{m}$.

We studied cell biomechanics in response to exposure to $1 \mathrm{~h}$ acid-washed MWCNTs. Control cells (Figure 3a) were elastically mapped using the extended Hertz model ${ }^{47,48} \cdot{ }^{46,47}$ The resulting indentation image of a control cell (Figure 3b) shows Young's modulus of the cell body in the 100-250 $\mathrm{kPa}$ range (Figure 3c); the higher stiffness noted at the cell periphery (up to 600 $\mathrm{kPa}$ ) may be due to the underlying substrate ${ }^{53}$. The highest region of the cell (dashed red in Figure 3a; the rest of the cell body is dashed black) corresponds to the cell nucleus; this region appears softer when compared to the rest of the cell and has Young's modulus values in between $40-80 \mathrm{kPa}$ (Figure 3d). 
a)

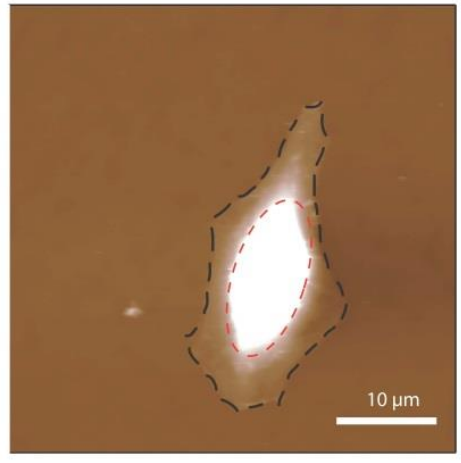

c) b)

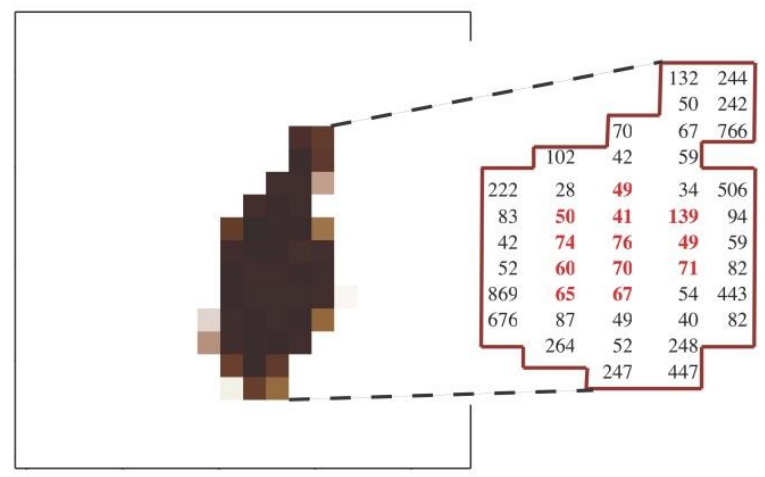

d)

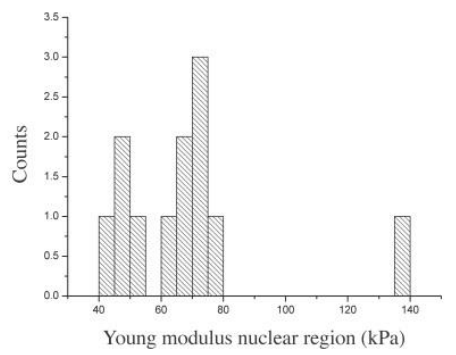

g) e)

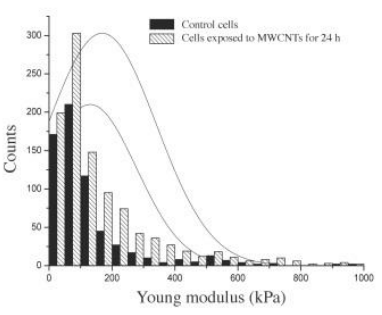

f)

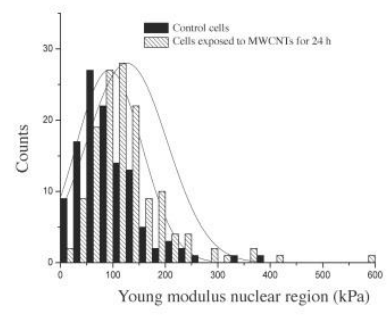

Figure 3: (a) Topography image of a single control cell; the cell body is dashed black and the cell nucleus is dashed red. (b) Indentation (elastic mapping) and Young modulus of the control cell identified in Figure 3a. (c) Histogram of the Young modulus distribution of the single control cell shown in Figure 3a. (d) Histogram of the Young modulus distribution of the nucleus region of the single control cell shown in Figure 3a. (e) Histogram of the Young modulus distribution of control cells and cells exposed to $1 \mathrm{~h}$ acid-washed MWCNTs for $24 \mathrm{~h}$. The Gaussian fit reveled a considerable shift towards higher stiffness for the cells exposed to $1 \mathrm{~h}$ acid-washed MWCNTs. (f) Histogram of the Young modulus distribution of nucleus region of control cells and cells exposed to $1 \mathrm{~h}$ acid-washed MWCNTs for $24 \mathrm{~h}$. The Gaussian fit shows 
that there is a considerable shift towards higher stiffness for the nucleus of the cells exposed to 1 $\mathrm{h}$ acid-washed MWCNTs. (g) Statistical analysis of average Young modulus distribution of control cells and cells exposed to $1 \mathrm{~h}$ acid-washed MWCNTs for $24 \mathrm{~h}$. All differences were considered statistically significant at $\mathrm{p}<0.05$.

Table 1 shows the Young modulus distribution of control cells and cells exposed to $1 \mathrm{~h}$ acid-washed MWCNTs for $24 \mathrm{~h}$. The cells exposed to $1 \mathrm{~h}$ acid-washed MWCNTs showed a significant increase in the Young's modulus when compared to the control cells $(\mathrm{p}<0.05)$. Specifically, the exposed cells have significant difference in their stiffness relative to control cells, with an overall increase of $29.8 \%$ in their Young's modulus and an increase of $36.6 \%$ in their cell nucleus Young's modulus. Further, for cells incubated with $1 \mathrm{~h}$ acid-washed MWCNTs there is a considerable shift of the Young modulus towards higher values at the cell nucleus. For instance, in between $100-400 \mathrm{kPa}$ there is an increase from $35.90 \%$ to $58.17 \%$ from control to $1 \mathrm{~h}$ acid-washed MWCNTs exposed cells. Moreover, the nucleus of the cells exposed to MWCNTs reached values as high as $600 \mathrm{kPa}$. The Gaussian fits of the cells exposed to $1 \mathrm{~h}$ acid-washed MWCNTs for the perinuclear or nuclear regions are shown in Figure $3 \mathrm{e}$ and $3 \mathrm{f}$ respectively, while the average Young's modulus of the exposed cells when compared to control cells is shown in Figure 3g. In control, when cells were incubated with $1 \mathrm{~h}$ acid-washed MWCNTs only for $1 \mathrm{~h}$ there was no shift in the Young's modulus of the exposed cells when compared to control cells (see Supporting Information Table S4). There was no significantly relevant shift observed neither for the perinuclear nor for the nuclear regions when the Gaussian fits of the cells exposed to $1 \mathrm{~h}$ acid-washed MWCNTs for $1 \mathrm{~h}$ was compared to the Gaussian fits of control cells (see Supporting Information Figure S1). It was however noted that the stiffness for both control and 1 h acid-washed MWCNTs exposed cells was about one order of magnitude larger than for living 
cells $^{54}$. This could be the result of either: (1) cell fixation with glutaraldehyde ${ }^{53}$; (2) large stiffness of the substrate ${ }^{53}$; or (3) the induced strains in the cells caused by the tip indented at low speed (i.e., $0.25 \mathrm{kHz})^{55}$.

\begin{tabular}{|c|c|c|c|c|c|c|}
\hline Group & Counts & $\begin{array}{l}0-100 \\
\text { kPa }\end{array}$ & $\begin{array}{l}\text { 100-200 } \\
\text { kPa }\end{array}$ & $\begin{array}{l}200-400 \\
\text { kPa }\end{array}$ & $\begin{array}{l}400-600 \\
\text { kPa }\end{array}$ & $\begin{array}{l}>600 \\
\mathrm{kPa}\end{array}$ \\
\hline Control cells & 647 & $58.89 \%$ & $25.04 \%$ & $8.96 \%$ & $5.10 \%$ & $2.31 \%$ \\
\hline $\begin{array}{l}\text { Cells incubated with } 1 \mathrm{~h} \text { acid- } \\
\text { washed MWCNTs for } 24 \mathrm{~h}\end{array}$ & 1025 & $48.98 \%$ & $23.71 \%$ & $17.46 \%$ & $5.85 \%$ & $4.00 \%$ \\
\hline Control cells (nucleus region) & 117 & $64.10 \%$ & $29.06 \%$ & $6.84 \%$ & $0 \%$ & $0 \%$ \\
\hline $\begin{array}{l}\text { Cells incubated with } 1 \mathrm{~h} \text { acid- } \\
\text { washed MWCNTs for } 24 \mathrm{~h} \\
\text { (nucleus region) }\end{array}$ & 141 & $40.43 \%$ & $48.94 \%$ & $9.23 \%$ & $1.4 \%$ & $0 \%$ \\
\hline
\end{tabular}

Table 1: Young modulus distribution of control cells (13 individual cells were analyzed) and cells incubated with $1 \mathrm{~h}$ acid-washed MWCNTs for $24 \mathrm{~h}$ (15 individual cells were analyzed). Randomized block design was used for the experimental design and data analysis.

Our findings are significant in that they relate for the first time the cellular changes in biomechanics upon MWCNTs exposure with the potential for genotoxicity and cancer development in the MWCNTs-exposed cells. Specifically, our study shows that after $24 \mathrm{~h}$ exposure, MWCNTs localize at the cell nucleus, with nanotube localization inducing changes in the nucleus mechanics by increasing its stiffness and overall Young's modulus with more than $36.6 \%$ than for control cells (either cells exposed to $1 \mathrm{~h}$ acid-washed MWCNTs for $1 \mathrm{~h}$ or $24 \mathrm{~h}$ to the control cells). Combining our data with previous reports that indicate that MWCNTs interact with microtubules ${ }^{34}$, the mitotic spindle ${ }^{34}$, DNA and cell division apparatus ${ }^{24}$, we propose now that the observed stiffness due to exposure to $1 \mathrm{~h}$ acid-washed MWCNTs could lead the reorganization of the three-dimensional cellular cytoskeletal network. Such reorganization could potentially disrupt the mitotic spindle, inducing errors in chromosome numbers to be propagated 
through further cellular division ${ }^{31}$ as characteristics of cancer cells ${ }^{56}$. This is also in agreement with comparative gene expression analysis that indicated that the molecular basis of the cell stiffness is reflective of the extensive molecular changes in cytoskeleton re modeling pathways ${ }^{57}$ and with previous reports that have shown that tumorgenic and metastatic potential are linked to cellular deformability. 


\section{Conclusion}

The demonstrations performed in this study are the first quantitative biomechanical measurements on how nanoindentation can be used as a valuable tool to obtain quantitative maps and spatial patterns of local cellular biomechanical changes upon exposure of human lung epithelial cells to MWCNTs. Our findings suggest significant differences in the distribution of elastic properties between the lung epithelial cells incubated with MWCNTs and control cells, with the nanomaterial incubation leading to stiffer and wider modulus distributions and reflecting nuclei modulus significantly stiffer than the cytoplasmic ones. The observations described herein may also suggest a new approach to the consideration of deleterious effects associated with CNTs exposure, and their characterization by means of forces and mechanical parameters. Our findings also provide complex data for modeling the processes associated with mechanotransduction and could lead to improved understanding of the changes in the physiological pulmonary function upon CNTs exposure and how this exposure is associated with CNTs-induced genetic instability. 
Supporting Information

\begin{tabular}{ccc}
\hline Element & $\begin{array}{c}\text { Pristine } \\
\text { MWCNTs (wt \%) }\end{array}$ & $\begin{array}{c}\text { 1 h Acid Washed MWCNTs } \\
\text { (wt \%) }\end{array}$ \\
\hline $\mathrm{C}$ & 92.04 & 91.37 \\
$\mathrm{O}$ & 4.81 & 5.61 \\
$\mathrm{Al}$ & 0.16 & 0.20 \\
$\mathrm{Si}$ & 0.10 & 0.08 \\
$\mathrm{~S}$ & 0.38 & 0.47 \\
$\mathrm{Fe}$ & 2.50 & 2.09 \\
\hline
\end{tabular}

Table S1: Energy dispersive X-ray analysis (EDX) allowed chemical characterization in the scanning electron microscope (SEM) of pristine and $1 \mathrm{~h}$ acid washed multi-walled carbon nanotubes (MWCNTs). Following the acid treatment, the content of oxygen $(\mathbf{O})$ increases while the contents of iron $(\mathrm{Fe})$ and carbon $(\mathrm{C})$ decreases in the $1 \mathrm{~h}$ acid treated sample.

\begin{tabular}{ccccc}
\hline Type & $\begin{array}{c}\text { DI Water } \\
(\mathbf{m g} / \mathbf{m l})\end{array}$ & PBS $(\mathbf{m g} / \mathbf{m l})$ & $\begin{array}{c}\text { DMEM } \\
(\mathbf{m g} / \mathbf{m l})\end{array}$ & $\begin{array}{c}\text { DMEM+FBS } \\
(\mathbf{m g} / \mathbf{m l})\end{array}$ \\
\hline $\begin{array}{c}\text { Pristine MWCNTs } \\
\text { 1 h Acid washed } \\
\text { MWCNTs }\end{array}$ & 0.13 & 0.13 & 0.38 & 1.88 \\
\hline
\end{tabular}

Table S2: Solubility of pristine and $1 \mathrm{~h}$ acid washed multi-walled carbon nanotubes (MWCNTs) in different solutions.

\begin{tabular}{ccc}
\hline Material & Mean (nm) & $\begin{array}{c}\text { Standard Deviation (SD) } \\
(\mathbf{n m})\end{array}$ \\
\hline Pristine MWCNTs & 5012 & 2675 \\
$1 \mathrm{~h}$ Acid Washed MWCNTs & 947 & 451 \\
\hline
\end{tabular}

Table S3: Length measurements of pristine and $1 \mathrm{~h}$ acid washed multi-walled carbon nanotubes (MWCNTs). The length measurement of both pristine and $1 \mathrm{~h}$ acid washed MWCNTs are presented as mean \pm standard deviation; at least 30 individual nanotubes were analyzed to obtain the average length distribution. 


\begin{tabular}{ccccccc}
\hline Group & Counts & $\mathbf{0 - 1 0 0}$ & $\mathbf{1 0 0 - 2 0 0}$ & $\mathbf{2 0 0 - 4 0 0}$ & $\mathbf{4 0 0 - 6 0 0}$ & $>\mathbf{6 0 0}$ \\
\hline Control cells & & $\mathbf{k P a}$ & $\mathbf{k P a}$ & $\mathbf{k P a}$ & $\mathbf{k P a}$ & $\mathbf{k P a}$ \\
\hline $\begin{array}{c}\text { Cells incubated with 1 h acid- } \\
\text { washed MWCNTs for 1 h }\end{array}$ & 594 & $48.31 \%$ & $28.96 \%$ & $16.33 \%$ & $4.40 \%$ & $2.00 \%$ \\
$\begin{array}{c}\text { Control cells (nucleus region) } \\
\begin{array}{c}\text { Cells incubated with 1 h acid- } \\
\text { washed MWCNTs for 1 h } \\
\text { (nucleus region) }\end{array}\end{array}$ & 119 & $68.07 \%$ & $28.57 \%$ & $3.36 \%$ & $0 \%$ & $0 \%$ \\
\end{tabular}

Table S4: Young modulus distribution of control cells (13 individual cells were analyzed) and cells incubated with $1 \mathrm{~h}$ acid-washed MWCNTs for $1 \mathrm{~h}$ (13 individual cells were analyzed). Randomized block design was used for the experimental design and data analysis.

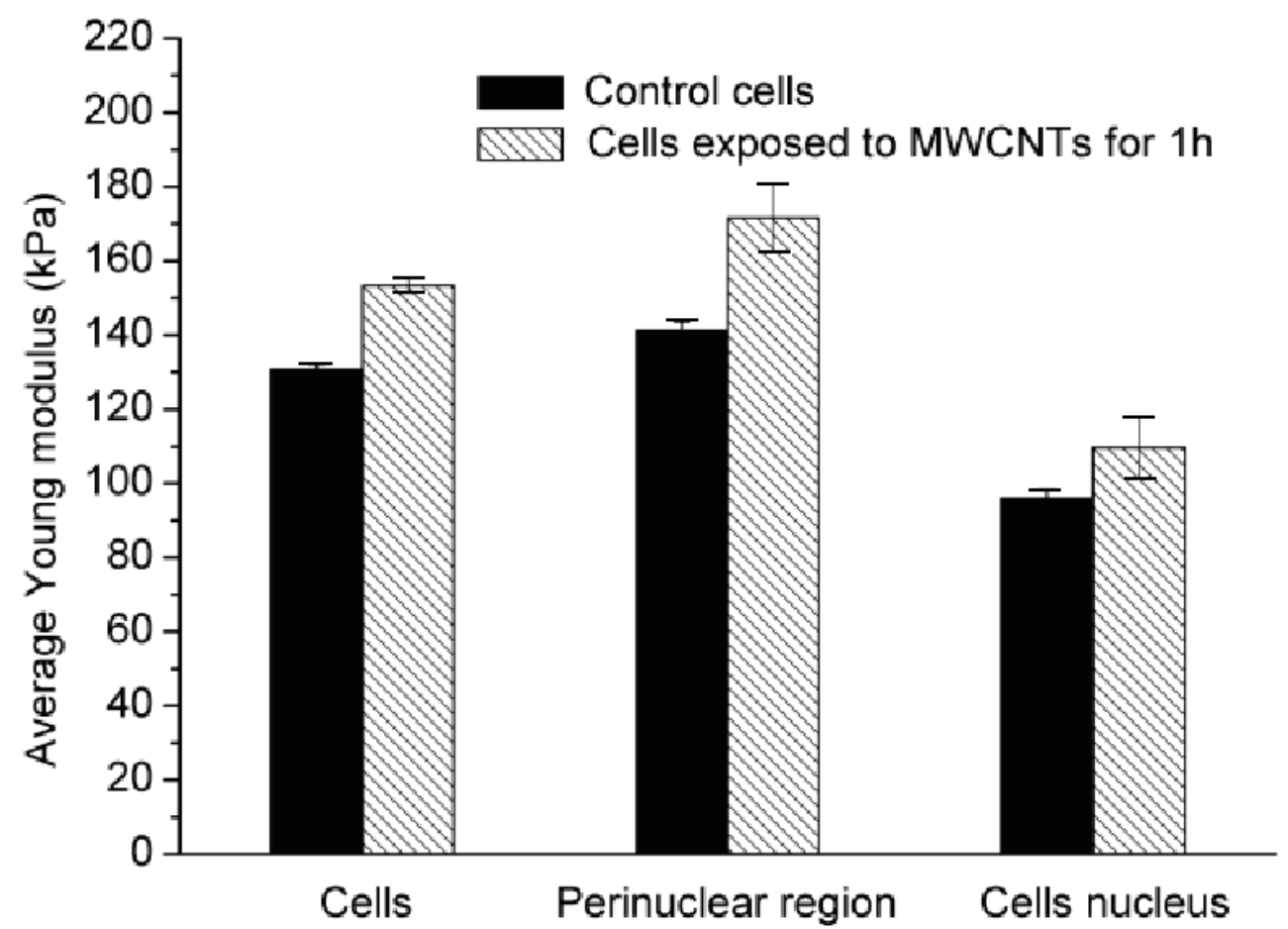

Figure S1: Statistical analysis of average Young modulus distribution of control cells and cells exposed to $1 \mathrm{~h}$ acid-washed MWCNTs. In these experiments the cells were exposed to MWCNTs for $1 \mathrm{~h}$. There are no statistically significant differences between the control cells and cells exposed to MWCNTs for $1 \mathrm{~h}$. 


\section{Reference}

1 Higginbotham, A. L., Kosynkin, D. V., Sinitskii, A., Sun, Z. Z. \& Tour, J. M. LowerDefect Graphene Oxide Nanoribbons from Multiwalled Carbon Nanotubes. Acs Nano 4, 2059-2069, doi:Doi 10.1021/Nn100118m (2010).

2 Kang, B., Chang, S. Q., Dai, Y. D., Yu, D. C. \& Chen, D. Cell Response to Carbon Nanotubes: Size-Dependent Intracellular Uptake Mechanism and Subcellular Fate. Small 6, 2362-2366 (2010).

3 Byrne, M. T. \& Gun'ko, Y. K. Recent Advances in Research on Carbon NanotubePolymer Composites. Adv Mater 22, 1672-1688, doi:DOI 10.1002/adma.200901545 (2010).

4 Meng, C. Z., Liu, C. H. \& Fan, S. S. A Promising Approach to Enhanced Thermoelectric Properties Using Carbon Nanotube Networks. Adv Mater 22, 535-+, doi:DOI 10.1002/adma.200902221 (2010).

5 Saeed, K. Review on Properties, Dispersion and Toxicology of Carbon Nanotubes. $J$ Chem Soc Pakistan 32, 559-564 (2010).

6 Liu, K. et al. Scratch-Resistant, Highly Conductive, and High-Strength Carbon Nanotube-Based Composite Yarns. Acs Nano 4, 5827-5834, doi:Doi 10.1021/Nn1017318 (2010).

7 Chen, P. C., Shen, G. Z., Shi, Y., Chen, H. T. \& Zhou, C. W. Preparation and Characterization of Flexible Asymmetric Supercapacitors Based on Transition-MetalOxide Nanowire/Single-Walled Carbon Nanotube Hybrid Thin-Film Electrodes. Acs Nano 4, 4403-4411, doi:Doi 10.1021/Nn100856y (2010).

8 Nouni, N., Ziaei-Rad, S., Adibi, S. \& Karimzadeh, F. Fabrication and mechanical 
property prediction of carbon nanotube reinforced Aluminum nanocomposites. Mater Design 34, 1-14, doi:DOI 10.1016/j.matdes.2011.07.047 (2012).

9 Xu, X. A., Jiang, S. J., Hu, Z. \& Liu, S. Q. Nitrogen-Doped Carbon Nanotubes: High Electrocatalytic Activity toward the Oxidation of Hydrogen Peroxide and Its Application for Biosensing. Acs Nano 4, 4292-4298, doi:Doi 10.1021/Nn1010057 (2010).

10 Chun, K. Y. et al. Highly conductive, printable and stretchable composite films of carbon nanotubes and silver. Nat Nanotechnol 5, 853-857, doi:Doi 10.1038/Nnano.2010.232 (2010).

11 Lota, G., Fic, K. \& Frackowiak, E. Carbon nanotubes and their composites in electrochemical applications. Energ Environ Sci 4, 1592-1605, doi:Doi 10.1039/C0ee00470g (2011).

$12 \mathrm{Li}, \mathrm{R}$. B. et al. P-Glycoprotein Antibody Functionalized Carbon Nanotube Overcomes the Multidrug Resistance of Human Leukemia Cells. Acs Nano 4, 1399-1408, doi:Doi 10.1021/Nn9011225 (2010).

13 Namgung, S., Baik, K. Y., Park, J. \& Hong, S. Controlling the Growth and Differentiation of Human Mesenchymal Stem Cells by the Arrangement of Individual Carbon Nanotubes. Acs Nano 5, 7383-7390, doi:Doi 10.1021/Nn2023057 (2011).

14 Nunes, A. et al. Hybrid Polymer-Grafted Multiwalled Carbon Nanotubes for In vitro Gene Delivery. Small 6, 2281-2291, doi:DOI 10.1002/smll.201000864 (2010).

15 Chen, J. Y. et al. Functionalized Single-Walled Carbon Nanotubes as Rationally Designed Vehicles for Tumor-Targeted Drug Delivery. J Am Chem Soc 130, 1677816785, doi:Doi 10.1021/Ja805570f (2008).

16 Kang, B. et al. Cancer-Cell Targeting and Photoacoustic Therapy Using Carbon 
Nanotubes as "Bomb" Agents. Small 5, 1292-1301, doi:DOI 10.1002/smll.200801820 (2009).

17 Singh, M. K. et al. Hydroxyapatite modified with carbon-nanotube-reinforced poly(methyl methacrylate): A nanocomposite material for biomedical applications. Adv Funct Mater 18, 694-700, doi:DOI 10.1002/adfm.200700888 (2008).

18 Liu, Z. et al. Drug delivery with carbon nanotubes for in vivo cancer treatment. Cancer Res 68, 6652-6660, doi:Doi 10.1158/0008-5472.Can-08-1468 (2008).

19 Choi, J. H. et al. Multimodal biomedical imaging with asymmetric single-walled carbon nanotube/iron oxide nanoparticle complexes. Nano Lett 7, 861-867, doi:Doi 10.1021/N1062306v (2007).

20 Dothager, R. S. \& Piwnica-Worms, D. Nano in Cancer: Linking Chemistry, Biology, and Clinical Applications In Vivo. Cancer Res 71, 5611-5615, doi:Doi 10.1158/00085472.Can-11-0817 (2011).

21 Liu, Z. et al. Supramolecular Stacking of Doxorubicin on Carbon Nanotubes for In Vivo Cancer Therapy. Angew Chem Int Edit 48, 7668-7672, doi:DOI 10.1002/anie.200902612 (2009).

22 Bhirde, A. A. et al. Targeted Killing of Cancer Cells in Vivo and in Vitro with EGFDirected Carbon Nanotube-Based Drug Delivery. ACS nano 3, 307-316, doi:Doi 10.1021/Nn800551s (2009).

23 Sokhi, R. S. et al. An integrated multi-model approach for air quality assessment: Development and evaluation of the OSCAR Air Quality Assessment System. Environ Modell Softw 23, 268-281 (2008).

24 Sargent, L. M., Reynolds, S. H. \& Castranova, V. Potential pulmonary effects of 
engineered carbon nanotubes: in vitro genotoxic effects. Nanotoxicology 4, 396-408, doi:Doi 10.3109/17435390.2010.500444 (2010).

25 Ryman-Rasmussen, J. P. et al. Inhaled Multiwalled Carbon Nanotubes Potentiate Airway Fibrosis in Murine Allergic Asthma. Am J Resp Cell Mol 40, 349-358, doi:DOI 10.1165/rcmb.2008-0276OC (2009).

26 Asakura, M. et al. Genotoxicity and Cytotoxicity of Multi-wall Carbon Nanotubes in Cultured Chinese Hamster Lung Cells in Comparison with Chrysotile A Fibers. J Occup Health 52, 9-20 (2010).

27 Sargent, L. M. et al. Induction of Aneuploidy by Single-Walled Carbon Nanotubes. Environmental and molecular mutagenesis 50, 708-717, doi:Doi 10.1002/Em.20529 (2009).

28 Barillet, S. et al. Toxicological consequences of $\mathrm{TiO} 2, \mathrm{SiC}$ nanoparticles and multiwalled carbon nanotubes exposure in several mammalian cell types: an in vitro study. $J$ Nanopart Res 12, 61-73, doi:DOI 10.1007/s11051-009-9694-y (2010).

29 Mouchet, F. et al. Characterisation and in vivo ecotoxicity evaluation of double-wall carbon nanotubes in larvae of the amphibian Xenopus laevis. Aquat Toxicol 87, 127-137, doi:DOI 10.1016/j.aquatox.2008.01.011 (2008).

30 Sargent, L. M. et al. Single-walled carbon nanotube-induced mitotic disruption. Mutation research 745, 28-37, doi:10.1016/j.mrgentox.2011.11.017 (2012).

31 Hubbs, A. F. et al. Nanotoxicology-A Pathologist's Perspective. Toxicol Pathol 39, 301324, doi:Doi 10.1177/0192623310390705 (2011).

32 Muller, J. et al. Clastogenic and aneugenic effects of multi-wall carbon nanotubes in epithelial cells. Carcinogenesis 29, 427-433, doi:10.1093/carcin/bgm243 (2008). 
33 Ma, S., Trivinos-Lagos, L., Graf, R. \& Chisholm, R. L. Dynein intermediate chain mediated dynein-dynactin interaction is required for interphase microtubule organization and centrosome replication and separation in Dictyostelium. J Cell Biol 147, 1261-1273 (1999).

34 Rodriguez-Fernandez, L., Valiente, R., Gonzalez, J., Villegas, J. C. \& Fanarraga, M. L. Multiwalled Carbon Nanotubes Display Microtubule Biomimetic Properties in Vivo, Enhancing Microtubule Assembly and Stabilization. Acs Nano 6, 6614-6625, doi:Doi 10.1021/Nn302222m (2012).

35 Patlolla, A. K., Hussain, S. M., Schlager, J. J., Patlolla, S. \& Tchounwou, P. B. Comparative Study of the Clastogenicity of Functionalized and Nonfunctionalized Multiwalled Carbon Nanotubes in Bone Marrow Cells of Swiss-Webster Mice. Environ Toxicol 25, 608-621, doi:Doi 10.1002/Tox.20621 (2010).

36 Fearon, E. R. Molecular Genetics of Colorectal Cancer. Annu Rev Pathol-Mech 6, 479507, doi:DOI 10.1146/annurev-pathol-011110-130235 (2011).

37 Yee, D. S. et al. The Wnt inhibitory factor 1 restoration in prostate cancer cells was associated with reduced tumor growth, decreased capacity of cell migration and invasion and a reversal of epithelial to mesenchymal transition. Mol Cancer 9, doi:Artn 162

Doi 10.1186/1476-4598-9-162 (2010).

38 Iyer, S., Gaikwad, R. M., Subba-Rao, V., Woodworth, C. D. \& Sokolov, I. Atomic force microscopy detects differences in the surface brush of normal and cancerous cells. Nat Nanotechnol 4, 389-393, doi:Doi 10.1038/Nnano.2009.77 (2009).

39 Hawkins, T., Mirigian, M., Yasar, M. S. \& Ross, J. L. Mechanics of microtubules. $J$ Biomech 43, 23-30, doi:DOI 10.1016/j.jbiomech.2009.09.005 (2010). 
$40 \mathrm{Xu}$, Y. et al. Revealing a core signaling regulatory mechanism for pluripotent stem cell survival and self-renewal by small molecules. Proceedings of the National Academy of Sciences of the United States of America 107, 8129-8134, doi:DOI 10.1073/pnas.1002024107 (2010).

41 Cross, S. E., Jin, Y. S., Rao, J. \& Gimzewski, J. K. Nanomechanical analysis of cells from cancer patients. Nat Nanotechnol 2, 780-783, doi:DOI 10.1038/nnano.2007.388 (2007).

42 Holt, B. D. et al. Carbon Nanotubes Reorganize Actin Structures in Cells and ex Vivo. Acs Nano 4, 4872-4878, doi:Doi 10.1021/Nn101151x (2010).

43 Marija Plodinec, M. L., Christophe A. Monnier, Ellen C. Obermann, Rosanna ZanettiDallenbach, Philipp Oertlem Janne T. Hyotylam Ueli Aebi, Mohamend Bentires-Alj, Roderick Y.H.Lim, Cora-Ann Schoeneberger The nanomechanical signature of breast cancer. Nat Nanotechnol 7, 757-765, doi:10.1038/nnano.2012.167 (2012).

44 Nuria Gavara, R. S. C. Determination of the elastic moduli of thin samples and adherent cells using conical atomic force microscope tips. Nat Nanotechnol 7, 733, doi:10.1038/nnano.2012.163 (2012).

45 Hubbs, A., Greskevitch, M., Kuempel, E., Suarez, F. \& Toraason, M. Abrasive blasting agents: designing studies to evaluate relative risk. Journal of toxicology and environmental health. Part A 68, 999-1016, doi:10.1080/15287390590912612 (2005).

46 Rotsch, C., Jacobson, K. \& Radmacher, M. Dimensional and mechanical dynamics of active and stable edges in motile fibroblasts investigated by using atomic force microscopy. P Natl Acad Sci USA 96, 921-926 (1999).

47 Radmacher, M., Fritz, M., Kacher, C. M., Cleveland, J. P. \& Hansma, P. K. Measuring 
the viscoelastic properties of human platelets with the atomic force microscope. Biophys $J$ 70, 556-567 (1996).

48 Laurent, V. M. et al. Gradient of rigidity in the lamellipodia of migrating cells revealed by atomic force microscopy. Biophys $J$ 89, 667-675, doi:DOI 10.1529/biophysj.104.052316 (2005).

49 Dinu, C. Z., Bale, S. S., Chrisey, D. B. \& Dordick, J. S. Manipulation of Individual Carbon Nanotubes by Reconstructing the Intracellular Transport of a Living Cell. Adv Mater 21, 1182-1186, doi:DOI 10.1002/adma.200801721 (2009).

50 Liu, J. et al. Fullerene pipes. Science 280, 1253-1256 (1998).

51 Marcolongo, G., Ruaro, G., Gobbo, M. \& Meneghetti, M. Amino acid functionalization of double-wall carbon nanotubes studied by Raman spectroscopy. Chem Commun, 49254927, doi:Doi 10.1039/B711249a (2007).

52 Datsyuk, V. et al. Chemical oxidation of multiwalled carbon nanotubes. Carbon 46, 833840, doi:DOI 10.1016/j.carbon.2008.02.012 (2008).

53 Rheinlaender, J., Geisse, N. A., Proksch, R. \& Schaffer, T. E. Comparison of Scanning Ion Conductance Microscopy with Atomic Force Microscopy for Cell Imaging. Langmuir 27, 697-704 (2011).

54 Rico, F., Alcaraz, J., Fredberg, J. J. \& Navajas, D. Nanomechanics of lung epithelial cells. Int J Nanotechnol 2, 180-194 (2005).

55 Ruiz, J. P., Pelaez, D., Dias, J., Ziebarth, N. M. \& Cheung, H. S. The effect of nicotine on the mechanical properties of mesenchymal stem cells. Cell health and cytoskeleton 4, 2935, doi:10.2147/CHC.S24381 (2012).

56 Silkworth, W. T., Nardi, I. K., Scholl, L. M. \& Cimini, D. Multipolar Spindle Pole 
Coalescence Is a Major Source of Kinetochore Mis-Attachment and Chromosome MisSegregation in Cancer Cells. Plos One 4, doi:Artn E6564 Doi 10.1371/Journal.Pone.0006564 (2009).

$57 \mathrm{Xu}, \mathrm{W}$. W. et al. Cell Stiffness Is a Biomarker of the Metastatic Potential of Ovarian Cancer Cells. Plos One 7, doi:ARTN e46609 DOI 10.1371/journal.pone.0046609 (2012). 


\title{
Chapter 3 Carbon nanotubes uptake induce biomechanical cellular changes in a time dependent manner
}

\begin{abstract}
Changes in cellular mechanics have been associated with malignant transformation and were shown to be genetically driven. Recently, it was shown that multi-walled carbon nanotubes (MWCNTs), a preferred nanomaterial for implementation in a wide variety of bioapplications localizes at the cell nucleus and associate with cellular elements possibly inducing early cell transformation, genotoxicity and cancer development. Herein we investigate how uptake of MWCNTs is directly correlated with their cellular biodistribution. Tracking changes in biomechanical properties of the exposed cells upon internalization of MWCNTs show significant cell transformation, increase in the cell elastic modulus, as well as MWCNTs-induced cellular toxicity upon only $6 \mathrm{~h}$ of exposure.
\end{abstract}




\section{Introduction}

As commercial engineered nanomaterials, carbon nanotubes (CNTs) have great versatility in physical and chemical properties including high strength to weight ratio ${ }^{1}$, high electrical and thermal conductivity ${ }^{2,3}$, high mechanical strength ${ }^{4}$ and ultra-light weight ${ }^{5}$. These unique properties make CNTs attractive materials candidates and provide great potential for their applications in different fields from electronic devices ${ }^{6}$, to sports equipments ${ }^{7}$, and aerospace industries $^{8}$, sensors ${ }^{9}$ and composite materials ${ }^{10}$. Recently, CNTs have also been explored for biomedical and biotechnological applications and used as drug delivery systems ${ }^{11}$, gene delivery tool $^{12}$, in bioimaging ${ }^{12}$, as therapeutic agents ${ }^{13}$ after functionalization with amino acid ${ }^{14}$, peptides $^{14}$, and other small biomolecules ${ }^{15}$. The biological and biomedical oriented applications of CNTs have however increased concerns regarding their potentially toxicity to consumer ${ }^{16}$.

We aimed to investigate the changes in cellular mechanical properties upon exposure to multi-walled carbon nanotubes (MWCNTs) and whether these changes are correlated with the cellular exposure time. Changes in cellular mechanical properties could be indicative of malignant transformation primarily driven by genetic mutations in the exposed cells ${ }^{17}$. MWCNTs have been chosen as model nanomaterials based on the existing concerns associated with their implementation in a wide variety of bioapplications ${ }^{18-20}$ and previous reports that have shown that their cellular uptake leads to nanotube localization at the cell nucleus upon only $24 \mathrm{~h}$ of exposure $^{21}$. In particular, changes in the cell elasticity ${ }^{22}$ have been reported upon in vitro MWCNTs association with cellular elements at this observation time point thus possibly hinting at the ability of the nanotubes to induce early cell transformation, genotoxicity ${ }^{23}$ and cancer development ${ }^{24}$. Association of the MWCNTs with microtubules cellular elements is of special 
concern taking into account the structural and functional roles of these cytoskeletal filaments in the formation of the division apparatus ${ }^{25}$. The similar aspect ratio of the microtubules and MWCNTs $^{26}$ could possibly lead to impairment of cell functionality and subsequently genotoxicity to explain the tumor formation in in vivo rats and mice studies ${ }^{27}$. 


\section{Materials and Methods}

\section{Multi-Walled Carbon Nanotubes (MWCNTs) preparation}

Commercial MWCNTs (95\% purity, PD15L5-20) purchased from Nanolab Inc. were washed in a mixture of 3:1 (V/V) concentrated sulfuric (96.4\%, Fisher, USA) and nitric $(69.5 \%$, Fisher, USA) acid. MWCNTs-acid mixture was sonicated in an ice bath sonicator (Branson 2510, Fisher, USA) at a temperature lower than $23^{\circ} \mathrm{C}$ for $1 \mathrm{~h}$. Subsequently, the MWCNTs-acid mixture was diluted in deionized (di) water $(2 \mathrm{~L})$, and filtered through a GTTP $0.2 \mu \mathrm{m}$ polycarbonate filter membrane (Millipore, Fisher, USA). The acid washed MWCNTs (simply called MWCNTs) isolated on the filter were subsequently redispersed in water and the filtration cycle was repeated at least 3 times to remove acid traces and any dissociated metal catalysts. The samples isolated on the filter paper were subsequently dried in a vacuum desiccator and stored at room temperature for future use.

\section{Formation of the MWCNTs-based conjugates}

Alexa 488 Bovine Serum Albumin 488 (Sigma, USA; Alexa-BSA) was covalently attached to MWCNTs using 1-ethyl-3-[3-dimethylaminopropyl] carbodiimide hydrochloride (EDC, Acros Organics, USA) and N-hydroxysuccinimide (NHS, Pierce, USA) chemistry. Briefly, $2 \mathrm{mg}$ of MWCNTs were dispersed in $160 \mathrm{mM}$ EDC and $80 \mathrm{mM}$ NHS (total volume of $2 \mathrm{~mL}$ in MES buffer (2-N-morpholino) ethanesulfonic acid sodium salt, $50 \mathrm{mM}$, pH 4.7, Sigma, USA) for $15 \mathrm{~min}$ at room temperature using a shaker operating at $200 \mathrm{rpm}$. EDC/NHS activated MWCNTs were then filtered through a $0.2 \mu \mathrm{m}$ filter membrane, washed thoroughly with MES buffer to remove any ester residues, and immediately re-dispersed in $2 \mathrm{~mL}$ of $1 \mathrm{mg} / \mathrm{mL}$ Alexa-BSA solution in Phosphate buffer (PBS), pH 7.4 for $3 \mathrm{~h}$ at room temperature with shaking at $200 \mathrm{rpm}$. 
When the time elapsed, the resulting Alexa-BSA-MWCNTs conjugates were filtered and washed extensively with PBS to remove any unbound protein. The supernatant and the first two washes were collected to quantify the amount of protein washed out (i.e., protein not bound to the MWCNTs).

\section{Determine the protein loading onto the MWCNTs}

The amount of Alexa-BSA immobilized onto MWCNTs (i.e., protein loading) was determined using the colorimetric BCA assay (bicinchoninic acid, Pierce, USA) by subtracting the amount of protein washed out in the supernatant and the two washes from the amount of protein initially added to the MWCNTs during the immobilization process. Briefly, the working reagent was prepared by mixing 50 parts of reagent A $(1000 \mu \mathrm{L})$, with 1 part of reagent $B(20$ $\mu \mathrm{L})$; subsequently, $1000 \mu \mathrm{l}$ of the working reagent was mixed with $50 \mu \mathrm{L}$ of each of the supernatant or washes. The resulting solution was vortexed lightly and incubated in a water bath at $37^{\circ} \mathrm{C}$ for $30 \mathrm{~min}$; subsequently the absorbance of the samples was monitored at $562 \mathrm{~nm}$ (Spectrophotometer, Evolution 300/600, Thermo Fisher, USA) and compared to the absorbance values of known free Alexa-BSA protein mixed with the working buffer.

\section{Determine the functionality of the immobilized protein}

The functionality of the Alexa-BSA immobilized onto the MWCNTs surface was determined by measuring the efficiency of the protein emission upon MWCNTs binding ${ }^{28}$. For this, we evaluated the absorbance spectra of $100 \mu \mathrm{g} / \mathrm{ml}$ of Alexa-BSA-MWCNTs conjugates relative to unlabeled MWCNTs and free Alexa-BSA in solution at the equivalent amount to the one loaded onto the MWCNTs. The absorbance spectrum of immobilized Alexa-BSA was 
subsequently quantified by subtracting the absorbance values of the labeled MWCNTs from the ones of the unlabeled MWCNTs. The functionality of the immobilized Alexa-BSA was determined by measuring the height of the absorbance peaks relative to the height of the peaks of free Alexa-BSA in solution.

\section{Characterization of MWCNTs}

A combination of analytical techniques were employed to determine the physical and chemical properties of the MWCNTs. Briefly, Energy Dispersive X-Ray spectroscopy (EDX) was used to investigate the elemental composition of the MWCNTs. The analysis was performed on a Hitachi S-4700 Field Emission Scanning Electron Microscope (USA) combining secondary (SE) and backscattered (BSE) electron detection operating in a single unit at $20 \mathrm{kV}$.

A RenishawIn Via Raman Spectrometer (CL532-100, $100 \mathrm{~mW}$, USA), was used to investigate the chemical structure of the MWCNTs. Briefly, $1 \mathrm{mg}$ sample was mounted onto clean glass substrates (Fisher, USA) and irradiated using an argon ion $\left(\mathrm{Ar}^{+}\right)$laser beam operating at $514.5 \mathrm{~nm}$ with laser spot below $0.01 \mathrm{~mm}^{2}$. The exposure time was set at $10 \mathrm{sec}$ to prevent sample heating effects; the scan range was set between 100 and $3200 \mathrm{~cm}^{-1}$.

Dispersity of the MWCNTs was evaluated by suspending the MWCNTs samples in three different dispersing agents, i.e. di water, PBS, and Dulbecco's Modified Eagle Media (DMEM, Invitrogen, USA) with or without $10 \%$ Fetal Bovine Serum (FBS, Invitrogen, USA). The corresponding solution ( $3 \mathrm{mg} / \mathrm{ml}$ of sample) was centrifuged at $3000 \mathrm{rpm}$ for $5 \mathrm{~min}$; subsequently, $0.8 \mathrm{~mL}$ of the supernatant was isolated, filtered through a $0.2 \mu \mathrm{m}$ GTTP membrane. The sample 
isolated in the filter paper was dried under vacuum and the amount of sample retained on the filter membrane was weighted. The dispersity was calculated in relation to the starting volumes.

\section{Cell culture}

Human bronchial epithelial cells (BEAS-2B, ATCC, USA) were cultured in DMEM media supplemented with $10 \%$ fetal bovine serum (FBS), 2 mML-glutamine and 100-units/ml penicillin/streptomycin (all reagents were purchased from Invitrogen, USA). Cells were passaged regularly using $0.25 \%$ (w/v) trypsin with $1.5 \mathrm{mM}$ EDTA (Molecular Probes, USA) and maintained in a humidified atmosphere at $37^{\circ} \mathrm{C}$ under $5 \% \mathrm{CO}_{2}$.

\section{Fluorescence activated cell sorting}

Cells were seeded at a density of $3.71 \times 10^{5}$ cells in T75 flasks (Fisher, USA) in DMEM media supplemented with $10 \%$ FBS for $24 \mathrm{~h}$ and subsequently treated with $24 \mu \mathrm{g} / \mathrm{cm}^{2}$ AlexaBSA-MWCNTs conjugates or similar concentration of unlabeled MWCNTs each dispersed by sonication in fresh media. Treatment was performed for different time periods, i.e., 1, 3, 6 or $12 \mathrm{~h}$ respectively. Control samples of untreated cells or cells incubated with free Alexa-BSA equivalent to the amount loaded onto the MWCNTs were performed in parallel.

For the uptake analysis, cells were washed with fresh PBS, collected using 0.25\% Trypsin (Invitrogen, USA), suspended in DMEM with 10\% FBS and centrifuged at 1200 for 5 min to remove any of the non-internalized or loosely bound MWCNTs or any free protein in solution. Subsequently the samples were washed with PBS, incubated at room temperature for $15 \mathrm{~min}$ with $100 \mu \mathrm{L}$ of glutaraldehyde solution (4\%), washed again with PBS and analyzed using FACS 
Caliber flow cytometer (Becton Dickinson, USA). The forward scatter (FSC) and side scatter (SSC) for the cells were adjusted using control cells to lay in a range of 0-1000 and were appropriately gated to include the majority of live cell population. FITC signal for the AlexaBSA-conjugates used excitation at $488 \mathrm{~nm}$ and emission at $515 \mathrm{~nm}$; at least 10000 events were contained in the gated area. Data was analyzed and plotted using Flow Jo v7.2.5 software.

\section{Biomechanical analysis}

Cells seeded at a concentration of $10^{5}$ cells in $50 \mathrm{~mm} \times 9 \mathrm{~mm}$ in parallel culture petri dishes (BD Biosciences, USA) were exposed to $24 \mu \mathrm{g} / \mathrm{cm}^{2}$ MWCNTs for $1,3,6$ or $12 \mathrm{~h}$, respectively. Subsequently, the exposed cells were washed with PBS two times (for 5 min each wash) and fixed with $4 \%$ glutaraldehyde solution (Sigma, USA) for 30 min. Washing steps were also employed to remove free glutaraldehyde and then the petri dishes were filled with PBS for further elasticity analysis. Elastic modulus of the BEAS-2B cells was probed using the MFP-3DBIO AFM integrated with an inverted fluorescence microscope. The location of the cantilever on the analyzed cell was confirmed using a $10 \mathrm{x}$ objective. The nanomechanical properties of control (untreated cells) and cells exposed to MWCNTs for different time points were evaluated using Sneddon's modification of the Hertz model developed for a four-sided pyramid ${ }^{29-31}$. Forcedisplacement curves obtained during elastic mapping were converted into force-indentation

curves ${ }^{32}$ based on the assumption that compared to the indentation depth ${ }^{33}$, the indented sample is extremely thick. The cells elasticity (Young's moduls, E) was evaluated knowing the indentation of the tip, $\delta$, the Poisson's ratio $v$ for the cell $\left(0.5^{31}\right)$ and $\alpha=36^{\circ}$, i.e. the opening angle of the tip. Cantilever spring constant was $k \sim 0.09 \mathrm{~N} / \mathrm{m}$; the cantilever was calibrated against plastic substrate. Analysis of 6 random cells from each time point were performed. To prevent 
influences from nearby cells, all the cells were selected as separated cells.

\section{Statistical analysis}

Results are presented as mean \pm standard deviation for Alexa-BSA loading onto MWCNTs and for the functionality calculations; experiments were repeated at least 6 times.

FACS uptake experiments were performed in triplicates and repeated at least three time, for a total of 9 replicates per each sample at every time point considered in the experimental design.

The elasticity experiments were performed using a complete randomized block design with each block contained 2 cell culture dishes. Three independent blocks were run in total. For each culture, cells were examined for the biomechanical analysis and averaged into a single value as cells from the same culture are not independent. The variables, including Young's modulus, surface area and height were analyzed using the Proc Mixed procedure in SAS/Stat for Windows (SAS, Cary NC) with experimental block modeled as a random effect. All differences were considered statistically significant at $\mathrm{p}<0.05$. 


\section{Results and discussion}

To investigate the cellular biomechanical changes induced by exposure to MWCNTs we used a multi-tiered exposure strategy in which human epithelial cells (BEAS-2B) were exposed to MWCNTs with known physical and chemical properties for $1,3,6$ and $12 \mathrm{~h}$ respectively. BEAS-2B are considered suitable model systems for in vitro toxicity research based on their ease of manipulation and their versatility that allows study of many types of engineered nanomaterials $^{34,35}$. The MWCNTs physical and chemical properties were investigated using standard characterization methods that allowed elemental composition identification as well as nanomaterial dispersity analysis. Briefly, for elemental composition samples of MWCNTs were investigated using energy dispersive X-ray spectroscopy (EDX) analysis ${ }^{36}$. Our results (Table S1) indicated that MWCNTs had minimum traces of iron $(\mathrm{Fe})$ and copper $(\mathrm{Cu})$ catalysts (combined, only $1.50 \mathrm{wt} \%)$, and the dominant element was carbon (C, $90.25 \mathrm{wt} \%)$. Oxygen (O) was also present, however, only $7.56 \mathrm{wt} \%$ and was presumably due to the pre-treatment of the pristine nanotubes which consisted in acid washing to remove impurities. Such washing step was previously shown to graft carboxyl functional groups onto the MWCNTs surface ${ }^{37}$. Carboxyl grafting was responsible for the observed increased dispersity of the MWCNTs samples relative to their pristine counterparts (Table S2) in both phosphate buffer and cellular media.

In our multi-tiered cellular exposure strategy, the fraction of the dose of nanomaterial used for cellular exposure was extrapolated from both the recommendations made by the Occupational Safety and Health Administration (OSHA) for particles less than $5 \mu \mathrm{m}$ in diameter ${ }^{38}$ as well as from the current exposure studies in mice and rats ${ }^{39,40}$. We first investigated MWCNTs uptake using Fluorescence activated cell sorting (FACS). To ensure full assessment of nanotubes 
uptake and eliminate the concerns associated with nanotube non-specific binding to the cell surface $^{41}$, we took full advantage of the presence of carboxyl grafted groups. In particular, we used the carboxyl grafting as anchors for zero-length covalent immobilization of 488 Alexa labeled Bovine Serum Albumin (Alexa-BSA). Previous reports have shown that MWCNTs are viable nanosupports for proteins immobilization, with MWCNTs' small curvature influencing the amount of loaded protein as well as protein functionality by increasing center-to-center distance between adjacent immobilized proteins and thus leading to reduced protein-protein interactions associated with protein deactivation ${ }^{42}$. Covalent immobilization also eliminates the concerns associated with removal of dyes from the nanotube surface during the sonication of this nanomaterial in cellular media; sonication is required prior to nanomaterial cellular exposure ${ }^{43}$.

Covalent binding and functionality of the Alexa-BSA was confirmed using spectroscopy analyses. Specifically, colorimetric assays confirmed both Alexa-BSA loading at about 0.22 $\pm 0.06 \mathrm{mg}$ protein per $\mathrm{mg}$ MWCNTs as well as functionality retention of $34 \pm 9 \%$ when compared to the free protein in solution (Figure 1a). The reduced functionality is presumably due to the interaction between nanomaterials and protein that could alter both its structure and function ${ }^{44}$. Raman spectroscopy also confirmed protein attachment as $\sim 21 \%$ increase in the $I_{D} / I_{G}$ ratio of Alexa-BSA-MWCNTs (0.967) relative to MWCNTs (0.799) respectively, where the $I_{D} / I_{G}$ represents the disorder degree of carbon structure with the $\mathrm{G}$ band being related to the presence of well-structured carbon species ${ }^{45}$ and the $\mathrm{D}$ band being associated with defects and non-crystal carbon species $^{46}$ (Figure 1b). 
a)

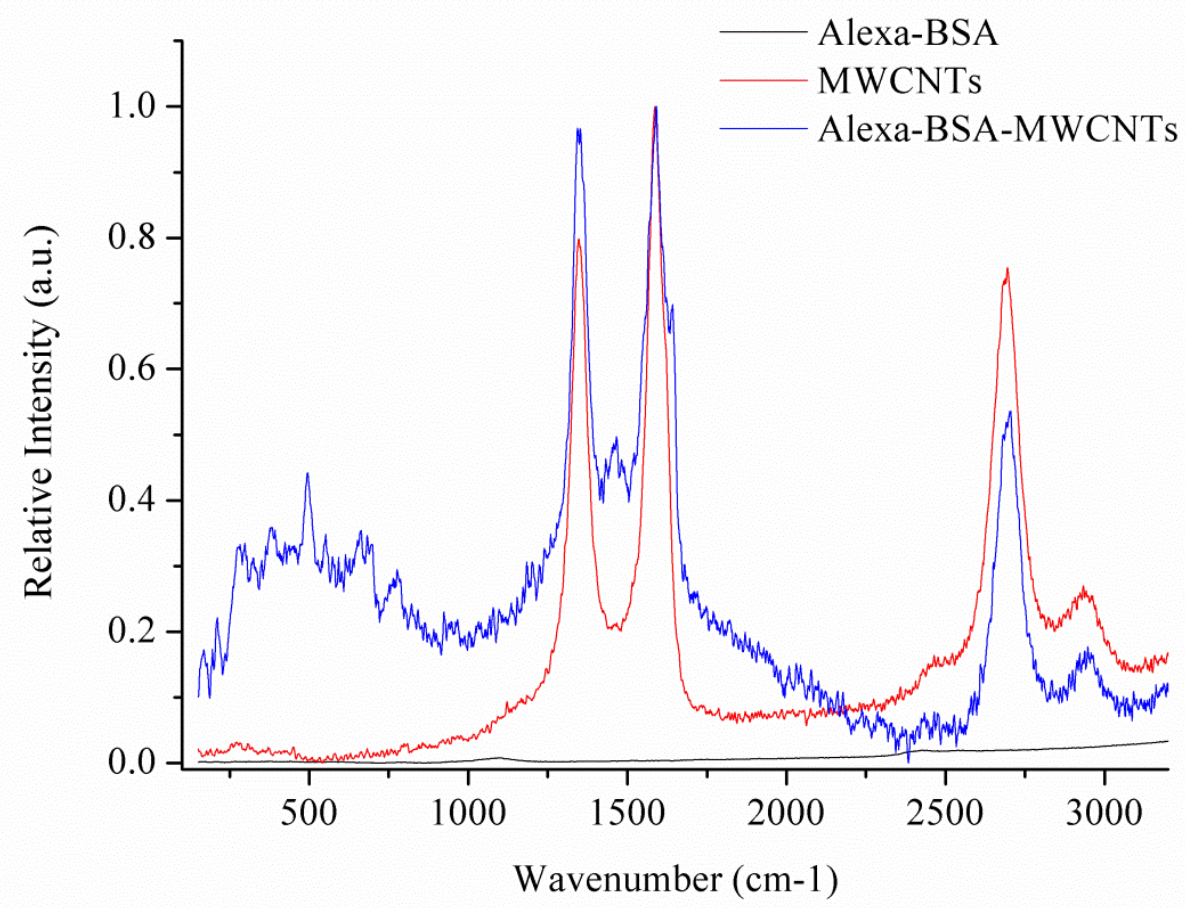

b)

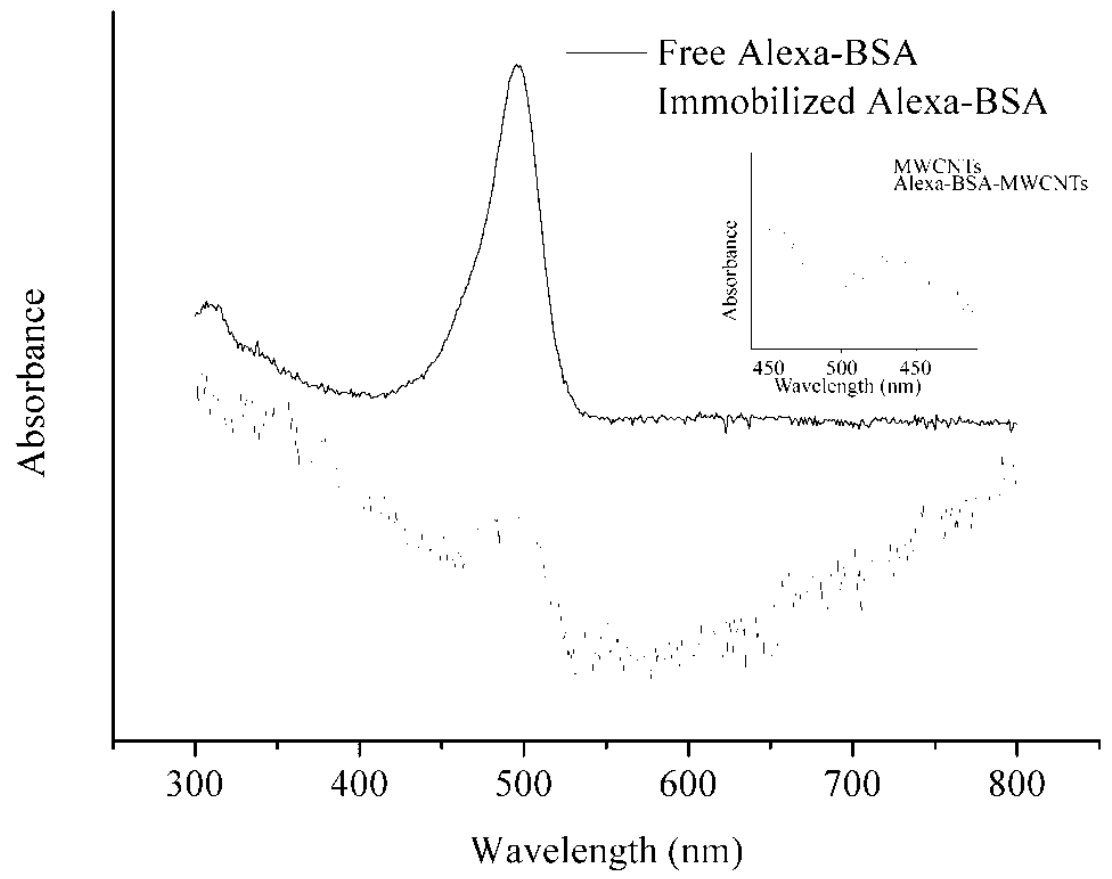

Figure 1: (a) Raman spectrum of Alexa-BSA, MWCNTs and Alexa-BSA-MWCNTs. (b) UV-Vis spectrophotometric analysis of free Alexa-BSA and Alexa-BSA immobilized onto the MWCNTs.

The time-dependent uptake of Alexa-BSA-MWCNTs was evaluated by measuring the 
FITC signal of the exposed cells and is shown in Figure 2. The cellular uptake can occur either by direct penetration and/or endocytosis until the cells reaches a "saturation point" where the uptake rate drops. Cellular uptake was measured as a change in the fluorescence intensity of cells exposed to Alexa-BSA-MWCNTs relative to controls (i.e., control cells, cells treated with free Alexa-BSA or MWCNTs in solution) (Table S3). Results showed that MWCNTs uptake followed a three parameter sigmoid curve and increased with the exposure time. Specifically, within the first hour of exposure the uptake was slow and resulted in minimal change in the FITC signal relative to controls $(15 \%$ relative to untreated cells, $11 \%$ relative to cells incubated with free Alexa-BSA, and 3.4\% relative to MWCNTs free in solution) (Figure 2a). However, longer exposure times (i.e, 3 h-Figure 2b, 6 h-Figure 2c, or 12 h-Figure $2 d$ ) led to an increase in the FITC signal suggesting higher uptake of the MWCNTs. Briefly, after 3h exposure, there was a 55\% change in the FITC signal of the cells exposed to Alexa-BSA-MWCNTs relative to control cells, a $18.3 \%$ change in the FITC signal of the cells exposed to Alexa-BSA-MWCNTs relative to cells exposed to free Alexa-BSA and $16.1 \%$ change in the FITC signal of the cells exposed to AlexaBSA-MWCNTs relative to MWCNTs free in solution. Similarly, after 6h incubation, the FITC signal of cells treated with Alexa-BSA-MWCNTs showed 92\%, 50\%, 20\% changes relative to control cells, MWCNTs and cells treated with free BSA, respectively. Further, after $6 \mathrm{~h}$ incubation, the uptake of Alexa-BSA-MWCNTs seemed to have reached a "saturation point" (Figure 2e). The FITC signal of cells treated with Alexa-BSA showed in Figure S1, the similar tendency of cells uptake Alexa-BSA was observed. 
a)

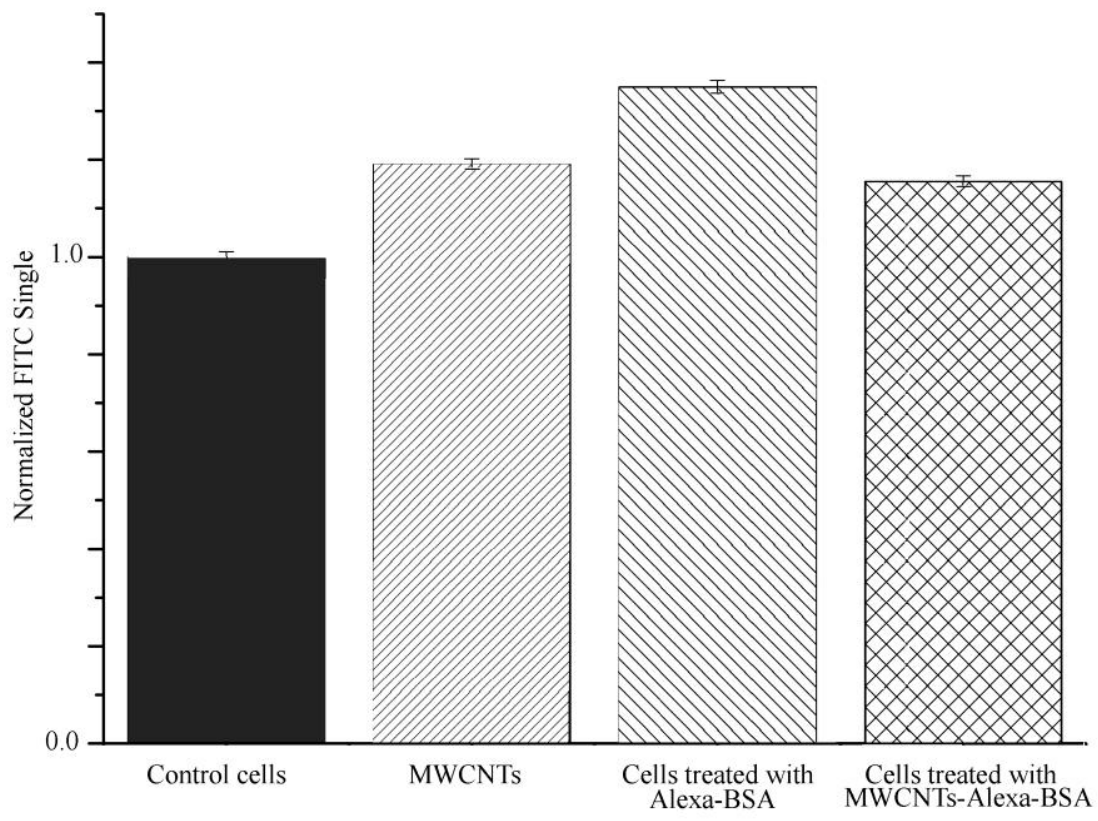

b)

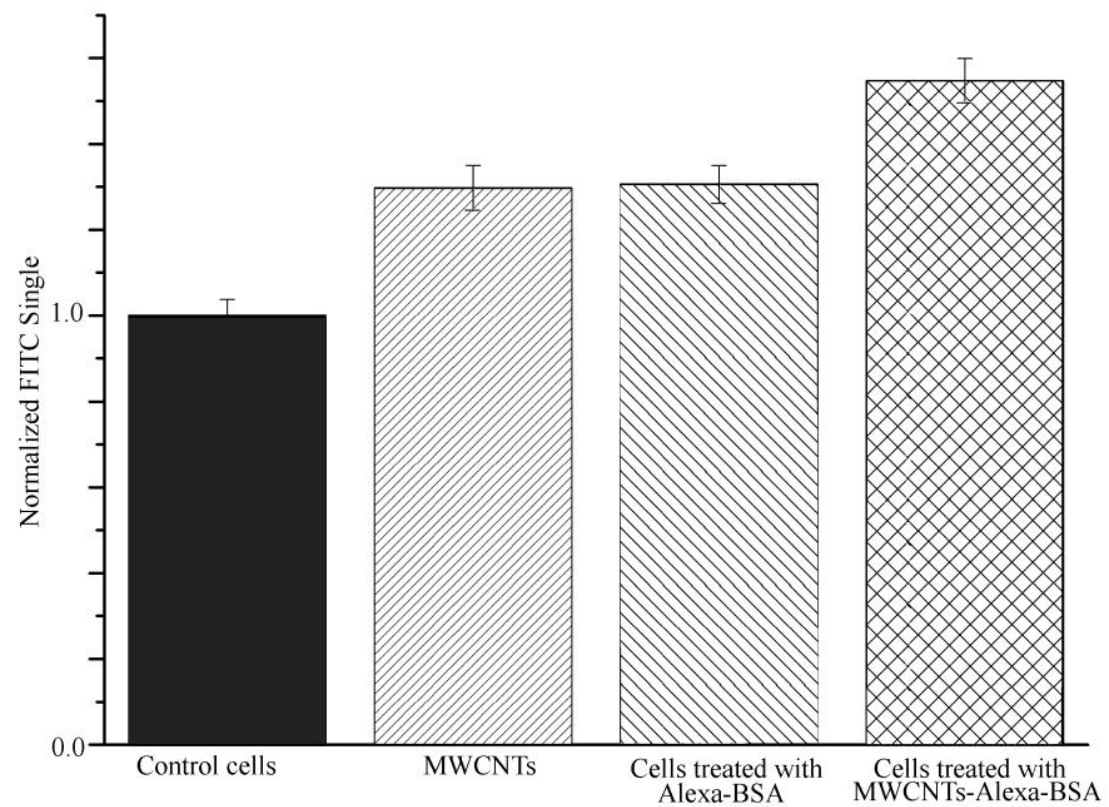


c)

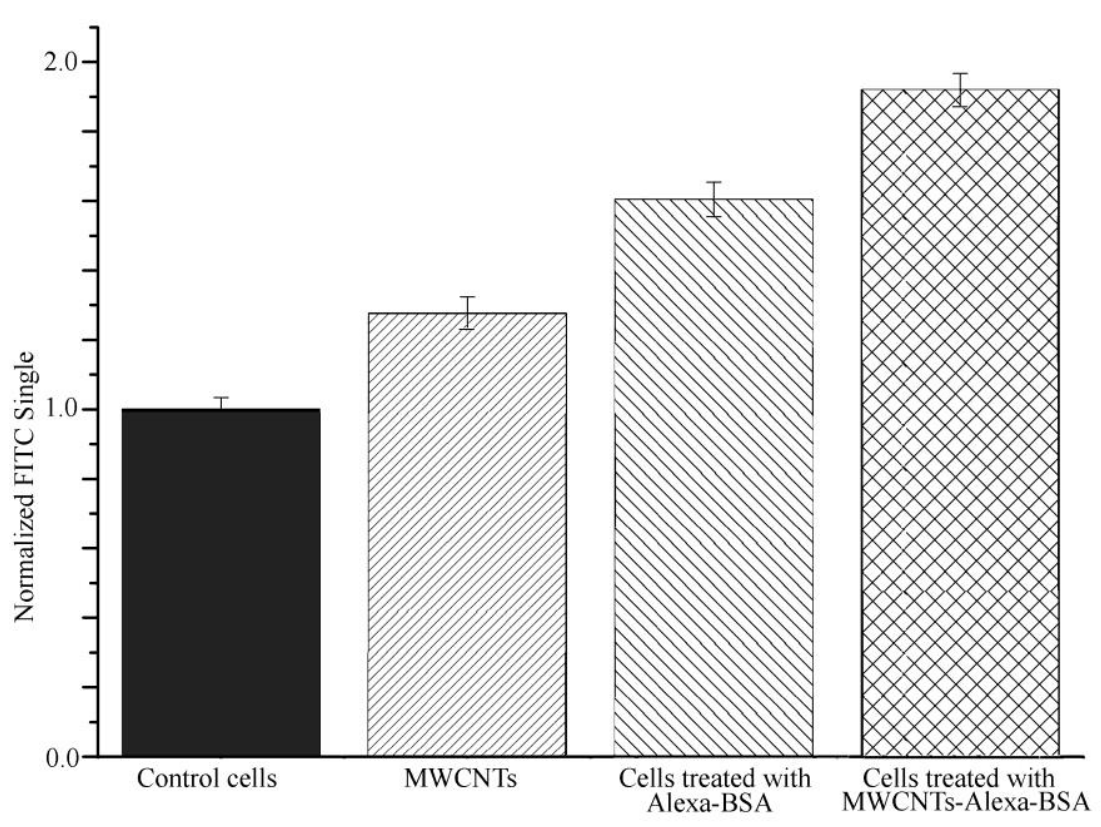

d)

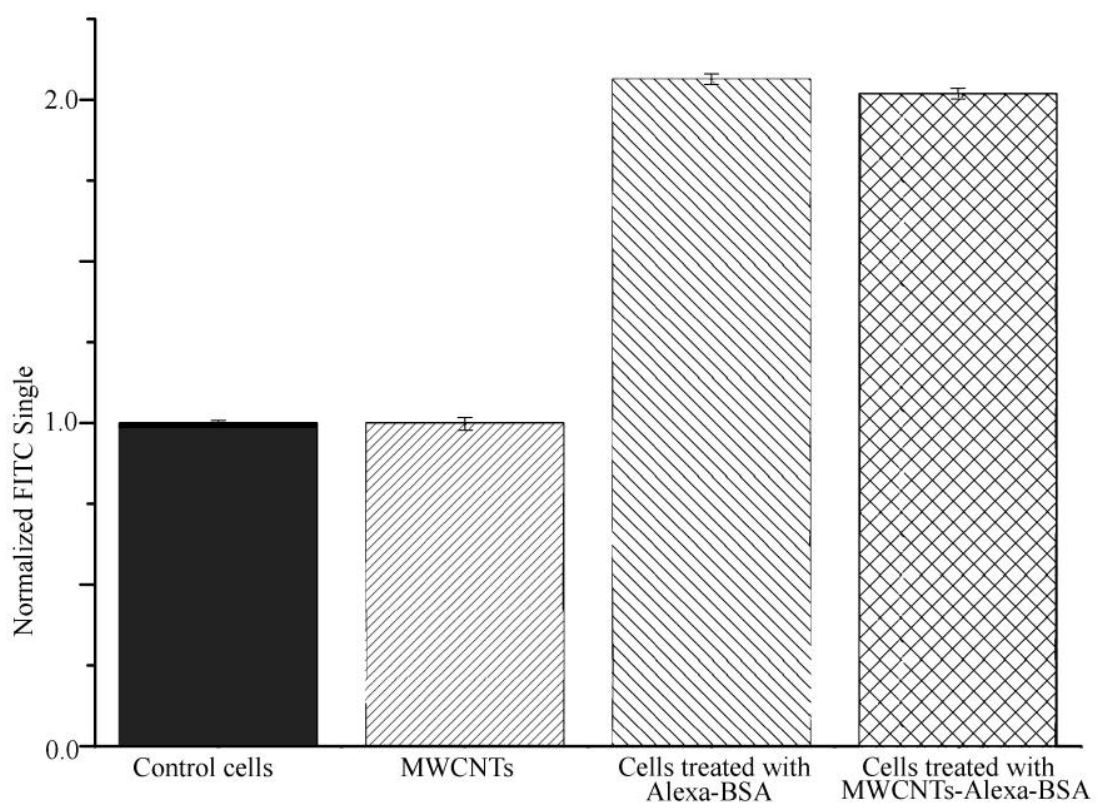


e)

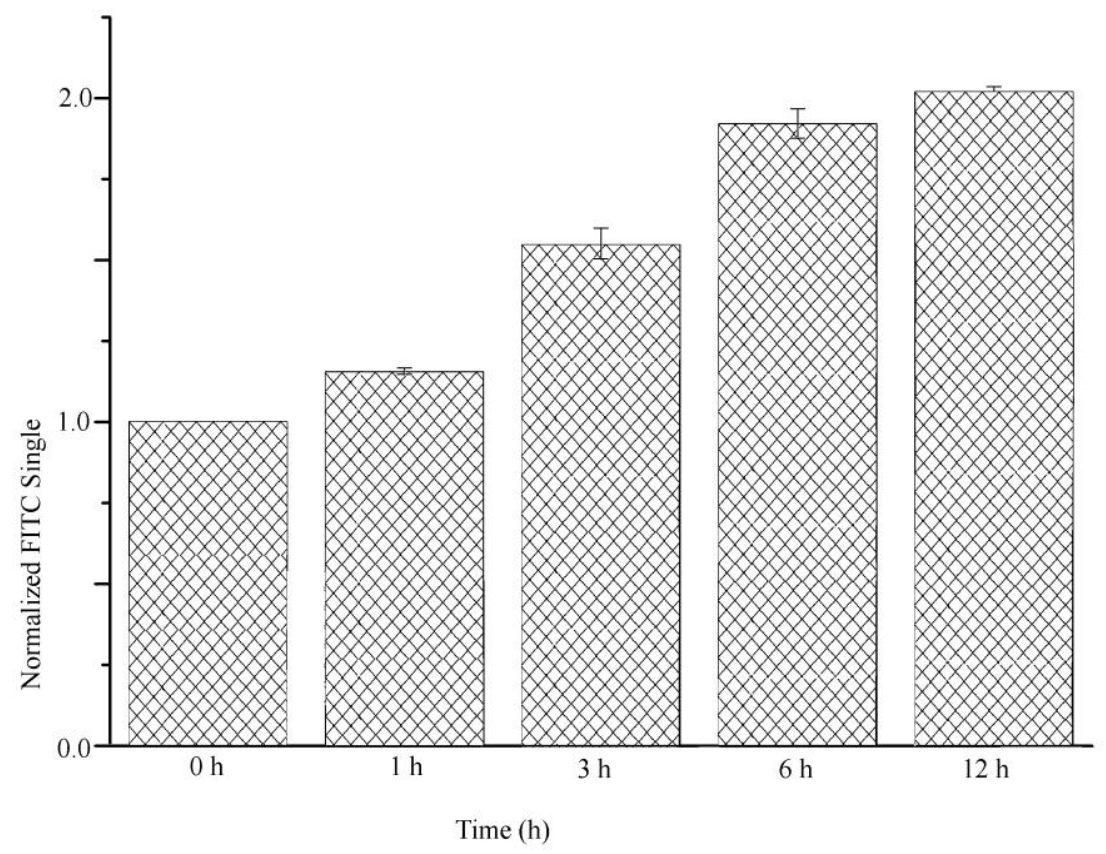

Figure 2: Normalized FITC signal for control cells, cells treated with MWCNTs, cells treated with Alexa-BSA and cells treated with Alexa-BSA-MWCNTs at (a) $1 \mathrm{~h} \mathrm{(b)} 3 \mathrm{~h}$ (c) $6 \mathrm{~h}$ (d) $12 \mathrm{~h}$ and (e) summary of FITC signal for cells treated with Alexa-BSA-MWCNTs at different time point

We further evaluated the biodistribution of the MWCNTs as a change in the cell mechanics upon uptake of the MWCNTs. The aim was to provide a comprehensive analysis of MWCNTs-induced cell transformation and how these correlate with the MWCNTs-cellular exposure time. Analysis of cellular biomechanical properties of MWCNTs exposed BEAS-2B cells for $1,3,6$ or $12 \mathrm{~h}$ were performed using an AFM nano-indentation setup ${ }^{47}$ and are shown in Figure 3. For these analyses, BEAS-2B cells were fixed with $4 \%$ glutaraldehyde after the specific time of exposure; the fixation was chosen as a mean to preserve the cellular properties during scanning, elastic mapping and analysis ${ }^{48}$. Analysis evaluated the elastic properties of both the whole cell body as well as the cell nuclear region since cell nucleus plays an important role in regulating cellular behavior, differentiation ${ }^{49}$, and division ${ }^{50}$. Changes in the nuclear elasticity 
could reflect mutations in nuclear components ${ }^{51}$ and alterations in the physiological state of the cellular system, which might be functionally linked to the MWCNTs-induced genotoxic effects.

Our analyses indicated that untreated control cells have Young's modulus ranging from 100 to $400 \mathrm{kPa}$ with higher values recorded at the cell periphery (> $600 \mathrm{kPa}$ ) due to the underling substrate effect ${ }^{52}$. The nuclear region appeared however softer when compared to the cellular body, with Young's modulus varying between 20-200 kPa (Figure 3a). The elastic modulus for both control and exposed cells was about one magnitude higher than that live cells ${ }^{52,53}$. This difference may be due to glutaraldehyde fixation effect on cells ${ }^{52}$ and/or AFM indentation approach performed at low speed ${ }^{54}$. The average Young's modulus of control cells and cells exposed to MWCNTs for different incubation times for both cell bodies and cell nucleus are depicted in Figure $3 b$ and $3 c$ respectively. The short incubation time with MWCNTs (i.e., $1 \mathrm{~h}$ ) did not result in significant changes in the elastic modulus of the exposed cells when compared to their control counterparts. However, longer incubation periods $(>6 \mathrm{~h})$, the elastic modulus of the cells treated with MWCNTs showed a significant increase relative to control cells $(p<0.05)$ for both the cell and its nuclear region. Specially, after $6 \mathrm{~h}$ of exposure, treated cells showed an overall increase of about $38.6 \%$ in cell bodies and an increase of $49.3 \%$ in cell nucleus Young's modulus related to control cells. Such increase in cellular stiffness could be due to MWCNTs interaction with cytoskeleton biopolymers ${ }^{25}$ like $_{\text {actin }^{55}}$ or microtubules ${ }^{56,57}$, as well as other cellular components such as DNA ${ }^{58}$. 
a)

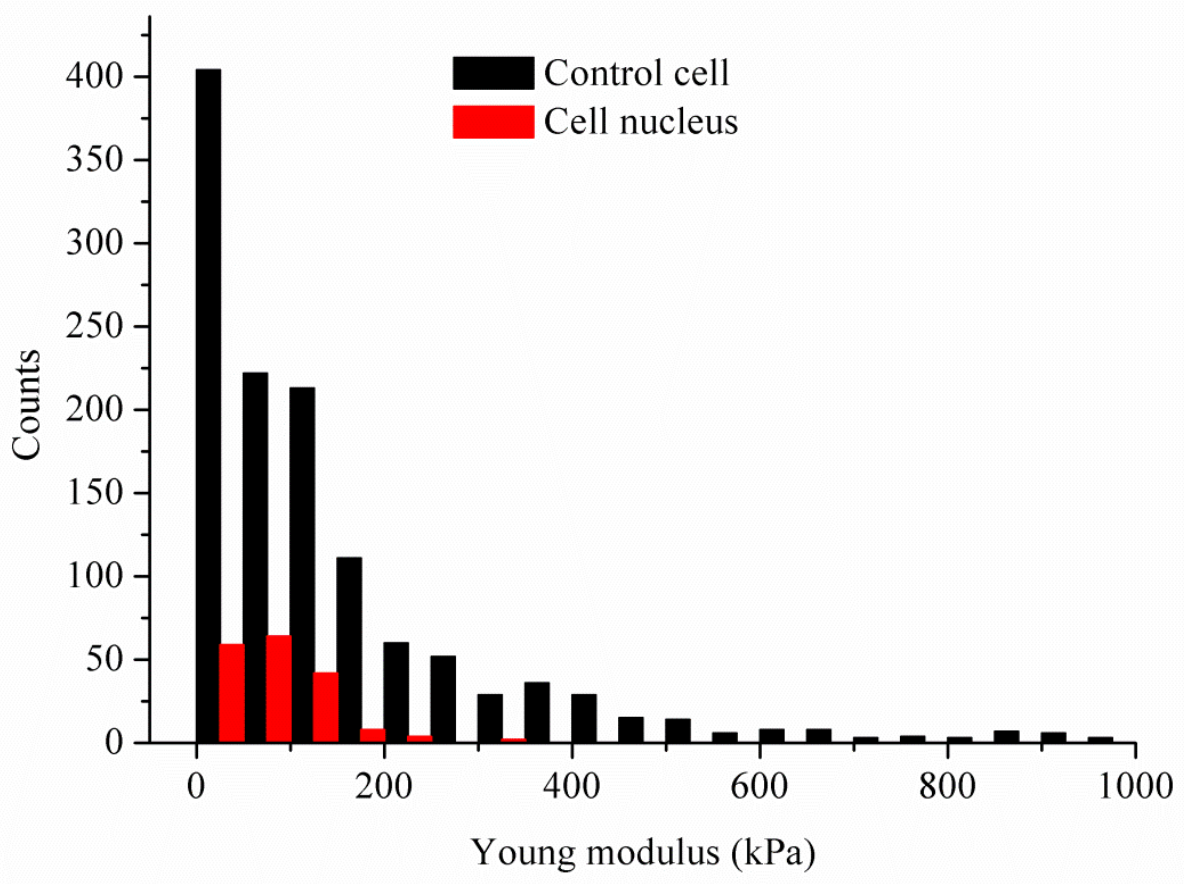

b)

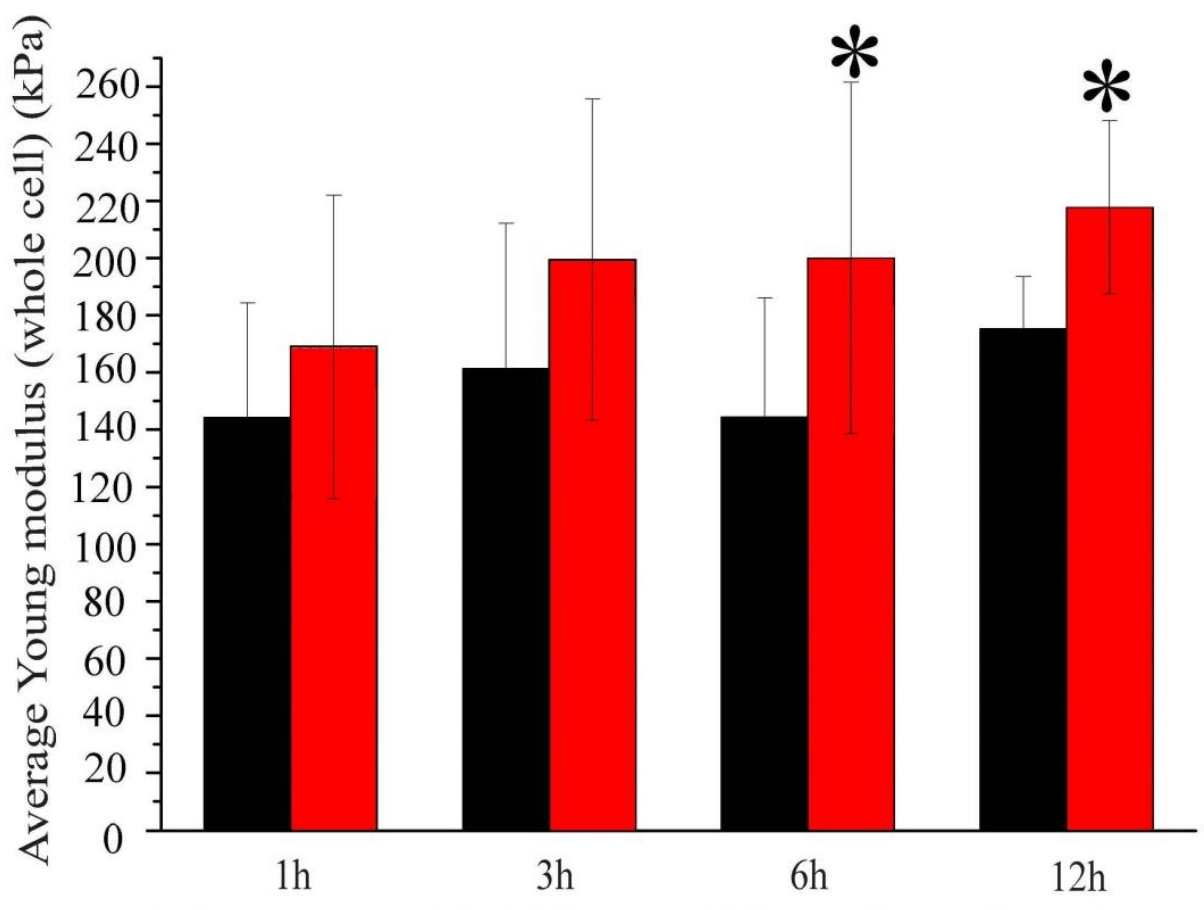

Cell treated with MWCNTs at different time points (h) 
c)

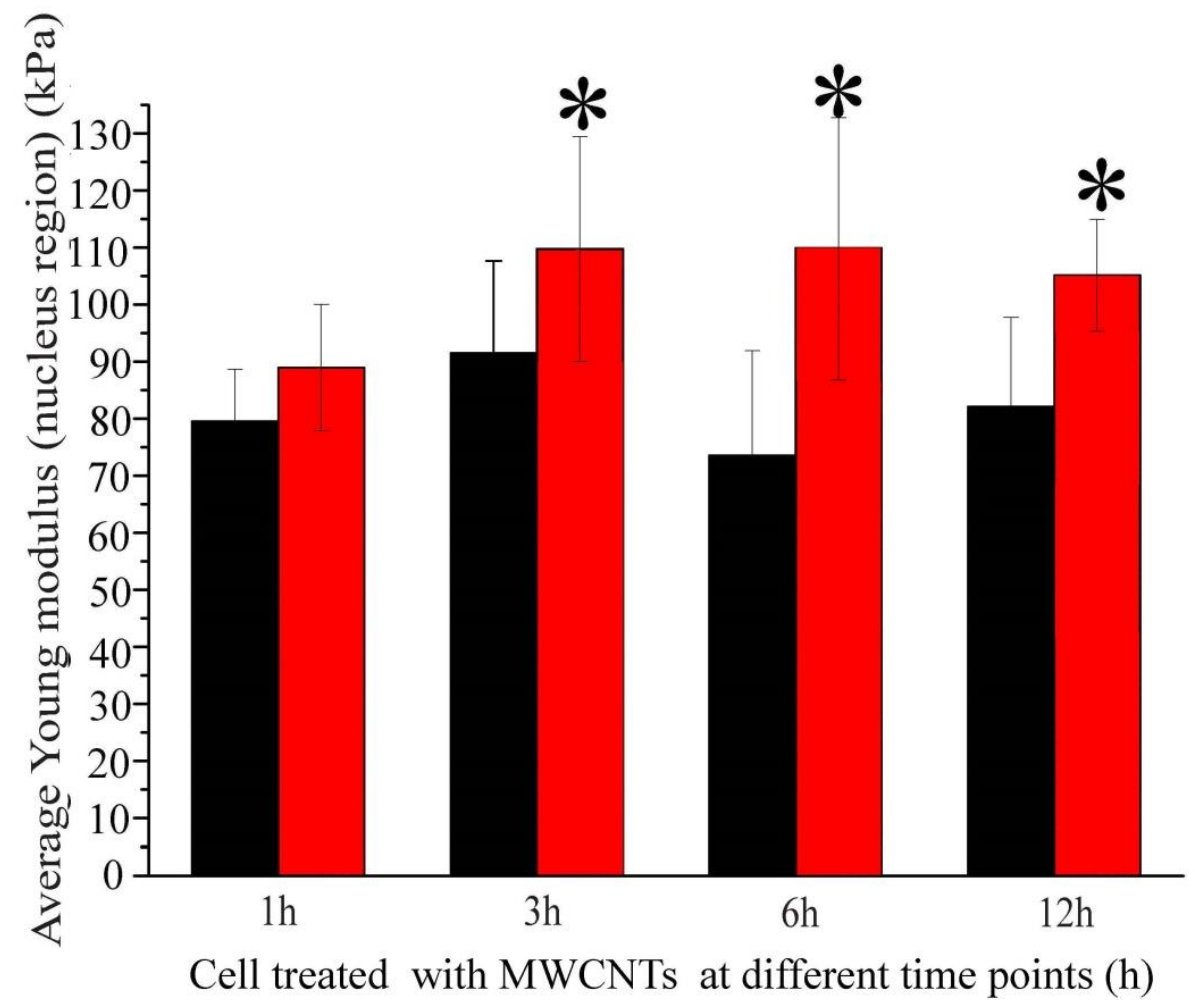

Figure 3: (a) Elastic modulus distribution histogram of control cells (b) Average elastic modulus of control cells and cells treated with MWCNTs at different time point (whole cell body) (c) Average elastic modulus of control cells and cells treated with MWCNTs at different time point (nucleus)

Combining our elasticity measurements with MWCNTs uptake results, we propose that MWCNTs induced biomechanics alterations are function of exposure time, the biodistribution and the translocation time of the nanotubes. Specifically, $1 \mathrm{~h}$ exposure leads to a limited amount of MWCNTs being internalized to associate with cytoskeleton structures and/or nuclear components and thus do not induce significant changes in cellular biomechanics. However, with the higher uptake after $3 \mathrm{~h}$ of exposure, a significant increase in the cell elastic modulus could indicate that MWCNTs begin to have affinity for nuclear components ${ }^{58}$. After $6 \mathrm{~h}$ incubation, the uptake amount of MWCNTs seemed to have reached its saturation value. This demonstration not 
only unravel the correlation between MWCNTs exposure duration, internalization and induced biomechanical changes in the cellular system but help provide a qualitative local nanoindentation map to help the structural characteristics of cells exposed to MWCNTs as a function of the exposure duration. 


\section{Conclusion}

Our findings indicated that changes in biomechanical properties of the cells are function of the uptake and internalization of the MWCNTs. Specifically, short exposure time $(1 \mathrm{~h})$ did not lead to considerable changes in the elastic properties. However, longer incubation periods, lead to a increased MWCNTs internalization and also a significant increase in the cellular elastic modulus both at the nucleus as well as in the cell body. Such changes could be related to CNTs interactions with cellular elements and help explain the MWCNTs intrinsic toxicity. The approach described herein may provide a new insight to the induced time-wise cytotoxicitic and/or genotoxicitic effects caused by CNTs exposure and could be further extended to other bionanoystems and toxins. 


\section{Supporting Information}

\begin{tabular}{ccc}
\hline Element & $\begin{array}{c}\text { Pristine } \\
\text { MWCNTs (wt \%) }\end{array}$ & $\begin{array}{c}\text { 1 h Acid Washed MWCNTs } \\
\text { (wt \%) }\end{array}$ \\
\hline $\mathrm{C}$ & 91.99 & 90.25 \\
$\mathrm{O}$ & 3.92 & 7.56 \\
$\mathrm{Si}$ & 0.82 & 0.42 \\
$\mathrm{~S}$ & 0.30 & 0.27 \\
$\mathrm{Cu}$ & 1.69 & 0.41 \\
$\mathrm{Fe}$ & 1.28 & 1.09 \\
\hline
\end{tabular}

Table S1: Energy dispersive X-ray analysis (EDX) allowed chemical characterization in the scanning electron microscope (SEM) of pristine and $1 \mathrm{~h}$ acid washed multi-walled carbon nanotubes (MWCNTs). Following the acid treatment, the content of oxygen $(\mathrm{O})$ increases while the contents of iron $(\mathrm{Fe})$, copper $(\mathrm{Cu})$ Silica $(\mathrm{Si})$ sulfur $(\mathrm{S})$ and carbon $(\mathrm{C})$ decreases in the $1 \mathrm{~h}$ acid treated sample.

\begin{tabular}{llllll}
\hline Type & $\begin{array}{l}\text { DI } \\
(\mathbf{m g} / \mathbf{m l})\end{array}$ & Water & $\begin{array}{l}\text { PBS } \\
(\mathbf{m g} / \mathbf{m l})\end{array}$ & $\begin{array}{l}\text { DMEM } \\
(\mathbf{m g} / \mathbf{m l})\end{array}$ & $\begin{array}{l}\text { DMEM+FBS } \\
(\mathbf{m g} / \mathbf{m l})\end{array}$ \\
\hline $\begin{array}{l}\text { Pristine MWCNTs } \\
\text { 1 h Acid washed }\end{array}$ & 0.19 & 0.25 & 0.44 & 1.69 \\
MWCNTs & 0.38 & 0.50 & 0.94 & 3.50 \\
\hline
\end{tabular}

Table S2: Solubility of pristine and $1 \mathrm{~h}$ acid washed multi-walled carbon nanotubes (MWCNTs) in different solutions.

\begin{tabular}{ccc}
\hline Time (h) & Type & Normalized Ave Signal Intensity \\
\hline 1 & Control cells & $1 \pm 0.01$ \\
1 & Cells treated with Alexa-BSA-MWCNTs & $1.15 \pm 0.01$ \\
1 & Cells treated with Alexa-BSA & $1.35 \pm 0.01$ \\
1 & MWCNTs & $1.19 \pm 0.01$ \\
3 & Control cells & $1 \pm 0.01$ \\
3 & Cells treated with Alexa-BSA-MWCNTs & $1.55 \pm 0.05$ \\
3 & Cells treated with Alexa-BSA & $1.31 \pm 0.04$ \\
3 & MWCNTs & $1.3 \pm 0.05$ \\
6 & Control cells & $1 \pm 0.03$ \\
6 & Cells treated with Alexa-BSA-MWCNTs & $1.92 \pm 0.05$ \\
6 & Cells treated with Alexa-BSA & $1.6 \pm 0.05$ \\
6 & MWCNTs & $1.28 \pm 0.05$ \\
12 & Control cells & $1 \pm .0 .01$ \\
12 & Cells treated with Alexa-BSA-MWCNTs & $2.02 \pm 0.02$ \\
12 & Cells treated with Alexa-BSA & $2.06 \pm 0.02$ \\
12 & MWCNTs & $1 \pm 0.02$ \\
\hline
\end{tabular}


Table S3: Normalized FITC signal intensity for control cells, MWCNTs, cells treated with Alexa-BSA, cells treated with Alexa-BSA and cells treated with Alexa-BSA-MWCNTs

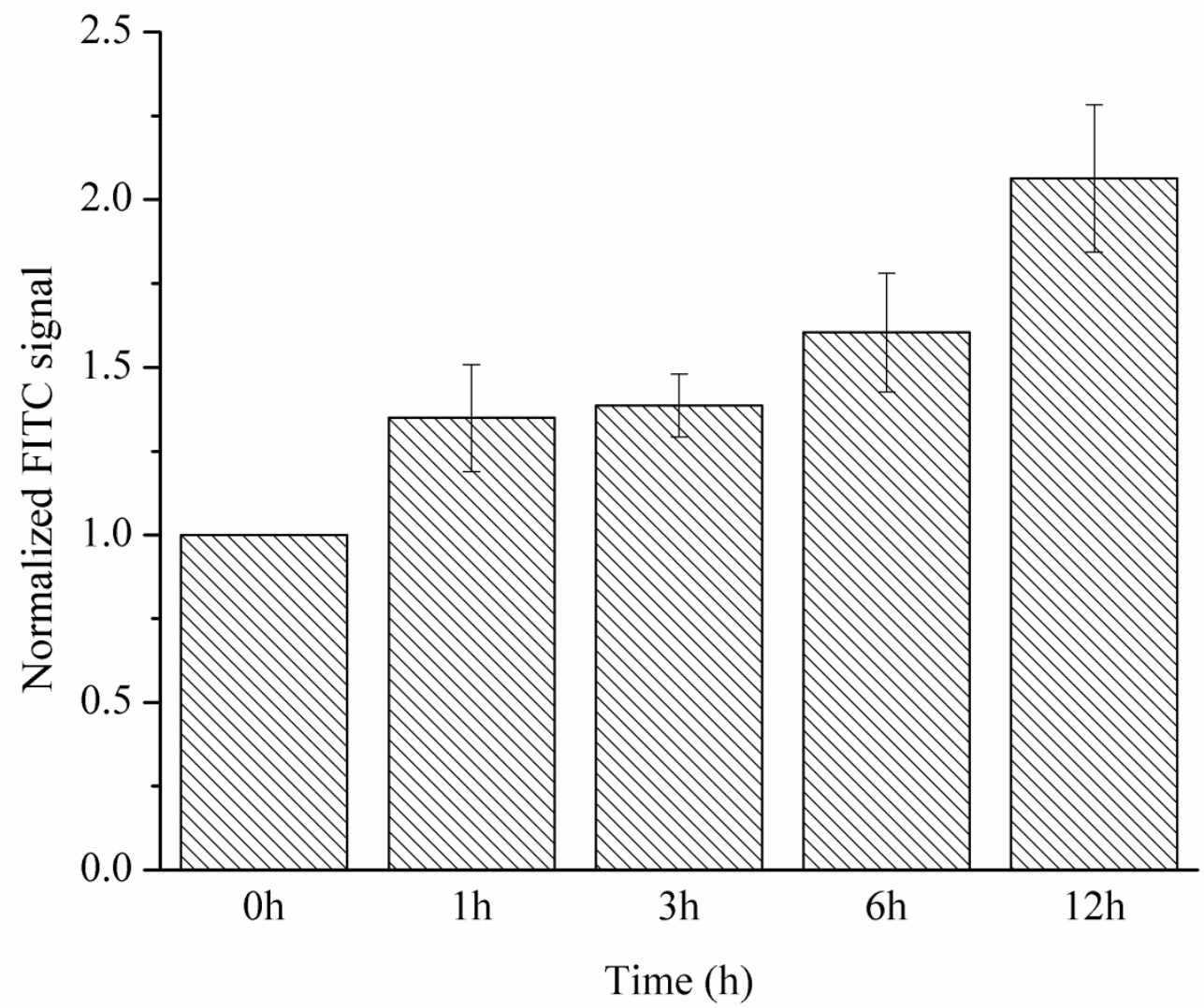

Figure S1 Summary of FITC signal for cells treated with Alexa-BSA at different time point 


\section{Reference}

1 Sun, D. M. et al. Flexible high-performance carbon nanotube integrated circuits. Nat Nanotechnol 6, 156-161 (2011).

2 Kim, D., Kim, Y., Choi, K., Grunlan, J. C. \& Yu, C. H. Improved Thermoelectric Behavior of Nanotube-Filled Polymer Composites with Poly(3,4-ethylenedioxythiophene) Poly(styrenesulfonate). Acs Nano 4, 513-523 (2010).

3 Byrne, M. T. \& Gun'ko, Y. K. Recent Advances in Research on Carbon NanotubePolymer Composites. Adv Mater 22, 1672-1688 (2010).

4 Ma, W. J. et al. High-Strength Composite Fibers: Realizing True Potential of Carbon Nanotubes in Polymer Matrix through Continuous Reticulate Architecture and Molecular Level Couplings. Nano Lett 9, 2855-2861 (2009).

5 Saeed, K. Review on Properties, Dispersion and Toxicology of Carbon Nanotubes. $J$ Chem Soc Pakistan 32, 559-564 (2010).

6 Lee, S. W., Kim, B. S., Chen, S., Shao-Horn, Y. \& Hammond, P. T. Layer-by-Layer Assembly of All Carbon Nanotube Ultrathin Films for Electrochemical Applications. $J$ Am Chem Soc 131, 671-679 (2009).

7 Tan, D. H. \& Zhang, Q. Research of Carbon Nanotubes/Polymer Composites for Sports Equipment. Adv Intel Soft Compu 119, 137-146 (2011).

8 Kumar, S., Li, B., Caceres, S., Maguire, R. G. \& Zhong, W. H. Dramatic property enhancement in polyetherimide using low-cost commercially functionalized multi-walled carbon nanotubes via a facile solution processing method. Nanotechnology 20 (2009).

9 Ding, L. et al. Selective Growth of Well-Aligned Semiconducting Single-Walled Carbon Nanotubes. Nano Lett 9, 800-805 (2009). 
10 Woan, K., Pyrgiotakis, G. \& Sigmund, W. Photocatalytic Carbon-Nanotube-TiO2 Composites. Adv Mater 21, 2233-2239 (2009).

11 Bhirde, A. A. et al. Targeted Killing of Cancer Cells in Vivo and in Vitro with EGFDirected Carbon Nanotube-Based Drug Delivery. Acs Nano 3, 307-316 (2009).

12 Herrero, M. A. et al. Synthesis and Characterization of a Carbon Nanotube-Dendron Series for Efficient siRNA Delivery. J Am Chem Soc 131, 9843-9848, doi:Doi 10.1021/Ja903316z (2009).

13 Kang, B. et al. Cancer-Cell Targeting and Photoacoustic Therapy Using Carbon Nanotubes as "Bomb" Agents. Small 5, 1292-1301, doi:DOI 10.1002/smll.200801820 (2009).

14 Kagan, V. E. et al. Carbon nanotubes degraded by neutrophil myeloperoxidase induce less pulmonary inflammation. Nat Nanotechnol 5, 354-359 (2010).

15 Liu, H. T. et al. Translocation of Single-Stranded DNA Through Single-Walled Carbon Nanotubes. Science 327, 64-67 (2010).

16 Porter, D. W. et al. Mouse pulmonary dose- and time course-responses induced by exposure to multi-walled carbon nanotubes. Toxicology 269, 136-147 (2010).

17 Plodinec, M. et al. The nanomechanical signature of breast cancer. Nat Nanotechnol 7, 757-765, doi:Doi 10.1038/Nnano.2012.167 (2012).

18 Deng, C. Y., Chen, J. H., Nie, Z. \& Si, S. H. A sensitive and stable biosensor based on the direct electrochemistry of glucose oxidase assembled layer-by-layer at the multiwall carbon nanotube-modified electrode. Biosens Bioelectron 26, 213-219, doi:DOI 10.1016/j.bios.2010.06.013 (2010).

19 Im, J. S., Bai, B. C. \& Lee, Y. S. The effect of carbon nanotubes on drug delivery in an 
electro-sensitive transdermal drug delivery system. Biomaterials 31, 1414-1419, doi:DOI 10.1016/j.biomaterials.2009.11.004 (2010).

20 Misra, S. K. et al. Characterization of carbon nanotube (MWCNT) containing $\mathrm{P}(3 \mathrm{HB}) /$ bioactive glass composites for tissue engineering applications. Acta Biomater $\mathbf{6}$, 735-742, doi:DOI 10.1016/j.actbio.2009.09.023 (2010).

21 Katelyn J Siegrist, S. H. R., Michael L Kashon, David T Lowry, Chenbo Dong, Ann F Hubbs, Shih-Houng Young, Jeffrey L Salisbury, Dale W Porter, Stanley A Benkovic, Michael McCawley, Michael J Keane, John T Mastovich, Kristin L Bunker, Lorenzo G Cena, Mark C Sparrow, Jacqueline L Sturgeon, Cerasela Zoica Dinu, Linda M Sargent. Genotoxicity of multi-walled carbon nanotubes at occupationally relevant doses. Part Fibre Toxicol 11, 6 (2014).

22 Dong, C. B. et al. Exposure to Carbon Nanotubes Leads to Changes in the Cellular Biomechanics. Advanced healthcare materials 2, 945-951, doi:DOI 10.1002/adhm.201200430 (2013).

23 Zhang, X. J. et al. Atomic Force Microscopy Study of the Effects of Water-Soluble Fullerenes on the Elasticity of Living Plant Cells. Chem-Asian J 8, 2388-2394, doi:DOI 10.1002/asia.201300522 (2013).

$24 \mathrm{Wu}$, P. et al. Focal Amplification of HOXD-Harboring Chromosome Region Is Implicated in Mulitiple-Walled Carbon Nanotubes-Induced Carcinogenicity. Nano Lett 13, 4632-4641, doi:Doi 10.1021/N1401658c (2013).

25 Dong, C. B. \& Dinu, C. Z. Molecular trucks and complementary tracks for bionanotechnological applications. Curr Opin Biotech 24, 612-619 (2013).

26 Pampaloni, F. \& Florin, E. L. Microtubule architecture: inspiration for novel carbon 
nanotube-based biomimetic materials. Trends Biotechnol 26, 302-310, doi:DOI 10.1016/j.tibtech.2008.03.002 (2008).

27 Sargent, L. M. et al. Promotion of lung adenocarcinoma following inhalation exposure to multi-walled carbon nanotubes. Part Fibre Toxicol 11, 3, doi:10.1186/1743-8977-11-3 (2014).

28 Zhao, X. C., Liu, R. T., Chi, Z. X., Teng, Y. \& Qin, P. F. New Insights into the Behavior of Bovine Serum Albumin Adsorbed onto Carbon Nanotubes: Comprehensive Spectroscopic Studies. J Phys Chem B 114, 5625-5631, doi:Doi 10.1021/Jp100903x (2010).

29 Rotsch, C., Jacobson, K. \& Radmacher, M. Dimensional and mechanical dynamics of active and stable edges in motile fibroblasts investigated by using atomic force microscopy. P Natl Acad Sci USA 96, 921-926 (1999).

30 Mathur, A. B., Truskey, G. A. \& Reichert, W. M. Atomic force and total internal reflection fluorescence microscopy for the study of force transmission in endothelial cells. Biophysical Journal 78, 1725-1735 (2000).

31 Radmacher, M., Fritz, M., Kacher, C. M., Cleveland, J. P. \& Hansma, P. K. Measuring the viscoelastic properties of human platelets with the atomic force microscope. Biophys $J \mathbf{7 0}$, 556-567 (1996).

32 Laurent, V. M. et al. Gradient of rigidity in the lamellipodia of migrating cells revealed by atomic force microscopy. Biophysical journal 89, 667-675, doi:10.1529/biophysj.104.052316 (2005).

33 Kuznetsova, T. G., Starodubtseva, M. N., Yegorenkov, N. I., Chizhik, S. A. \& Zhdanov, R. I. Atomic force microscopy probing of cell elasticity. Micron 38, 824-833, 
doi:10.1016/j.micron.2007.06.011 (2007).

34 Heng, B. C. et al. Toxicity of zinc oxide $(\mathrm{ZnO})$ nanoparticles on human bronchial epithelial cells (BEAS-2B) is accentuated by oxidative stress. Food Chem Toxicol 48, 1762-1766, doi:DOI 10.1016/j.fct.2010.04.023 (2010).

35 Veranth, J. M., Kaser, E. G., Veranth, M. M., Koch, M. \& Yost, G. S. Cytokine responses of human lung cells (BEAS-2B) treated with micron-sized and nanoparticles of metal oxides compared to soil dusts. Part Fibre Toxicol 4, 2, doi:10.1186/1743-8977-4-2 (2007).

36 Wepasnick, K. A. et al. Surface and structural characterization of multi-walled carbon nanotubes following different oxidative treatments. Carbon 49, 24-36, doi:DOI 10.1016/j.carbon.2010.08.034 (2011).

37 Zhou, J. M., Li, H. Y., Lin, G. D. \& Zhang, H. B. Purification of Multiwalled Carbon Nanotubes and Characterization of Their Oxygen-Containing Surface Groups. Acta PhysChim Sin 26, 3080-3086 (2010).

38 Sargent, L. M. et al. Single-walled carbon nanotube-induced mitotic disruption. Mutation research 745, 28-37, doi:10.1016/j.mrgentox.2011.11.017 (2012).

39 Kuempel, E. D., Tran, C. L., Castranova, V. \& Bailer, A. J. Lung dosimetry and risk assessment of nanoparticles: Evaluating and extending current models in rats and humans. Inhalation toxicology 18, 717-724 (2006).

40 Schulte, P. A., Murashov, V., Zumwalde, R., Kuempel, E. D. \& Geraci, C. L. Occupational exposure limits for nanomaterials: state of the art. J Nanopart Res 12, 1971-1987 (2010).

41 Graham, E. G., MacNeill, C. M. \& Levi-Polyachenko, N. H. Quantifying folic acidfunctionalized multi-walled carbon nanotubes bound to colorectal cancer cells for 
improved photothermal ablation. J Nanopart Res 15, doi:Artn 1649

Doi 10.1007/S11051-013-1649-7 (2013).

42 Campbell, A. S., Dong, C., Dordick, J. S. \& Dinu, C. Z. BioNano engineered hybrids for hypochlorous acid generation. Process Biochemistry 48, 1355-1360, doi:http://dx.doi.org/10.1016/j.procbio.2013.06.011 (2013).

43 Saifuddin, N., Raziah, A. Z. \& Junizah, A. R. Carbon Nanotubes: A Review on Structure and Their Interaction with Proteins. J Chem-Ny, doi:Artn 676815

Doi 10.1155/2013/676815 (2013).

44 Wu, Z. C., Zhang, B. \& Yan, B. Regulation of Enzyme Activity through Interactions with Nanoparticles. Int J Mol Sci 10, 4198-4209, doi:Doi 10.3390/Ijms10104198 (2009).

45 McNally, T. et al. Polyethylene multiwalled carbon nanotube composites. Polymer 46, 8222-8232, doi:DOI 10.1016/j.polymer.2005.06.094 (2005).

46 Bokova, S. N. et al. Raman diagnostics of multi-wall carbon nanotubes with a small wall number. Phys Status Solidi B 247, 2827-2830, doi:DOI 10.1002/pssb.201000237 (2010).

$47 \mathrm{Li}$, J. et al. Rejuvenation of chondrogenic potential in a young stem cell microenvironment. Biomaterials 35, 642-653, doi:10.1016/j.biomaterials.2013.09.099 (2014).

48 Murata, K. \& Zhang, D. Z. Applicability of LIVE/DEAD BacLight Stain with Glutaraldehyde Fixation for the Measurement of Bacterial Cell Concentration and Viability in the Air. Aerosol Air Qual Res 13, 1755-1767, doi:DOI 10.4209/aaqr.2012.10.0293 (2013).

49 Lamin-A in the cell nucleus regulates tissue stiffness, driving differentiation. BoneKEy reports 3, 491, doi:10.1038/bonekey.2013.225 (2014). 
50 Dupin, I., Camand, E. \& Etienne-Manneville, S. Classical cadherins control nucleus and centrosome position and cell polarity. J Cell Biol 185, 779-786 (2009).

51 Cross, S. E., Jin, Y. S., Rao, J. \& Gimzewski, J. K. Nanomechanical analysis of cells from cancer patients. Nat Nanotechnol 2, 780-783, doi:DOI 10.1038/nnano.2007.388 (2007).

52 Rheinlaender, J., Geisse, N. A., Proksch, R. \& Schaffer, T. E. Comparison of Scanning Ion Conductance Microscopy with Atomic Force Microscopy for Cell Imaging. Langmuir 27, 697-704 (2011).

53 Rico, F., Alcaraz, J., Fredberg, J. J. \& Navajas, D. Nanomechanics of lung epithelial cells. Int J Nanotechnol 2, 180-194 (2005).

54 Juan P Ruiz, D. P., Janice Dias, Noël M Ziebarth, Herman S Cheung. The effect of nicotine on the mechanical properties of mesenchymal stem cells. Cell Health Cytoskelet 4, 29-35 (2012).

55 Holt, B. D. et al. Carbon Nanotubes Reorganize Actin Structures in Cells and ex Vivo. Acs Nano 4, 4872-4878 (2010).

56 Rodriguez-Fernandez, L., Valiente, R., Gonzalez, J., Villegas, J. C. \& Fanarraga, M. L. Multiwalled Carbon Nanotubes Display Microtubule Biomimetic Properties in Vivo, Enhancing Microtubule Assembly and Stabilization. Acs Nano 6, 6614-6625 (2012).

57 Dinu, C. Z., Bale, S. S., Zhu, G. Y. \& Dordick, J. S. Tubulin Encapsulation of Carbon Nanotubes into Functional Hybrid Assemblies. Small 5, 310-315, doi:DOI 10.1002/smll.200801434 (2009).

58 Roxbury, D., Tu, X. M., Zheng, M. \& Jagota, A. Recognition Ability of DNA for Carbon Nanotubes Correlates with Their Binding Affinity. Langmuir 27, 8282-8293, doi:Doi 10.1021/La2007793 (2011). 


\title{
Chapter 4: Toxicity and biomechanical induced effects of purified MWCNTs on live epithelial cell
}

\begin{abstract}
Toxicity of engineered nanomaterials is associated with their inherent properties, both physical and chemical. Recent studies have shown that exposure to multi-walled carbon nanotubes (MWCNTs) promote tumors and tumor-associated pathologies in model in vivo systems and have the potential to lead to carcinogenesis. Herein we assessed the potential of purified forms of MWCNTs with increased hydrophilicity to affect human lung epithelial cells when used at occupational relevant exposure doses for particles not otherwise regulated. Specially, we performed a WST assay to assess MWCNTs influence on cell viability, tested MWCNTs induced biophysical-biomechanical properties changes in cellular system, applied FACS to analysis MWCNTs exposure effects on cell cycle and correlated the observed results to unravel systematic effects of MWCNTs on live cell. Our results showed that exposure to MWCNTs affects the dynamics and the biomechanical properties of the live cells by reducing the metabolic activity of the mitochondria and inducing cell cycle arrest. Our analysis emphasizes that cellular toxicity observed upon exposure to purified MWCNTs is a synergism resulting from multiple types of interactions that could be analyzed by means of intracellular mechanical changes.
\end{abstract}




\section{Introduction}

Nanomaterials of carbon or carbon nanotubes (CNTs) have been widely used to fabricate various analytical tools from molecular sensors ${ }^{1}$ to diagnostic systems ${ }^{2}$, and from drug delivery systems $^{3}$ to decontamination agents ${ }^{4}$. With the increase in bio-related applications of CNTs there are corresponding concerns regarding their potential toxicological impacts. Previous studies revealed that multi-walled carbon nanotubes (MWCNTs) are toxic to human neuroblastoma cells, with exposure to such nanomaterials leading to generation of intracellular reactive oxygen species (ROS) and causing damage to mitochondria ${ }^{5}$. Other studies have shown that cellular exposure to CNTs lead to DNA damage and chromosomal abnormalities and thus raise CNTs potential to induce genotoxicity ${ }^{6}$.

Consistent evidence today relates the cytotoxic and genotoxic effects of MWCNTs to both physical and chemical properties of these nanomaterials ${ }^{7}$. In particular, studies showed that thin MWCNTs $(9.4 \mathrm{~nm})$ have significantly increased toxicity when compared to their thicker counterparts $(70 \mathrm{~nm})$ when used for both in vitro and in vivo tests ${ }^{8}$. Studies also showed that impure CNTs (containing Fe on their external or internal walls) induce immunological toxicity in BALB/c mice at a higher extent than purified $\mathrm{CNTs}^{9}$, while shorter MWCNTs $(4.8 \mu \mathrm{m})$ have a higher toxicity relative to longer ones $(9.5 \mu \mathrm{m})$ in mouse and in leukaemic monocyte macrophages ${ }^{10}$. Lastly, analysis has shown that longer CNTs illicit a much stronger inflammatory and toxicity response in the pleural cavity of the mice due to frustrated cellular phagocytosis $^{11}$.

Strong acid oxidation is known to provide convenient and effective means to modify MWCNTs chemical and physical properties, shorten these nanotubes and improve their 
solubility $^{12}$. Compared with larger size nanotubes, shorter nanotubes have stronger affinity for biological systems ${ }^{13,14}$. Similarly, dispersed MWCNTs seem to cause greater toxic effects when compared to highly agglomerated samples ${ }^{15}$. Further, our research showed that shorter and more soluble MWCNTs change the mechanical properties of epithelial cells upon exposure ${ }^{16}$. However, it is still subject to debate which of these properties influence CNTs toxicity or if CNTs physical and chemical properties work synergistically to lead to toxicity. Moreover, the biomechanical and biochemical mechanisms underlying nanotube-induced toxicity, and how exposure to MWCNTs brings about cell death, are still conflicting.

We proposed to systematically investigate the effects of MWCNTs on the fate and dynamics of live human bronchial epithelial cells (BEAS-2B). Our hypothesis was that exposure to purified MWCNTs induces both cytotoxic and genotoxic effects causing derailed 3D cellular rearrangement thus leading to cell death. Knowing that the respiratory tract is the primary route of exposure by inhalation ${ }^{17}$, lung-derived BEAS-2B cells line were used as a suitable model systems to study in vitro toxicity of nanomaterials ${ }^{18,19}$. These types of cells were previously used to study the effects of several chemical and biological agents ${ }^{20,21}$, to evaluate in vitro toxicity of different types of $\mathrm{TiO}_{2}$ nanowires ${ }^{22}$, engineered $\mathrm{ZnO}$ nanoparticles ${ }^{23}$ or $\mathrm{MWCNTs}^{24}$. We investigated the dynamics of live cellular systems upon MWCNTs exposure by combining water soluble tetrazolium salts (WST) assay that measures cell viability with Atomic Force Microscopy (AFM) studies that assess physical properties of cells upon exposure to MWCNTs. WST was previously used to evaluate nanomaterials cytotoxicity on biological systems ${ }^{25}$, while AFM was used to assess the elastic properties of the cells ${ }^{26}$ and relate changes in cellular elasticity to nanomaterial exposure ${ }^{16}$. Correlation of our analysis of MWCNTs exposure measured by 
conventional biocellular assays with changes in cellular biomechanical properties measured by the $\mathrm{AFM}^{27}$ could potentially lead to novel means to unravel the biomechanics and biochemistry of MWCNTs toxicity in biological systems. 


\section{Materials and Methods}

\section{Multi-walled carbon nanotubes (MWCNTs) purification}

MWCNTs (Nanolab Inc.) were purified by incubation in a strong acid mixture. Initially, MWCNTs powders (100 mg) were immersed in sulfuric (Fisher Scientific, 96.4\%) and nitric (Fisher Scientific, 69.5\%) acid (volume ratio 3:1). The mixture was subsequently ultrasonicated (Branson 2510, Fisher Scientific) for $1 \mathrm{~h}$ at a constant temperature of $23^{\circ} \mathrm{C}$. Upon time expiration, the solution was diluted in deionized water (DI water) and filtered through a polycarbonate membrane (Fisher Scientific, GTTP $0.2 \mu \mathrm{m}$ ). This process was repeated several times to wash away acidic residues or impurities such as metal catalysts dissociated during the acid incubation. The purified MWCNTs collected on the filter were subsequently dried in a vacuum desiccator and stored at room temperature.

\section{MWCNTs physical and chemical properties characterization}

Fourier Transform Infrared Spectroscopy (FTIR, Digilab FTS 7000) equipped with diamond Attenuated Total Reflection (ATR) crystal was used to investigate the chemical properties of pristine and $1 \mathrm{~h}$ purified MWCNTs. Scans ranging from 100 to $4000 \mathrm{~cm}^{-1}$ were collected.

Elemental quantitative analyses of pristine and $1 \mathrm{~h}$ purified MWCNTs $(1 \mathrm{mg} / \mathrm{mL})$ were performed using Energy Dispersive X-ray spectroscopy (EDX). Corresponding samples (1 $\mathrm{mg} / \mathrm{mL}$ in DI water) were dropped on silica wafers and dried under vacuum. The analysis was 
performed on a Hitachi S-4700 Field Emission Scanning Electron Microscope (Hitachi HighTechnologies Corporation) supplemented with a S-4700 detector combining secondary (SE) and backscattered (BSE) electron detection (all in a single unit) operating at $20 \mathrm{KV}$. Results are shown as weight percent of elements relative to the most dominant element present in the sample.

MWCNTs dispersity was tested in DI water and Dulbecco's Modified Eagle Media (DMEM, Invitrogen) with 10\% Fetal Bovine Serum (FBS, Invitrogen). Specially, MWCNTs were dispersed by sonication in the testing solution (at a concentration of $5 \mathrm{mg} / \mathrm{mL}$ ) and subsequently centrifuged at $3000 \mathrm{rpm}$ for $5 \mathrm{~min}$. Part of the corresponding supernatant $(0.8 \mathrm{~mL})$ was collected and filtered through a $0.2 \mu \mathrm{m}$ filter membrane. After filtration the corresponding supernatant was dried under vacuum and the amount of MWCNTs on the filter membrane was weighted; the dispersity was calculated relative to the starting volumes for each individual sample.

MWCNTs length distribution (pristine and $1 \mathrm{~h}$ purified MWCNTs) was evaluated using tapping mode Atomic Force Microscopy (AFM) performed in air $^{28}$ using Si tips (Asylum Research, AC240TS, 50 to $90 \mathrm{kHz}$ ). At least 3 scan pictures in scanning areas of $10 \mu \mathrm{m} \times 10 \mu \mathrm{m}$ were obtained for each of the MWCNTs sample being analyzed. A minimum of 30 individual MWCNTs were measured to generate their length distribution. 


\section{Functionalization of MWCNTs with fluorescent protein}

Alexa 488-labeled Bovine Serum Albumin (Alexa-BSA, Sigma) was covalently bound to $1 \mathrm{~h}$ purified MWCNTs using 1-ethyl-3-[3-dimethylaminopropyl] carbodiimide hydrochloride (EDC, Acros Organics) and N-hydroxysuccinimide (NHS, Pierce) chemistry. Briefly, 2 mg of 1 $\mathrm{h}$ purified MWCNTs were dispersed in $160 \mathrm{mM}$ EDC and $80 \mathrm{mM}$ NHS (total volume of $2 \mathrm{~mL}$ in 2-(N-morpholino) ethanesulfonic acid sodium salt or MES, $50 \mathrm{mM}$, pH 4.7, (Sigma)) for $15 \mathrm{~min}$ at room temperature and $200 \mathrm{rpm}$. EDC/NHS activated MWCNTs were subsequently filtered through a $0.2 \mu \mathrm{m}$ filter membrane, washed thoroughly with MES buffer to remove any ester residues, and immediately re-dispersed in $2 \mathrm{~mL}$ of $1 \mathrm{mg} / \mathrm{mL}$ Alexa-BSA solution in Phosphate Saline Buffer (PBS, Fisher), pH 7.4. The mixture was incubated for $3 \mathrm{~h}$ at room temperature with shaking at $200 \mathrm{rpm}$. Upon incubation, the resulting Alexa-BSA-MWCNTs conjugates were filtered and washed extensively with PBS to remove any unbound protein while the supernatant and the first two washes were collected to quantify protein loading.

\section{Protein loading}

The amount of Alexa-BSA bound to $1 \mathrm{~h}$ purified MWCNTs (i.e., protein loading) was determined using standard bicinchoninic acid assay (BCA, Fisher). The working reagent was prepared by mixing 50 parts of reagent $A(1000 \mu \mathrm{L})$, with 1 part of reagent $B(20 \mu L)$. Subsequently, $1000 \mu \mathrm{l}$ of the working reagent was mixed with $50 \mu \mathrm{L}$ of each of each of the collected supernatants or washes. The resulting solution was gently vortexed and incubated in a water bath at $37^{\circ} \mathrm{C}$ for $30 \mathrm{~min}$. Absorbance values were measured at $562 \mathrm{~nm}$ on a Spectrophotometer (Evolution 300/600, Thermo Fisher). Control calibration curves were prepared using serial dilutions of Alexa-BSA in the working buffer. The relative amount of 
Alexa-BSA bound to $1 \mathrm{~h}$ purified MWCNTs was estimated from the difference between the amount of protein initially added to the MWCNTs and the amount of the protein removed in the supernatant and washes.

\section{Cell culture}

Immortalized human bronchial epithelial cells (BEAS-2B, ATCC) were cultured in DMEM media with $10 \%$ FBS, $0.1 \%$ L-glutamine and $1 \%$ penicillin/streptomycin (Invitrogen). Cells were maintained in a humidified atmosphere at $37^{\circ} \mathrm{C}$ and $5 \% \mathrm{CO}_{2}$ and passaged weekly using $0.25 \%$ trypsin (Invitrogen).

\section{Fluorescence Activated Cell Sorting (FACS)}

BEAS-2B cells were seeded at a density of $3.71 \times 10^{5}$ cells in T75 flasks (Fisher, USA)

for $24 \mathrm{~h}$. Subsequently, the cells were treated for $24 \mathrm{~h}$ with $24 \mu \mathrm{g} / \mathrm{cm}^{2}$ Alexa-BSA-MWCNTs diluted in fresh media. Control samples, i.e. untreated cells in PBS, and cells treated with free Alexa-BSA at the equivalent amount to the Alexa-BSA amount bound onto the MWNTs (based on the loading) were performed in parallel. Upon $24 \mathrm{~h}$ incubation with Alexa-BSA or AlexaBSA-MWCNTs, cells were washed with PBS, trypsinized (0.25\% trypsin), suspended in DMEM with $10 \%$ FBS and centrifuged at $1200 \mathrm{rpm}$ for $5 \mathrm{~min}$ to remove any free protein or noninternalized/loosely bound nanotube conjugates. Upon centrifugation the samples were washed with PBS, fixed with $100 \mu \mathrm{L} \mathrm{4 \%} \mathrm{glutaraldehyde} \mathrm{solution} \mathrm{(Fisher} \mathrm{Scientific,} \mathrm{USA)} \mathrm{for} 15$ min at room temperature, and then extensively washed with PBS to remove free glutaraldehyde. FACS analysis were performed on a FACS Caliber flow cytometer (Becton Dickinson, CA). The 
forward scatter (FSC) and side scatter (SSC) were used to gate the cells to include the majority of the live cell population. Specially, the live cells were chosen based on their size distribution on the FSC and SSC scatter. If an event/ cell is too small or too big, or tubular it will be excluded them and majority of the cells that have a normal size distribution will be taken. (these are the live cells) the small cells are assumed to be debris and the too large ones might be swollen cells, or other deformities. FITC signal for the BSA-based conjugates used excitation at $488 \mathrm{~nm}$ and emission at $515 \mathrm{~nm}$; at least 30000 events were recorded for each sample. Data was analyzed and plotted using FlowJo v7.2.5 software.

\section{Cell viability}

To determine the effect of $1 \mathrm{~h}$ purified MWCNTs on cell viability, BEAS-2B cells were seeded into a 96-well plate overnight, at a density of $1.5 \times 10^{4}$. Cells were subsequently treated with $24 \mu \mathrm{g} / \mathrm{cm}^{2}$ of $1 \mathrm{~h}$ purified MWCNTs dispersed by brief sonication in culture medium for 24 , 48 and $72 \mathrm{~h}$ respectively. Upon time elapse, $10 \mu \mathrm{l}$ of tetrazolium salt 2- (4-iodophenyl) - 3- (4nitrophenyl) - 5-(2,4-disulfophenyl) -2H-tetrazolium, known as WST-1 (Roche), was added to each well and incubated for $2 \mathrm{~h}$. Changes in cell fate were based on the cells ability to cleave

WST-1 salt to farmazan by enzyme dehydrogenase ${ }^{29}$. The amount of farmazan dye formed was assessed using a BioTek 96 plate reader (BioTek) and by measuring the absorbance at $450 \mathrm{~nm}$. Specially, the control and MWCNTs treated cell shown different color, the changes in the color are related with cell viability which could be detected using a spectrophotometer plate reader. Relative viability was calculated as the percentage of live cells in treated samples relative to control samples of untreated cells. 


\section{Cell cycle analysis}

To study the effects of $1 \mathrm{~h}$ purified MWNTs on the cell cycle progression, BEAS-2B cells were seeded overnight in 6 well plate at a concentration of $3 \times 10^{5}$ cells/well, and exposed to $24 \mu \mathrm{g} / \mathrm{cm}^{2} 1 \mathrm{~h}$ purified MWCNTs dispersed in cellular media for $24 \mathrm{~h}$. Following treatment with MWCNTs, cells were trypsinized, collected, washed twice with PBS, centrifuged at $1500 \mathrm{rpm}$ for $6 \mathrm{~min}$ and fixed overnight in $2 \mathrm{~mL}$ of $70 \%$ ethanol at $-20^{\circ} \mathrm{C}$. Subsequently, the cells were washed again, resuspended in $0.2 \%$ Tween 20 (Sigma Chemicals) for 15 min, treated with $10 \mu \mathrm{l}$ $0.05 \%$ RNase for 15 min and stained with $30 \mu \mathrm{l}$ propidium iodide (Sigma Aldrich). The DNA content was determined using BD LSR Fortessa Flow cell analyzer (BD Biosciences). The forward scatter (FSC) and side scatter (SSC) were used to gate the majority of the live cell population; 20000 events were collected for each sample using BD FACS Diva software (Verity Software House) and analyzed to measure DNA content for only single cells using FlowJo software V10.0.7 (Tree Star Inc.). The selection was based on knowing that cells that are in the G0/G1 phase (before DNA synthesis) have a defined amount of DNA (i.e., a diploid chromosomal DNA content) while within the G2 or M phases (G2/M), cells have double the amount of DNA (i.e., a tetraploid chromosomal DNA content). During the $\mathrm{S}$ phase (DNA synthesis), cells contain between one to two DNA levels. Experiments were repeated three times each with three replicates for a total of 9 replicates.

\section{Cell topography and nanomechanical analyses}

BEAS-2B cells were seeded overnight in $50 \mathrm{~mm} \times 9 \mathrm{~mm}$ parallel culture Petri dishes (BD Biosciences) at a density of $1 \times 10^{5}$ cells per dish. Cells were exposed to $24 \mu \mathrm{g} / \mathrm{cm}^{2} 1 \mathrm{~h}$ purified MWCNTs for $24 \mathrm{~h}$. MFP-3D-BIO AFM (Asylum Research, TE2000-U) was used to evaluate 
Young modulus. Individual cells were selected using optical microscopy and scanned in contact mode in liquid using an Olympus TR400-PB cantilever with a spring constant of $0.09 \mathrm{~N} / \mathrm{m}$. Elastic modulus analysis was performed using the Sneddon's modification of the Hertz model

for a four-sided pyramid ${ }^{30,31}$. Stiffness was then calculated knowing the indentation of the tip and the Poisson's ratio of the cell $\left(v=0.5^{31}\right)$.

\section{Statistical Analysis}

Statistical comparisons between treatment groups for the physical parameters of the cell and the cell cycle data were performed with SAS/STAT software (v9.2) for Windows. Two-way analysis of variance (ANOVA) and unpaired two-tailed Student's t-test were performed SigmaPlot 10.0 (Systat Software Inc.) to study the effects of MWCNTs on cellular viability. The Proc Mixed function was utilized to carry out mixed model analyses of variance where block was incorporated as a random variable. Differences were considered significant at $\mathrm{p}<0.05$. 


\section{Results and Discussion}

We aimed to investigate the potential of purified MWCNTs to induce toxicity. For this, we used pristine MWCNTs purified in sulfuric/nitric acid mixture for $1 \mathrm{~h}^{32}$; purification eliminates concerns associated with possible toxic effects induced by catalyst precursors usually present during the nanotube synthesis ${ }^{33}$. Pristine and acid purified MWCNTs samples were investigated using Attenuated Total Reflection Fourier Transform Infrared Spectroscopy (ATRFTIR), AFM and Energy Dispersive X-ray spectroscopy (EDX) spectroscopy to assess whether acid purification led to changes in MWCNTs physical structure and/or chemical properties. ATR-FTIR spectroscopy analysis showed that free carboxyl groups were generated onto the surface of the purified MWCNTs (Figure 1a). The peak at $3370 \mathrm{~cm}^{-1}$ was a result of the O-H stretching vibration while the peak at around $1670 \mathrm{~cm}^{-1}$ was attributed to the $\mathrm{C}=\mathrm{O}$ stretching vibration of the carboxyl group. In addition, the small peak at around $1330 \mathrm{~cm}^{-1}$ was associated with the $\mathrm{O}-\mathrm{H}$ stretching and bending vibration in carboxyl group ${ }^{34}$, while the wide range of peaks between $1000-1250 \mathrm{~cm}^{-1}$ were associated with the $\mathrm{C}-\mathrm{O}$ stretching vibration ${ }^{35}$.

The presence of carboxyl groups onto MWCNTs was further confirmed by EDX (Table $\mathrm{S} 1)$. Specifically, the increase in the $\mathrm{O}$ and $\mathrm{C}$ contents observed for the purified relative to pristine MWCNTs samples indicated that acid incubation altered the structural integrity of the nanotubes and induced $\mathrm{O}$ incorporation into the nanotube sidewalls thus leading to the formation of free carboxylic groups ${ }^{33}$. Further, a decrease in $\mathrm{Fe}$ and $\mathrm{Cu}$ was observed for the purified MWNCTs when compared to pristine counterparts suggesting that the acid purification also removed the metal catalysts present in the pristine sample ${ }^{12}$. 
The solubility of pristine and purified MWCNTs was tested.Since well-dispersed solutions containing homogenous MWCNTs are necessary to avoid potential mass transfer limitations when studying the interactions of MWCNTs with cellular systems ${ }^{36}$. Our dispersity analysis showed that purified MWCNTs had 100\% higher dispersity relative to their pristine counterparts in all the solutions considered. A higher dispersity was observed in DMEM media when compared to the dispersity in DI water (Table S2). The increase in the dispersity was attributed to: (1) formation of carboxylate anions upon generation of active carboxylic groups onto the nanotube surface ${ }^{12}$, and/or (2) the hydrodynamic size of the purified MWCNTs. For the first, the negative charges or the carboxylate anions induced upon MWCNTs purification lead to strong electrostatic repulsion in between individual nanotubes when in aqueous environment ${ }^{37}$. Similarly, the presence of proteins and amino $\operatorname{acid}^{38}$ in the media will aid to the increased dispersion. For the former, the average length of the purified MWCNTs as determined by AFM was about $19 \%$ smaller $(792 \pm 254 \mathrm{~nm})$ when compared to their pristine counterparts $(4261 \pm 2354$ $\mathrm{nm}$; Table S3). Such reduction in MWCNTs length is consistent with previous reports that indicated that strong acid react with the $\mathrm{C}-\mathrm{C}$ bands in the nanotube structure at the defective inducing shortening of the nanotubes and carboxyl functionalities generation at their defect sites $^{39}$.

To study the effects of purified MWCNTs on cellular activity, we first assessed the extent of MWCNTs cellular uptake using Fluorescence Assisted Cell Sorting (FACS). Uptake, internalization, intracellular translocation, and association with cellular elements are of utmost importance when aiming to elucidate MWCNTs-induced cellular fate. Previous reports have shown that MWCNTs uptake consist of direct penetration or piercing and endocytosis ${ }^{40}$. For the 
uptake evaluation, human bronchial respiratory epithelial (BEAS-2B) cells were exposed to 24 $\mu \mathrm{g} / \mathrm{cm}^{2}$ of $1 \mathrm{~h}$ purified Alexa-BSA-MWNCT conjugates with Alexa-BSA for $24 \mathrm{~h}$. Untreated cells, cells exposed to $1 \mathrm{~h}$ purified MWCNTs or cells exposed to free Alexa-BSA were used as controls (Figure 1b). The MWCNTs dose of exposure was determined by extrapolating from in vivo model studies mimicking human exposure of 20 weeks at the Occupational Safety and Health Administration (OSHA) permissible limits for particles not otherwise regulated ${ }^{41}$. Our results showed a significantly higher FITC signal for cells treated with Alexa-BSA-MWCNTs conjugates relative to control cells, free Alexa-BSA treated cells or cells treated with $1 \mathrm{~h}$ purified MWCNTs alone. The higher FITC signal of cells containing incubated with Alexa-BSAMWCNTs conjugates is consistent with those cells internalizing the conjugates; the relative lower intensity signal for the cells exposed to free Alexa-BSA is presumably a result of the increased free protein susceptibility for proteosomal degradation relative to the immobilized $\operatorname{protein}^{42}$.

To assess cellular viability upon exposure to purified MWCNTs, we used WST-1 assay to measure the mitochondrial dehydrogenase activity of the exposed cells (Figure 1c). Mitochondria are relatively sensitive organelles known respond to cellular stresses caused by the uptake of CNTs ${ }^{43}$. WST-1 was preferred to the MTT assay due to existing concerns regarding CNTs interaction with the tetrazolium salt contained in the former assay ${ }^{44}$. The values of cells viability are assessed as percentages of MWCNTs treated cells relative to control cells Thus the control cells (cells without treated with MWCNTs).are 100\% viable. 
a)

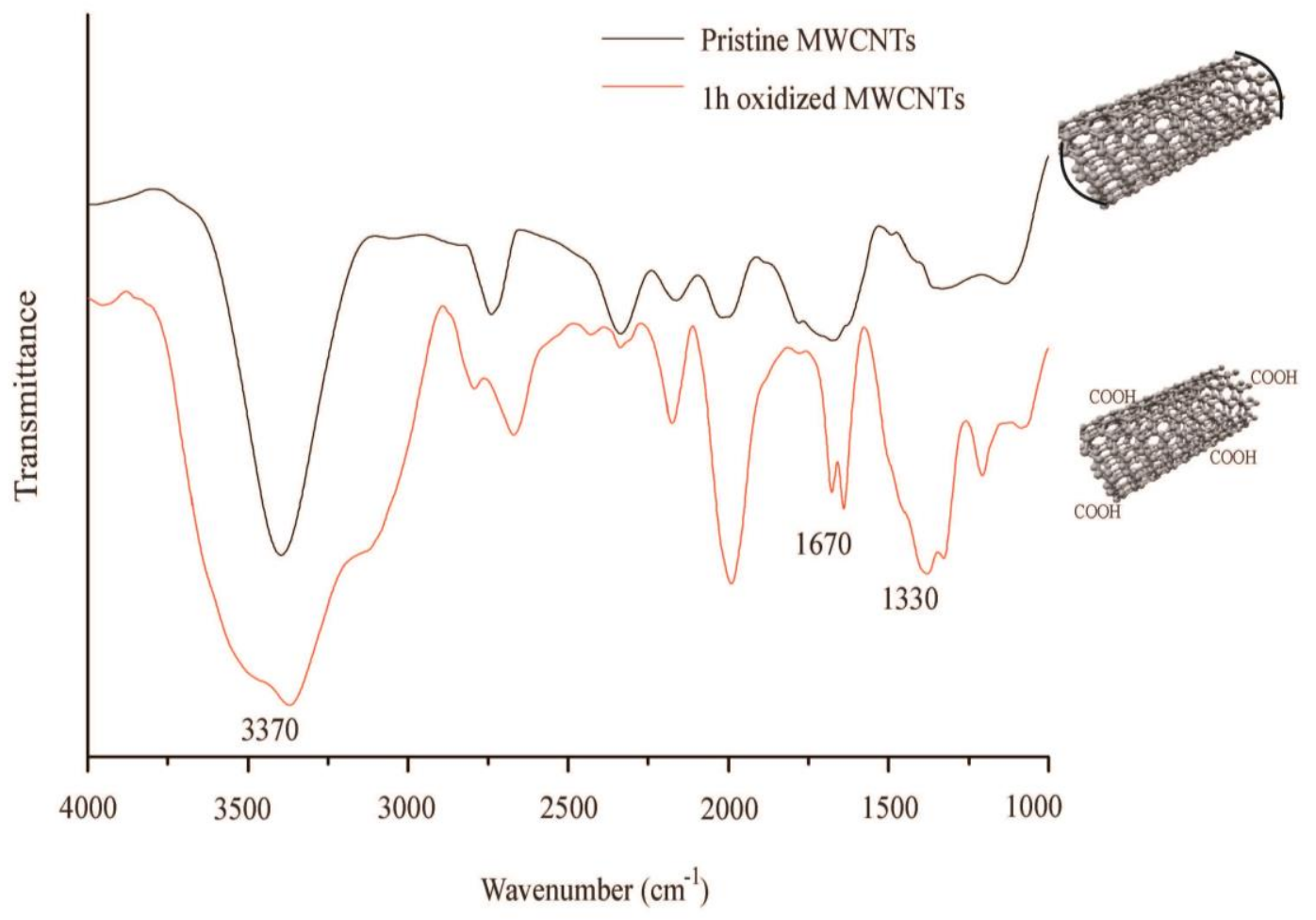

b)

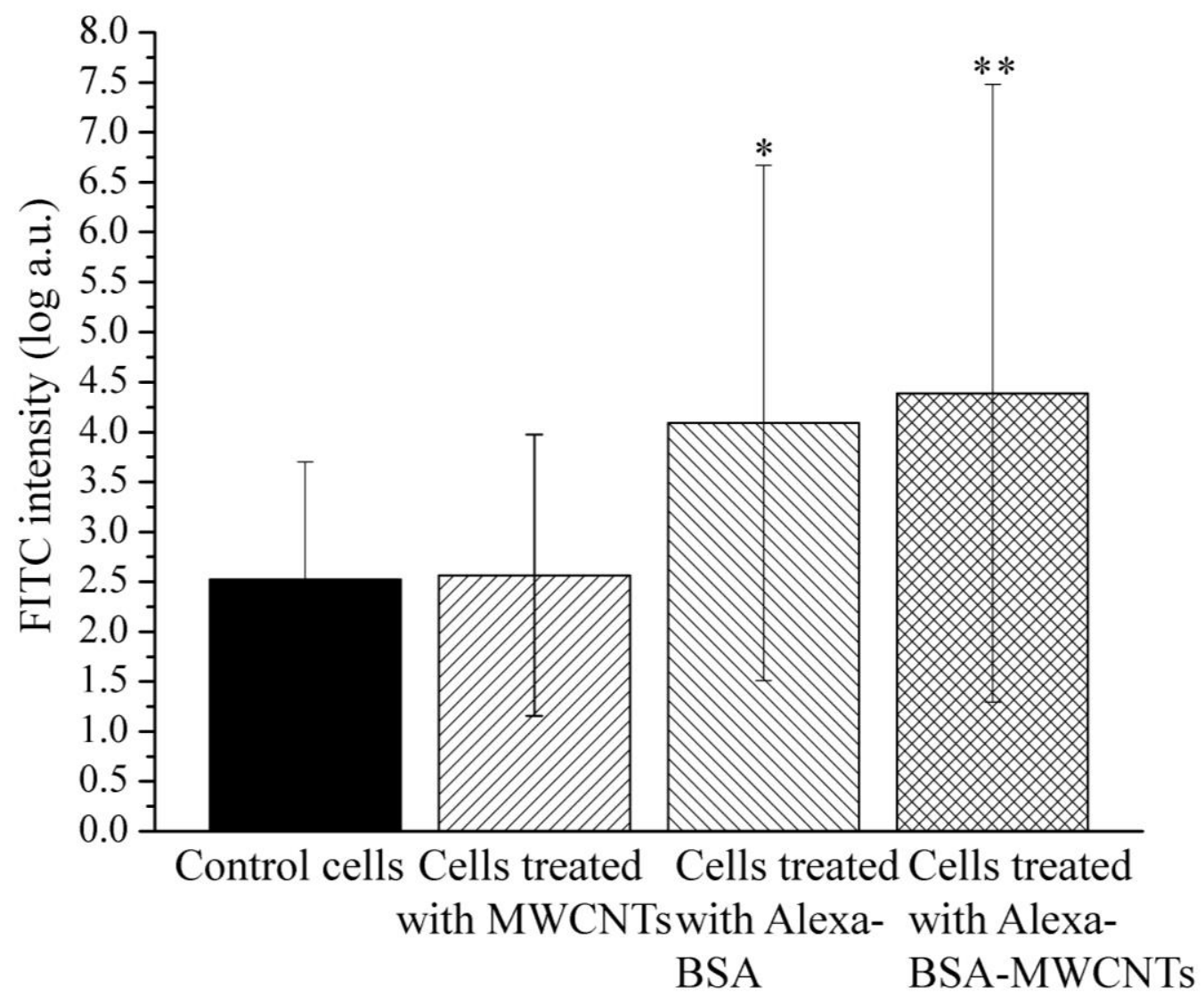


c)

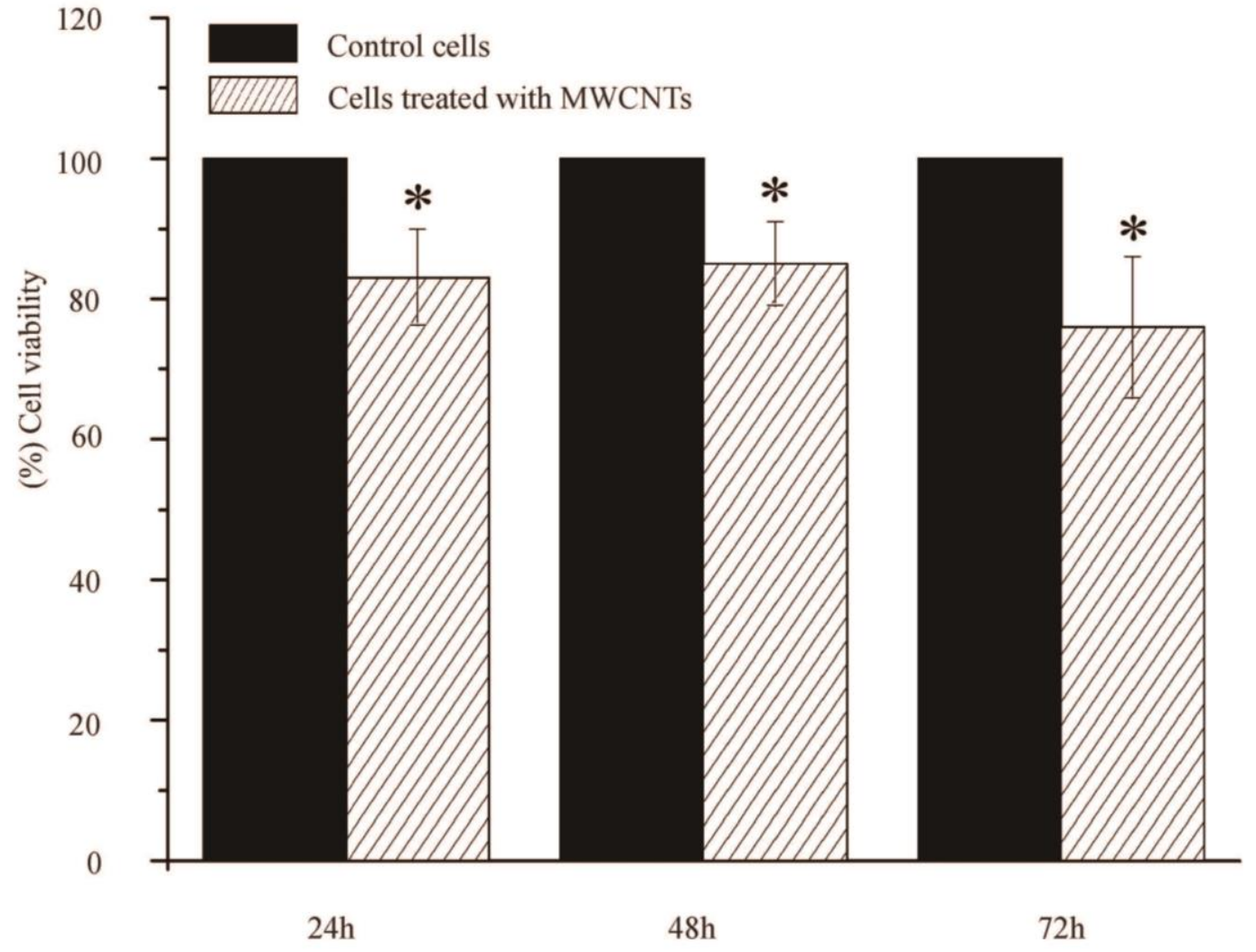

Figure 1: (a) FTIR spectrum of pristine MWCNTs and $1 \mathrm{~h}$ purified MWCNTs. (b) FITC intensity of control cells, $1 \mathrm{~h}$ purified MWCNTs, BEAS-2B cells treated with Alexa-BSA and cells treated with Alexa-BSA-MWCNTs conjugates. (c) (\%) Changes in the viability of the cells exposed to $24 \mu \mathrm{g} / \mathrm{cm}^{2}$ of $1 \mathrm{~h}$ purified MWCNTs. Changes are considered significant for $\mathrm{p}<0.05$.

Our results showed a significant reduction in cellular viability after 24,48 , and $72 \mathrm{~h}$ exposure to $1 \mathrm{~h}$ purified MWCNTs. The reduction in cellular viability was presumably due to the internalized MWCNTs initiating cell apoptosis ${ }^{45,46}$. Specifically, when the mitochondrion encounters a stress, the levels of cytoplasmic $\mathrm{Ca}^{2+}$ increase ${ }^{46}$ which lead to changes in the mitochondrial permeability transition membrane pores (MPTPs) and a decrease in the 
mitochondrial membrane potential ${ }^{47}$. Studies have shown that when MPTPs are open, the cytochrome c a pro-apoptotic factor located in the inner membrane of the mitochondria ${ }^{48}$ and $\mathrm{Ca}^{2+}$ diffuse into the mitochondrial matrix and triggers caspases- $8,-9$ and -3 signaling ${ }^{46,49}$ eventually leading to cell apoptosis ${ }^{48}$. The observed decrease in cellular viability could also be associated with MWCNTs interaction with intracellular structures. Specifically, previous studies showed that carboxyl functionalized CNTs tend to enter cells via endocytosis and get encapsulated in the endosomes ${ }^{50}$. Partial release of CNTs from the "endosomes capsule" can occur after several hours ${ }^{51}$ thus causing accumulation of CNTs in the cytoplasm and leading to CNTs with the cytoskeleton filaments and cell nucleus ${ }^{52,53}$.

To delineate the mechanisms responsible for the reduced cellular viability as observed by WST-1 performed after $24 \mathrm{~h}$ of cellular exposure to $1 \mathrm{~h}$ purified MWCNTs, we first analyzed the changes in nuclear DNA content. The hypothesis was that initiation of mitochondrial response upon exposure to MWCNTs could be further translated into cellular events associated with cell cycle progression. The analysis of the cell cycle was chosen due to the highly dynamic and regulated series of biological processes associated with such phases from cellular proliferation, to differentiation, and cellular apoptosis ${ }^{54}$. The effects of $1 \mathrm{~h}$ purified MWCNTs on cell cycle progression are shown in Figure 2. Results indicated a cell cycle arrest at the G1/S phase $24 \mathrm{~h}$ post exposure to MWCNTs. Specifically, cells treated with $1 \mathrm{~h}$ purified MWCNTs showed a statistically significant increase in G1 (gap) phase $(13 \pm 5.35 \%)$ and a significant decrease in S (synthesis) phase $(25 \pm 6.42 \%)$ both relative to controls $(* \mathrm{p}<0.05)$. Such increase in G1 could be further associated with an extensive change in the DNA content and/or cell volume, and/or increased synthesis of mRNA and proteins ${ }^{55,56}$. Further, the decrease in $\mathrm{S}$ phase could be 
associated with a decrease of available cellular DNA content ${ }^{57}$ since MWCNTs are known to possess high affinity for DNA ${ }^{52,58,59}$. Such changes in the cell cycle phases could lead to defects during DNA synthesis and chromosome segregation and hint at the possibility of MWCNTs to induce genotoxicity in cellular systems ${ }^{16,60,61}$. Our data complements previous reports that have shown that exposure to MWCNTs could induce DNA or chromosomal damage ${ }^{62}$, generation of reactive oxygen species (ROS) ${ }^{63}$, changes in the distribution of multipolar mitotic spindles ${ }^{64}$ and centrosome fragmentation ${ }^{65}$.

a)

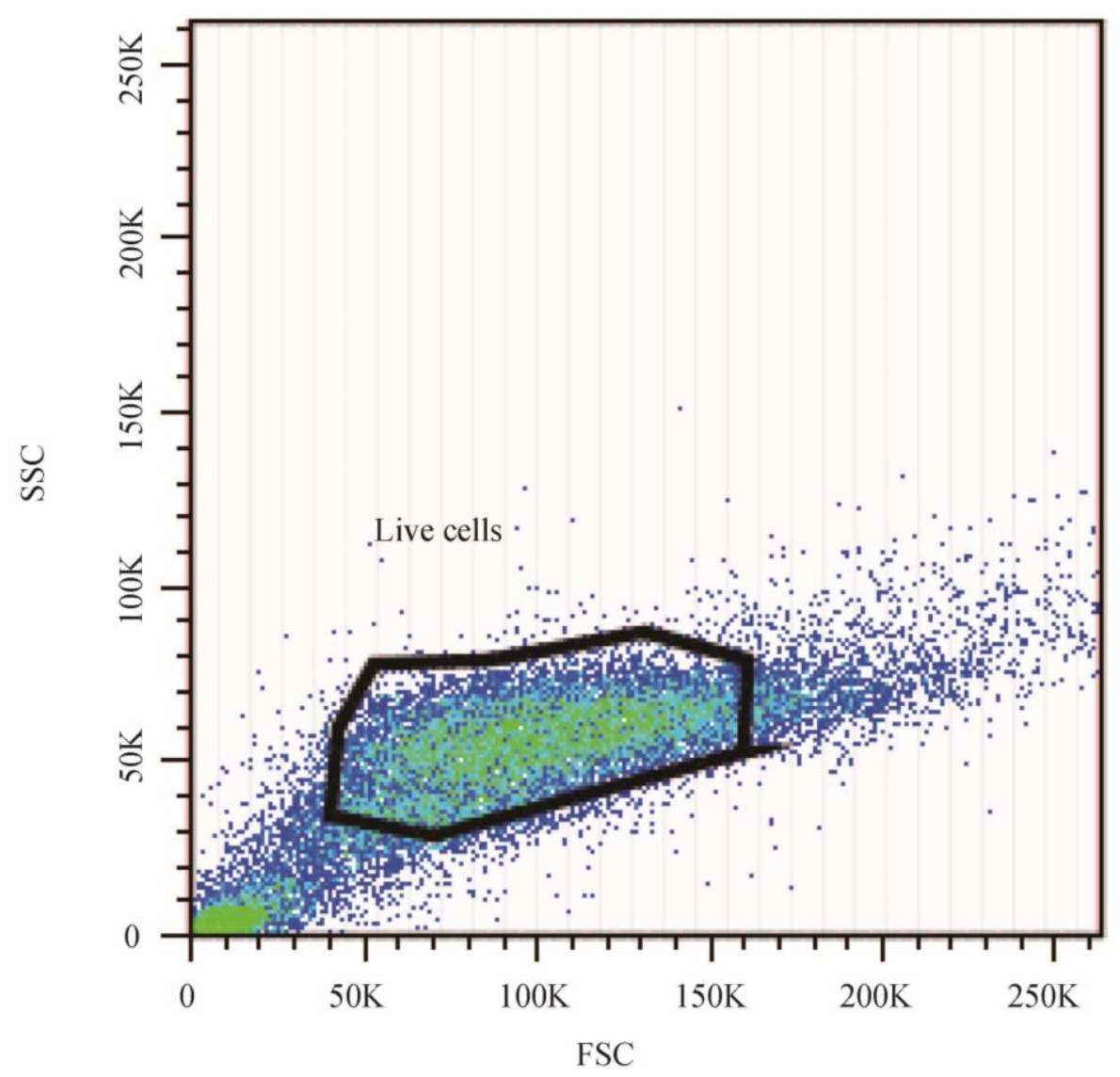


b)

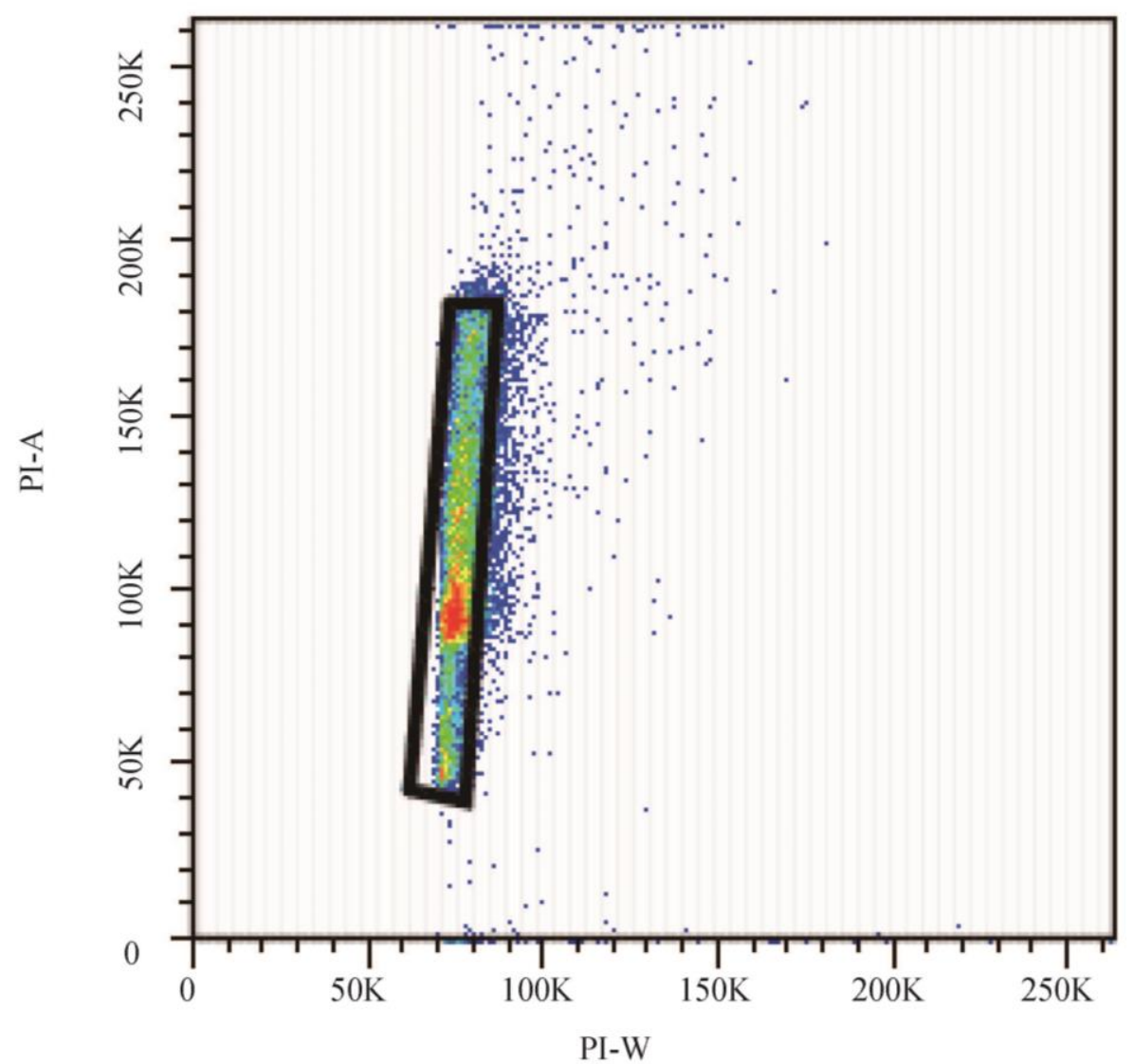

c)

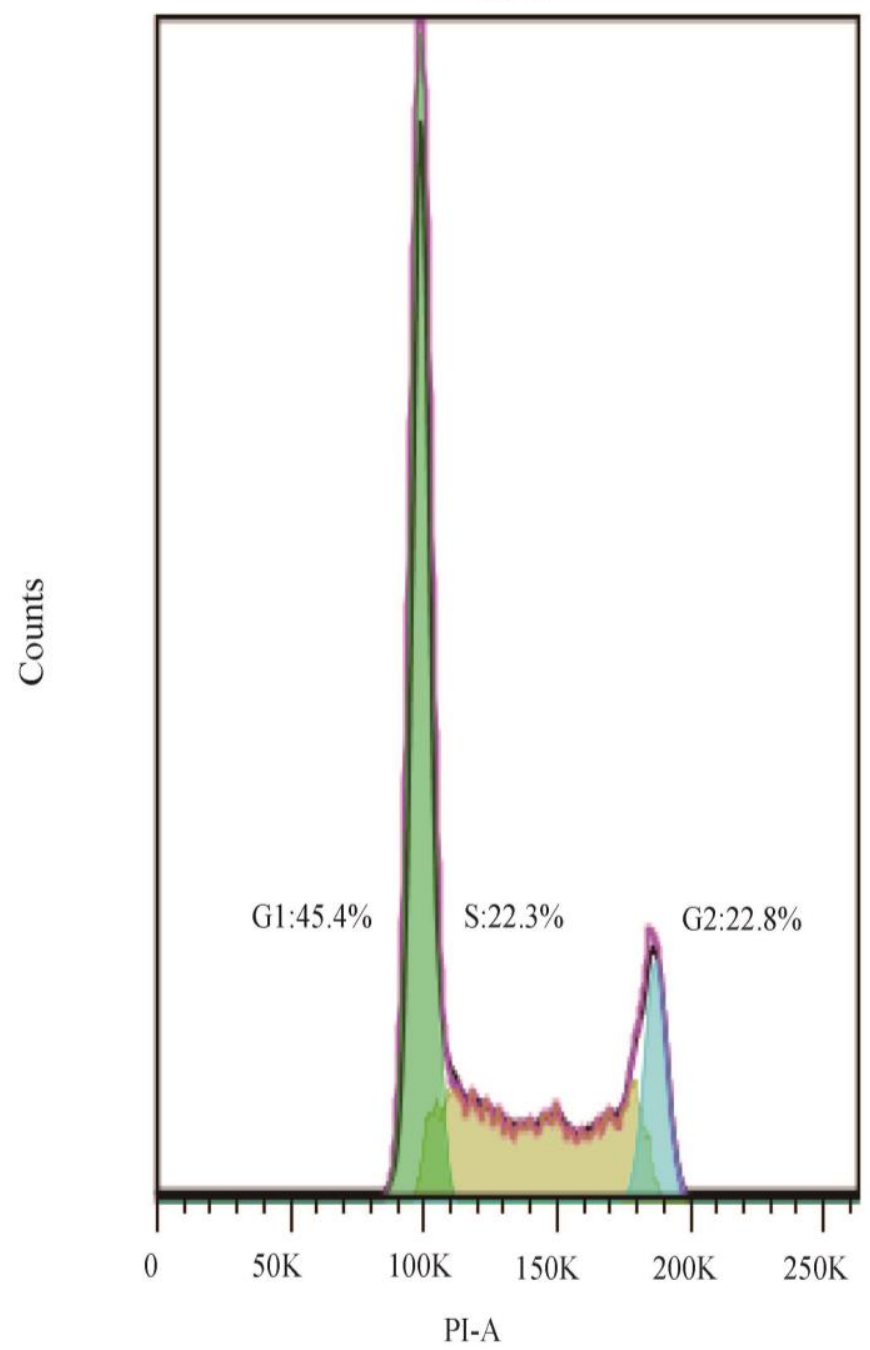


d)

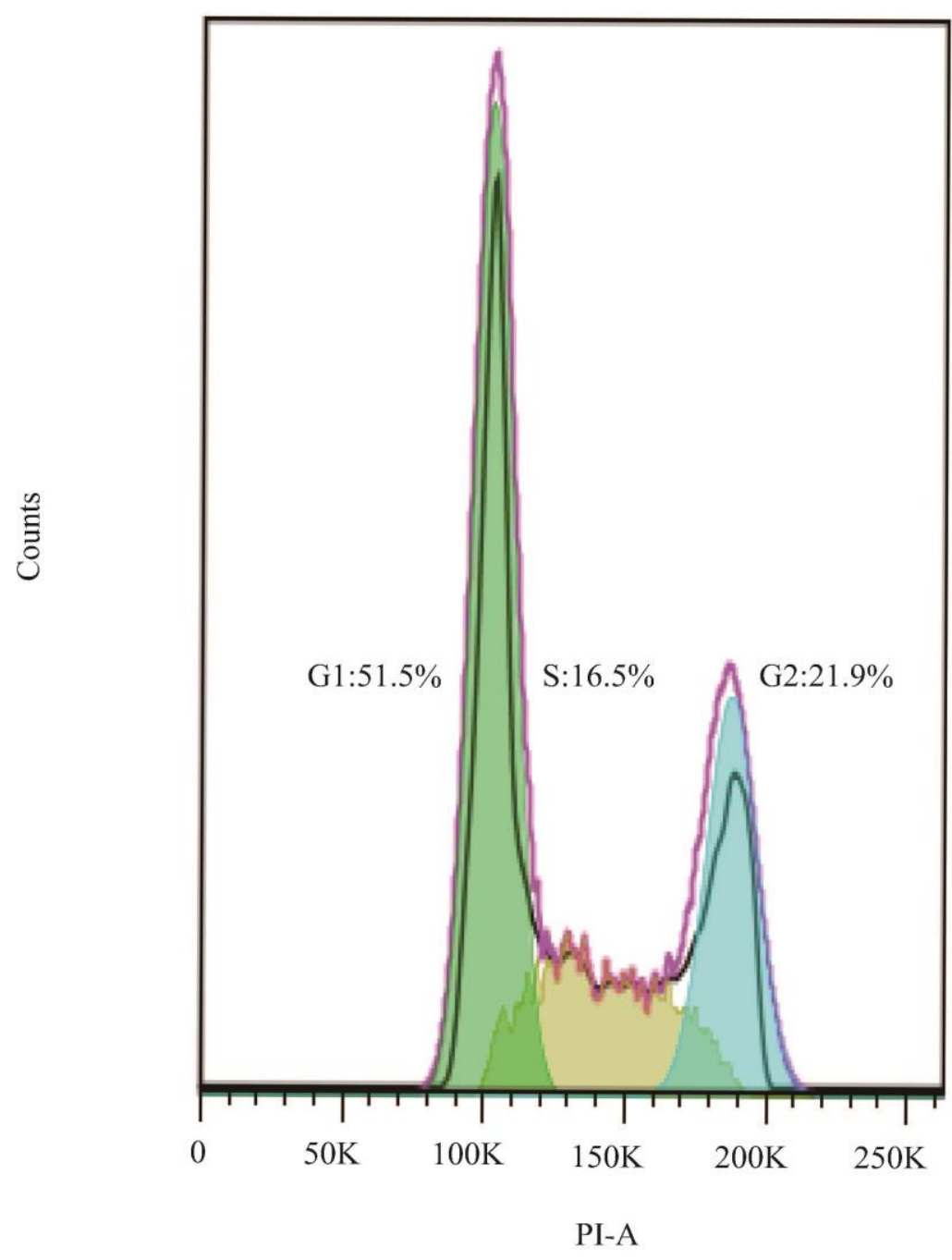

Figure 2: Fluorescence Activated Cell Sorting (FACS) was used to evaluate the changes in cell cycle upon exposure to purified MWCNTs. Gating and cell cycle analysis were done for PIstained BEAS-2B cells upon $24 \mathrm{~h}$ exposure to $1 \mathrm{~h}$ purified MWCNTs. (a) Forward scatter (FSC) and side scatter (SSC) 2D-plot showing a representative gating of the live cell population. (b) Scatter plot selection of single cells. Cell cycle analysis of controls (c) and Cells exposed to $1 \mathrm{~h}$ purified MWCNTs respectively (d).

To even further delineate the mechanisms responsible for the reduced cellular viability as observed by WST-1 performed after $24 \mathrm{~h}$ of cellular exposure to $1 \mathrm{~h}$ purified MWCNTs, we 
further studied whether exposure to MWCNTs induced biomechanical cellular changes. The hypothesis was that if such changes are observed, then they confirm MWCNTs association with cytoskeletal filaments further confirming the ability of MWCNTs to induce genotoxicity based on the role of the cytoskeleton fibers in maintaining cell shape and structure ${ }^{66}$. Proving the proposed hypothesis would allow to synergistically link cytotoxic (reduced cellular viability as result of decreased mitocondria activities) and genotoxic (MWCNTs association with cytoskeletal elements) effects by providing realistic conditions to mimic the interactions of the nanomaterials with human epithelial cells and how these interactions depend on the material properties.

To prove this hypothesis, we employed AFM and studied the mechanical properties of live cells incubated with the purified MWCNTs for $24 \mathrm{~h}$. Cellular elasticity plays a key role in regulating the cell behavior and fate; previous studies have shown that changes in elasticity are associated with disease progression from cardiomyopathies, vascular and kidney diseases, to Alzheimer's dementia ${ }^{67}$ and cancer $^{68}$. AFM was previously used to investigate biomechanical properties changes of fixed cells treated with MWCNTs and identified cancer cells from a mixture with normal cells ${ }^{69}$. Complementary, previous reports have shown that the interactions between MWCNTs and cytoskeletal filaments could alter cell morphology ${ }^{52}$. Changes in the morphology and cellular biomechanical properties with an increase in cell deformability correlate with the progression of a cell to a transformed phenotype, i.e., from a benign to a malignant phenotype $\mathrm{e}^{69,70}$. 
Topography images of live BEAS-2B control cells and cells exposed to $1 \mathrm{~h}$ purified MWCNTs were acquired using contact mode and are shown in Figure $3 \mathrm{a}$ and $3 \mathrm{~b}$ respectively. Morphology analysis associated the lighter color parts of the cell with the highest cellular region, i.e., the cell nucleus. The topography of the control BEAS-2B cells appeared smoother and more uniform when compared to the topography of the live cells incubated with purified MWCNTs. The average height of the nuclear region of controls $(3.13 \pm 0.75 \mu \mathrm{m})$ was comparable to the average height of the cells incubated with purified MWCNTs $(2.60 \pm 0.37 \mu \mathrm{m})$. Similarly, the average surface area of the MWCNTs-exposed cells $\left(629 \pm 252 \mu \mathrm{m}^{2}\right)$ was comparable to the average area of the controls $\left(534 \pm 132 \mu \mathrm{m}^{2}\right)$ (Figure 3c). The average values of surface area of the cells incubated with MWCNTs relative to control cells was slightly different than previously reported. In particular, previous results have shown that cells incubated with a similar dose of MWCNTs with similar properties, fixed and analyzed with AFM, showed $37.7 \%$ increase in their surface area when compared to the control cells. This is presumably due to the cellular responses in dynamic conditions which are significantly different from those in static conditions $^{71}$. Further, the differences observed upon exposure of live cell to purified MWCNTs could also be due to the cellular integration of the MWCNTs either into the endosomal structures or microtubule polymerization and hybrid-cytoskeleton filaments assembly and disassembly ${ }^{59}$.

a)

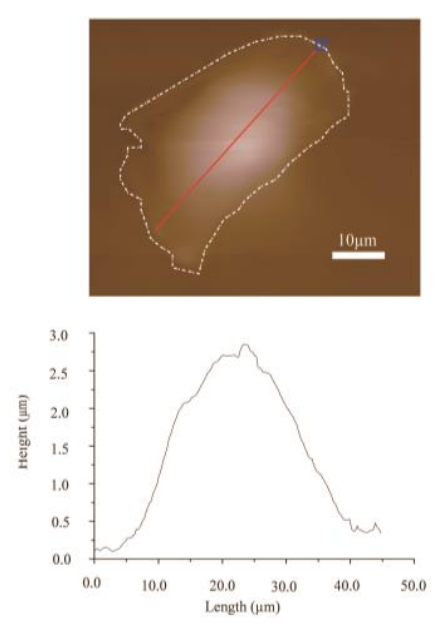

111 
b)
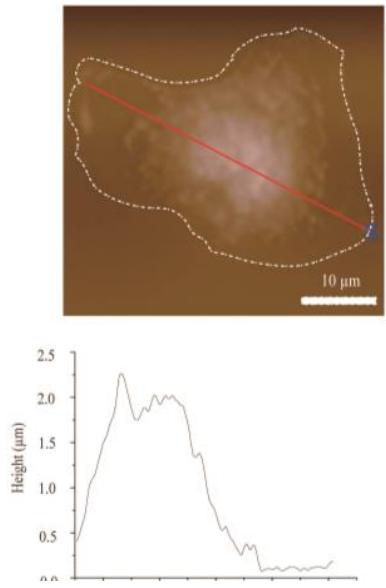

c)

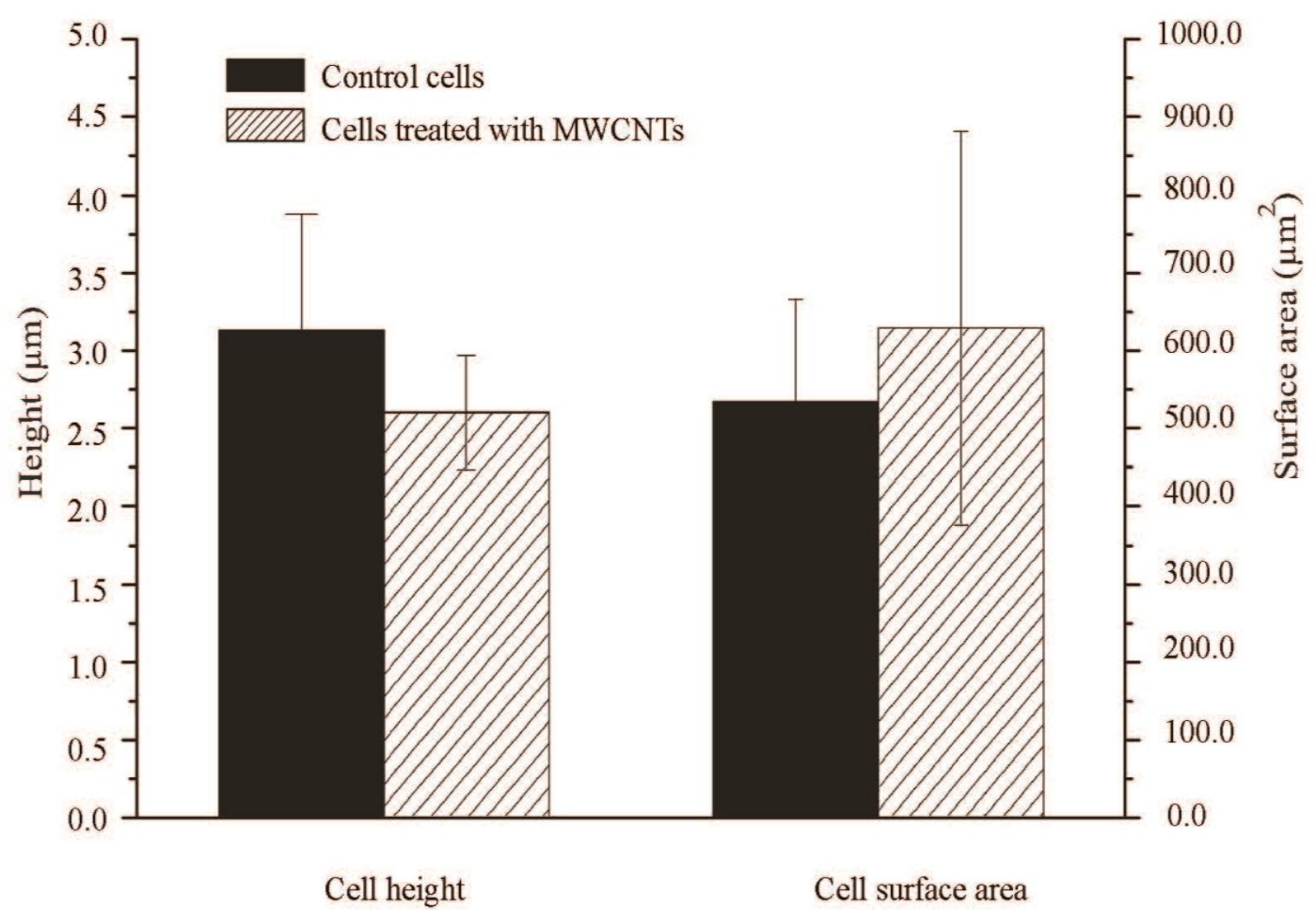

Figure 3: (a) Topography of a control BEAS-2B cell and height profile of the cell body. (b) Topography of a cell treated with $1 \mathrm{~h}$ purified MWCNTs and height profile of the cell body. (c) Average height and surface area of control cells and cells exposed to $1 \mathrm{~h}$ purified MWCNTs; 15 individual cells have been analyzed for each sample and changes are considered significant for $\mathrm{p}<0.05$. 
To further confirm the role of MWCNTs in changing the cellular dynamics by inducing rearrangement of the 3D cytoskeleton network, we performed nanoindentation studies. Previous reports have shown that AFM nanoindentation method could be used as a powerful tool to track 3D cytoskeleton network reorganization and monitor physiological states of cells treated with chemical agents ${ }^{72}$. The average elastic modulus distributions of control and exposed cells (both cell bodies and the nuclei ${ }^{73}$ ) are shown in Table 1 . A typical example of force-indentation (F-Z) curve recorded in the nucleus region for control and exposed BEAS-2B cell respectively showed that at similar loading, the indentation distance for control cell was greater than for the treated counterparts thus suggesting that the control cells had lower elastic modulus (Figure 4a). Further, since the cell nucleus is the thickest part of the cell which thus contains less concentrated cytoskeleton structures, the engaging of the nanoindentation tip upon this area was weaker than the engaging of the tip at the cell edges typically consisting of concentrated cytoskeleton fibers ${ }^{74}$. The higher elastic modulus $(\sim 20 \mathrm{kPa})$ at the cell periphery was attributed to the effects of the plastic substrate on the force-distance curves ${ }^{75}$.

Comparison between the elastic modulus of MWCNTs-exposed cells and controls showed a relatively narrow Young modulus distribution for nucleus region $(0-6 \mathrm{kPa})$ and a much wider distribution for the whole cell bodies (0-12 kPa; Figure 4b). Specifically, the obtained average Young modulus for whole cell bodies were $2.72 \pm 0.96$ and $3.84 \pm 1.12 \mathrm{kPa}$ for control and treated cells, respectively. At the nucleus region, the estimated elastic modulus was $1.58 \pm 0.67$ and $2.20 \pm 0.59 \mathrm{kPa}$, for control and exposed cells respectively. As shown, the cells elastic modulus increased significantly for both the cytoplasm and nucleus region of the MWCNTs exposed cells relative to controls further suggesting MWCNTs association with the cytoskeleton 
52,53 . Interestingly, the recorded elastic modulus value for control BEAS-2B cells was higher than previously reported $(\sim 75 \%)^{74}$. Such difference may be caused by both the variation in the cell culture condition as well as in the nanoindentation conditions being used. It has been previously demonstrated that cell culture media plays important role in elastic properties of the cells since components of the growth medium can activate or deactivate certain proteins that regulate the formation of the cytoskeleton thus affecting the cell elastic modulus ${ }^{76}$.

\begin{tabular}{ccccccc}
\hline Group & Counts & $\begin{array}{c}\mathbf{0 - 2} \\
\mathbf{k P a}\end{array}$ & $\mathbf{2 - 4}$ & $\mathbf{4 - 6}$ & $\mathbf{6 - 1 0}$ & $>\mathbf{1 0}$ \\
& & $\mathbf{k P a}$ & $\mathbf{k P a}$ & $\mathbf{k P a}$ \\
\hline $\begin{array}{c}\text { Control live cells } \\
\quad \text { (whole cell) }\end{array}$ & 380 & $50.79 \%$ & $31.84 \%$ & $10.79 \%$ & $6.05 \%$ & $0.53 \%$ \\
$\begin{array}{c}\text { Live cells incubated with } \\
\text { MWCNTs for 24 h }\end{array}$ & 475 & $37.89 \%$ & $35.58 \%$ & $14.32 \%$ & $7.79 \%$ & $0.62 \%$ \\
$\begin{array}{c}\text { Control live cells (nucleus } \\
\text { region) }\end{array}$ & 104 & $76.92 \%$ & $21.53 \%$ & $1.55 \%$ & $0 \%$ & $0 \%$ \\
$\begin{array}{c}\text { Live cells incubated with } \\
\text { MWCNTs for 24 h (nucleus } \\
\text { region) }\end{array}$ & 122 & $57.38 \%$ & $30.07 \%$ & $12.55 \%$ & $0 \%$ & $0 \%$ \\
\hline
\end{tabular}

Table 1: Young's modulus distribution of control cells and cells exposed to purified MWCNTs.

a)
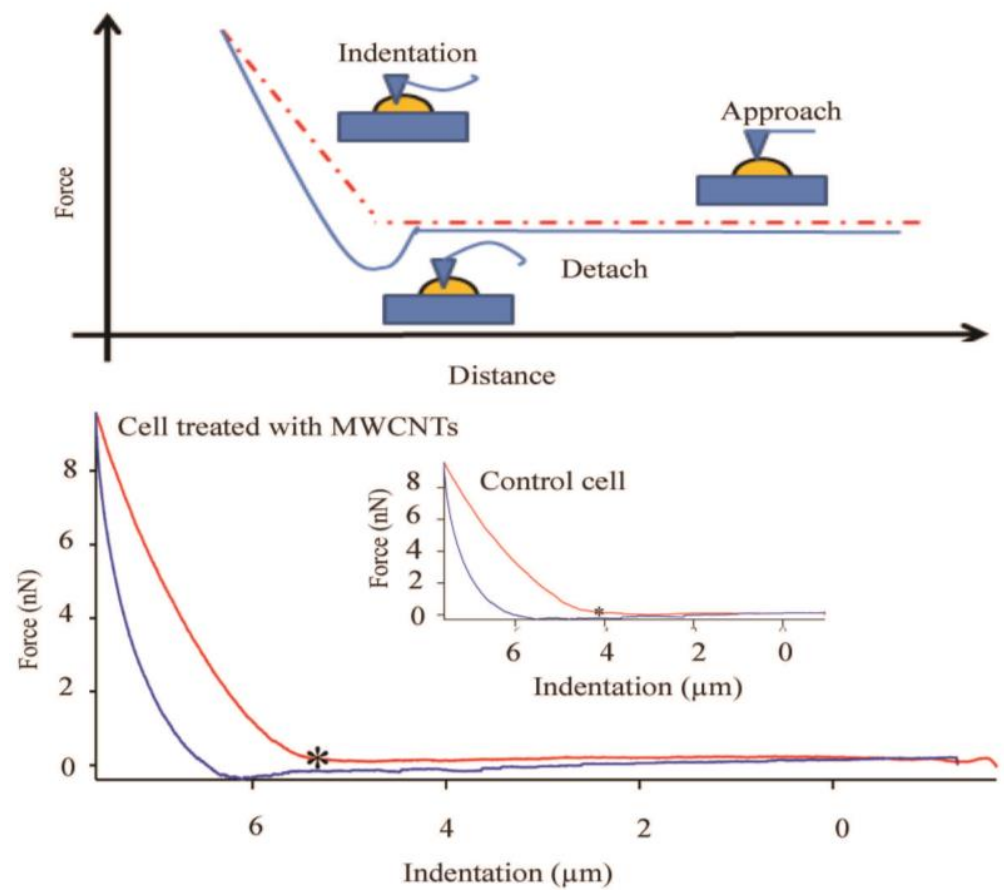
b)

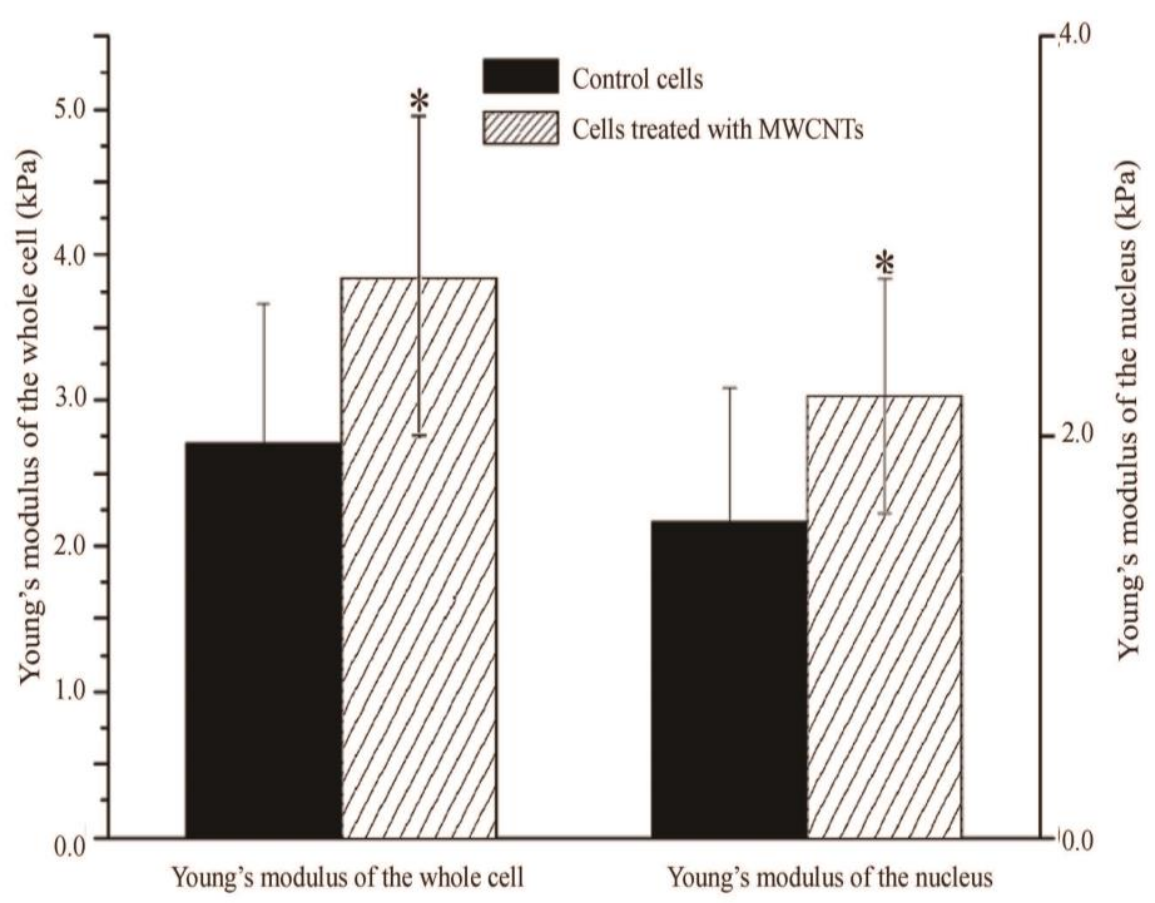

Figure 4: (a) Schematic diagram of force-indentation profile of control and cell exposed to purified MWCNTs. The red curve represents the approach curve of the tip and the blue curve is detached curve of tip from the surface. "*” indicates the point of that tip deflected during the acquisition of the force-indentation measurement profile. (b) Histogram of the Young modulus distribution of the whole cell and the nucleus region of control BEAS-2B cells and cells exposed to $1 \mathrm{~h}$ purified MWCNTs for $24 \mathrm{~h}$. All differences $(*)$ were considered statistically significant for $\mathrm{p}<0.05$.

Based on the observed cytosolic and nuclear changes we propose that the toxicity observed after cellular exposure to purified MWCNTs is not an either-or mechanism but a series of concurrent cellular processes (Figure 5). Specifically, in our experimental set-up, the uptake and internalization of the purified MWCNTs could have led to changes in cellular activity and structure upon association of MWCNTs with the cytoskeleton filaments. Such association could 
have possibly induced 3D filament reorganization, led to increased cellular rigidity, and possible inhibition and/or blockage of intracellular biomolecular transport functions of mitochondria and cell cycle progression. The analysis provided herein provides a comprehensive outlook at the synergistic changes associated with exposure to MWCNTs that could potentially lead to cell apoptosis and cancer progression.

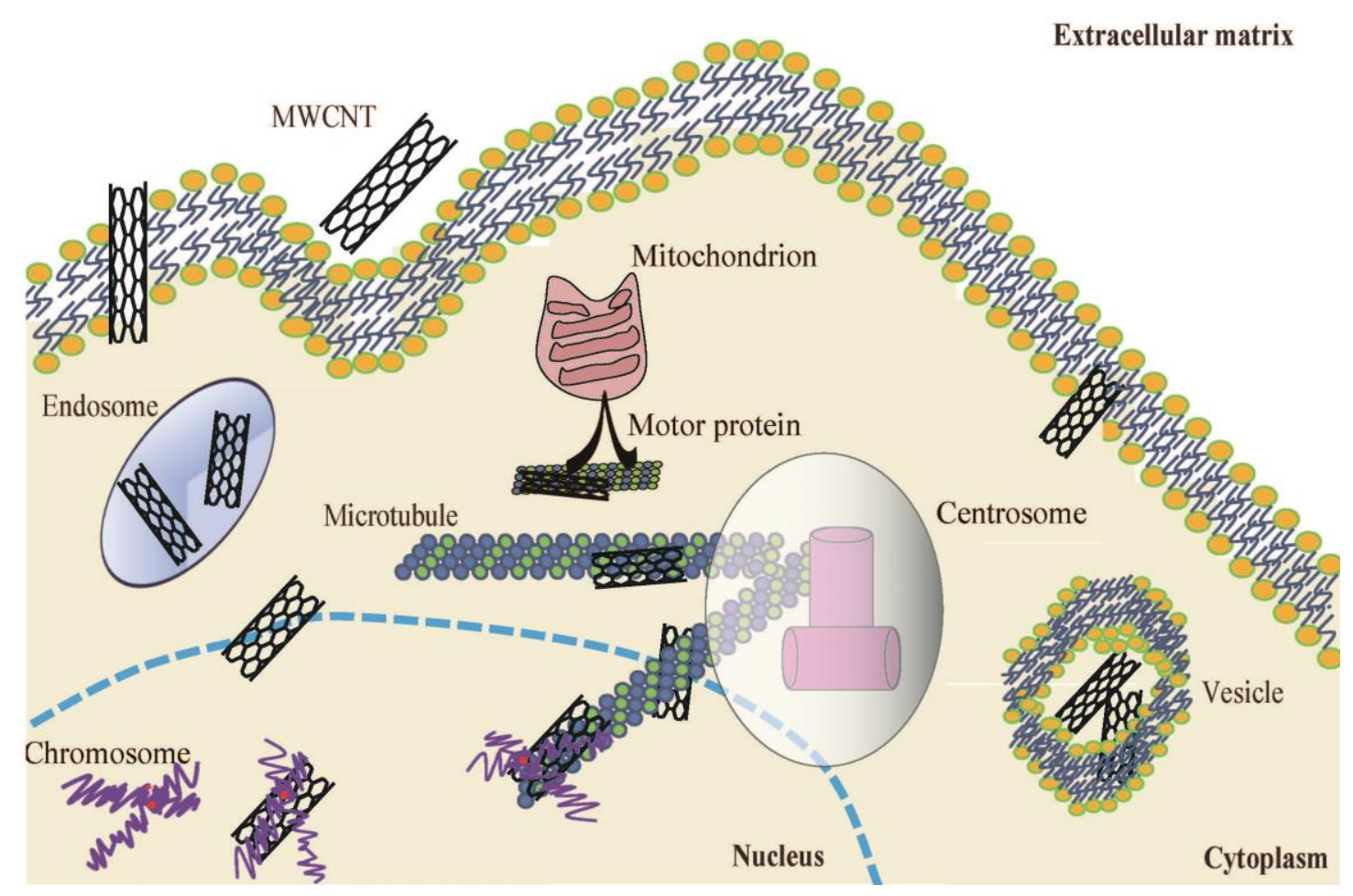

Figure 5: Proposed mechanism for the MWCNTs-induced cyto- and geno-toxicity. Upon cellular uptake, the 1h purified MWCNTs associate with microtubules to inhibit the transport or affect the activity of mitochondria, and induce cellular biomechanical changes. 


\section{Conclusions}

Our study provided a systematic approach for analysis of the changes induced by cellular exposure to purified MWCNTs. Specifically, we showed that purified MWCNTs have the potential to induce cyto- and geno-toxicity by affecting overall the mitochondria activity and by changing the biomechanical properties of the exposed cells. The approaches described herein could offer new means to interpreting toxicity of nanomaterials as being a blend of material, physical and chemical properties that lead to complex synergistically induced cell transformations. 


\section{Supporting Information}

\begin{tabular}{|c|c|c|}
\hline Element wt\% & Pristine MWCNTs & 1h purified MWCNTs \\
\hline $\mathrm{C}$ & 87.41 & 86.53 \\
\hline $\mathrm{O}$ & 3.88 & 10.65 \\
\hline $\mathrm{Si}$ & 1.09 & 0.76 \\
\hline$S$ & 0.23 & 0.00 \\
\hline $\mathrm{Cu}$ & 6.15 & 1.17 \\
\hline $\mathrm{Fe}$ & 1.24 & 0.89 \\
\hline \multicolumn{3}{|c|}{$\begin{array}{l}\text { Table S1: Energy dispersive X-ray analysis (EDX) of pristine and } 1 \text { h purified MWCNTs. Upon } \\
\text { acid treatment, the content of oxygen }(\mathrm{O}) \text { increases while the contents of iron }(\mathrm{Fe}) \text {, copper }(\mathrm{Cu}) \\
\text { silica ( } \mathrm{Si}) \text {, sulfur }(\mathrm{S}) \text { and carbon }(\mathrm{C}) \text { decreases. }\end{array}$} \\
\hline Type & DI Water (mg/ml) & DMEM+FBS (mg/ml) \\
\hline Pristine MWCNTs & 0.13 & 1.57 \\
\hline 1h purified MWCNTs & 0.26 & 2.82 \\
\hline
\end{tabular}

Table S2: Dispersity analysis of pristine and $1 \mathrm{~h}$ purified MWCNTs in different media.

\begin{tabular}{ccc}
\hline Length $(\boldsymbol{\mu m})$ & Mean & Standard Deviation \\
\hline Pristine MWCNTs & 4261 & 2354 \\
1h purified MWCNTs & 792 & 254 \\
\hline
\end{tabular}

Table S3: Length distribution of pristine and $1 \mathrm{~h}$ purified MWCNTs. 


\section{Reference}

1 Leghrib, R. et al. Gas sensors based on multiwall carbon nanotubes decorated with tin oxide nanoclusters. Sensor Actuat B-Chem 145, 411-416 (2010).

2 Ali-Boucetta, H. \& Kostarelos, K. Carbon nanotubes in medicine \& biology - Therapy and diagnostics. Adv Drug Deliv Rev 65, 1897-1898, doi:10.1016/j.addr.2013.11.002 (2013).

3 Yan, L., Zhao, F., Li, S., Hu, Z. \& Zhao, Y. Low-toxic and safe nanomaterials by surface-chemical design, carbon nanotubes, fullerenes, metallofullerenes, and graphenes. Nanoscale 3, 362-382, doi:10.1039/c0nr00647e (2011).

4 Ren, X. M., Li, J. X., Tan, X. L. \& Wang, X. K. Comparative study of graphene oxide, activated carbon and carbon nanotubes as adsorbents for copper decontamination. Dalton T 42, 5266-5274 (2013).

5 Vittorio, O., Raffa, V. \& Cuschieri, A. Influence of purity and surface oxidation on cytotoxicity of multiwalled carbon nanotubes with human neuroblastoma cells. Nanomed-Nanotechnol 5, 424-431 (2009).

6 Toyokuni, S. Genotoxicity and carcinogenicity risk of carbon nanotubes. Adv Drug Deliv Rev 65, 2098-2110, doi:10.1016/j.addr.2013.05.011 (2013).

7 Shen, M. W. et al. Polyethyleneimine-Mediated Functionalization of Multiwalled Carbon Nanotubes: Synthesis, Characterization, and In Vitro Toxicity Assay. J Phys Chem C 113, 3150-3156, doi:Doi 10.1021/Jp809323e (2009).

8 Fenoglio, I. et al. Thickness of Multiwalled Carbon Nanotubes Affects Their Lung Toxicity. Chem Res Toxicol 25, 74-82, doi:Doi 10.1021/Tx200255h (2012). 
9 Koyama, S. et al. In vivo immunological toxicity in mice of carbon nanotubes with impurities. Carbon 47, 1365-1372, doi:DOI 10.1016/j.carbon.2009.01.028 (2009).

10 Bussy, C. et al. Critical role of surface chemical modifications induced by length shortening on multi-walled carbon nanotubes-induced toxicity. Part Fibre Toxicol 9 (2012).

11 Murphy, F. A., Schinwald, A., Poland, C. A. \& Donaldson, K. The mechanism of pleural inflammation by long carbon nanotubes: interaction of long fibres with macrophages stimulates them to amplify pro-inflammatory responses in mesothelial cells. Part Fibre Toxicol 9 (2012).

12 Dong, C. B. et al. Effects of acid treatment on structure, properties and biocompatibility of carbon nanotubes. Appl Surf Sci 264, 261-268 (2013).

13 Kang, B., Chang, S. Q., Dai, Y. D., Yu, D. C. \& Chen, D. Cell Response to Carbon Nanotubes: Size-Dependent Intracellular Uptake Mechanism and Subcellular Fate. Small 6, 2362-2366 (2010).

14 Canton, I. \& Battaglia, G. Endocytosis at the nanoscale. Chem Soc Rev 41, 2718-2739 (2012).

15 Lin, C., Fugetsu, B., Su, Y. B. \& Watari, F. Studies on toxicity of multi-walled carbon nanotubes on Arabidopsis T87 suspension cells. J Hazard Mater 170, 578-583 (2009).

16 Dong, C. B. et al. Exposure to Carbon Nanotubes Leads to Changes in the Cellular Biomechanics. Advanced healthcare materials 2, 945-951, doi:DOI 10.1002/adhm.201200430 (2013).

17 Mercer, R. R. et al. Distribution and fibrotic response following inhalation exposure to multi-walled carbon nanotubes. Part Fibre Toxicol 10 (2013). 
18 Heng, B. C. et al. Toxicity of zinc oxide $(\mathrm{ZnO})$ nanoparticles on human bronchial epithelial cells (BEAS-2B) is accentuated by oxidative stress. Food Chem Toxicol 48, 1762-1766, doi:DOI 10.1016/j.fct.2010.04.023 (2010).

19 Baber, O., Jang, M., Barber, D. \& Powers, K. Amorphous silica coatings on magnetic nanoparticles enhance stability and reduce toxicity to in vitro BEAS-2B cells. Inhalation toxicology 23, 532-543 (2011).

20 Sun, H., Clancy, H. A., Kluz, T., Zavadil, J. \& Costa, M. Comparison of Gene Expression Profiles in Chromate Transformed BEAS-2B Cells. Plos One 6, doi:ARTN e17982 DOI 10.1371/journal.pone.0017982 (2011).

21 Xiao, D. et al. Diallyl Trisulfide Selectively Causes Bax- and Bak-Mediated Apoptosis in Human Lung Cancer Cells. Environ Mol Mutagen 50, 201-212, doi:Doi 10.1002/Em.20431 (2009).

22 Park, E. J., Shim, H. W., Lee, G. H., Kim, J. H. \& Kim, D. W. Comparison of toxicity between the different-type $\mathrm{TiO} 2$ nanowires in vivo and in vitro. Arch Toxicol 87, 12191230, doi:DOI 10.1007/s00204-013-1019-3 (2013).

23 Wilhelmi, V. et al. Zinc Oxide Nanoparticles Induce Necrosis and Apoptosis in Macrophages in a p47phox-and Nrf2-Independent Manner. Plos One 8, doi:ARTN e65704 DOI 10.1371/journal.pone.0065704 (2013).

24 He, X. Q. et al. Multiwalled Carbon Nanotubes Induce a Fibrogenic Response by Stimulating Reactive Oxygen Species Production, Activating NF-kappa B Signaling, and Promoting Fibroblast-to-Myofibroblast Transformation. Chem Res Toxicol 24, 22372248, doi:Doi 10.1021/Tx200351d (2011). 
25 Liao, K. H., Lin, Y. S., Macosko, C. W. \& Haynes, C. L. Cytotoxicity of graphene oxide and graphene in human erythrocytes and skin fibroblasts. ACS applied materials \& interfaces 3, 2607-2615, doi:10.1021/am200428v (2011).

26 Li, J. T. et al. Rejuvenation of chondrogenic potential in a young stem cell microenvironment. Biomaterials 35, 642-653, doi:DOI 10.1016/j.biomaterials.2013.09.099 (2014).

27 Zhang, X. J. et al. Atomic Force Microscopy Study of the Effects of Water-Soluble Fullerenes on the Elasticity of Living Plant Cells. Chem-Asian J 8, 2388-2394, doi:DOI 10.1002/asia.201300522 (2013).

28 A. Campbell, C. D., J.S. Dordick, C.Z. Dinu. BioNano Engineered Hybrids for Hypochlorous Acid Generation. Process Biochem 48, 1355-1360 (2013).

29 Solhaug, A. et al. Polycyclic aromatic hydrocarbons induce both apoptotic and antiapoptotic signals in Hepa1c1c7 cells. Carcinogenesis 25, 809-819 (2004).

30 Rotsch, C., Jacobson, K. \& Radmacher, M. Dimensional and mechanical dynamics of active and stable edges in motile fibroblasts investigated by using atomic force microscopy. P Natl Acad Sci USA 96, 921-926 (1999).

31 Radmacher, M., Fritz, M., Kacher, C. M., Cleveland, J. P. \& Hansma, P. K. Measuring the viscoelastic properties of human platelets with the atomic force microscope. Biophys $J$ 70, 556-567 (1996).

32 Scheibe, B., Borowiak-Palen, E. \& Kalenczuk, R. J. Oxidation and reduction of multiwalled carbon nanotubes - preparation and characterization. Mater Charact 61, 185$191(2010)$. 
33 Porter, A. E. et al. Uptake of Noncytotoxic Acid-Treated Single-Walled Carbon Nanotubes into the Cytoplasm of Human Macrophage Cells. Acs Nano 3, 1485-1492 (2009).

34 Ros, T. G., van Dillen, A. J., Geus, J. W. \& Koningsberger, D. C. Surface oxidation of carbon nanofibres. Chem-Eur J 8, 1151-1162 (2002).

35 Wang, L. et al. A comparison study of catalytic oxidation and acid oxidation to prepare carbon nanotubes for filling with Ru nanoparticles. Carbon 49, 2022-2032 (2011).

36 Atwell BJ, K. P., Turnbull CGN. in Plants in Action: Adaptation in Nature, Performance in Cultivation (ed Kriedemann PE Atwell BJ, Turnbull CGN, Eamus D, Bieleski RL, Farquhar G) Ch. 4, (Macmillan Education Australia Pty Ltd, 1999).

37 Li, R. B. et al. Surface Charge and Cellular Processing of Covalently Functionalized Multiwall Carbon Nanotubes Determine Pulmonary Toxicity. Acs Nano 7, 2352-2368 (2013).

38 Ge, C. C. et al. Binding of blood proteins to carbon nanotubes reduces cytotoxicity. Proc Nat Acad Sci U S A 108, 16968, doi:DOI 10.1073/pnas.1105270108 (2011).

39 Forrest, G. A. \& Alexander, A. J. A model for the dependence of carbon nanotube length on acid oxidation time. J Phys Chem C 111, 10792-10798 (2007).

40 Mu, Q., Broughton, D. L. \& Yan, B. Endosomal Leakage and Nuclear Translocation of Multiwalled Carbon Nanotubes: Developing a Model for Cell Uptake. Nano Letters 9 , 4370-4375, doi:10.1021/n1902647x (2009).

41 Sargent, L. M. et al. Single-walled carbon nanotube-induced mitotic disruption. Mutation research 745, 28-37, doi:10.1016/j.mrgentox.2011.11.017 (2012). 
$42 \mathrm{Li}, \mathrm{C}$. Y. et al. Highly biocompatible multi-walled carbon nanotube-chitosan nanoparticle hybrids as protein carriers. Acta Biomater 7, 3070-3077 (2011).

43 Chen, T. et al. Water-Soluble Taurine-Functionalized Multi-Walled Carbon Nanotubes Induce Less Damage to Mitochondria of RAW 264.7 Cells. J Nanosci Nanotechno 12, 8008-8016 (2012).

44 Worle-Knirsch, J. M., Pulskamp, K. \& Krug, H. F. Oops they did it again! Carbon nanotubes hoax scientists in viability assays. Nano Lett 6, 1261-1268, doi:Doi 10.1021/N1060177c (2006).

45 Cheng, W.-W. et al. Single-walled carbon nanotube induction of rat aortic endothelial cell apoptosis: Reactive oxygen species are involved in the mitochondrial pathway. The International Journal of Biochemistry \& Cell Biology 43, 564-572, doi:http://dx.doi.org/10.1016/j.biocel.2010.12.013 (2011).

46 Wang, X. et al. Multi-walled carbon nanotubes induce apoptosis via mitochondrial pathway and scavenger receptor. Toxicology in Vitro 26, 799-806, doi:http://dx.doi.org/10.1016/j.tiv.2012.05.010 (2012).

47 Lemasters, J. J. et al. The mitochondrial permeability transition in cell death: a common mechanism in necrosis, apoptosis and autophagy. Bba-Bioenergetics 1366, 177-196 (1998).

48 Chen, T. et al. Water-soluble taurine-functionalized multi-walled carbon nanotubes induce less damage to mitochondria of RAW 264.7 cells. Journal of nanoscience and nanotechnology 12, 8008-8016 (2012). 
49 Zhong, W. et al. Induction of Endoplasmic Reticulum Stress by Sonoporation: Linkage to Mitochondria-Mediated Apoptosis Initiation. Ultrasound in Medicine \& Biology 39, 2382-2392, doi:http://dx.doi.org/10.1016/j.ultrasmedbio.2013.08.005 (2013).

50 Neves, V. et al. Uptake and Release of Double-Walled Carbon Nanotubes by Mammalian Cells. Adv Funct Mater 20, 3272-3279, doi:DOI 10.1002/adfm.201000994 (2010).

51 Serag, M. F. et al. Trafficking and Subcellular Localization of Multiwalled Carbon Nanotubes in Plant Cells. Acs Nano 5, 493-499, doi:Doi 10.1021/Nn102344t (2011).

52 Rodriguez-Fernandez, L., Valiente, R., Gonzalez, J., Villegas, J. C. \& Fanarraga, M. L. Multiwalled Carbon Nanotubes Display Microtubule Biomimetic Properties in Vivo, Enhancing Microtubule Assembly and Stabilization. Acs Nano 6, 6614-6625 (2012).

53 Holt, B. D. et al. Carbon Nanotubes Reorganize Actin Structures in Cells and ex Vivo. Acs Nano 4, 4872-4878 (2010).

54 Iwamoto, K., Tashima, Y., Hamada, H., Eguchi, Y. \& Okamoto, M. Mathematical modeling and sensitivity analysis of G1/S phase in the cell cycle including the DNAdamage signal transduction pathway. Biosystems 94, 109-117, doi:http://dx.doi.org/10.1016/j.biosystems.2008.05.016 (2008).

55 Bertoli, C., Skotheim, J. M. \& de Bruin, R. A. Control of cell cycle transcription during G1 and S phases. Nature reviews. Molecular cell biology 14, 518-528, doi:10.1038/nrm3629 (2013).

56 Saber, A. T. et al. Particle-induced pulmonary acute phase response correlates with neutrophil influx linking inhaled particles and cardiovascular risk. Plos One 8, e69020, doi:10.1371/journal.pone.0069020 (2013). 
57 Kotogany, E., Dudits, D., Horvath, G. V. \& Ayaydin, F. A rapid and robust assay for detection of S-phase cell cycle progression in plant cells and tissues by using ethynyl deoxyuridine. Plant methods 6, 5, doi:10.1186/1746-4811-6-5 (2010).

58 Nunes, A. et al. Hybrid polymer-grafted multiwalled carbon nanotubes for in vitro gene delivery. Small 6, 2281-2291, doi:10.1002/smll.201000864 (2010).

59 Dinu, C. Z., Bale, S. S., Zhu, G. Y. \& Dordick, J. S. Tubulin Encapsulation of Carbon Nanotubes into Functional Hybrid Assemblies. Small 5, 310-315, doi:DOI 10.1002/smll.200801434 (2009).

60 Malumbres, M. \& Barbacid, M. Cell cycle, CDKs and cancer: a changing paradigm. Nature reviews. Cancer 9, 153-166, doi:10.1038/nrc2602 (2009).

61 Siegrist, K.J. et al. Genotoxicity of multi-walled carbon nanotubes at occupationally relevant doses. Part Fibre Toxicol 6 (2014). doi:10.1186/1743-8977-11-6

62 Migliore, L. et al. Carbon Nanotubes Induce Oxidative DNA Damage in RAW 264.7 Cells. Environmental and molecular mutagenesis 51, 294-303 (2010).

63 Kisin, E. R. et al. Genotoxicity of carbon nanofibers: Are they potentially more or less dangerous than carbon nanotubes or asbestos? Toxicology and Applied Pharmacology 252, 1-10, doi:http://dx.doi.org/10.1016/j.taap.2011.02.001 (2011).

64 Kato, T. et al. Genotoxicity of multi-walled carbon nanotubes in both in vitro and in vivo assay systems. Nanotoxicology 7, 452-461 (2013).

65 Sargent, L. M. et al. Single-walled carbon nanotube-induced mitotic disruption. Mutation Research/Genetic Toxicology and Environmental Mutagenesis 745, 28-37, doi:http://dx.doi.org/10.1016/j.mrgentox.2011.11.017 (2012). 
66 Dong, C. B. \& Dinu, C. Z. Molecular trucks and complementary tracks for bionanotechnological applications. Curr Opin Biotech 24, 612-619, doi:DOI 10.1016/j.copbio.2013.01.007 (2013).

67 Codan, B., Martinelli, V., Mestroni, L. \& Sbaizero, O. Atomic force microscopy of 3T3 and SW-13 cell lines: An investigation of cell elasticity changes due to fixation. Materials Science and Engineering: C 33, 3303-3308, doi:http://dx.doi.org/10.1016/j.msec.2013.04.009 (2013).

68 Plodinec, M. et al. The Nanomechanical Signature of Breast Cancer. Biophys J 104, 321a-321a (2013).

69 Cross, S. E., Jin, Y. S., Rao, J. \& Gimzewski, J. K. Nanomechanical analysis of cells from cancer patients. Nat Nanotechnol 2, 780-783, doi:DOI 10.1038/nnano.2007.388 (2007).

70 Snyder-Talkington, B. N., Schwegler-Berry, D., Castranova, V., Qian, Y. \& Guo, N. L. Multi-walled carbon nanotubes induce human microvascular endothelial cellular effects in an alveolar-capillary co-culture with small airway epithelial cells. Part Fibre Toxicol 10, doi:Artn 35 Doi 10.1186/1743-8977-10-35 (2013)

71 Patel, H. J. \& Kwon, S. Length-dependent effect of single-walled carbon nanotube exposure in a dynamic cell growth environment of human alveolar epithelial cells. $J$ Expo Sci Env Epid 23, 101-108 (2013).

72 Rotsch, C. \& Radmacher, M. Drug-induced changes of cytoskeletal structure and mechanics in fibroblasts: an atomic force microscopy study. Biophys $J \mathbf{7 8}, 520-535$, doi:10.1016/S0006-3495(00)76614-8 (2000). 
73 Yim, E. K. F., Darling, E. M., Kulangara, K., Guilak, F. \& Leong, K. W. Nanotopography-induced changes in focal adhesions, cytoskeletal organization, and mechanical properties of human mesenchymal stem cells. Biomaterials 31, 1299-1306 (2010).

74 Alcaraz, J. et al. Microrheology of human lung epithelial cells measured by atomic force microscopy. Biophys J 84, 2071-2079 (2003).

75 Rheinlaender, J., Geisse, N. A., Proksch, R. \& Schaffer, T. E. Comparison of Scanning Ion Conductance Microscopy with Atomic Force Microscopy for Cell Imaging.

Langmuir 27, 697-704 (2011).

76 Nikkhah, M., Strobl, J. S., Schmelz, E. M. \& Agah, M. Evaluation of the influence of growth medium composition on cell elasticity. J Biomech 44, 762-766, doi:DOI 10.1016/j.jbiomech.2010.11.002 (2011). 


\section{Molecular trucks and complementary tracks for bionanotechnological applications Chenbo Dong and Cerasela Zoica Dinu}

\begin{abstract}
Molecular motors are cellular trucks that help regulate structure and function, and enable cells to operate far from equilibrium by transporting cargo (i.e. organelles and other molecules of interest) to designed locations. Cargo transport is performed against concentration gradients and through the exchange of chemical energy into mechanical work. The truck-based transport system provides the inspiration for the next generation of intricate nanodevices and synthetic platforms to be used for lab-on-chip analyte detection and sensing with increased efficiency and scalability.
\end{abstract}

\section{Address \\ Department of Chemical Engineering, West Virginia University, Morgantown, WV 26506, USA}

Corresponding author: Dinu, Cerasela Zoica (ceraselazoica.dinu@mail.wvu.edu)

Current Opinion in Biotechnology 2013, 24:612-619

This review comes from a themed issue on Nanobiotechnology

Edited by Michael C Jewett and Fernando Patolsky

For a complete overview see the Issue and the Editorial

Available online 4th February 2013

0958-1669/\$ - see front matter, (C) 2013 Elsevier Ltd. All rights reserved.

http://dx.doi.org/10.1016/j.copbio.2013.01.007

\section{Introduction}

Manufacturing has become increasingly automated and efficient. The next generation of manufactured devices will need to account for the escalating demand in evershrinking dimensions of ever-increasing complexity. Areas from biomedicine [1] to information technology [2], from diagnosis to sensors and antennas [3], and from energy storage systems [4] to 'smart' materials [5], can benefit from such increased intricacy. Biology provides a great 'toolbox' to inspire solving growing manufacturing demands. Specifically, cells are 'chemical factories' [6] that perform highly precise and systematic processes using specialized nanoscale orientation and transport mechanisms, all with high resolution and in a highthroughput fashion. Numerous of these nanoscale mechanisms are performed by a set of 'engines' $\left[7^{\bullet \bullet}, 8\right]$ and through the conversion of chemical energy of adenosine triphosphate (ATP) dephosphorylation into mechanical work $\left[9^{\bullet \bullet}\right]$. In and beyond life sciences, molecular motors are now being studied for nanofabrication $\left[10^{\circ}\right]$, 'cargo' transport $\left[10^{\circ}, 11\right]$, propulsion of nanoscale devices $\left[12^{\circ}\right]$, biosensing [13], diagnosis and sorting of molecules on 'lab-on-the-chip' devices $\left[13,14^{\bullet \bullet}\right]$. The next step would be to exploit the capability of these cellular engines to manipulate, assemble and pattern objects in a synthetic three-dimensional space, with ultrahigh resolution, in a user-controlled fashion, and over large scale.

The first part of this review describes the molecular motors and their functions in vivo, while the second part focuses on their in vitro applications, as well as their roles and existing challenges in building the next generation of nanodevices. Lastly, the review discusses future trends and applications of motors for intricate nanodevice fabrication.

\section{Cellular 'trucks' and 'tracks'}

In the cell, molecular motors (i.e. kinesins, dyneins and myosins) serve as 'trucks' while their complement cytoskeleton filaments (i.e. microtubules or actin) are regarded as 'tracks' $\left[7^{\bullet \bullet}, 9^{\bullet \bullet}\right]$. Such 'truck-track' systems play important roles in mediating cellular behavior and functions.

\section{Microtubule track and its associated trucks in vivo}

Microtubule cytoskeletal 'track' is formed from heterodimers of alpha and beta tubulin that assemble in a 'headto-tail' fashion to lead to a polar structure $\left[9^{\bullet \bullet}, 10^{\bullet}\right]$. Owing to its asymmetric assembly, a microtubule has a fastgrowing end ('plus-end') and a slow-growing end ('minus-end'). In vivo, microtubules are highly dynamic and accommodate the demands for changes in the cellular structure and functions by undergoing sequential shrinking and growing dynamic instability $\left[7^{\bullet \bullet}, 15\right]$.

Microtubules serve as scaffolds for a wide variety of microtubule-associated molecular motors or 'trucks' (i.e. kinesins and dyneins families, Figure 1a) [ $\left.7^{\bullet \bullet}\right]$. Kinesin and dynein trucks have a motor domain, a microtubule and a cargo-binding domain. There are more than forty mammalian kinesin superfamilies $\left[7^{\bullet \bullet}, 9^{\bullet \bullet}, 10^{\bullet}\right]$ and only three dynein families (i.e. cytoplasmic, intraflagella and axonemal dyneins [16]) currently identified. Many kinesins move towards the plus end of the microtubule and participate in anterograde transport, that is, transporting cargo from the cellular body towards cell periphery $\left[7^{\bullet \bullet}, 10^{\bullet}\right]$. By contrast, retrogate transport (i.e. from the cell periphery towards the cell body) is carried out by most of the cytoplasmic dyneins [16].

Kinesins and dyneins control microtubule's length. By gripping its end, mitotic centromere associated kinesin 


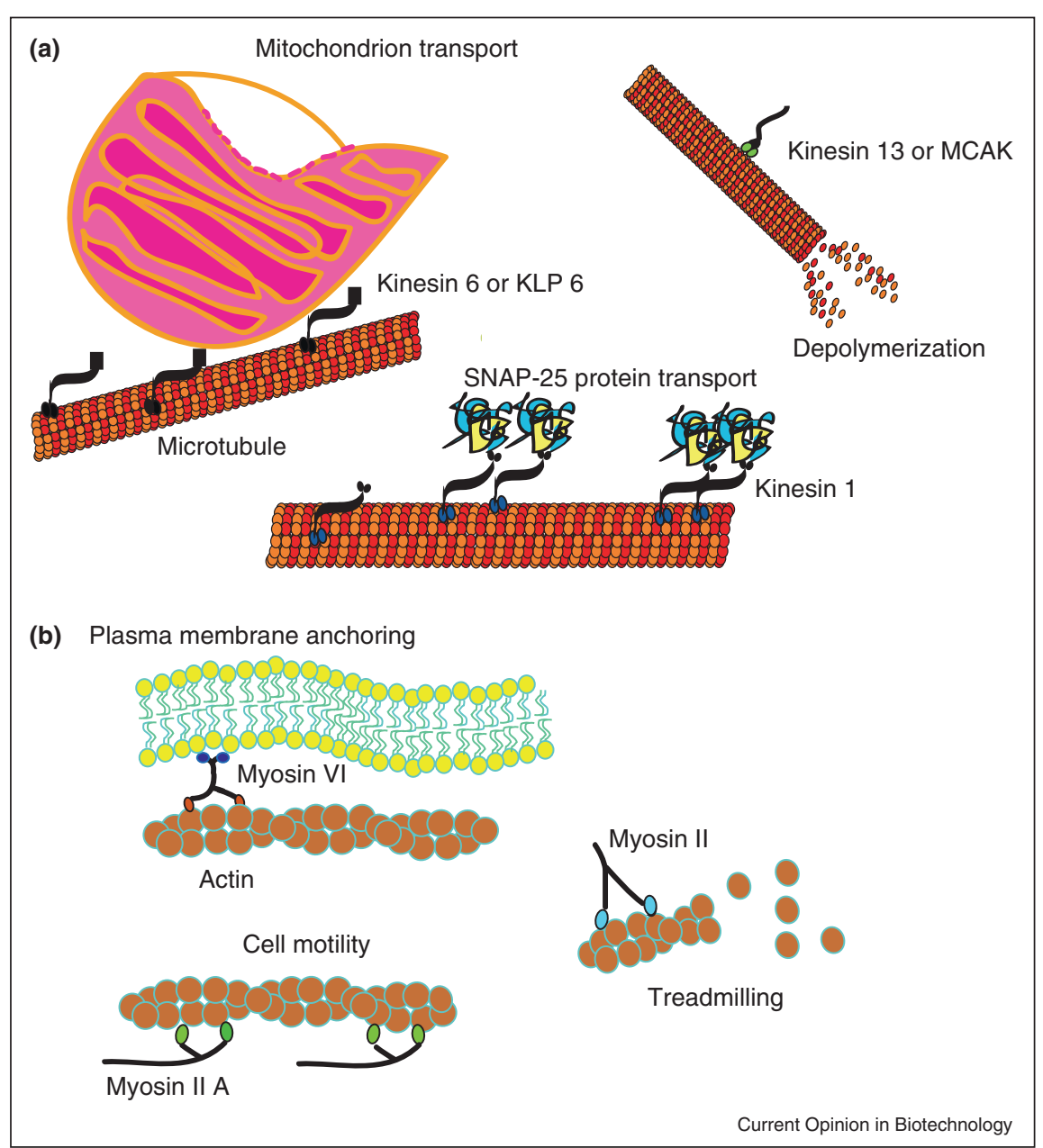

Molecular motor 'trucks' and their cytoskeleton 'tracks' regulate cellular behavior and functions in vivo. (a) Kinesin motors bind to their microtubule cytoskeletal track and mediate protein [20] and mitochondria [19] transport, or microtubules depolymerization [23]. (b) Myosin motors bind to their dynamic actin track. Actin can undergo treadmilling [35]. Myosin-actin system controls plasma membrane anchoring [33] and cell motility [34].

(MCAK) induces microtubule depolymerization [17], while by hindering microtubule's growth cytoplasmic dynein centers its track during aster formation [18].

Kinesin motors are involved in many microtubule-dependent transport pathways in both neuronal (kinesin 6 or KLP6) [19] and non-neuronal cells (kinesin 1) [20], as well as in mitosis (kinesin 7 or CENP-E) [21], meiosis (kinesin 14) [22], remodeling ciliogenesis (kinesin 13) [23], mediating interkinetic nuclear migration (kinesin 3) [24], contributing to chromosomes segregation and maintaining genome integrity (kinesin 5 or Eg5) [25]. Complementary, intrinsic interaction between dynein and dynamic microtubule ends modulates spindle positioning during embryonic cell division [18]. Cytoplasmic dynein also contributes to endosomal motility and fixation of the Golgi apparatus at pericentrosomal location [26].
Competition, cooperation and inhibition exist among trucks during cargo transport. For instance, when kinesin motor density increases, competition and inhibition occur and result in 'traffic jams' that reduce the molecular transport efficiency and could lead to abnormal aggregations of cargoes and neurodegeneration [27]. Complementary, cooperation between kinesins and dyneins lead to cargo transport over longer distances otherwise not achievable if only one of the individual motors would be involved [28].

\section{Actin track and its associated trucks in vivo}

Actin monomer subunits assemble to form polar structures called actin cytoskeletal filaments. These structures, like microtubules, exhibit a fast growing plus-end and a slow growing minus-end [29]. Actin undergoes structure rearrangement and/or remodeling through 
subsequent growing and shrinking treadmilling processes [30].

Molecular motors that are associating with the actin tracks move towards their minus end and belong to the myosin superfamily (Figure 1b) [31 ${ }^{\bullet \bullet}$ ]. Previous studies demonstrated that myosins are involved in intramolecular communication (myosin VI) [32], anchoring of plasma membrane (myosin VI) [33], cell motility (myosin II) [34], or cytoskeleton structure reorganization (myosin II) [35]. In addition, studies showed that myosin $\mathrm{Va}$ has the ability to regulate vesicular neurotransmission [36], while myosin $\mathrm{X}$ is involved in rearrangement of actin filaments and protrusion of fillopodia [37].

Cooperation exists among actin's trucks. For instance, myosin Va cooperates with Protein Kinase A (PKA) to maintain the size and integrity of the synapses. Further, such cooperation modifies acetylcholine receptors lifetime [38]. In contrast, myosin V and VI oppose rather than cooperate by promoting in vivo organelle docking [39]. Myosin VI modulates the concentration of proteins on the axon; disruption of the this motor's function induces abnormal dendritic localization of the axonal proteins and leads to neurodegeneration [40].

\section{Trucks and associated tracks: manipulation in synthetic environment}

Harnessing the structure and function of the truck-track systems in vitro provides proof-of-principle demonstrations for the assembly of the next generation of bionanodevices.

\section{Manipulation of truck-track systems in vitro}

The truck-track systems have unique characteristics. For instance, kinesin 1 truck moves in a processive 'handover-hand' manner, towards the plus end of a microtubule, with a step length of about $8.2 \mathrm{~nm}$, with each step correlated to an ATP hydrolysis event $\left[7^{\bullet \bullet}\right]$. Contrary, myosin II walks towards the minus end of its actin track in a non-processive one-step-at-a-time fashion [ $\left.41^{\bullet}\right]$. The transport velocity (or relative slip speed of tracks on complementary truck-coated surfaces) is system dependent, with kinesin moving at about $0.5 \mu \mathrm{m} / \mathrm{s}$ [42], while myosin can reach up to $5 \mu \mathrm{m} / \mathrm{s}$ [43]. Recent studies showed that by combining microtubule and actin tracks in vitro hybrid delivery systems could be formed (Figure 2a). Such hybrid systems have the ability to function as dual 'rovers' to allow flexibility in their transport functions, that is, transport either on kinesin or myosin trucks-coated surfaces $\left[14^{\bullet \bullet}\right]$.

Using molecular truck-track systems, in vitro demonstrations of cargo transport were performed. For instance, kinesin 1 transported optically tagged protein analytes [13], and carbon nanomaterials $\left[10^{\circ}\right]$, while myosin-actin systems transported liposomes [44]. Research has shown that tracks can be loaded and unloaded with cargo to allow integration and fabrication of future motor-based devices $\left[10^{\bullet}, 45\right]$. Controlled manipulation and delivery of cargos can lead to miniaturization of current lab-on-a-chip nanoscale devices and development of hybrid bionano-transport systems $\left[14^{\bullet \bullet}\right]$. One recent example of such controlled manipulation was achieved through photoactivation, that is, the motility of kinesin-microtubule on user-fabricated azobenzene monolayers was photoactively controlled [46].

Recent studies showed that nearly a millimeter long microtubule wire can be generated by the assembly of extended bundles of biotinylated microtubules crosslinked with streptavidin [ $\left[47^{\circ}\right]$. The mesoscale assembly of such microtubule bundles promises to bridge the gap between self-assembly (relying on diffusion) and robotic assembly, to allow the formation of the next generation of hybrid devices (Figure 2b). Further, when high densities of microtubules were being used, microtubules aligned locally and created loops/bundles due to steric interactions with other neighboring microtubules $\left[48^{\circ}\right]$. Even though such bundles are naturally stiff, altering their synthesis conditions in vitro could lead to structure rearrangements and user-controlled fabrication of clockwise or counterclockwise ring-shaped entities for next generation of ATP-fueled artificial biodevices [49].

\section{Trucks and tracks for sensing}

Compared to the currently used microfluidic-based detection systems, motor-based detection meets the requirement of smaller, simpler and low cost next generation of biosensors $\left[12^{\circ}\right]$. Further, because such systems are ATP-fueled, delivery of analytes could be rapid and efficient, and not rely on additional energy sources $[13,47,50]$. Recent reports showed that optically tagged proteins can be sensed and discriminated in real-time using kinesin 1 trucks [13]. Further, specific attachment of streptavidin and biotin biomolecules can be used to separate individual targets from multiple analytes simply on the basis of target-analyte recognition capability [51]. Such in vitro affinity purification strategy isolated entities in the detection area and increased the detection limits by eliminating the undesired physical binding in the sensor part. Additionally, it was proposed that antibody-functionalized microtubules transported on kinesin-coated surfaces could be used to selectively capture analytes from solution and deliver them to a sensor part to form efficient nanoscale biosensors [51], while reactor liposomes labeled with single stranded DNA ssDNA and encapsulating a hydrophilic fluorescent dye can be used for biosensing-based sorting [ $\left.52^{\circ}\right]$. Specifically, in an autonomous system, 15-base ssDNA attached to microtubules and gliding over kinesin-coated surfaces were used to transport liposome cargos labeled with 23-base ssDNA. Liposome unloading was performed via DNA hybridization and 


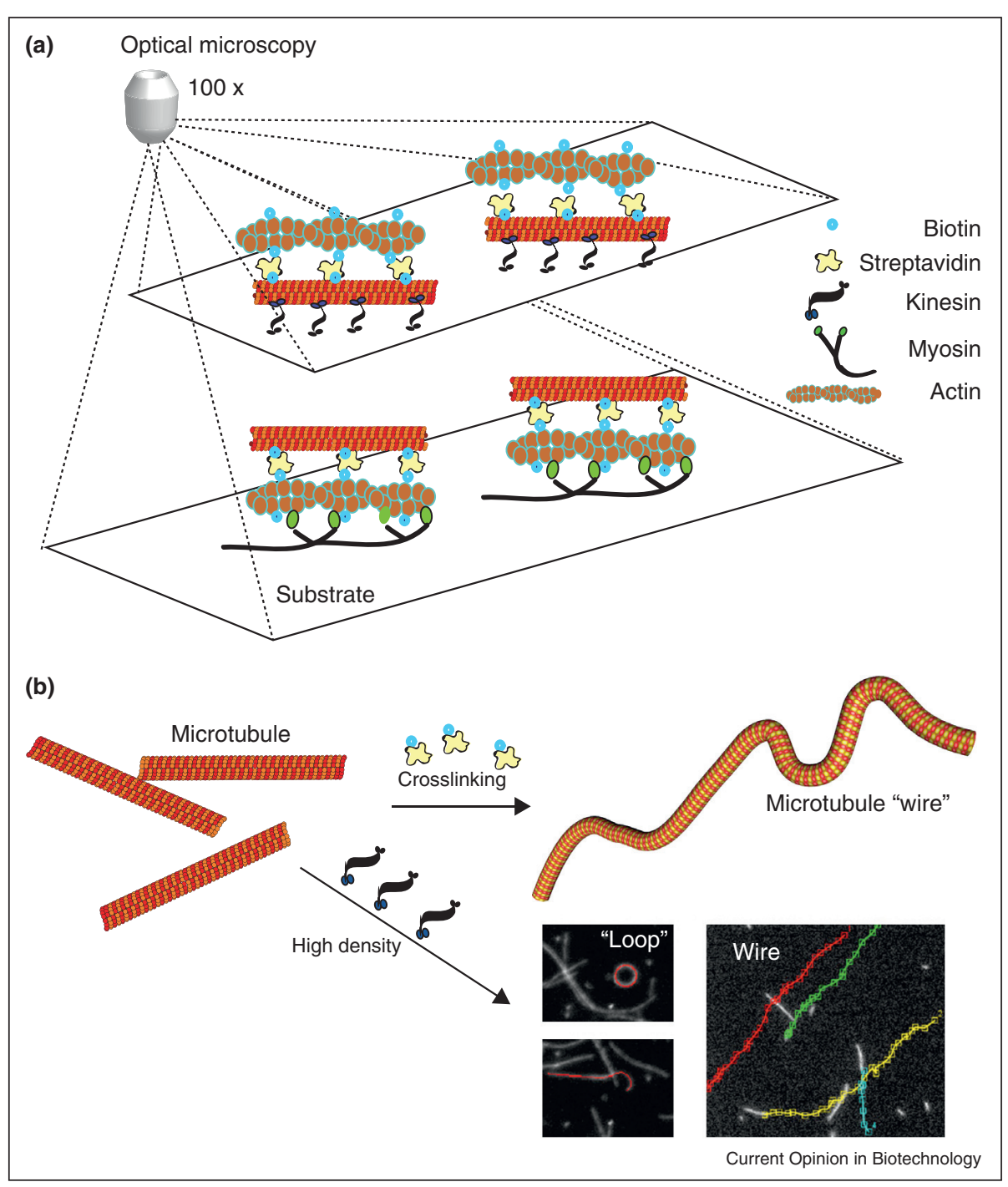

Proof-of-principle of in vitro manipulation of trucks-track systems in order to assembly the next generation of bionanodevices. (a) Optical microscopy allows observation of dual rovers or hybrid transport systems formed from microtubule-kinesin and actin-myosin systems. Kinesin- or myosin-coated surfaces transport microtubule-actin-based hybrids [44]. The schematic diagram shows the synthesis of the hybrids through the crosslinking and recognition properties between the biological molecules of biotin and streptavidin. Figure adapted from Choi et al [14*0] (b) Kinesin motors attached to surfaces assist to the formation of millimeter scale engineering microtubules wires [47] and microtubules loops [48 ${ }^{\circ}$. The wire-like structures are formed by partial coating of the microtubules with streptavidin that could result in microtubule crosslinking into bundles. At a high density of microtubules on kinesin-coated surfaces and during the microtubules transport, microtubules collide and loop-like conformations are formed. (Permission to reproduce granted by the authors and Ref. [48] doi:10.1088/0953-8984/23/37/374104). These two examples of kinesin-based selfassembly of mesoscale structures promise to bridge the gap between self-assembly relying on diffusion and robotic assembly for the next generation of hybrid devices.

at a 'docking' station consisting of 23-base ssDNA patterned sites. These listed methods can capture and concentrate biological analytes while ensuring their subsequent deposition at a sensing site for enhanced sensorial detection. Functionalization of either of the platforms with multiple analytes can lead to parallel detection of multiple targets in a high-throughput fashion. Furthermore, such detection capability could be combined with the dual-rover characteristics (i.e. both kinesin-microtubule and actin-myosin systems) [14 $\left.{ }^{\bullet \bullet}\right]$ to ensure user-directed manipulation, and enhance cargo loading, unloading and delivery.

\section{Challenges in molecular motor-based nanodevices}

Although great advances have been made towards developing nanodevice-based molecular motors, the intricate structure and functions of the motors and their 
complementary tracks currently preclude their industrial implementation. One of most pressing challenges that limits further development of track-truck-based systems is their in vitro limited lifetime. This not only precludes detailed and comprehensive investigations in the design and functions of nanodevice-based molecular motors, but it further makes the performance of such devices in synthetic environment questionable [53]. Attempts were made to increase the lifetime of the motor-based nanodevices either by implementing storage of truck-track model system in an inert gas that allows isolation from the damaging effects associated with reactive oxygen species generation [55], or by preserving it at low temperature before its usage [53,54]. Further, when biosensors applications $\left[12^{\bullet}, 13,14^{\bullet \bullet}\right]$ of the truck-track systems are envisioned, major concerns are associated with the limited detection specificity since non-specific interaction between unwanted analytes and their tracks may occur. Such unwanted interactions may result in decreased sensitivity and thus could lead to contamination or even activity lost of molecular motor-based nanodevices. Each of the issues raised above provides interesting targets of opportunity for future research.

\section{Future research trends for truck-track systems}

The examples included in this review showed that twodimensional manipulation of track-truck systems in synthetic environments could lead to the assembly of next generation of nanodevices. Further, these examples demonstrated that harnessing and implementing the track-truck systems in vitro promise to connect disparate fields such as biological science, chemistry, nanoscience, with engineering in order to solve pressing health and manufacturing demands. Specifically, molecular communication on the basis of truck-track systems could permit the formation of biochips that selectively encapsulate and transport small concentration of biomolecules associated with diseases or stress to a designated receiver-analyzer sensor [56]. Furthermore, for manufacturing demands, truck-track systems can aid nanoscale biosensors with enhanced performance (i.e. enhanced sensitivity and response time) [51], microscopic pumps for efficient energy harvesting [57], or assist molecular nanoelectronics [58]. Whether or not the truck-track systems would be able to fulfill these demands is still under investigation, however, their complexity and their unique ability to

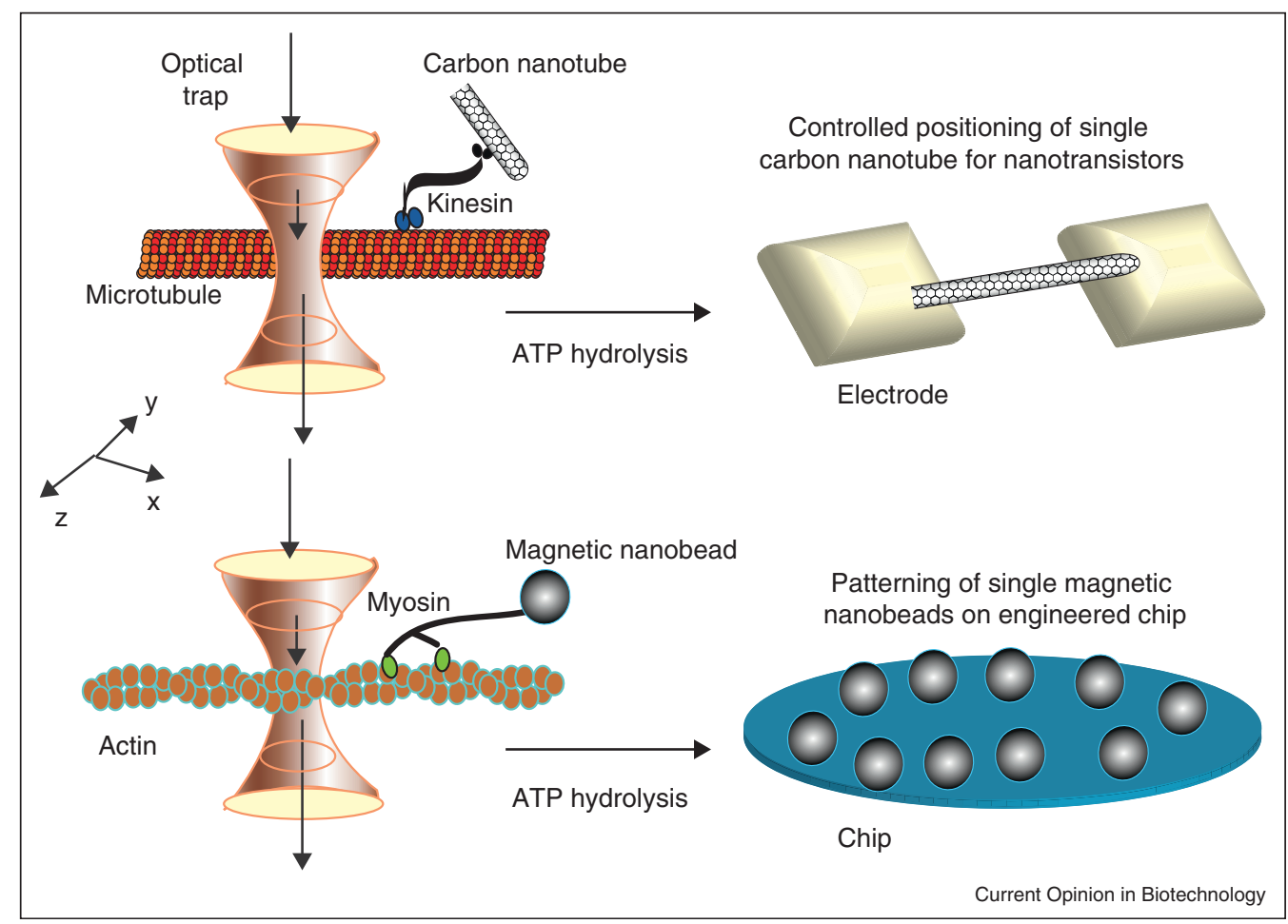

Model for optical trapping of individual tracks (microtubule or actin) loaded with trucks (kinesin or actin) functionalized with nanostructures (carbon nanotube or magnetic nanobead) to facilitate nanodevice assembly. Combinatorial truck-track interactions allow deposition of single nanostructure on engineered surfaces, under the ATP energy and with ultrahigh resolution. The ultrahigh resolution is a result of the track walking on the complementary track with a step size below $10 \mathrm{~nm}$. Further, user-controlled placing of the nanostructures can be additionally controlled by individual manipulation of the traps in $x, y, z$ direction. 
manipulate and design novel nanodevices has not only revolutionized the current research landscape but it further promises to stimulate new research directions to resolve classic problems in biomedical engineering and therapeutics [53].

The future revolution in truck-track systems woud be achieved when the user will learn to exploit the ability of the cell factories to manipulate, assemble and pattern objects in an engineered three-dimensional space, with ultrahigh resolution, in a controlled manner, one-by-one fashion and over large scale. One could envision patterning individual nanostructures on engineered surfaces to create the next generation of miniaturized nanodevices to be used for data storage, plasmonics, sensor arrays or nanotransistors. For instance, user-controlled manipulation of optically trapped tracks (either microtubule or actin) loaded with trucks functionalized with nanostructures (kinesin functionalized with carbon nanotube or myosin functionalized with magnetic nanobeads) can create hybrid nanostructures (either on nanoelectrodes or nanochips) to serve as novel nanodevices (Figure 3). Unprecedented ability to dynamically change the properties of each optical trap by moving them independently would make possible nanostructure deposition with ultrahigh resolution (below $10 \mathrm{~nm}$ ) with each cargo deposition being performed under an ATP hydrolysis event [42]. Further, the optically trapped tracks can be reused to deposit other nanostructures simply on the basis of the truck-track assembly properties. Achieving such capabilities could potentially lead to controlled nanomanufacturing with orientation, positioning and placing monitored by the user in real-time. Ideally, such concept would also permit the creation of combinatorial libraries and would further support library integration into scalable nanosystems to assist the breakthrough necessary for advances in fields as diverse as proteomics, diagnosis, drug discovery or nanoelectronics.

\section{Acknowledgements}

This work was supported by the NSF/CBET 1033266, NSF/CMMI 1049150, NSF/EPS-1003907 and NanoSAFE.

\section{References and recommended reading}

Papers of particular interest, published within the period of review, have been highlighted as:

- of special interest

•• of outstanding interest

1. Ruberti JW, Roy AS, Roberts CJ: Corneal biomechanics and biomaterials. Annu Rev Biomed Eng 2011, 13:269-295.

2. Manem H, Rajendran J, Rose GS: Design considerations for multilevel CMOS/nano memristive memory. ACM J Emerg Technol Comput Syst 2012:8.

3. Chen KI, Li BR, Chen YT: Silicon nanowire field-effect transistor-based biosensors for biomedical diagnosis and cellular recording investigation. Nano Today 2011, 6:131-154.

4. Liu R, Duay J, Lee SB: Heterogeneous nanostructured electrode materials for electrochemical energy storage. Chem Commun 2011, 47:1384-1404.
5. Madsen M, Takei K, Kapadia R, Fang H, Ko H, Takahashi T, Ford AC, Lee MH, Javey A: Nanoscale semiconductor ' $X$ ' on substrate ' $Y$ ' - processes, devices, and applications. Adv Mater 2011, 23:3115-3127.

6. Mao ZW, Cartier R, Hohl A, Farinacci M, Dorhoi A, Nguyen TL, Mulvaney P, Ralston J, Kaufmann SHE, Mohwald $\mathrm{H}$ et al.: Cells as factories for humanized encapsulation. Nano Lett 2011, 11:2152-2156.

7. Hirokawa N: From electron microscopy to molecular cell -. biology, molecular genetics and structural biology: intracellular transport and kinesin superfamily proteins, KIFs: genes, structure, dynamics and functions. $J$ Electron Microsc 2011, 60:S63-S92.

The highlighted review article emphasizes the role of the intracellular transport in maintaining cell function and structure. Current characterization methods of the cellular transport led to the discovery of kinesin superfamily molecular motors, KIFs. Further, the review article identifies and characterizes the molecular motor functions using molecular cell biology and molecular genetics. KIFs roles in transporting various cargoes along microtubule rails, as well as their fundamental roles on various important physiological processes such as learning and memory, brain wiring, development of central nervous system and peripheral nervous system, activity-dependent neuronal survival, development of early embryo, left-right determination of the body and tumourigenesis are also mentioned. The review is a good example of integrative multidisciplinary life sciences approaches for studying functions of molecular motors.

8. Kaan HYK, Hackney DD, Kozielski F: The structure of the Kinesin-1 motor-tail complex reveals the mechanism of autoinhibition. Science 2011, 333:883-885.

9. Muresan V, Muresan Z: Unconventional functions of .- microtubule motors. Arch Biochem Biophys 2012, 520:17-29. The authors focus on the role of microtubule-associated motors in organelle biogenesis, and in the remodeling of the cytoskeleton, especially through the regulation of microtubule dynamics. They also discuss the function of microtubule associated motors as static anchors of the cargo at the destination, and their participation in regulating signaling cascades by modulating interactions between signaling proteins, including transcription factors. The authors overall goal is to provide an overview of the unexpected functions of microtubule associated motors, and to incite future research in this expanding field.

10. Dinu CZ, Bale SS, Dordick JS: Kinesin I ATPase manipulates

- biohybrids formed from tubulin and carbon nanotubes. Methods Mol Biol 2011, 743:77-93.

This book chapter describes fabrication of novel protein-nanotube hybrid conjugates in the presence of molecular motors. Such method provides platform for the preparation of biosensors based or protein assemblies or biological templates for nanofabrication.

11. Reis GF, Yang G, Szpankowski L, Weaver C, Shah SB, Robinson JT, Hays TS, Danuser G, Goldstein LS: Molecular motor function in axonal transport in vivo probed by genetic and computational analysis in Drosophila. Mol Biol Cell 2012, 23:1700-1714.

12. Malcos JL, Hancock WO: Engineering tubulin: microtubule

- functionalization approaches for nanoscale device applications. Appl Microbiol Biotechnol 2011, 90:1-10.

A comprehensive review of different methods for microtubule functionalization to provide the next generation of microscale and nanoscale engineered devices or for basic biology research.

13. Bachand M, Bachand GD: Effects of potential environmental interferents on kinesin-powered molecular shuttles. Nanoscale 2012, 4:3706-3710.

14. Choi DS, Byun KE, Hong S: Dual transport systems based on -. hybrid nanostructures of microtubules and actin filaments. Small 2011, 7:1755-1760.

This article provides means to construct microtubule-actin hybrid nanoscale structures in vitro. Such structures exhibit microtubule-like motility capabilities when they are placed on kinesin-coated surfaces and or actin-like motility capabilities when they are placed on myosin-coated surfaces. This paper is an excellent example of proof of concept in fabrication of hybrid multifunction motors proteins based transport device in vitro that have dual characteristics and thus allow for flexibility in cargo transport and loading.

15. Lomakin AJ, Kraikivski P, Semenova I, Ikeda K, Zaliapin I, Tirnauer JS, Akhmanova A, Rodionov V: Stimulation of the CLIP170-dependent capture of membrane organelles by 
microtubules through fine tuning of microtubule assembly dynamics. Mol Biol Cell 2011, 22:4029-4037.

16. Carter AP, Cho C, Jin L, Vale RD: Crystal structure of the dynein motor domain. Science 2011, 331:1159-1165.

17. Diez S: Multi-talented MCAK: microtubule depolymerizer with a strong grip. Nat Cell Biol 2011, 13:738-740.

18. Laan L, Pavin N, Husson J, Romet-Lemonne G, van Duijn M Lopez MP, Vale RD, Julicher F, Reck-Peterson SL, Dogterom M: Cortical dynein controls microtubule dynamics to generate pulling forces that position microtubule asters. Cell 2012 148:502-514.

19. Tanaka K, Sugiura Y, Ichishita R, Mihara K, Oka T: KLP6: a newly identified kinesin that regulates the morphology and transport of mitochondria in neuronal cells. J Cell Sci 2011, 124 2457-2465

20. Morton AM, Cunningham AL, Diefenbach RJ: Kinesin-1 plays a role in transport of SNAP-25 to the plasma membrane. Biochem Biophys Res Commun 2010, 391:388-393.

21. Huang YJ, Wang WW, Yao $P$, Wang XW, Liu X, Zhuang XX, Yan F, Zhou JH, Du J, Ward T et al.: CENP-E kinesin interacts with SKAP protein to orchestrate accurate chromosome segregation in mitosis. J Biol Chem 2012, 287: 1500-1509.

22. Rank KC, Chen CJ, Cope J, Porche K, Hoenger A, Gilbert SP Rayment I: Kar3Vik1, a member of the Kinesin-14 superfamily, shows a novel kinesin microtubule binding pattern. J Cell BiO 2012, 197:957-970.

23. Kobayashi T, Tsang WY, Li J, Lane W, Dynlacht BD: Centriolar kinesin Kif24 interacts with CP110 to remodel microtubules and regulate ciliogenesis. Cell 2011, 145:914-925.

24. Kulikova S, Abatis M, Heng C, Lelievre V: Interkinetic nuclear migration: reciprocal activities of dynein and kinesin. Cell Adh Migr 2011, 5:277-279.

25. Charlebois BD, Kollu S, Schek HT, Compton DA, Hunt AJ: Spindle pole mechanics studied in mitotic asters: dynamic distribution of spindle forces through compliant linkages. Biophys $J 2011$, 100:1756-1764.

26. Yadav S, Linstedt AD: Golgi positioning. Cold Spring Harbor Perspect Biol 2011:3.

27. Leduc C, Padberg-Gehle K, Varga V, Helbing D, Diez S, Howard J: Molecular crowding creates traffic jams of kinesin motors on microtubules. Proc Natl Acad Sci U S A 2012, 109:6100-6105.

28. Schuster M, Kilaru S, Fink G, Collemare J, Roger Y, Steinberg G: Kinesin-3 and dynein cooperate in long-range retrograde endosome motility along a nonuniform microtubule array. $\mathrm{Mol}$ Biol Cell 2011, 22:3645-3657.

29. Narita A, Mueller J, Urban E, Vinzenz M, Small JV, Maeda Y: Direct determination of actin polarity in the cell. $\mathrm{J} \mathrm{Mol} \mathrm{Biol} 2012$ 419:359-368.

30. Narita A: Minimum requirements for the actin-like treadmilling motor system. Bioarchitecture 2011, 1:205-208.

31. Hartman MA, Spudich JA: The myosin superfamily at a glance.

•. Cell Sci 2012, 125:1627-1632.

This article talks about the characteristics of myosin superfamily and their contribution in regulating cellular processes. Next, the authors discuss myosin-cargo interactions and present a summary of the roles of myosin proteins in the cells, focusing on actin-based projections and the endomembrane system. The authors also provide an overview of the diseases associated with myosin mutations and give perspective on the future of the myosin field.

32. Elting MW, Bryant Z, Liao JC, Spudich JA: Detailed tuning of structure and intramolecular communication are dispensable for processive motion of Myosin VI. Biophys $J$ 2011, 100: 430-439.

33. Sakurai K, Hirata M, Yamaguchi H, Nakamura Y, Fukami K: Phospholipase $\mathbf{C}$ delta 3 is a novel binding partner of myosin $\mathrm{VI}$ and functions as anchoring of myosin VI on plasma membrane. Adv Enzyme Regul 2011, 51:171-181.
34. Szabo B, Unnep R, Marko K, Kornyei Z, Mehes E, Czirok A: Inhibition of myosin II triggers morphological transition and increased nuclear motility. Cytoskeleton 2011, 68:325-339.

35. Wilson CA, Tsuchida MA, Allen GM, Barnhart EL, Applegate KT Yam PT, Ji L, Keren K, Danuser G, Theriot JA: Myosin II contributes to cell-scale actin network treadmilling through network disassembly. Nature 2010, 465:373-377.

36. Chaudhury A, He XD, Goyal RK: Role of myosin Va in purinergic vesicular neurotransmission in the gut. Am J Physiol: Gastroint Liver Physiol 2012, 302:G598-G607.

37. Umeki N, Jung HS, Sakai T, Sato O, lkebe R, Ikebe M: Phospholipid-dependent regulation of the motor activity of myosin X. Nat Struct Mol Biol 2011, 18:783-788.

38. Roder IV, Strack S, Reischl M, Dahley O, Khan MM, Kassel O, Zaccolo M, Rudolf R: Participation of myosin Va and Pka Type in the regeneration of neuromuscular junctions. PLOS ONE 2012:7.

39. Pathak D, Sepp KJ, Hollenbeck PJ: Evidence that myosin activity opposes microtubule-based axonal transport of mitochondria. J Neurosci 2010, 30:8984-8992.

40. Lewis TL, Mao TY, Arnold DB: A role for myosin $\mathbf{V I}$ in the localization of axonal proteins. PLOS Biol 2011:9

41. Chen L, Nakamura M, Schindler TD, Parker D, Bryant Z:

- Engineering controllable bidirectional molecular motors based on myosin. Nat Nanotechnol 2012, 7:252-256.

This paper provides a viable method for constructing bidirectional engineered myosin motors that can reversibly change their direction in response to a calcium signal. This is first time that motors have been reported to move bidirectionally on actin-coated surfaces.

42. Fort AG, Murray JW, Dandachi N, Davidson MW, Dermietzel R, Wolkoff AW, Spray DC: In vitro motility of liver connexin vesicles along microtubules utilizes kinesin motors. J Biol Chem 2011 286:22875-22885.

43. Purcell TJ, Naber N, Franks-Skiba K, Dunn AR, Eldred CC Berger CL, Malnasi-Csizmadia A, Spudich JA, Swank DM, Pate E et al.: Nucleotide pocket thermodynamics measured by EPR reveal how energy partitioning relates myosin speed to efficiency. $J$ Mol Biol 2011, 407:79-91.

44. Iwabuchi S, Takahashi T, Hatori K: Transport of actin-decorated liposomes along myosin molecules in vitro. Biochem Biophys Res Commun 2012, 422:164-168.

45. Ali MY, Kennedy GG, Safer D, Trybus KM, Sweeney HL, Warshaw DM: Myosin Va and myosin VI coordinate their steps while engaged in an in vitro tug of war during cargo transport. Proc Natl Acad Sci U S A 2011, 108:E535-E541.

46. Rahim MK, Fukaminato T, Kamei T, Tamaoki N: Dynamic photocontrol of the gliding motility of a microtubule driven by kinesin on a photoisomerizable monolayer surface. Langmuir 2011, 27:10347-10350.

47. Idan O, Lam A, Kamcev J, Gonzales J, Agarwal A, Hess H:

- Nanoscale transport enables active self-assembly of millimeter-scale wires. Nano Lett 2012, 12:240-245.

This paper shows that millimeter scale microtubule bundles can be formed by active self-assembly and when microtubules are placed on kinesin-coated surfaces. A basic model is also given to reveal the proposed microtubules bundles grow mechanism. Such examples of active self-assembly in synthetic environment provides platforms to develop future hybrid and synthetic systems on the basis of molecular motors and their truck.

48. Liu L, Tuzel E, Ross JL: Loop formation of microtubules during - $\quad$ gliding at high density. J Phys Condens Matter 2011:23.

This paper discusses the influence of the density of microtubules on their self-organization and structure formation in vitro and when placed on kinesin-coated surfaces. The article also provides insight into how cellular crowded conditions might affect the microtubule and motor behavior and thus lead to cytoskeleton reorganization in vivo.

49. Kakugo A, Kabir AM, Hosoda N, Shikinaka K, Gong JP: Controlled clockwise-counterclockwise motion of the ring-shaped microtubules assembly. Biomacromolecules 2011, 12 . 3394-3399. 
50. Efremov A, Wang Z: Universal optimal working cycles of molecular motors. Phys Chem Chem Phys 2011, 13:6223-6233.

51. Katira $P$, Hess $H$ : Two-stage capture employing active transport enables sensitive and fast biosensors. Nano Lett 2010, 10:567-572.

52. Hiyama S, Moritani Y, Gojo R, Takeuchi S, Sutoh K: Biomolecular- motor-based autonomous delivery of lipid vesicles as nano- or microscale reactors on a chip. Lab Chip 2010, 10:2741-2748.

This paper describes the formation of an autonomous on-chip system to perform targeted delivery of lipid vesicles using kinesin-microtubule systems. The reactor-liposomes are labeled with ssDNA and introduced in a flow cell where microtubules coated with complementary ssDNA are gliding on kinesin-coated surfaces. The loading of the liposomes is a result of the complementarity of the sSDNA and its hybridization properties; unloading is a result of preferred hybridization with a second ssDNA patterned at user-controlled locations. The authors further demonstrated the feasibility of selective and parallel loading, transport and unloading of the lipid vesicles and discussed how the rate of loading or unloading depends on the glinding speeds of the microtubules on the kinesincoated surfaces. The authors envision the development of a liposomebased lab-on-a-chip systems to perform targeted contents-mixing of transported reactor-liposomes to designed locations.
53. Hess $\mathrm{H}$ : Engineering applications of biomolecular motors. Annu Rev Biomed Eng 2011, 13:429-450.

54. Albet-Torres N, Mansson A: Long-term storage of surfaceadsorbed protein machines. Langmuir 2011, 27:7108-7112.

55. Kabir AMR, Inoue D, Kakugo A, Kamei A, Gong JP: Prolongation of the active lifetime of a biomolecular motor for in vitro motility assay by using an inert atmosphere. Langmuir 2011, 27:13659-13668.

56. Hiyama S, Moritani Y: Molecular communication: harnessing biochemical materials to engineer biomimetic communication systems. Nano Commun Netw 2010, 1:20-30.

57. Bull JL, Hunt AJ, Meyhofer E: A theoretical model of a molecular-motorpowered pump. Biomed Microdevices 2005, 7:21-33.

58. Dinu CZ, Opitz J, Pompe W, Howard J, Mertig M, Diez S: Parallel manipulation of bifunctional DNA molecules on structured surfaces using kinesin-driven microtubules. Small 2006, 2:1090-1098. 


\title{
Antibacterial and surface-enhanced Raman scattering (SERS) activities of $\mathrm{AgCl}$ cubes synthesized by pulsed laser ablation in liquid
}

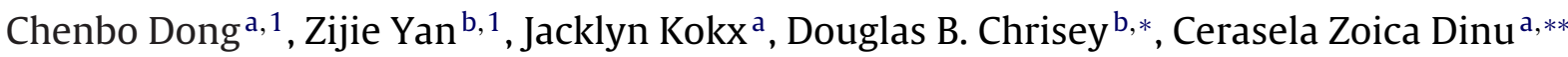 \\ a Department of Chemical Engineering, West Virginia University, Morgantown, WV 26506, USA \\ ${ }^{\mathrm{b}}$ Department of Materials Science and Engineering, Rensselaer Polytechnic Institute, Troy, NY 12180, USA
}

\section{A R T I C L E I N F O}

\section{Article history:}

Available online 9 August 2011

\section{Keywords:}

AgCl cubes

E. coli

Antibacterial

Killing capabilities

\begin{abstract}
A B S T R A C T
We used pulsed laser ablation in liquid to fabricate silver chloride $(\mathrm{AgCl})$ nanocubes directly from a bulk Ag target in sodium chloride $(\mathrm{NaCl})$ solution. We optimized particle size and investigated the surface properties of the cubes for their Surface Enhanced Raman Scattering (SERS) behavior relative to Rhodamine 6G (R6G). The SERS behavior was related to the surface properties, clearness, and morphology, i.e., varied atomic arrangements and surface energies of different facets of the cubes. In addition, we have demonstrated that our easily synthesized $\mathrm{AgCl}$ cubes were antibacterial with a high efficiency to decontaminate Escherichia coli upon contact. Our results can be extended to generate particle-based coatings with antibacterial properties.
\end{abstract}

(c) 2011 Elsevier B.V. All rights reserved.

\section{Introduction}

Silver-based materials are being used in the development of biological and pharmaceutical processes [1], as coating materials for medical devices [2], for orthopedic or dental graft materials [3], or for water sanitization [4]. Since silver displays multiple modes of inhibitory action to microorganisms [5-7], with the arising and increased resistance of number of microorganism toward multiple antibiotics [8], and continuous emphasis on reducing health cost, research has also focused on developing new types of low cost, effective coatings [9-11]. Recent research has shown that silver chloride $(\mathrm{AgCl})$ exhibits surface enhanced Raman scattering (SERS) capabilities and can be employed for the fabrication of photographic paper and photochromic lenses [12-19]. These capabilities are considered to originate from the controlled shape of Ag clusters formed in the $\mathrm{AgCl}$ lattice $[13,15,16,18,19]$, although the surface $\mathrm{Ag}^{+}$complexes may also play an important role [12]. The Ag clusters form by a self-sensitization process of $\mathrm{AgCl}$, namely, $\mathrm{Ag}^{+}$ions

\footnotetext{
* Corresponding author at: Department of Materials Science and Engineering, Department of Biomedical Engineering, School of Engineering, Rensselaer Polytechnic Institute, 110 8th Street, Troy, NY, 12180-3590, USA. Tel.: +1 518276 3303; fax: +1 5182768554

** Corresponding author at: Department of Chemical Engineering, West Virginia University, College of Engineering and Mineral Resources, PO Box 6102, ESB 445, Morgantown, WV, 26506, USA. Tel.: +1 304293 9338; fax: +1 3042934139.

E-mail addresses: chrisd@rpi.edu (D.B. Chrisey)

cerasela-zoica.dinu@mail.wvu.edu (C.Z. Dinu).

1 The authors contributed equally to this work.
}

combine with photo-induced electrons to form $\mathrm{Ag}^{0}$ atoms/clusters upon light irradiation [20]. Despite their large SERS-based applications there had been only few methods available to generate $\mathrm{AgCl}$ materials with fine control over their properties for SERS detection. Moreover, to our knowledge, there has been no previous study that combines the inhibitory effects of $\mathrm{AgCl}$ with its SERS detection capabilities to generate analytical tools used for detection and decontamination.

$\mathrm{AgCl}$-related materials were synthesized by precipitation reactions between $\mathrm{Ag}^{+}$and $\mathrm{Cl}^{-}$ions via wet chemical methods; the shape of the clusters was controlled when surfactant was used in the preparation $[13,16,18,19]$. $\mathrm{AgCl}$ cubes were fabricated with the use of poly(vinyl pyrrolidone) and further modified into $\mathrm{AgCl}: \mathrm{Ag}$ by post heat-treatment at elevated temperatures [19]. Recently, $\mathrm{AgCl}$ nanocubes fabrication was demonstrated via a simple reaction between silver nitrate $\left(\mathrm{AgNO}_{3}\right)$ and sodium chloride $(\mathrm{NaCl})$ in ethylene glycol [21]. Our group has shown that excimer laser ablation of $\mathrm{Ag}$ target in aqueous solutions of $\mathrm{NaCl}$ directly generates $\mathrm{AgCl}$ cubes in the absence of surfactant molecules [14]. Pulsed laser ablation in liquid is a technique widely used for nanocrystal fabrication $[22,23]$. The technique is not only reliable and easily applicable, but also skips additional steps that could lead to surface contaminations thus increasing the potential applications related to surface properties of the synthesized particles. Current research trend in this area is to fabricate functional nanostructures utilizing the merits of this technique [24] with focus on the synthesis of the nanostructure formation and growth. Herein we report for the first time on the antibacterial activity and efficiency of $\mathrm{AgCl}$ nanocubes and nanobars prepared by pulsed laser ablation of $\mathrm{Ag}$ target in 
(a)
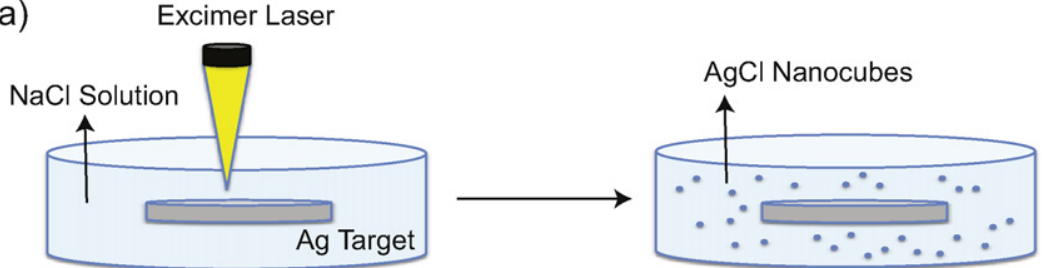

Laser Ablation in Liquid

(b)

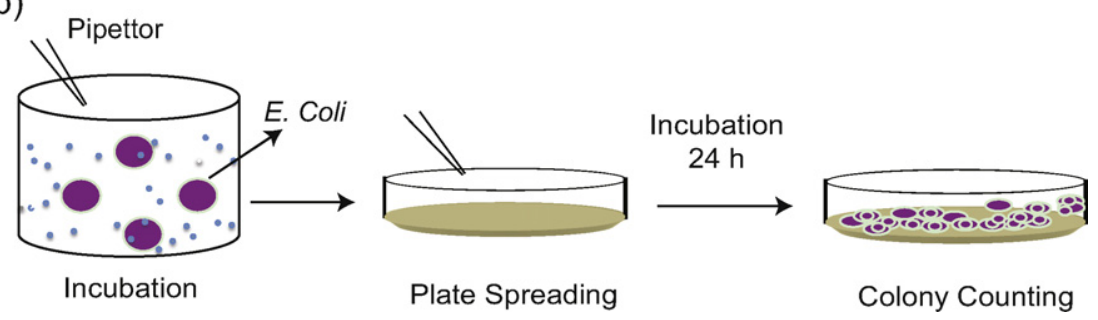

Scheme 1. Concept figure of the $\mathrm{AgCl}$ preparation by pulsed laser ablation of $\mathrm{Ag}$ target in $\mathrm{NaCl}$ solution (a) and their antibacterial testing using standard plating assay and gram negative bacteria (b).

aqueous solutions of $\mathrm{NaCl}$. We also investigate their SERS activities against Rhodamine $6 \mathrm{G}$ in order to formulate new analytical tools for detection and decontamination.

\section{Materials and methods}

\subsection{Fabrication and characterization of $\mathrm{AgCl}$ cubes}

$\mathrm{AgCl}$ particles in the form of cubes were fabricated using a laser ablation method previously described [14]. Briefly, a silver target (99.99\% pure, Kurt J. Lesker Company, USA) was placed in a rotating glass beaker filled with aqueous solution of $0.005 \mathrm{M} \mathrm{NaCl}(\geq 99.0 \%$ pure, Mallinckrodt Baker, Inc., USA). A KrF excimer laser with wavelength of $248 \mathrm{~nm}$, pulse width of $30 \mathrm{~ns}$, and repetition frequency of $10 \mathrm{~Hz}$, was focused onto the target surface. Continuous ablation of the target was performed for $20 \mathrm{~min}$ at a laser fluence of $\sim 8 \mathrm{~J} / \mathrm{cm}^{2}$. The products were isolated and collected by centrifugation. Purification and re-dispersion steps in Milli-Q water were also employed to remove any residual $\mathrm{NaCl}$. Scanning electron microscopy (SEM) was performed on a JEOL JSM-6330F field emission at $10 \mathrm{kV}$. X-ray diffraction (XRD) patterns were collected on an X-ray diffractometer (Bruker D8) with $\mathrm{Cu} \mathrm{K \alpha}$ radiation.

\subsection{Preparation of Escherichia coli (E.coli)}

A seed culture of Escherichia coli was prepared by inoculating $2 \times$ YT media $(16 \mathrm{~g} / \mathrm{L}$ tryptone, $10 \mathrm{~g} / \mathrm{L}$ yeast extract and $5 \mathrm{~g} / \mathrm{L} \mathrm{NaCl}$; Fisher Scientific, USA) supplemented with $200 \mu \mathrm{g} / \mathrm{ml}$ ampicillin (Fisher Scientific, USA) and $30 \mu \mathrm{g} / \mathrm{ml}$ chloramphenicol (Fisher Scientific, USA) with a frozen cell stock of $E$. coli BL21 Star (DE3) pLysS cells (Invitrogen, USA). The seed culture was incubated overnight at $37^{\circ} \mathrm{C}$ on an orbital shaker and then used to inoculate a main culture of $1 \mathrm{~L} 2 \times$ YT media also supplemented with $200 \mu \mathrm{g} / \mathrm{ml}$ ampicillin and $30 \mu \mathrm{g} / \mathrm{ml}$ chloramphenicol. The main culture was incubated at $37^{\circ} \mathrm{C}$ at $250 \mathrm{rpm}$ in a $2 \mathrm{~L}$ baffled flask until an optical density at $600 \mathrm{~nm}$ (OD600) of 0.6 was reached. Cells were subsequently pelleted by centrifugation at $4500 \mathrm{rpm}$ for $5 \mathrm{~min}$ and resuspended in a phosphate buffer solution (PBS, $10 \mathrm{mM}, \mathrm{pH} 7.5$, Dulbecco's Phosphate Buffered Saline, Sigma, USA). This step was repeated at least 3 times to remove all the nutrient media. In order to obtain an approximate measure of cell density in terms of $\mathrm{CFU} / \mathrm{ml}$, the adsorption of the bacterial suspension was measured at $600 \mathrm{~nm}$ (Absorbance of 1 at $600 \mathrm{~nm}$ corresponds to $8 \times 10^{8} \mathrm{CFU} / \mathrm{ml}$ ) [25].

\subsection{Antibacterial efficiency of $\mathrm{AgCl}$ cubes}

To evaluate the antibacterial efficiency of $\mathrm{AgCl}$ cubes produced as previously described, a vial containing the cubes $(1 \mathrm{mg} / \mathrm{ml})$ was incubated with different concentrations of bactericidal suspensions $\left(2-5 \times 10^{5} \mathrm{CFU} / \mathrm{ml}\right)$ and placed on a shaker at $300 \mathrm{rpm}$. For evaluating the kinetics of bactericidal killing, $10 \mu \mathrm{l}$ solution was withdrawn after $30 \mathrm{~min}, 1,3,6,12,18$ and $24 \mathrm{~h}$ respectively and spread onto a nutrient agar plate. The nutrient agar plates were obtained by poring a sterilized mixture of $1 \mathrm{~L}$ Milli-Q water containing nutrient broth ( $8 \mathrm{~g}$, Difco, USA) and $12 \mathrm{~g}$ of Agar (Sigma, USA) in 100 O.D. $\times 15 \mathrm{~mm}$ H Petri dishes (Fisher, USA). The nutrient agar plates were plated with the $10 \mu \mathrm{l}$ of bacteria or bacteria incubated with $\mathrm{AgCl}$ were incubated at $37^{\circ} \mathrm{C}$ for $24 \mathrm{~h}$. Bactericidal efficiency was determined by counting colonies grown on the nutrient agar surface and by comparing colony counts obtained after bacteria incubation with $\mathrm{AgCl}$ cubes with those obtained from control nutrient agar plates (i.e., where the bacteria was plated without exposure to the $\mathrm{AgCl}$ nanocubes). Every experiment was performed in duplicate and five independent sets of experiments were performed per total and for a relevant statistic.

\subsection{Bactericidal efficiency of $\mathrm{AgCl}$ containing plates}

In other experiments, $10 \mu \mathrm{l}$ of $\mathrm{AgCl}$ cubes were incubated in $\sim 20 \mathrm{ml}$ mixture containing nutrient broth and agar (prepared as previously described) at $90^{\circ} \mathrm{C}$. The mixture was pored onto Petri dishes and left to cool down at room temperature. The plates were then incubated with $10 \mu \mathrm{l}$. coli solution at $10^{5} \mathrm{CFU} / \mathrm{ml}$ and the antibacterial efficiency by slow release of the $\mathrm{Ag}^{+}$ions was evaluated after incubation of the plates at $37^{\circ} \mathrm{C}$ for $24 \mathrm{~h}$. The antibacterial efficiency was reported relative to control experiments (i.e., bacteria grown on nutrient agar plates).

\subsection{SERS tests}

Several drops of solution containing $\mathrm{AgCl}$ cubes were deposited on silicon wafers; the wafer was dried in air and at room temperature. Rhodamine 6G (R6G, 99\% pure, Acros Organics, USA) aqueous solutions (concentration of $10^{-11}-10^{-5} \mathrm{M}$ ) were then dripped on the $\mathrm{AgCl}$ deposits and evaporated. The SERS spectra were recorded with a Renishaw S2000 Raman spectroscope using an argon-ion laser $(514.5 \mathrm{~nm})$ and through a $50 \times$ microscope objective. The 


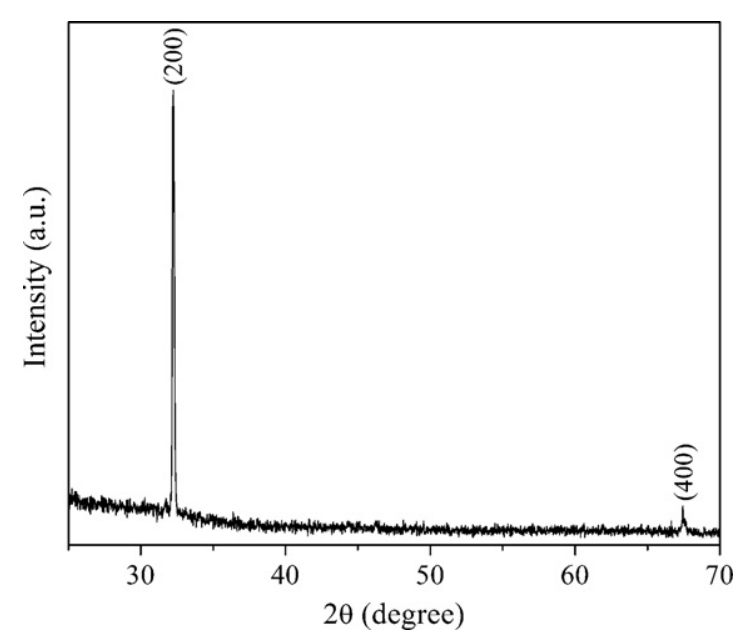

Fig. 1. XRD spectrum of the products fabricated by excimer pulsed laser ablation of Ag target in $\mathrm{NaCl}$ solution.

incident laser power was kept at $10 \%$ of $50 \mathrm{~mW}$ with accumulation time of $10 \mathrm{~s}$.

\section{Results and discussions}

$\mathrm{AgCl}$ particles were prepared using pulsed laser ablation of $\mathrm{Ag}$ target in $\mathrm{NaCl}$ solution (Scheme $1(\mathrm{a})$ ). To remove any residual $\mathrm{NaCl}$, particles were washed and redispersed by centrifugation and filtration in Milli-Q water. The structure of the laser-produced particles was characterized by XRD. Fig. 1 shows the XRD spectrum; the peaks can be indexed into cubic phase of $\mathrm{AgCl}$ (JCPDS card no.
31-1238). The predominance of (200) and (400) peaks indicates that the $\mathrm{AgCl}$ particles have cubic shapes.

To further confirm the morphology of particles produced by pulsed laser ablation in liquid, we performed SEM analysis (Fig. 2). As shown in Fig. 2(a), the nanoparticles have well-defined cubic morphologies with the edge lengths of the cubes being about 100-200 nm (Fig. 2(b)). The pulsed laser ablated sample also contained nanobars; the arrows in Fig. 2(c) and (d), respectively pointed out five independent nanobars. As shown, the nanobars have different aspect ratios: [1] 1.6, [2] 2.5, [3] 2.6, [4] 3.6, and [5] 6.7, respectively. To our knowledge, no previous demonstration of nanobars was reported. Nanobars could offer unique immobilization nanosupports because of their high volume-surface ratio [26]. Our results also show that smaller nanoparticles seem to have appeared on the surface of the nanobars and nanocubes as revealed by Fig. 2(d). This was previously reported for $\mathrm{AgCl}$ under intensive electron beam irradiation, with the irradiation heat partially decomposing the $\mathrm{AgCl}$ [14].

As synthesized and purified nanocubes were further tested for their antibacterial properties upon contact with gram negative $E$. coli grown following standards protocols (Scheme 1(b)). Fig. 3(a) shows the atomic force microscopy of the bacterial colonies while the inset shows the 3D image of a single $E$. coli isolated from the culture. The nanocubes were incubated in the bacterial solution; samples were extracted after different incubation periods and plated onto nutrient agar plates. The antibacterial efficiency was reported relative to the control nutrient agar plates, namely plates incubated with non-exposed $E$. coli. Our results showed that there is a considerable decrease in the number of colonies of $E$. coli upon their incubation with the nanocubes (Fig. 3(b)). Visual counting reveals $>95 \%$ antibacterial efficiency against $10^{5} \mathrm{CFU} / \mathrm{ml}$ of bacteria in only $3 \mathrm{~h}$ incubation, all relative to control samples (Fig. 3(c)).
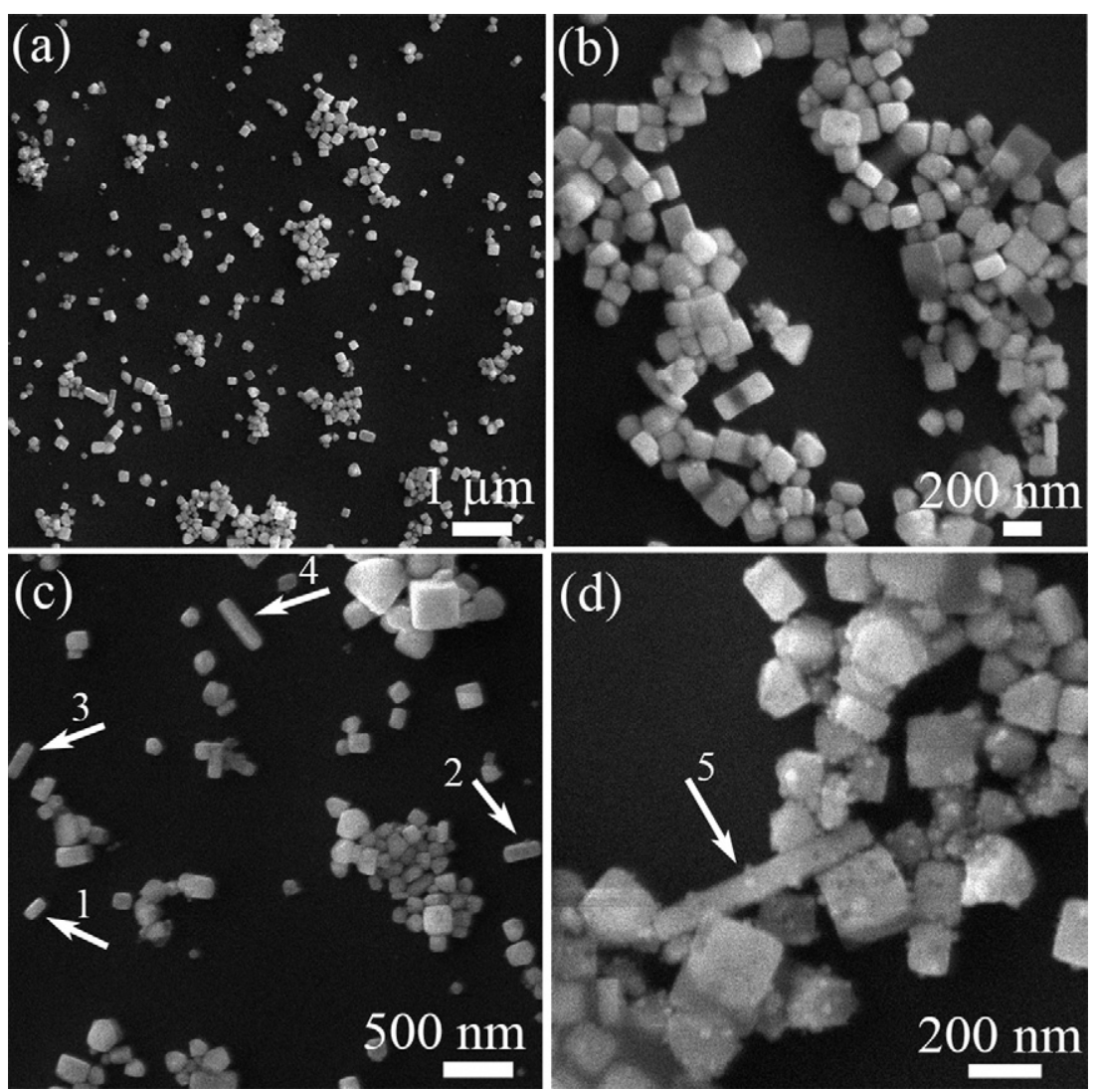

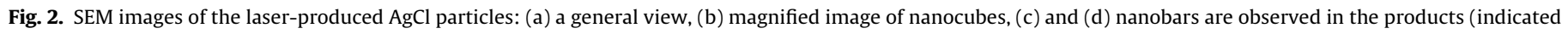
by the arrows). 
(a)

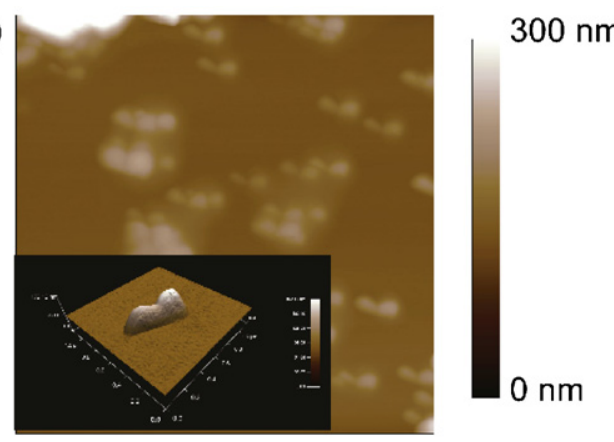

(c)

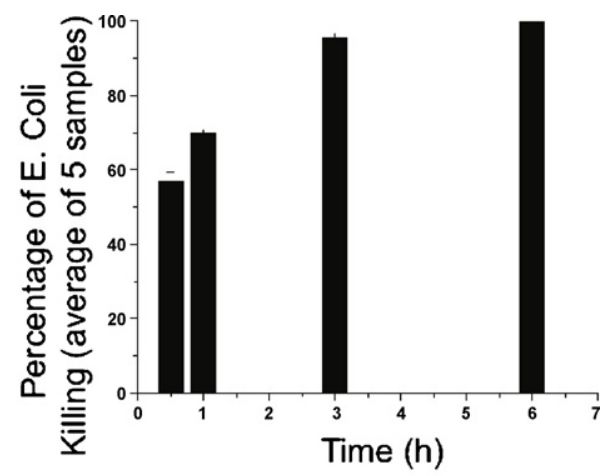

(b)

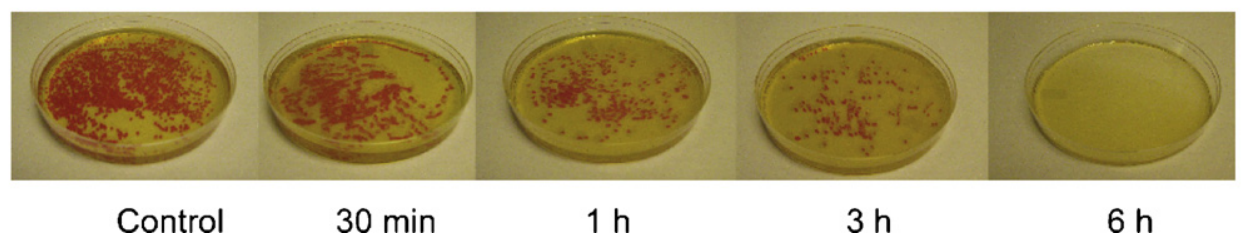

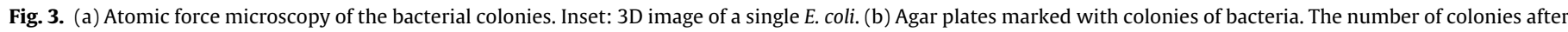

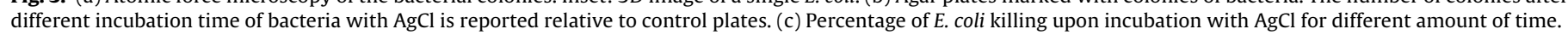

We correlated the high decontamination capability recorded in our experiments with the shape of the $\mathrm{AgCl}$ particles. Specifically, on their $\{100\}$ facets these synthesized $\mathrm{AgCl}$ nanocubes are either positively or negatively charged and thus active, leading to enhanced bacterial adsorption and thus increased decontamination [27].

The bacterial samples (with or without nanocubes) were also inspected with SEM to further confirm that there were no bacteria left after incubation with $\mathrm{AgCl}$ nanocubes. Fig. 4(a) shows bacteria in SEM while Fig. 4(b) identifies nanocubes embedded in cellular debris. To confirm the presence of bacteria or cellular debris and nanocubes, we also used Energy Dispersive X-ray analysis (EDX). The EDX spectra (Fig. 4(a) and (b) inset, respectively) display peaks corresponding to the difference of energy levels for which the most $\mathrm{X}$-rays had been emitted by each individual sample tested; each of these peaks corresponds to a single element in the specimen. As shown, no $\mathrm{Ag}$ or $\mathrm{Cl}$ peaks were indentified for bacteria (Fig. 4(a) inset), however the spectrum changed to include those elements and others (which were the mark of the cellular debris) upon incubation of bacteria with $\mathrm{AgCl}$.

We suggest that, due to their controlled geometry and capacity for decontamination (as shown by our results), one can use pulsed laser synthesized nanocubes as a contact biocidal compound. We envision incorporating the nanocubes into a polymer or paint matrix that spatially stabilize and physically immobilize them at the surface while the porosity of the matrix will further allow for ion $\left(\mathrm{Ag}^{+}\right)$or small molecule diffusion. Such matrix interactions would further be used for antibacterial decontamination. An interesting capability of such matrix would also permit detection of the decontaminant upon binding.

To test the feasibility of our hypothesis we performed preliminary SERS analysis. The SERS activities of $\mathrm{AgCl}$ nanocubes were evaluated by using R6G as probing molecules. Fig. 5 shows the Raman spectra of $10^{-11}-10^{-5} \mathrm{M}$ R6G. On bare Si wafer coated with $10^{-5} \mathrm{M} \mathrm{R6G}$, only a peak at $520 \mathrm{~cm}^{-1}$ associating with Si was observed, while on $\mathrm{AgCl}$ nanocubes coated with $10^{-5} \mathrm{M}$ R6G, multiple peaks were observed. The observed peaks were identified with the fingerprint features of R6G Raman spectrum [28]. These results indicate that $\mathrm{AgCl}$ nanocubes could largely enhance the Raman signal of R6G molecules. We observed that the intensities of the peaks are concentration dependent, with a decrease in the peak intensity being recorded when the R6G concentration decreases. At concentrations of $10^{-7}$ and $10^{-9} \mathrm{M}$, only the band peaked at $1598 \mathrm{~cm}^{-1}$ dominates, while at $10^{-11} \mathrm{M}$ all the peaks were invisible because much fewer R6G molecules were present on $\mathrm{AgCl}$ cubes. This result indicates that the $\mathrm{AgCl}$ nanocubes obtained using pulsed laser
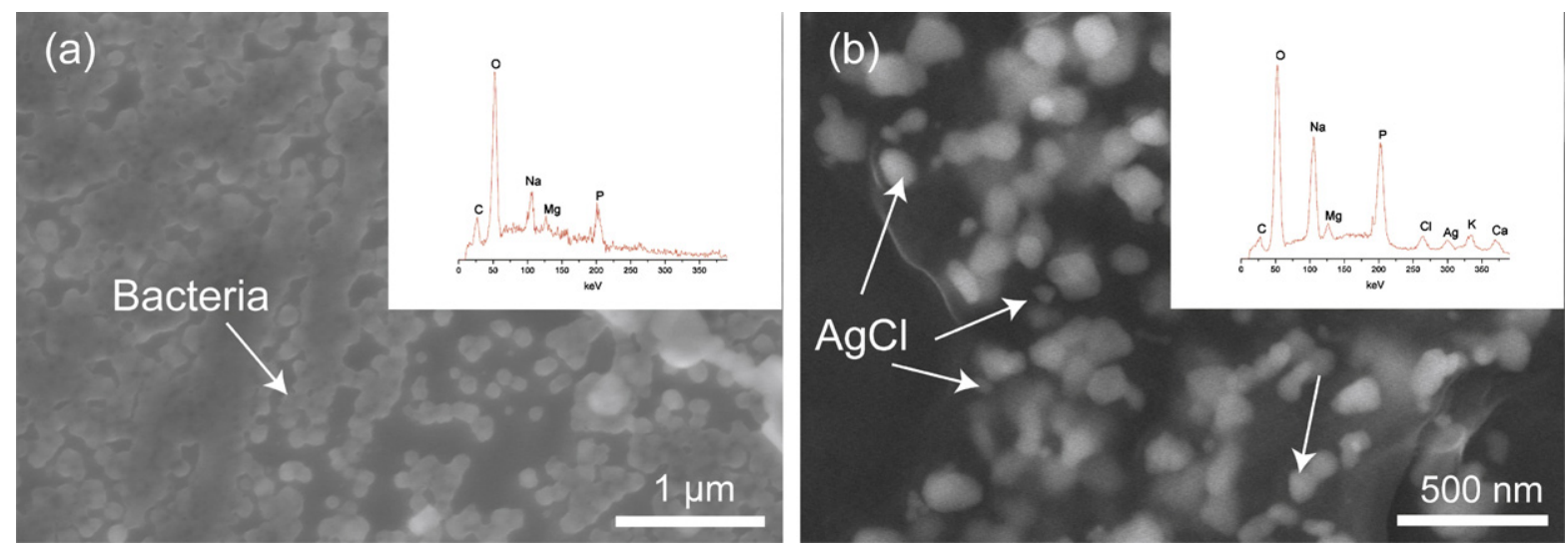

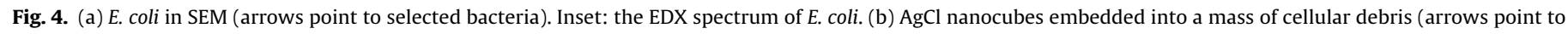
selected nanocubes). Inset: the EDX spectrum of the $\mathrm{AgCl}$ embedded in the cellular debris. 


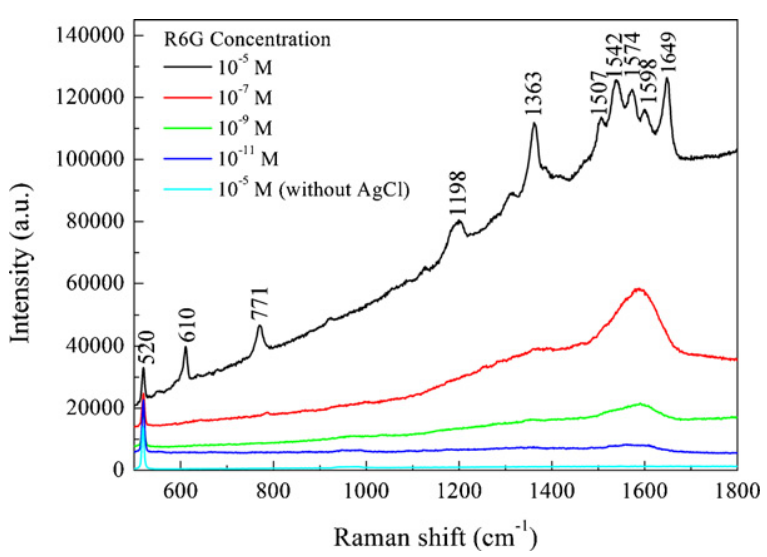

Fig. 5. SERS spectra of R6G on $\mathrm{AgCl}$ particles and bare Si wafer (control).

ablation can be used in the analytical environment for routine SERS detection measurements. Further, we also performed preliminary experiments in which we incorporated the nanocubes in nutrient agar plates and tested their decontamination properties by slow release of $\mathrm{Ag}^{+}$ions and upon exposure to bacteria. Our results show that for only $5 \mu \mathrm{g}$ of nanocubes there was $92 \%$ killing of $E$. coli by slow release of ions.

Combining $\mathrm{AgCl}$ SERS with $\mathrm{AgCl}$ antibacterial efficiency and suspending such $\mathrm{AgCl}$ nanocubes or nanobars in paint of polymer matrices, would lead to generation of coatings with detection and bactericidal capabilities. Moreover, if deposition by drop-coating or nebulizer spray techniques of $\mathrm{AgCl}$ nanocubes onto copper, silicon, and plastic substrates is chosen, one could extend even further the applications of such nanoparticles for detection and decontamination.

\section{Conclusions}

We have synthesized nanocubes and nanorods of $\mathrm{AgCl}$ using a simple and efficient process of pulsed laser ablation in liquid. The synthesized nanocubes possess antibacterial properties with high decontamination capability of gram-negative bacteria, namely E. coli. Moreover, as synthesized nanocubes have SERS detection capabilities, that makes them potential candidates for analytical laboratories.

\section{Acknowledgements}

The authors thank Adrienne McGraw, WVU/Chemical Engineering for help with SEM and EDX analysis. The work performed in Dr. Dinu lab was supported by the NSF/CBET 1033266, NSF/CMMI 1049150, NSF/EPS-1003907, and WVNano. Work performed in Dr. Chrisey's lab was supported by the NSF/CMMI 1049147.

\section{References}

[1] Z. Wang, X. Chen, M. Chen, L. Wu, Facile fabrication method and characterization of hollow $\mathrm{Ag} / \mathrm{SiO}_{2}$ double shelled spheres, Langmuir 7 (2009) 7646-7651.

[2] A. Babapour, B. Yang, S. Bahang, W. Cao, Low-temperature sol-gel-derived nanosilver-embedded silane coating as biofilm inhibitor, Nanotechnology 22 (2011) 155602.

[3] H. Rosengren, A. Dixon, Antibacterial prophylaxis in dermatologic surgery: an evidence-based review, Am. J. Clin. Dermatol. 11 (2010) 35-44.
[4] B. De Gusseme, T. Hennebel, E. Christiaens, H. Saveyn, K. Verbeken, J.P. Fitts, N. Boon, W. Verstraete, Virus disinfection in water by biogenic silver immobilized in polyvinylidene fluoride membranes, Water Res. 45 (2011) 18561864.

[5] R.T. Carbon, S. Lugauer, U. Geitner, A. Regenfus, M. Boswald, J. Greil, T. Bechert, S.I. Simon, H.P. Hummer, J.P. Guggenbichler, Reducing catheter-associated infections with silver-impregnated catheters in long-term therapy of children, Infection 27 (Suppl. 1) (1999) S69-S73.

[6] J.P. Guggenbichler, M. Boswald, S. Lugauer, T. Krall, A new technology of microdispersed silver in polyurethane induces antimicrobial activity in central venous catheters, Infection 27 (Suppl. 1) (1999) S16-S23.

[7] P.L. Tran, A.A. Hammond, T. Mosley, J. Cortez, T. Gray, J.A. ColmerHamood, M. Shashtri, J.E. Spallholz, A.N. Hamood, T.W. Reid, Organoselenium coating on cellulose inhibits the formation of biofilms by Pseudomonas aeruginosa and Staphylococcus aureus, Appl. Environ. Microbiol. 75 (2009) 3586-3592.

[8] C.P. Andam, G.P. Fournier, J.P. Gogarten, Multi-level populations and the evolution of antibiotic resistance through horizontal gene transfer, FEMS Microbiol. Rev. (2011).

[9] R. Dastjerdi, M. Montazer, S. Shahsavan, A novel technique for producing durable multifunctional textiles using nanocomposite coating, Colloids Surf. B: Biointerfaces 81 (2010) 32-41.

[10] R. Dastjerdi, M. Montazer, A review on the application of inorganic nanostructured materials in the modification of textiles: focus on anti-microbial properties, Colloids Surf. B: Biointerfaces 79 (2010) 5-18.

[11] S.D. Gittard, R.J. Narayan, C. Jin, A. Ovsianikov, B.N. Chichkov, N.A. MonteiroRiviere, S. Stafslien, B. Chisholm, Pulsed laser deposition of antimicrobial silver coating on Ormocer microneedles, Biofabrication 1 (2009) 041001.

[12] L. Dawei, W. Jian, X. Houwen, S. Xu, L. Fan-chen, Enhancement origin of SERS from pyridine adsorbed on $\mathrm{AgCl}$ colloids, Spectrochim. Acta, Part A 43 (1987) 379-382.

[13] M. Volkan, D.L. Stokes, T. Vo-Dinh, A sol-gel derived AgCl photochromic coating on glass for SERS chemical sensor application, Sens. Actuators, B 106 (2005) 660-667.

[14] Z. Yan, G. Compagnini, D.B. Chrisey, Generation of AgCl Cubes by excimer laser ablation of bulk Ag in aqueous NaCl solutions, J. Phys. Chem. C 115 (2010) 5058-5062.

[15] Y.Y. Li, Y. Ding, Porous AgCl/Ag nanocomposites with enhanced visible light photocatalytic properties, J. Phys. Chem. C 114 (2010) 3175-3179.

[16] P. Wang, B.B. Huang, Z.Z. Lou, X.Y. Zhang, X.Y. Qin, Y. Dai, Z.K. Zheng, X.N. Wang, Synthesis of highly efficient $\mathrm{Ag} @ \mathrm{AgCl}$ plasmonic photocatalysts with various structures, Chem. Eur. J. 16 (2010) 538-544.

[17] B. Tomsic, B. Simoncic, B. Orel, M. Zerjav, H. Schroers, A. Simoncic, Z. Samardzija, Antimicrobial activity of $\mathrm{AgCl}$ embedded in a silica matrix on cotton fabric, Carbohydr. Polym. 75 (2009) 618-626.

[18] P. Wang, B. Huang, X. Qin, X. Zhang, Y. Dai, J. Wei, M.-H. Whangbo, Ag@AgCl: a highly efficient and stable photocatalyst active under visible light, Angew. Chem. Int. Ed. 47 (2008) 7931-7933.

[19] C.H. An, S.N. Peng, Y.G. Sun, Facile synthesis of sunlight-driven AgCl:Ag plasmonic nanophotocatalyst, Adv. Mater. 22 (2010) 2570-2574.

[20] K. Pfanner, N. Gfeller, G. Calzaferri, Photochemical oxidation of water with thin AgCl layers, J. Photochem. Photobiol., A 95 (1996) 175-180.

[21] C. An, S. Peng, Y. Sun, Facile synthesis of sunlight-driven $\mathrm{AgCl}: \mathrm{Ag}$ plasmonic nanophotocatalyst, Adv. Mater. 22 (2010) 2570-2574.

[22] G.W. Yang, Laser ablation in liquids: applications in the synthesis of nanocrystals, Prog. Mater. Sci. 52 (2007) 648-698.

[23] X.Z. Lin, P. Liu, J.M. Yu, G.W. Wang, Synthesis of CuO nanocrystals and sequential assembly of nanostructures with shape-dependent optical absorption upon laser ablation in Liquid, J. Phys. Chem. C 113 (2009), 1754317547.

[24] P. Liu, H. Cui, C.X. Wang, G.W. Yang, From nanocrystal synthesis to functional nanostructure fabrication: laser ablation in liquid, Phys. Chem. Chem. Phys. 12 (2010) 3942-3952.

[25] T. Christensen, K. Trabbic-Carlson, W. Liu, A. Chilkoti, Purification of recombinant proteins from Escherichia coli at low expression levels by inverse transition cycling, Anal. Biochem. 360 (2007) 166-168.

[26] C.Z. Dinu, S.S. Bale, G. Zhu, J.S. Dordick, Tubulin encapsulation of carbon nanotubes into functional hybrid assemblies, Small 5 (2009) 310-315.

[27] X. Wang, H. Wu, Q. Kuang, R. Huang, Z. Xie, L. Zheng, Shape-dependent antibacterial activities of $\mathrm{Ag}_{2} \mathrm{O}$ polyhedral particles, Langmuir 26 (2009) 27742778.

[28] L. Lu, A. Kobayashi, K. Tawa, Y. Ozaki, Silver nanoplates with special shapes: controlled synthesis and their surface plasmon resonance and surface-enhanced raman scattering properties, Chem. Mater. 18 (2006) 48944901. 